\title{
STUDY ABROAD AND ITS EFFECT ON THE PRAGMATIC PERFORMANCE OF ENGLISH REQUESTS BY HONG KONG ENGLISH LANGUAGE STUDENTS
}

By

Misty So-Sum WAI-COOK

\author{
A thesis \\ Submitted to the Victoria University of Wellington \\ in fulfilment of the requirements for the degree of \\ Doctor of Philosophy \\ in Linguistics
}

Victoria University of Wellington 



\section{Abstract}

This thesis investigates the study abroad experience and its effect on the pragmatic development of second language learners.

The research first describes affective and environmental dimensions of the study abroad experience as undertaken by a group of Hong Kong learners over a nine-month period of study at an Australian university. Second, it investigates changes in the way these learners performed requests in English over the duration of the study abroad experience. This data provides insights into their pragmatic development in English. Comparisons of request devices were made with a matched group of learners who continued their studies in Hong Kong and with a group of Australian native speakers. Finally the research examines the relationship between affective and environmental dimensions of the study abroad experience and changes in the performance of requests across the nine month study abroad period by the learners.

This research takes a quantitative and qualitative approach to data analysis. A quantitative approach, using inferential statistics (ANOVA) was used to analyse learner self-report data gathered before and during the study abroad period using the Language Contact Profile. This data included information on time spent interacting or listening in English, attitudes and reasons for learning English, perceptions of the target language community, perceptions of Australia, self-rated proficiency and self-rated confidence scores. Similarly, inferential statistics (ANOVA and chi-square tests) were used to analyse and compare request performances obtained through oral Enhanced Discourse Completion Tests (EDCTs) and role-plays by three groups: the study abroad learners; an equivalent group of students in Hong Kong; and by a group of Australian native speakers. Finally, Spearman's rho correlation was used to analyse the relationship between study abroad learners' pragmatic performance and the affective and environmental dimensions of their experience. Qualitative data in the form of interview data and student entries in introspective diaries was collected to provide in-depth explanations for responses to the oral EDCTs and role-plays. 
Three main findings emerged from this study. The first finding relates to the environmental and affective dimensions of learners' study abroad experience. Analyses revealed that, unsurprisingly, there was an overall increase in the number of hours study abroad learners listened and interacted face-to-face in English. Nevertheless, this increase plateaued after the first four months of learners' sojourn in Australia and their interactions were mostly with other English learners who were their classmates, flat mates or friends through the Hong Kong Association at the university. These findings suggest learners established their network of friends in the first months of their sojourn in Australia, and it was unlikely learners went beyond this circle of friends during their stay in Australia. Thus, learners' contact with fluent/native English speakers was limited.

Additionally, and contrary to the common belief that there is a 'homestay advantage', learners living with a host family did not necessarily have more face-to-face interaction with fluent/native English speakers than those living in a student dormitory. Interaction between the host and the learner depended heavily on the individual learner's attitude towards the host family. Furthermore, learners' English input and face-to-face interaction correlated significantly with the increase in learners' self-perceived confidence in speaking, communication and grammar, but not self-perceived proficiency.

The second main finding concerns the pragmatic performance of English requests by at-home and study abroad learners, focusing specifically on three features of requests: request heads, softeners and external modifications. Results showed no change in the occurrence of these three features in requests made by the at-home learners at the beginning of the data collection period and again four months later. Similarly there was no change in the type of request heads and softeners used by the study abroad learners by the end of ninth months study in Australia. However, they had begun to use some of the request external modifiers that were frequently employed by native speakers of Australian English and used significantly more request external modifiers. These results lend support to the Complexification Hypothesis (Trosborg 1995) because learners first used the more routinised features before developing proficiency in the non-formulaic features of request external modifiers.

More importantly, this study offered further support for the Bulge Theory (Wolfson 1986). The results in this study indicated that after nine months of being in Australia, the learners used a less familiar structure 'conventional indirect request' in close distance situations, such 
as with friends. However, in maximum social distance interactions between higher and lower status interlocutors, the learners employed direct requests to reduce cognitive burden to free more processing capacity for using external modifiers to express politeness.

The third main finding relates to the effect of environmental and affective factors on the study abroad learners' performance of English request devices. This study showed the number of request external modifiers study abroad learners used significantly increased with time. Furthermore, the results showed that by the end of the nine months, the number of request external modifiers study abroad learners used correlated significantly with a number of environmental and affective factors: learners' overall English input, learners' face-to-face interaction with English speakers in the living environment, as well as learners' selfperceived proficiency and self-perceived confidence in speaking and communication, but not with their self-perceived proficiency in grammar.

Overall, the research shows that learners can improve their pragmatic performance through exposure to English in the target language community in ways that are not seen in the language development of learners learning in an English as a foreign language setting. However, the results also show that study abroad learners may have quite limited opportunities to interact with English speakers during their sojourn abroad. 



\section{Acknowledgements}

Well, this is it. Three countries, two children and six years later-I have finally completed my $\mathrm{PhD}$ ! I would not have been able to complete my $\mathrm{PhD}$ without the following people throughout the journey.

My deepest gratitude goes to my supervisors Dr Jonathan Newton and Prof. Janet Holmes for guiding me through my research and the write-up of my thesis-thank you! Thank you for your guidance, encouragement and invaluable feedback during my $\mathrm{PhD}$.

Dr Arthur McNeil, thank you for being such a remarkable boss during my time at the English Language Teaching Unit, The Chinese University of Hong Kong. Your guidance and wisdom on teaching English as a second language has encouraged and inspired me to embark on a $\mathrm{PhD}$ in second language acquisition.

Prof. Gwendolyn Gong, Prof Jane Jackson and Prof Peter Skehan from the Department of English, The Chinese University of Hong Kong. Thank you for being such wonderful mentors during the initial discussions of my $\mathrm{PhD}$.

The recruitment of participants from Australian universities was one of the biggest challenges I faced in this project. It would have been impossible for me to recruit a sufficient number of participants without the help from Dr Keith Allan, Ms Anna Parkin and Ms Miriam Poon.

My proofreaders, Alexina Burkett, Harry Burkett and Patrick Coelho, who read different sections and drafts of my thesis. Thank you for taking time out of your busy schedule to read my thesis and giving me very useful feedback on the earlier drafts of this thesis.

Finally, my wonderful family, I am so fortunate to have all of you in my life. In particular, I would like to use this opportunity to thank my parents, as well as my grandparents and my five truly amazing aunties in Hong Kong. You have loved and shaped me into the person that I am today and I would not be where I am without you in my life. My brother, Peter, you are an awesome guy. Thank you for always being there for me. Your expertise in Excel and 
Word has saved me a lot of time in the write-up of this thesis. And, of course my super husband, Brendan, thank you for being so encouraging, supportive and patient throughout my entire $\mathrm{PhD}$ journey. As always, you put your family before yourself and I would not have been able to complete this $\mathrm{PhD}$ without you. My beautiful children, Amelia and Vincent, thank you for being such little angels. One of the worst guilt I have as a mother is putting work in front of my family and sacrificing time with you to work. Amelia and Vincent, thank you for being such little troopers in the last few months of my thesis write-up. Amelia, you have once again amazed us with what a truly incredible five-year-old you are. You were there to look after Vincent at times when I needed to work and could not be there for you and Vincent, and despite you not wanting to stay at childcare for such long hours, you understood why you had to and complied (even if it were somewhat begrudgingly).

Brendan, Amelia and Vincent, together we have reached another milestone in life! I love you with all my heart.

Now that I have had a taste of what it takes to be a researcher and learned so much more about the impact of environment on language learning, I am extremely excited about the prospect of applying these skills in teaching and researching English as a second/foreign language. I look forward to having the opportunities to contribute to the existing knowledge in the fields of study abroad and second language teaching and acquisition. 


\section{Table of contents}

$\begin{array}{lll}\text { Chapter } 1 & \text { Introduction } & 1\end{array}$

1.1 Rationale for the research 1

1.2 Purpose of the research 3

1.3 Outline of the study 5

$\begin{array}{lll}\text { Chapter } 2 \text { Requests } & 7\end{array}$

$\begin{array}{lll}2.1 & \text { Introduction } & 7\end{array}$

$\begin{array}{lll}2.2 & \text { Politeness theories } & 7\end{array}$

2.2.1 Traditional approach to politeness $\quad 7$

$\begin{array}{lll}\text { 2.2.2 Post-modern approach to politeness } & 10\end{array}$

2.2.3 Neo-politeness approach to politeness 12

2.3 The development of interlanguage pragmatics research:

From pragmatics to interlanguage pragmatics 13

$\begin{array}{lll}\text { 2.3.1 } & \text { Cross-cultural pragmatics } & 14\end{array}$

$\begin{array}{ll}\text { 2.3.2 Interlanguage pragmatics } & 21\end{array}$

2.4 Summary 31

Chapter 3 Environmental and affective dimensions of the study abroad $\begin{array}{ll}\text { experience } & 33\end{array}$

$\begin{array}{lll}3.1 & \text { Introduction } & 33\end{array}$

3.2 Process of acquiring L2 pragmatic competence 33

3.2.1 Definition of pragmatic competence 34

3.2.2 Grammatical and pragmatic competence 34

$\begin{array}{lll}\text { 3.2.3 Pragmatic transfer } & 37\end{array}$

3.2.4 Complexification hypothesis and Bulge Theory 39

3.3 Environmental and affective dimensions of learners' experience abroad 40

3.3.1 At-Home vs study abroad environment 43 
3.3.2 Learners' length of residence abroad 46

3.3.3 Input and interactions in target language community 48

3.3.4 Self-perceived confidence and self-perceived proficiency $\quad 51$

3.3.5 Perceptions of the target language learning environment 53

$\begin{array}{lll}3.4 & \text { Summary } & 58\end{array}$

$\begin{array}{lll}\text { Chapter } 4 \quad \text { Methodology } & 61\end{array}$

$\begin{array}{lll}4.1 & \text { Introduction } & 61\end{array}$

$\begin{array}{lll}4.2 & \text { Research Design } & 61\end{array}$

$\begin{array}{lll}\text { 4.3 Participants and recruitment } & 62\end{array}$

$\begin{array}{ll}\text { 4.3.1 Participants } & 62\end{array}$

4.3.2 Recruitment 64

$\begin{array}{lll}4.4 & \text { Instruments } & 65\end{array}$

$\begin{array}{lll}\text { 4.4.1 Pilot study } & 65\end{array}$

$\begin{array}{lll}\text { 4.4.2 Main study } & 66\end{array}$

$\begin{array}{lll}4.5 & \text { Reflections on the procedure } & 75\end{array}$

$\begin{array}{lll}\text { 4.5.1 Interviews } & 75\end{array}$

$\begin{array}{lll}\text { 4.5.2 Oral EDCTs } & 75\end{array}$

$\begin{array}{lll}4.5 .3 & \text { Role-plays } & 75\end{array}$

$\begin{array}{lll}4.6 & \text { Procedure } & 76\end{array}$

$\begin{array}{lll}\text { 4.6.1 Time Intervals } & 76\end{array}$

$\begin{array}{lll}\text { 4.6.2 Meetings } & 77\end{array}$

$\begin{array}{lll}\text { 4.7 Data coding and analyses } & 78\end{array}$

$\begin{array}{lll}4.8 & \text { Summary } & 84\end{array}$

Chapter 5 Environmental and affective dimensions of Hong Kong learners' study abroad experience $\quad 87$

$\begin{array}{llr}5.1 & \text { Introduction } & 87\end{array}$

$\begin{array}{lll}5.2 & \text { Environmental factors } & 87\end{array}$

5.2.1 Listening input and interaction in target language community 88 
5.2.2 Number of hours that SALs spoke in L1 (Cantonese)

5.2.3 Discussion of listening input and interaction in target language community

5.2.4 Relationship between SALs' living arrangement and the amount of listening and face-to-face interaction in English

5.3 Affective factors

5.3.1 Perceptions of the target language learning environment

5.3.2 SALs' self-perceived proficiency and self-perceived confidence111

5.4 Summary

Chapter 6 Effect of study abroad on SALs' pragmatic performance of English request devices

6.1 Introduction

6.2 Request heads and request softeners

6.2.1 Request heads

6.2.2 Request softeners

6.2.3 Discussion of request heads and request softeners

6.3 External modifiers

6.3.1 Total number of external modifiers

6.3.2 Acquisition of external modifiers by SALs

$\begin{array}{lll}\text { 6.3.3 Discussion of modifiers } & 158\end{array}$

6.3.4 Discussion of SALs' pragmatic performance 175

6.4 Summary

Chapter 7 Effect of affective and environmental factors on SALs' performance of request external modifiers

7.1 Introduction

7.2 Correlations between SALs' self-rated proficiency and self-rated confidence and the number of request external modifiers in $T_{1}$ and $T_{3}$ 
7.3 Correlations between SALs' English listening input in the target language community and the number of request external modifiers

7.4 Correlation between SALs' English interaction with ENGs and NNSs in the target language community and the total number of request external modifiers

7.5 Living environment

7.6 Discussion of environmental and affective dimensions and SALs' pragmatic performance

7.6.1 Length of residence in Australia

7.6.2 Self-perceived proficiency and self-rated confidence

7.6.3 Input and interactions in target language community

7.6.4 Living environment

7.7 Summary

\section{Chapter 8 Conclusion}

8.1 Major findings

8.1.1 Environmental and affective dimensions of the study abroad experience

8.1.2 Performance of English request devices by study abroad learners

8.1.3 Effect of affective and environmental factors on SALs' performance of English requests

8.2 Research contribution

8.3 Limitations

8.4 Future research

8.5 Concluding remarks

I Advertisement for the recruitment of native speakers of Australian English

II Advertisement for the recruitment of SALs 
$\begin{array}{ll}\text { III Introductory letter } & 207\end{array}$

$\begin{array}{ll}\text { IV Consent form } & 208\end{array}$

V Language Contact Profile (LCP) 209

VI Pre- and post- oral EDCTs (The questions were presented in different order in the three rounds of data collection 225

$\begin{array}{ll}\text { VII Open role-plays } & 227\end{array}$

VIII Interview questions on at-home and study abroad learners' experiences and attitudes towards learning English 229

IX Instructions for writing diaries 233

$\begin{array}{lll}X & \text { Transcription conventions } & 234\end{array}$

$\begin{array}{ll}\text { References } & 235\end{array}$

\section{List of figures}

Figure 5.1: $\quad$ Average of the total number of hours per week SALs' listened in English from $T_{0}$ and $T_{3}$

Figure 5.2: $\quad$ Average number of hours per week SALs used Cantonese with friends from Hong Kong from $\mathrm{T}_{0}$ and $\mathrm{T}_{3}$

Figure 5.3: $\quad$ SALs' living arrangements and mean number of hours of English listening input in $\mathrm{T}_{1}$

Figure 5.4: $\quad$ SALs' living arrangements and mean number of hours of English listening input in $\mathrm{T}_{3}$

Figure 5.5: $\quad$ SALs' living arrangement and types of interaction in $\mathrm{T}_{1}$

Figure 5.6: $\quad$ SALs' living arrangement and types of interaction in $\mathrm{T}_{3}$ 


\section{List of tables}

Table 2.1: $\quad$ Classifications of external modifiers, functions and examples

Table 4.1: $\quad$ SALs' self-ratings on their view on whether learning English is fun

Table 4.2: $\quad$ SALs' reasons for learning English

Table 4.3: Questionnaires completed by three groups of participants in the study

Table 4.4: $\quad$ Time intervals between testing

Table 5.1: $\quad$ Average number of hours per week SALs listened in English from $\mathrm{T}_{0}$ and $\mathrm{T}_{3}$

Table 5.2: $\quad$ Average number of hours per week SALs used English in different types of interactions from $\mathrm{T}_{0}$ and $\mathrm{T}_{3}$

Table 5.3: $\quad$ SALs' mean number of hours of English listening input in different types of living arrangements in $\mathrm{T}_{1}$

Table 5.4: $\quad$ SALs' mean number of hours of English listening input in different types of living arrangements in $\mathrm{T}_{3}$

Table 5.5: $\quad$ ANOVA analyses of SALs' mean number of hours of English listening input in different types of living arrangement in $\mathrm{T}_{1}$ and $\mathrm{T}_{3}$

Table 5.6: $\quad$ SALs' mean number of hours of interactions in different types of living arrangement in $\mathrm{T}_{1}$

Table 5.7: $\quad$ SALs' mean number of hours of interactions in different types of living arrangement in $\mathrm{T}_{3}$

Table 5.8: $\quad$ ANOVA analyses of SALs' mean number of hours of English listening input in different types of living arrangement in $\mathrm{T}_{1}$ and $\mathrm{T}_{3}$

Table 5.9: $\quad$ Mean of SALs' likeness to Australia in the target language community

Table 5.10: $\quad$ SALs' self-perceived proficiency scores in $\mathrm{T}_{1}$ and $\mathrm{T}_{3}(\mathrm{n}=21)$

Table 5.11: $\quad$ SALs' self-perceived confidence scores in $T_{1}$ and $T_{3}(n=21)$

Table 5.12: Correlations between SALs' self-perceived proficiency and self-perceived confidence scores in $\mathrm{T}_{1}$ and $\mathrm{T}_{3}$

Table 5.13: Correlations between SALs' amount of listening in English and self-perceived proficiency and self-perceived confidence in $\mathrm{T}_{1}$

Table 5.14: Correlations between SALs' listening input in English and self-perceived proficiency and self-perceived confidence in $\mathrm{T}_{3}$ 
Table 5.15: Correlations between types of interactions and SALs' self-perceived proficiency and self-perceived confidence scores T1

Table 5.16: Correlations between types of interactions and SALs' self-perceived proficiency and self-perceived confidence scores $\mathrm{T}_{3}$

Table 5.17: $\quad$ SALs' self-perceived proficiency and self-perceived confidence scores in different types of living arrangement in $\mathrm{T}_{1}$

Table 5.18: $\quad$ SALs' self-perceived proficiency and self-perceived confidence scores in different types of living arrangement in $\mathrm{T}_{3}$

Table 5.19: ANOVA analyses between SALs' self-perceived proficiency and self-perceived confidence with living arrangements in $\mathrm{T}_{1}$ and $\mathrm{T}_{3}$

Table 6.1: Descriptive statistics for the number of request heads used by ENGs, AHLs and SALs (\%)

Table 6.2: Chi-square tests for cross-group comparisons of request heads used by AHLs, SALs and ENGs

Table 6.3: $\quad$ Chi-square tests for comparisons of request heads used by SALs in $\mathrm{T}_{1}$ and $\mathrm{T}_{3}$

Table 6.4: Descriptive statistics for the number of request softeners used by AHLs, SALs and ENGs (\%)

Table 6.5: Chi-square tests for cross-group comparisons of request softeners used by AHLs, SALs and ENGs

Table 6.6: $\quad$ Descriptive statistics for the types the request softeners used by ENGs $(\mathrm{n}=30)(\%)$

Table 6.7: $\quad$ Descriptive statistics for the types the request softeners used by AHLs $(n=30)(\%)$

Table 6.8: Descriptive statistics for the distribution of request softeners used by SALs $(n=21)(\%)$

Table 6.9: $\quad$ Descriptive statistics for the total number of external modifiers per request used by ENGs, AHLs and SALs

Table 6.10: $\quad$ ANOVA tests for cross-group comparisons of request external modifiers used by AHLs, SALs and ENGs

Table 6.11: $\quad$ ANOVA repeated measures t-tests for the comparisons of request external modifiers used by SALs between $T_{1}, T_{2}$ and $T_{3}$

Table 6.12: Descriptive statistics for cross-group comparisons between the number of pre-request external modifiers used by AHLs, SALs and ENGs 
Table 6.13: $\quad$ ANOVA tests for cross-group comparisons between the number of pre-request external modifiers used by AHLs, SALs and ENGs

Table 6.14: $\quad$ ANOVA repeated measures t-tests for comparisons of pre-request external modifiers used by SALs in $\mathrm{T}_{1}, \mathrm{~T}_{2}$ and $\mathrm{T}_{3}$

Table 6.15: Descriptive statistics for cross-group comparisons between the number of post-request external modifiers used by AHLs, SALs and ENGs

Table 6.16: ANOVA tests for cross-group comparisons of the number of post-request external modifiers used by AHLs, SALs and ENGs

Table 6.17: $\quad$ ANOVA repeated measures t-tests for comparisons of post-request external modifiers used by SALs in $\mathrm{T}_{1}, \mathrm{~T}_{2}$ and $\mathrm{T}_{3}$

Table 6.18: Descriptive statistics for the average number of external modifiers used by ENGs and SALs as pre-requests (speaker at mutual status with interlocutor)

Table 6.19: Descriptive statistics for the average number of external modifiers used by ENGs and SALs as pre-requests (speaker at higher status than interlocutor)

Table 6.20: Descriptive statistics for the average number of external modifiers used by ENGs and SALs as pre-requests (speaker at lower status than interlocutor)

Table 6.21: $\quad$ Repeated measures for comparisons of pre-request external modifiers used by SALs in $\mathrm{T}_{1}, \mathrm{~T}_{2}$ and $\mathrm{T}_{3}$

Table 6.22: $\quad$ ANOVA tests for cross-group comparisons of the number of pre-request external modifiers used by ENGs and SALs

Table 6.23: Descriptive statistics for the average number of external modifiers used by ENGs and SALs as post-requests (speaker of mutual status as the interlocutor)

Table 6.24: Descriptive statistics for the average number of external modifiers used by ENGs and SALs as post-requests (speaker at higher status than interlocutor)

Table 6.25: Descriptive statistics for the average number of external modifiers used by ENGs and SALs as post-requests (speaker at lower status than interlocutor)

Table 6.26: Repeated measures for comparisons of post-requests external modifiers used by SALs in $\mathrm{T}_{1} \mathrm{~T}_{2}$ and $\mathrm{T}_{3}$

Table 6.27: ANOVA tests for cross-group comparisons of the number of post-request external modifiers used by ENGs and SALs 
Table 6.28: Descriptive statistics for the average number of external modifiers used by ENGs and SALs as pre-requests (speaker at mutual status than interlocutor)

Table 6.29: Descriptive statistics for the average number of external modifiers used by ENGs and SALs as pre-requests (speaker at higher status than interlocutor)

Table 6.30: Descriptive statistics for the average number of external modifiers used by ENGs and SALs as pre-requests (speaker at lower status than interlocutor)

Table 6.31: $\quad$ Repeated measures for comparisons of request external modifiers used by SALs in $\mathrm{T}_{1}, \mathrm{~T}_{2}$ and $\mathrm{T}_{3}$

Table 6.32: $\quad$ Distribution of pre-warning devices used by SALs ( $\mathrm{n}=21)(\%)$

Table 6.33: ANOVA tests for cross-group comparisons of the number of pre-request external modifiers used by SALs and ENGs

Table 6.34: Descriptive statistics for the average number of external modifiers used by ENGs and SALs as post-requests (speaker of mutual status as the interlocutor)

Table 6.35: Descriptive statistics for the average number of external modifiers used by ENGs and SALs as post-requests (speaker at higher status than interlocutor)

Table 6.36: Descriptive statistics for the average number of external modifiers used by ENGs and SALs as post-requests (speaker at lower status than interlocutor)

Table 6.37: Repeated measures for comparisons of post-request used by SALs in $\mathrm{T}_{1}, \mathrm{~T}_{2}$ and $\mathrm{T}_{3}$

Table 6.38: ANOVA tests for cross-group comparisons of the number of post-request external modifiers used by SALs and ENGs

Table 7.1: $\quad$ Correlations between SALs' self-rated proficiency and self-rated confidence and the number of request external modifiers in mutual, high and low statuses $\left(\mathrm{T}_{1}\right)$

Table 7.2: $\quad$ Correlations between SALs' self-rated proficiency and self-rated confidence and the number of request external modifiers in mutual, high and low statuses $\left(\mathrm{T}_{3}\right)$

Table 7.3: Correlations between SALs' English listening input and the number of request external modifiers in mutual, high and low statuses in $\mathrm{T}_{1}$

Table 7.4: Correlations between SALs' English listening input and the total number of request external modifiers in mutual, high and low statuses in $\mathrm{T}_{3}$ 
Table 7.5: Correlations between SALs' types of interaction in English and total number of request external modifiers in mutual, high and low statuses in $\mathrm{T}_{1}$

Table 7.6: Correlations between SALs' types of interaction in English and total number of request external modifiers in mutual, high and low statuses in $\mathrm{T}_{3}$

Table 7.7: Average number of request external modifiers used by SALs at homestay, a student dormitory and alone/other NNSs living environment across three statuses in $\mathrm{T}_{1}$

Table 7.8: $\quad$ Average number of request external modifiers used by SALs at homestay, a student dormitory and alone/other NNSs living environment across three statuses in $\mathrm{T}_{3}$

Table 7.9: $\quad$ ANOVA tests for the number of request external modifiers used by SALs in three different types of living environment in the target language community across the three statuses in $\mathrm{T}_{1}$ and $\mathrm{T}_{3}$

\section{List of abbreviations}

AHLs

DCTs

EDCTs

ENGs

ILP

L1

L2

LCP

NSs

NNSs

NP

SALs

SLA

VP
At-home learners

Discourse completion tasks

Enhanced Discourse Completion Tasks

Fluent/native speakers of Australian English

interlanguage pragmatics

First language

Second language

Language Contact Profile

Native speakers

Non-native speakers

Noun phrase

Study Abroad Learners

Second language acquisition

Verb phrase 


\section{Chapter 1 Introduction}

\subsection{Rationale for the research}

With the number of Hong Kong and mainland Chinese students enrolled in schools in Australia rising from 69,937 in 2002 to 164,155 in December 2011 in the last decade (Australian Education International 2011). The major reasons international students study in Australia is because they want to gain experience living and studying in another country and/or culture and improve English (International Student Survey 2010: 10). It is, therefore, crucial to gain a better picture of learners' experiences and examine the factors that can promote learning in the target language community.

It is believed that one of the biggest benefits for learners in studying abroad is that they have more opportunities for richer and more authentic input and interaction in a target language community than learners in an at-home context (Bardovi-Harlig \& Griffin 2005; Barron 2003, 2005 in Barron 2007a, 2007a,b; Code \& Anderson 2001; Schauer 2006a,b). With this in mind, researchers in applied linguistics have predominantly investigated the effect of study abroad on learners' pragmatic competence (e.g., Barron 2003, 2005 in Barron 2007a, 2007a, 2008; Bouton 1988, 1994, 1996; Felix-Brasdefer 2004; Kinginger \& Belz 2005; Kinginger \& Farrell 2004; Matsumura 2003, 2007; Olshtain \& Blum-Kulka 1985; Schauer 2006a,b, 2007, 2008; Shardakova 2005; Takahashi 1996).

Typically, study abroad learners' pragmatic growth has been measured by assessing how well they can use and realise speech acts like requests. In fact, request devices have been popularly used by researchers to assess learners' pragmatic development as they are considered as face-threatening acts by traditional politeness theorists $(1978,1987)$. Though Brown and Levinson's politeness premises are widely criticised because biases toward Western culture have led to problems concerning the equivalence of politeness and directness, politeness and universality, and the notion of face, the concept of speech acts and politeness has laid the groundwork for both interlanguage pragmatics and study abroad research. 
It is fascinating to examine when and how learners are able to maintain social harmony by learning to use and realise appropriate request devices to minimise threat and save face between interlocutors of, for example, mutual, higher and lower status. In other words, to be pragmatically competent in using requests, learners have to use the appropriate request heads to express politeness and then use suitable external and internal modification to minimise the imposition of the requests. Language learners must be able to identify what devices are appropriate to use depending on social context and culture. Research on requests in the interlanguage pragmatics discipline is based heavily on the categorisation of request devices coded in the Cross Cultural Speech Act Realisation Project (CCSARP 1989, in Blum-Kulka, House \& Kasper 1989a). To date, research has primarily focused on the acquisition of English by learners of another European language, or typically an Asian language such as Japanese learners of English. Very little research has been conducted with Chinese learners of English. And, of these studies, a majority focused on Mandarin Chinese, not Cantonese. The studies that have examined Cantonese learners of English requests have only examined learners' acquisition of request heads, not request modifiers (see, for example, Rose 2000, 2005; Lee 2005, 2011).

Research on request devices in second language acquisition and study abroad has shown that learners of English generally progress from direct to conventional indirect then nonconventional indirect request heads (e.g., Barron 2003, 2007a, 2008; Cook \& Liddicoat 2002; Hassall 2003). Additionally, researchers have typically found that learners' use of external modification increases with increasing competence (Economidou-Kogesidis 2008, 2009, 2010; Otçu \& Zeyrek 2006). However, learners usually develop internal modifiers prior to external modifiers. Schauer $(2006 a, b)$ concluded that the acquisition sequence is linked to the length of stay in the target environment but that individual learners develop the use of modifiers at different rates.

From a study abroad research perspective, researchers have continued to show great interest in investigating whether, and how, exposure to the target language community through a study abroad experience affects L2 pragmatic performance (e.g., DuFon \& Churchill 2006; Freed, Dewey, Segalowitz, Halter 2004; Hassall 2006; Pellegrino 2006; Rose 2005; Schauer 2006a,b, 2007, 2008). Though a majority of researchers have reported on the advantages that learners' exposure to the target language environment have on their pragmatic development, there are inconsistencies in the findings. Some researchers (e.g., Warga \& Schölmberger 
2007) found no correlation between study abroad learners' pragmatic development and their length of stay in the target language community. Others found no difference between the pragmatic development of study abroad learners and at-home learners (Rodríguez 2001, in Cohen \& Shively 2007), while some researchers found that learners tended to move towards non-native-like pragmatic development as they spent more time in the target environment (e.g., Bardovi-Harlig \& Hartford 1996; Warga \& Schölmberger 2007). Where research has shown benefits, learners' pragmatic gain has generally been attributed to their exposure to a large amount of authentic input from the target language environment (e.g., Barron 2003, 2005, in Barron 2007a; Kasper \& Schmidt 1996). Until now, research has not been able to fully account for the variations between learners' pragmatic acquisition, nor provide the reasons why some pragmatic features are acquired before others (e.g., Schauer 2006a,b). Some researchers have offered explanations from a cognitive processing perspective using the noticing hypothesis and Complexification Hypothesis (e.g., Hassall 2001; Trosborg 1995), or in terms of the relationship between interlocutors' social distance and their speech behaviour described in the Bulge Theory (Wolfson 1986). None have explicitly looked at the affective and the environmental dimensions of learners' pragmatic development together in a study abroad context. In addition, the existing studies have not investigated whether learners' pragmatic gain relates to affective dimensions such as self-rated proficiency and selfperceived confidence in speaking, communication and grammar; as well as environmental dimensions such as length of stay in the target language community, amount and types of input and interactions in the target language community, attitude towards learning L2, and attitudes towards the target language community.

The identification of these gaps in the research prompted this current study into the effect of study abroad on the performance of English request devices by Hong Kong university students in Australia.

\subsection{Purpose of the research}

This study investigates the acquisition of Australian English request devices by native Chinese (Cantonese) speakers during their nine-month period in a target language community-Australia, compared to their counterparts in Hong Kong and native Australian English speakers. It draws on quantitative and qualitative data to further investigate the 
factors that influenced the pragmatic development of the study abroad learners during their nine-month sojourn abroad in Australia.

To achieve this aim, multiple data collection instruments are used in this study. While acknowledging the importance of collecting authentic discourse data, it was not possible to collect naturalistic data in this study due to the limitation in time and difficulty in recruiting and keeping learners in the study. Nevertheless, multiple methods were used in this study to collect both quantitative and qualitative data in an attempt to increase the reliability and generalisability of the data. The methods included the oral Enhanced Discourse Completion Tasks and open roleplays in an attempt to elicit a range of request devices (request heads and external modifiers) in maximum social distant interactions (status unequals and strangers) and the middle distant social interactions (non-intimates, status equals friends co-workers and acquaintances) as defined by Wolfson's (1988) Bulge Theory. Wolfson (1988) also described a minimal distance group (intimates, status equals), but this group is not the focus of this study. In addition, the Language Contact Profile and face-to-face interviews elicit study abroad learners' affective experience (self-rated proficiency and self-perceived confidence) and environmental experience (amount and types of input and interactions in target language community, attitude towards learning L2, attitudes towards the target language community, particularly their living environment).

Data from Australian English native speakers was used for baseline comparisons, and data from Hong Kong learners of English studying in Hong Kong was used as control measures. The study abroad learners were tested three times over a nine-month period, with each test at four-month intervals. The AHLs were tested twice and the NSs were tested only once.

This study addresses five research questions:

RQ1: What effect did study abroad have on the students' engagement with English outside formal education settings?

RQ2: What effect did study abroad have on learners' self-rated proficiency and self-rated confidence in English? 
RQ3: What effect did study abroad have on learners' attitudes towards the target language community?

RQ4: What was the effect of study abroad on the learners' performance of requests in English?

RQ5: To what extent did environmental, affective or attitudinal factors in the study abroad experience correlate with the acquisition of more native-like request devices in English?

\subsection{Outline of the study}

This thesis comprises eight chapters. This chapter has provided the rationale and purpose of this research project, and presented the questions. The next two chapters review literature relevant to research on politeness, cross-cultural and interlanguage pragmatics and study abroad disciplines. Chapter 2 reviews the development of speech act and politeness theories, and covers the general definitions and research on interlanguage pragmatics. As this study aims to investigate the acquisition of Australian English request devices by native Chinese (Cantonese) speakers, this chapter ends with an overview of research on requests from the cross-cultural and interlanguage pragmatic disciplines-with emphasis on Chinese and Australian English. Chapter 3 reviews literature on the affective and environmental dimensions that potentially influence learners' pragmatic performance during their sojourn abroad.

Chapter 4 describes the methodology of the present study. It includes a summary of the research design, details of participants and the recruitment process, instruments used in the pilot study and the main study. The final part of this chapter provides details of the procedure and an account of the data coding and analyses in order to address the five main research questions in this study.

Chapters 5, 6 and 7 provide quantitative and qualitative analyses and discussion of the findings pertaining to the five research questions. Chapter 5 investigates the environmental and affective dimensions of Hong Kong learners' study abroad experience (research questions 1-3). It begins with analyses of the environmental dimensions of learners' experience during their sojourn in Australia. It focuses on the number of hours study abroad 
learners listened and interacted face to face in English, and how much Cantonese was used during their time in Australia. It examines the results of the effect of study abroad learners' living arrangement on their input and interaction.

Chapter 6 examines study abroad learners' pragmatic performance on English request devices. It presents results relating to the fourth research question-whether a group of Hong Kong learners studying in Australia developed pragmatic competence to use request devices over their nine-month sojourn abroad. This chapter presents results concerning the learners' use of request heads, request softeners and request external modifiers during their first nine months of stay in Australia. The results from English speakers and at-home learners were used in cross group comparisons as baseline. Data used for this study are from participants' oral responses for three oral Enhanced Discourse Completion Tasks where the participants were of mutual, higher and lower status than the interlocutor in a given scenario.

Chapter 7 describes the relationship between affective and environmental factors in the study abroad experience and learners' performance of requests (research question 5). Analyses compared study abroad learners' request devices and affective factors (self-perceived proficiency and self-perceived confidence). The latter part of this chapter addresses the relationship between learners' use of request devices and environmental factors. Environmental factors investigated include length of stay abroad, self-perceived proficiency and self-perceived confidence in speaking, communication and grammar, input and interaction in the target language community and the living environment.

The final chapter, Chapter 8, summarises the major findings, discusses this study's contributions to academic knowledge and suggests directions in future research. 


\section{Chapter 2 Requests}

\subsection{Introduction}

The chapter comprises four main sections. The first two sections provide an overview of speech act and politeness theories. The third section covers general definitions and research on interlanguage pragmatics. As this study aims to investigate the acquisition of Australian English request devices by native Chinese (Cantonese) speakers, the fourth section will focus on research on requests from the disciplines of cross-cultural and interlanguage pragmatic disciplines with an emphasis on Chinese and Australian English.

\subsection{Politeness theories}

This section will provide an overview of the development of politeness theory from Brown and Levinson's (1987; hereafter B\&L) to post-modern and neo-politeness approaches to politeness.

\subsubsection{Traditional approach to politeness}

Early theorists of politeness in pragmatics (Lakoff 1973; Leech 1983; B\&L 1987) based much of their work on the premise from speech act theorists (Austin 1962; Grice 1957, 1975; Searle $1969,1975,1979)$ that utterances are frequently used in communication to perform certain kinds of actions (i.e. speech acts).

Based on Grice's $(1957,1975)$ assumption that participants in conversations cooperate by following maxims of quantity, quality, relation and manner to convey and interpret implicatures, researchers in the traditional politeness approach accounted for flouting of Cooperative Principles (CP) in terms of speech acts. Lakoff (1973) was amongst the first to connect Grice's Cooperative Principles with politeness. Lakoff (1973: 298) proposed three politeness rules: don't impose; give options; and make the other person feel good and be friendly. Leech (1983) defined politeness as speakers' social goals of establishing and maintaining harmonious relationships or avoiding conflict in conversations. Leech's (1983: 
132) framework considered politeness along with the $\mathrm{CP}$, but accounted for deviations from politeness by proposing maxims of tact, generosity, approbation, modesty, agreement, and sympathy.

Firstly, from a social and psychological standpoint, B\&L (1987) argued that certain speech acts, like refusals and requests, are 'Face Threatening Acts' (FTAs). In short, the 'seriousness' or 'weightiness' of FTAs is measured by social distance and relative power between interlocutors, as well as the ranking of imposition of an act in a particular culture. The more imposing the FTAs are, the more politeness is required and indirectness is preferred over directness. Accordingly, this determines which of the following politeness devices are used to minimise the imposition of the FTAs to prevent threatening one's 'face': bald on-record, positive politeness, negative politeness, off-record and avoidance.

Secondly, B\&L (1987, 1992) adopted Goffman's (1967, 1974) notion of 'face' and 'face work', and defined 'face' as the public self-image that every individual wants to have. The two fundamental motivations behind politeness are 'negative face' (the desire not to impose) and 'positive face' (the desire to have approval or be appreciated). Accordingly, the speakers' face is vulnerable and speakers will defend it when threatened. Therefore, the concept of politeness is based on interlocutors' mutually monitoring potential threats to each other's 'face' and using appropriate devices to maintain face and avoid conflict.

Though this theory remains one of the most influential theories of politeness to date, it has been heavily criticised in recent years by advocates of the post-modern politeness approach (e.g., Eelen 2001; Geyer 2008; Mills 2003; Spencer-Oatey 2000b; Watts 2003) and neopoliteness approach (e.g., Fletcher 1999; Holmes 2012; Holmes, Marra \& Schnurr 2008; Mullany 2004, 2006, 2007).

The problems with B\&L's (1987) politeness theory stem from analyses of individual speech acts at the single utterance level with the exclusion of context and culture, and the focus is on speakers only. Consequently, the categories are considered to be too rigid and static, the weightiness of the three sociolinguistic variable formulae too simplistic, and its universal claims on 'politeness' and 'face' biased towards Western culture. 
Firstly, B\&L's (1987) categorisation of FTAs has been claimed to be too rigid and static. Researchers in more recent years who have explained politeness using qualitative (e.g., Mills 2003; Okamoto 1999; Watts 2003) and quantitative (Terkourafi 2004, 2005) analyses of ongoing authentic discourse point out it is feasible to have face-enhancing effects even in a potential FTA (O'Driscoll 2007a: 469). Conversely, even the least threatening act can promote a face-threatening effect (Geyer 2008; O’Driscoll 2007b: 247-248). Geyer (2008), for example, showed that linguistic acts such as collaborative disagreements, teasing and troubles can be simultaneously face-threatening, face-enhancing and face-neutral through an ongoing conversation.

Secondly, the weightiness formula of the three dimensions has been described as too simplistic as analyses were performed without considering how individuals interact in different social contexts (Heritage 2004; Kasper 1990; Spencer-Oatey 2003, 2005). For instance, Brown and Gilman (1989, in Duthler 2006) argued that weightiness depends on the degree of imposition and power, and that social distance does not affect the enactment of politeness. Harris (2003) found that more powerful individuals in institutions also make extensive use of mitigating forms and other politeness devices that were neglected in B\&L's formula for computing the weightiness of an FTA. Therefore, these researchers argue it is too simple to consider the relationship between social variables and politeness acts as unidirectional and to suggest that only those three social variables affect the use of politeness devices.

Thirdly, researchers (e.g., Spencer-Oatey \& Jiang 2003) who examined politeness in speech acts performed in a second language have reported on cross-cultural differences in the performance and perception of politeness in various speech acts. For instance, Liang and Han's (2005) contrastive study of politeness devices in disagreements between American English and mainland Chinese Mandarin speakers revealed that Chinese students generally employed more politeness devices and address forms than the American students when disagreeing with the superior. Additionally, female students were more sensitive to politeness and used more politeness devices than male subjects. The American students and Chinese respondents also showed different trends in disagreement. American students' contradictory statements increased and politeness devices decreased as social distance increased. In contrast, Chinese students' use of disagreement decreased and politeness devices increased as social distance increased. This indicates that cultural differences influence how different 
politeness devices are used by speakers of different cultures, and supports Triandis and Singelis' (1998: 36) claim that 'East Asians are collectively more eager to maintain harmonious relationships while Americans are individualists more concerned with clearly giving opinions'.

Another major point of contention is that cultural aspects are inadequately considered in B\&L's (1987, 1992) notion of positive and negative face (e.g., Ide 1989; Matsumoto 1988, 1989; Spencer-Oatey 2000a). Researchers investigating politeness in non-Western languages (Gu 1990; Mao 1994; Zhang 1995a,b for Chinese invitations/requests; Matsumoto 1988; Nwoye 1992 and Sifianou 1993, 1995 for requests in Japanese) argued that B\&L's (1987) positive and negative 'face' is language- and cultural-specific (Fukushima 2002; O'Driscoll 2007b; Watts 2003), and that 'face' is applicable to highly individualistic, Western culture only (Geyer 2008).

Mao (1994: 471) also defined two types of face orientations - individual and social face. Mao also proposed that the Chinese 'face' has two aspects-'mianzi' refers to the need of an individual to conform to social conventions and express one's desire to be part of the community, and 'lian' which defines a need to show one's moral sense of place and role. Both roles revolve around one's desire for social prestige, reputation or sanction (Mao 1994). Face-balance is central in Chinese facework-giving face simultaneously enhances one's own face and, conversely, depriving another's face damages one's own face. To be polite 'you limao' in Chinese discourse 'is to know how to attend to each other's 'lian' and 'mianzi' and to perform speech acts appropriate to and worthy of such an image' (Mao 1994: 19). This implies second language (L2) learners have to learn devices that enable them to maintain politeness in L2, and become aware of the differences in politeness in first language (L1) and L2.

\subsubsection{Post-modern approach to politeness}

The post-modern approach theorists emphasise that politeness is defined by participants in interactions, and that many contextual factors contribute in complex and richly relevant ways to interpretation and analysis (Holmes 2012). 
In fact, one of the earlier post-modern approaches (Spencer-Oatey 2000b: 3) to politeness had already emphasised the importance of the dynamic nature of interactions, and noted 'politeness depends on individual's assessment of appropriateness, and culture plays an important role in how individuals determine appropriateness' (Spencer-Oatey 2000c: 41). Spencer-Oatey (2000b: 3) proposed politeness in terms of rapport management across five inter-related domains of discourse (illocutionary, discourse, participation, stylistic and nonverbal) to 'promote, maintain or threaten harmonious social relationships in interaction' (2000b: 3). Spencer-Oatey (2000a; 2002; 2007) proposed the notion of 'sociality rights' (people's right to claim their interactions with others following expected social conventions) and argues that two interrelated faces explain people's basic desires for approval: 'quality face' (desire to have positive evaluation of one's own personal qualities) and 'identity face' (desire to have one's social identities or roles acknowledged and upheld). In a sense, quality face corresponds to B\&L's notion of positive face.

More recently, post-modern researchers such as Eelen (2001), Mills (2003) and Watts (2003) have argued that politeness is negotiated among interactants in a discourse, and both speakers' and listeners' interpretations are of paramount importance in a dynamic, ongoing interaction.

Eelen (2001), for example, differentiated between politeness1 (everyday notion of politeness) and politeness2 (more universal notion, scientific notions of politeness). Watts (2003: 23), on the other hand, claimed the concept of (im)politeness cannot be applied to social interaction across cultures, subcultures and languages and rejects politeness2. Instead, Watts (2003: 21) distinguished between 'politic' (linguistic and non-linguistic behaviour that participants construct as appropriate in an ongoing social interaction) and 'polite' (behaviour beyond what is perceived to be appropriate to the ongoing social interaction) behaviour. Watts (2003) also proposed that politeness theory is a descriptive theory of politeness 1 and it should be able 'to offer a way of assessing how the members themselves may have evaluated that behaviour' without politeness2 (Watts 2003: 19).

Post-modern theorists also differed in how they place politeness in a group of interactants. Eelen (2001) and Watts (2003) first proposed this dynamic ongoing process between interactants as 'social practice'. The 'social' component encompasses what goes on between individuals in the construction of social reality (Eelen 2001: 246), and 'practice is observable 
in instances of ongoing social interaction amongst individuals, which most often involves language' (Watts 2003: 148). While Eelen (2001) and Watts (2003) claimed politeness is carried out within 'arbitrary social organisations of space and time' (Watts 2003: 149), they did not define social groups. Mills (2003), however, added to Eelen's (2001) and Watts' (2003) notion of social practice by proposing that interactants in a discourse are social groups and suggesting that politeness can be only defined within a 'Community of Practice' (CofP, Lave \& Wenger 1991; Wenger 1998). A CofP is defined as 'a group of people who are mutually engaged on a particular task and who have a shared repertoire of negotiable resources accumulated over time' (Wenger 1998: 76).

According to Mills (2003: 4), participants' actions and assessments of their interactants contribute to the constant changes that take place within a CofP (Wenger 2003: 30). Postmodern theorists (e.g., Eelen 2001; Mills 2003; Watts 2003) generally agree that individuals assess appropriateness and (im)politeness based on their history and past experiences of interactions (called habitus, adopted from Bourdieu 1977, 1991). However, at the same time, the present interaction also constitutes and influences individuals' own habitus. These theorists argue that it is essential to evaluate devices such as (im)politeness behaviour in the context of ongoing authentic verbal communication on a positive-negative continuum (Watts 2003: 23$)$.

\subsubsection{Neo-politeness approach to politeness}

The post-modern approach argues that only interactants in the discourse can assess politeness and that viability and individual creativity can only be seen in a discourse. The problem with this is that it implies it is no longer possible to predict behaviour. More recently, researchers (e.g., Fletcher 1999; Holmes 2012; Holmes, Marra \& Schnurr 2008; Mullany 2004, 2006, 2007) have taken a neo-politeness approach by combining some notions of Goffman's (1967) notion of face, and proposed a less rigid approach of B\&L's (1987) FTA category, while adopting Mills' CofP based approach.

Firstly, unlike the post-modern politeness theorists who proposed that only interactants in the CofP can interpret politeness, neo-politeness theorists (Holmes 2005; Holmes, Marra \& Schnurr 2008) argue that sociolinguists can identify linguistic devices individuals use to 
express politeness in discourse and this can enhance our understanding of how language works (Holmes, Marra, \& Schnurr 2008: 195).

Secondly, the neo-politeness approach takes a broader and more flexible approach to B\&L's notions of politeness instead of following the traditional approach of mitigation or avoidance of threatening other's positive/negative face in FTAs. Based on the work of their Language in the Workplace Project, Holmes and her colleagues (Holmes 2006; Holmes \& Marra 2004; Holmes \& Schnurr 2005) proposed the concept of 'Relational Practice' to refer to 'a way of working that reflects a relational logic of effectiveness and requires a number of relational skills such as empathy, mutuality, reciprocity, and sensitivity to emotional contexts' (Fletcher 1999: 84). One of the premises of relational practice is the consideration of B\&L's positive and negative face needs/wants for others. Relational practice includes friendly, positive, or supportive verbal behaviour, which considers people's need to feel valued (positive politeness), as well as linguistic devices and non-imposing distancing linguistic behaviours which show respect toward others (negative politeness).

In summary, this section has provided an overview of the development of the traditional approach to politeness theory in the early to mid-1980s, and the post-modern and neopoliteness approaches to politeness. The latter two approaches differ distinctively from B\&L's theory as analyses are based on authentic discourses and politeness is defined by interactants in the discourse, considering context and cultural differences. The neo-politeness approach, however, recognises the merits of using a less rigid approach to categorisation of FTAs, politeness and face. Despite criticisms, B\&L's politeness theory has advanced politeness research and, more importantly, prompted significant research in the cross-cultural and second language acquisition fields. The next section will provide an overview of research in cross-cultural pragmatics and interlanguage pragmatic studies.

\subsection{The development of interlanguage pragmatics research: From cross- cultural pragmatics to interlanguage pragmatics}

Based on B\&L's (1987) categorisation of FTAs, and one's need to use politeness devices to minimise the imposition/threats to others' face, researchers began the 'Cross-Cultural Speech Act Realisation Patterns' (CCSARP) project in the early 1980s to compare politeness devices 
across different speech acts in different cultures and languages ${ }^{1}$, particularly focussing on FTAs like refusals and requests. A request is defined as a speaker's attempt to get the hearer to do something. It usually requires the hearer's time, energy or material resources (CCSARP 1989, in Blum-Kulka, House \& Kasper 1989a). This section will review research from crosscultural to interlanguage pragmatics on request heads and external modifiers.

\subsubsection{Cross-cultural pragmatics}

Following Searle's $(1969,1975,1979)$ assumptions that certain forms of indirectness are conventionally used by people within a speech community, and that people need to use politeness devices to minimise the threat to one's face, a team of researchers ${ }^{2}$ in the CCSARP project investigated a repertoire of linguistic behaviour across various languages to establish both the similarities and differences between cultures. The researchers' first set of crosscultural pragmatic studies on apology and request devices contributed significantly toward the understanding of linguistic behaviour across numerous cultures (e.g., Blum-Kulka 1982, 1983, 1987, 1989; Blum-Kulka, Danet \& Gerson 1985; Blum-Kulka \& House 1989; BlumKulka \& Olshtain 1984; House \& Kasper 1981). Requests have attracted much attention because they give insight into the different associations between the forms and functions of a speech act based on context across cultures (Blum-Kulka, House \& Kasper 1989b). For this reason, this study focuses on the learners' development of request devices. The rest of this section will review research on request heads and external modifiers, particularly focussing on comparisons between Australian English and Chinese.

\subsubsection{Request heads}

Based on the earlier empirical work (Blum-Kulka, Danet \& Gerson 1985; House \& Kasper 1981), the CCSARP project researchers reported three universal levels of directness in request devices, and have coded types of request strategy based on the degree of directness: direct, conventional indirect and nonconventional indirect requests:

Direct Request: The illocutionary force of the request is expressed in the utterance by grammatical, lexical or semantic items. It is the most direct, explicit form of requesting. The three types of direct requests are imperatives, performatives and want statements.

\footnotetext{
${ }^{1}$ The CCSARP examined the following languages: Australian English, American English, British English, Canadian French, Danish, German, Hebrew and Russian.

${ }^{2}$ The CCSARP research team comprised Shoshana Blum-Kulka, Claus Farch, Julian House, Gabriele Kasper, Elite Olstein, Jenny Thomas, Eija Ventola, Elda Weizman and Nessa Wolfson.
} 
Conventional indirect request: The illocutionary force of the request is made via fixed linguistic conventions established in the speech community. The illocutionary act has two functions. To be able to interpret a question of ability as an indirect request, the addressee does not have to go through a long analysis process. This is because addressees can exploit the grammatical structures of questions as conventionally used to signal indirect requests.

Nonconventional indirect request: This is expressed by addressers making partial reference to the requested act, object or addressees' involvement. The interpretation of these devices requires addressees to compute the illocution from the context. This is because the addresser's request that the addressee carry out an act is expressed in such a way that the recognition of the addressee's intention is not made explicit in the utterance meaning. This gives both the addresser and the addressee the opportunity to opt out of performing the request at any stage. In CCSARP coding, statement hints and pre-request questions are the most indirect and nonconventional form of requesting.

Although the semantics of a request can be applied across cultures, the conventions of these request devices have been found to vary across cultures ${ }^{3}$ (Blum-Kulka \& House 1989; BlumKulka, 1989, 1991; Weizman, 1989, 1993). There is evidence that the levels of directness, meanings and the appropriate use of request devices is situation- and culture-specific (see Blum-Kulka 1982, 1987; Færch \& Kasper 1989; Blum-Kulka, House \& Kasper, 1989b; Fraser, Rintell \& Walters 1980).

Blum-Kulka and House (1989) found that cross-cultural variations in request directness varied across cultures when participants were asked to make a request expressing a desire for the addressee to perform an act such as 'clean the kitchen' or 'borrow notes'. The Australian English speakers were the least direct, with a minority of the request devices phrased as direct requests such as imperatives (about 10\%). A majority of requests were phrased as indirect requests (about 90\%). In fact, a great proportion of indirect requests were formed as modal + verb phrase (VP) as in 'Could you + VP?', 'Would you + VP?', or 'Would you mind + VP?' (total of $80 \%$ ), and a minority of requests were hinting devices (8\%). In contrast, Argentine

\footnotetext{
${ }^{3}$ American English, Australian English, Argentine Spanish, Canadian French, and Hebrew (Blum-Kulka 1989; Blum-Kulka and House, 1989); German (House, 1989); Japanese (Takahashi, S. \& DuFon 1989, in Takahashi, S. 1992; Takahashi, S. 1990, 1992, 1996; Takahashi, S. \& Roitblat, 1994) and more recently, Chinese (Zhang 1995, in Kasper \& Schmidt 1996).
} 
Spanish speakers used more direct devices (60\%) than indirect requests (40\%) (Blum-Kulka \& House 1989: 134).

A series of studies carried out by Takahashi $(1990,1992,1996)$ showed that the forms used to express requests in one language differed in meaning from another language, which could lead to cross-cultural miscommunication (Thomas 1983; Tannen 1984). For instance, the utterance 'Can you + VP?' functions as an indirect request in English, whereas in Japanese 'Can you + VP?' functions only as a question of ability (and, similarly, with Chinese, as Bouton 1988). Therefore, Japanese speakers could mistakenly interpret the English request 'Can you + VP?' as a question of ability (e.g., Takahashi 1992). This phenomenon can be clearly illustrated by Blum-Kulka's (1989) study which reported that there is a rich repertoire of devices in all three directness levels of requests. For instance, native speakers (NSs) of Australian English prefer and frequently use the forms 'Can/Could you + VP?' (66.5\%), 'Will/Would you + VP?' (17.7\%), 'Would you mind' (10.5\%), instead of using possibility $(1.0 \%)$-'How about' (1.3\%), and 'Why don't you' (1\%)— to express indirect requests. Therefore, the meaning of the illocutionary force of such forms may be lost when translated into other languages.

Interestingly, other researchers (e.g., Heinemann 2006; Vinkhuyzen \& Szymanski 2005, in Curl \& Drew 2008) have suggested speakers orient their use of request devices to the appropriateness of certain linguistic forms based on situation. For example, in a study conducted by Vinkhuyzen and Szymanski (2005, in Curl \& Drew 2008) that examined customers' use of forms such as 'I need ...' and 'Can you make ...?', they found that customers' use of 'I need + VP' and 'Can you make + VP?' were associated with their knowledge of whether the organization (a copy shop) provided the particular service they were requesting, which, in turn, may be related to customers' relative expertise. Curl \& Drew (2008) extended the comparison to two other syntactic forms of conventional requests English speakers used to make requests 'Can you' and 'I wonder'. They investigated ordinary telephone calls between family and friends and out-of-hours calls to the doctor. Accordingly, speakers used 'Can/Could you + VP?' and 'I want + VP' forms in an everyday or an institutional setting and where they felt the conditions necessary for their request to be granted were unproblematic. Speakers tended to use 'I wonder + VP' where they were unsure whether the request conditions could be met (e.g., when schedules, procedures, or practices were not known), or they perceived themselves as potentially lacking entitlement. This 
suggests different syntactic forms have different levels of impositions in English (Curl \& Drew 2008: 148). For example, the 'I wonder + VP' structure does not exist as a request form in Chinese. Learners are more likely to primarily rely on the 'modal + VP'. Thus, researchers have not reported on Chinese speakers of English using 'I wonder' as a request in English.

\subsubsection{External modifiers}

Within B\&L's (1987) framework, requests are viewed as inherently FTAs. According to Blum-Kulka, House \& Kasper (1989b: 255), external and internal modifiers are used as a source to mitigate the imposition of requests and protect face. This study focuses specifically on external modifiers. This section will provide frameworks for external modifiers developed by CCSARP researchers (e.g., Blum-Kulka, House \& Kasper 1989a; Blum-Kulka \& Olshtain 1984; House \& Kasper 1987; Trosborg 1995).

External modifiers are supporting statements that are used by a requester outside the request head to persuade the hearer to carry out the desired act. Table 1 illustrates these supportive moves, functions and examples (adapted from the CCSARP Manual 1989, in Blum-Kulka, House \& Kasper 1989a; Economidou-Kogetsidis 2008, 2009; Schauer 2007; Trosborg 1995) in CCSARP expressions used by the student writers in this study.

Table 2.1: Classifications of external modifiers, functions and examples

\begin{tabular}{|l|l|l|}
\hline $\begin{array}{l}\text { Types of external } \\
\text { modifiers }\end{array}$ & Function of devices & Examples \\
\hline Alerter & $\begin{array}{l}\text { Used to get interlocutor's } \\
\text { attention; precedes the Head. }\end{array}$ & Excuse me; hi; Professor/Jane \\
\hline Preparator & $\begin{array}{l}\text { Used to prepare the interlocutor } \\
\text { for the request; can follow or } \\
\text { substitute the alerter. }\end{array}$ & Can you do me a favour? \\
\hline $\begin{array}{l}\text { Getting pre- } \\
\text { commitment }\end{array}$ & $\begin{array}{l}\text { Used to commit the hearer to the } \\
\text { request prior to the actual } \\
\text { request. }\end{array}$ & $\begin{array}{l}\text { Could you do me a favour? } \\
\text { from yesterday's class? }\end{array}$ \\
\hline $\begin{array}{l}\text { Acknowledging the } \\
\text { imposition of the } \\
\text { request }\end{array}$ & $\begin{array}{l}\text { Used to show awareness of the } \\
\text { inconvenience caused to the } \\
\text { hearer and acknowledges the } \\
\text { imposition created by the } \\
\text { requested action. }\end{array}$ & $\begin{array}{l}\text { Imposition. } \\
\text { impland this is an }\end{array}$ \\
\hline $\begin{array}{l}\text { Complimenting the } \\
\text { addressee }\end{array}$ & $\begin{array}{l}\text { Used to compliment the } \\
\text { addressee. }\end{array}$ & $\begin{array}{l}\text { My teacher said that you are the } \\
\text { top student in the class. }\end{array}$ \\
\hline
\end{tabular}




\begin{tabular}{|c|c|c|}
\hline Showing gratitude & $\begin{array}{l}\text { Used to thank the hearer for } \\
\text { his/her help. }\end{array}$ & Thank you for your help. \\
\hline $\begin{array}{l}\text { Pointing out the } \\
\text { importance of the } \\
\text { request }\end{array}$ & $\begin{array}{l}\text { Used to emphasise the } \\
\text { importance of making the } \\
\text { request. }\end{array}$ & $\begin{array}{l}\text { I must borrow your notes by } \\
\text { today. }\end{array}$ \\
\hline Apologising & $\begin{array}{l}\text { Used to apologise for an } \\
\text { inappropriate act or for the } \\
\text { inconvenience caused to the } \\
\text { addressee. }\end{array}$ & $\begin{array}{l}\text { I am very sorry you have to pay } \\
\text { for my lunch. }\end{array}$ \\
\hline $\begin{array}{l}\text { Offering } \\
\text { compensation }\end{array}$ & $\begin{array}{l}\text { Used as an offer to compensate } \\
\text { the hearer for the inconvenience } \\
\text { caused by the requested act. }\end{array}$ & $\begin{array}{l}\text { I can pay you interest on the } \\
\text { money you lend me. }\end{array}$ \\
\hline $\begin{array}{l}\text { Pointing out the } \\
\text { negative } \\
\text { consequences of } \\
\text { refusal to the } \\
\text { listener }\end{array}$ & $\begin{array}{l}\text { Used to point out the negative } \\
\text { consequences for the speaker if } \\
\text { the request is rejected. }\end{array}$ & $\begin{array}{l}\text { I will hand in my work late and } \\
\text { lose marks if you don't show me } \\
\text { how to finish it. }\end{array}$ \\
\hline $\begin{array}{l}\text { Pointing out the } \\
\text { benefits the author } \\
\text { would gain if the } \\
\text { request were } \\
\text { approved }\end{array}$ & $\begin{array}{l}\text { Used to point out the benefits for } \\
\text { the speaker if the request were } \\
\text { approved. }\end{array}$ & $\begin{array}{l}\text { You will get bonus marks if you } \\
\text { present your work today. }\end{array}$ \\
\hline Grounder & $\begin{array}{l}\text { Used as an explanation for the } \\
\text { request. }\end{array}$ & Please be quiet, I need to sleep. \\
\hline Disarmer & $\begin{array}{l}\text { Used to pre-empt the hearer's } \\
\text { potential objections. }\end{array}$ & $\begin{array}{l}\text { I know you are really busy but } \\
\text { could you hand in your } \\
\text { assignment earlier? }\end{array}$ \\
\hline $\begin{array}{l}\text { Imposition } \\
\text { minimizer }\end{array}$ & $\begin{array}{l}\text { Used to reduce the imposition of } \\
\text { the request. }\end{array}$ & $\begin{array}{l}\text { I will return them immediately, } \\
\text { the next day. }\end{array}$ \\
\hline Sweetener & $\begin{array}{l}\text { Used to flatter the hearer and to } \\
\text { put him/her into a positive } \\
\text { mood. }\end{array}$ & $\begin{array}{l}\text { I think you are the perfect } \\
\text { person to do it. }\end{array}$ \\
\hline $\begin{array}{l}\text { Promise of } \\
\text { Reward }\end{array}$ & $\begin{array}{l}\text { Used to offer the hearer a reward } \\
\text { for fulfilling the request. }\end{array}$ & $\begin{array}{l}\text { I will cook your dinner if you } \\
\text { clean the toilet. }\end{array}$ \\
\hline Small talk & $\begin{array}{l}\text { Used at the beginning of the } \\
\text { request as a way to establish a } \\
\text { positive atmosphere. }\end{array}$ & Good to see you. \\
\hline Appreciator & $\begin{array}{l}\text { Used at the end of the request to } \\
\text { positively reinforce the request. }\end{array}$ & $\begin{array}{l}\text { It would be wonderful if you } \\
\text { could hand in your work early. }\end{array}$ \\
\hline Considerator & $\begin{array}{l}\text { Used at the end of the request to } \\
\text { show consideration towards the } \\
\text { interlocutor's situation. }\end{array}$ & $\begin{array}{l}\text { Only if you've got the time of } \\
\text { course. }\end{array}$ \\
\hline
\end{tabular}




\begin{tabular}{|l|l|l|}
\hline $\begin{array}{l}\text { Asking for } \\
\text { forgiveness }\end{array}$ & $\begin{array}{l}\text { Used to ask for forgiveness for } \\
\text { what s/he has done. }\end{array}$ & Please forgive me. \\
\hline $\begin{array}{l}\text { Giving options to } \\
\text { the hearer }\end{array}$ & $\begin{array}{l}\text { Used to provide options to the } \\
\text { hearer as far as the details of } \\
\text { carrying out the request and the } \\
\text { possible rejection of the request } \\
\text { are concerned. }\end{array}$ & $\begin{array}{l}\text { You could choose the place and } \\
\text { the time for the interview. }\end{array}$ \\
\hline Showing sincerity & $\begin{array}{l}\text { Used to emphasise speaker's } \\
\text { desire to receive a positive reply. }\end{array}$ & $\begin{array}{l}\text { I sincerely hope that you can } \\
\text { help } \text { me }\end{array}$ \\
\hline
\end{tabular}

In addition to the research conducted on the range of external modifiers provided above, research has also studied the use of 'please' in a speech act like request. Researchers have reported two main functions of 'please'-addressee-focal politeness marker (e.g. BlumKulka \& Levenston 1987; Dalton-Puffer 2005; Economidou-Kogetsidis 2005; Færch \& Kasper 1989; House \& Kasper 1981; Lwanga-Lumu 2002; Stubbs 1983; Trosborg 1995) and request marker (e.g., House 1989; Lee-Wong 1994a; Pedlow, Wales \& Sanso 2001; Wichmann 2004). Researchers who contended 'please' is an addressee-focal politeness marker proposed 'please' is a lexical downgrader, which functions as a softener in an inherently face-threatening act carried by the specific request and/or by the formal aspects of imperative sentences (e.g. Blum-Kulka \& Levenston 1987; Dalton-Puffer 2005; Economidou-Kogetsidis 2005; Færch \& Kasper 1989; House \& Kasper 1981; Lwanga-Lumu 2002; Stubbs 1983; Trosborg 1995). In contrast, researchers who argued 'please' functions as a request marker have proposed 'please' is a highly ritualised, formulaic expression used as part of a request (Gleason, Perlmann \& Greif 1984; Watts 2003).

While some researchers have primarily focussed on determining whether 'please' is used as an external (e.g., Martinez-Flor 2009) or internal (Achiba 2003; House \& Kasper 1981; Trosborg 1995) request modifier to mitigate its imposition of a request, other researchers (e.g., Sato 2008; Wichmann 2004) have examined the functions of 'please' in a request relative to its position in a turn constructional unit. Sato (2008), for example, found that New Zealand and American English speakers frequently used 'please' as an external or internal modifier in requests to express different levels of directive force. The directive force of 'please' is strongest when it appears as an external modifier either at the beginning or at the end of a request. An English request with 'please' at the beginning signals demands, pleas, a sense of urgency, and enthusiasm. For instance, in a directive such as 'Please come home. 
Something's wrong.', a speaker intends to assert compliance and shows little willingness to negotiate or compromise. In such an utterance in English, the speaker adheres to claiming his/her face needs rather than observing the face needs of others, and therefore do not intend to convey politeness to the interlocutor.

A request with 'please' in the final position is claimed to be as equally powerful as one in which it is in the initial position. However, speakers who use 'please' at the end of a request intend to appeal to the hearer's judgment about how a sensible social individual is expected to act in a given context (Sata 2008: 1273). For instance, in a request such as 'Come home please', speakers intend to show they are acting appropriately in a social situation while making a request. Although the level of imposition appears lower than when 'please' is used at the front of a request, compliance is strongly presumed in these cases since the requests are designed to appeal to the hearer's desire to maintain his/her public self-image, the loss of which is thought to be detrimental to the hearer.

On the other hand, 'please' inside a request ranges in different levels of forcefulness. The use of 'please' in a command is a more direct way to request people to comply to a request. In a direct request like 'you are asked please to assess the evidence in a cool...way', compliance is enforced on the basis of the requester asserting authority over the recipient. If the recipient chooses not to comply, s/he may face a serious social consequences. However, when 'please' is used inside a conventional polite request, the requester acknowledges the request is a facethreatening act and engages in facework based on an egalitarian stance. Compliance can neither be enforced nor presumed; it can only be secured through the process of negotiation with the hearer.

From a cross-cultural perspective on the use of external and internal request modifiers, Færch and Kasper (1989) also reported that internal and external modification work independently. While internal modification is important, external modification is optional in languages such as British English, German and Danish. Chinese is the opposite. Even though Chinese indirectness is realised as conventional indirect requests and exists in interaction, indirectness is not used without external modifications preceding the request (e.g., Kasper \& Zhang 1995; Lee 2011; Zhang 1995a,b). The formulation of the utterance itself and its internal modification do not constitute indirectness. Chinese indirectness seems to be linked with information sequence. English indirectness depends on whether the speaker's intended 
proposition precedes any small talk or supportive moves, and how the speaker intends to convey a communicative intention before explicitly bringing it up. The degree of indirectness is determined by the length of the supportive moves which do not contain, explicitly, the intended proposition (e.g., Kasper \& Zhang 1995; Lee 2011; Zhang a,b).

This section has provided an overview of the differences as to how speakers use politeness devices to minimise the imposition of a request. Interestingly, even though both Australian English and Chinese speakers use conventionally indirect requests, Australian English speakers frequently employ external modification to express indirectness, which equates to politeness. However, Chinese politeness does not equate indirectness and speakers do not use external modification to minimise the imposition of requests.

\subsubsection{Interlanguage pragmatics}

Interlanguage Pragmatics (ILP) is the interdisciplinary study of pragmatics and second language acquisition (SLA) research. Learners' 'interlanguage' describes the stage when they begin to transit from using their first language linguistic features to learning linguistic features of the second language (Selinker 1972). Learners' interlanguage systems can be identified through learners' errors and are defined by Larsen-Freeman and Long (1991) as systematic deviations made by learners who have not yet mastered the rules of the second language. This section will present findings from request devices, with particular focus on research in English and Chinese.

ILP researchers typically compare the similarities and differences between the way learners and NSs produce a speech act (Blum-Kulka, House \& Kasper 1989b; Hassall 2001; Trosborg 1995), or measure learners' pragmatic performance/development in comprehension or production of a speech act such as refusal or request (Cook 1993; Rose 2000; Kogetsidis \& Woodfield 2007; Woodfield 2008a, 2012). Much of the research conducted on speech act categories and external modifiers (e.g., for requests) is based on the work of the CCSARP researchers (1989).

In order to communicate effectively in a second language, interlocutors must realise the form and meaning of direct request devices in that language as well as the illocutionary force of indirect request devices. That is, learners must be able to interpret when speakers say one 
thing while meaning something else, and how the intended meaning can be expressed in the L2. In addition, learners have to acquire the ability to appropriately use internal and external modifiers with a request head to minimise the imposition of a request (Kasper \& Blum-Kulka 1993). The following section reviews interlanguage pragmatics research on request heads and external modifiers.

\subsubsection{Request heads}

ILP researchers who have examined learners' ability to comprehend and use request heads tend to measure learners' pragmatic proficiency, and compare their performance to NS norms.

Developmental studies in ILP have consistently demonstrated learners are likely to progress from direct to more conventionally indirect request devices as they become more proficient (e.g., Barron 2003, 2007a, 2008; Bouton 1994, 1996, 1999; Carrell 1984; Cook \& Liddicoat 2002; Garcia 2004; Hassall 2001, 2003, 2006; Holtgraves 2007; Kasper 1984; Takahashi \& Roitblat 1994; Taguchi 2002, 2005, 2008a,b, 2010). Research has generally shown that learners' use of request heads and modifications converge on more L2 norms with increasing competence. Kasper and Rose's (2002: 157) review of pragmatic developmental studies indicates that, especially in requests, learners tend to rely on direct forms of request heads in the early stages of development, with a gradual move to conventionally indirect request heads. The literature has also consistently indicated that learners' use of external modifications increases in frequency and range with increasing competence (e.g., BardoviHarlig 2006, 2008; Barron 2003, 2007a; Schauer 2006a,b 2008).

A growing number of L2 studies have examined the ability to comprehend speakers' intentions that are not explicitly stated (Bouton \& Kacuru 1994; Cook \& Liddicoat 2002; Garcia 2004; Holtgraves 2007; Kasper 1984; Koike 1996; Taguchi 2002, 2005, 2008a,b, 2010; Takahashi \& Roitblat 1994). These studies revealed that successful comprehension of implied meaning depends on the levels of indirectness encoded in the utterances as well as learners' general L2 competence. Implicatures conveyed through conventional forms are easier to comprehend, once the conventions are learned or shared between L1 and L2. Nonconventional implicatures, on the other hand, are difficult to comprehend because they require extensive inferential processing. 
Rose (2000) revealed in his cross-sectional study examining English requests produced by L1 Cantonese-speaking primary school children that all children preferred to use conventional indirect requests in Cantonese. Most learners in the highest grade (Grade 6) preferred conventional indirect English requests followed by English learners in Grade 4, and with Grade 2 learners using mostly direct requests. Rose (2000) explained as learners' proficiency increased, they were less likely to transfer their Cantonese direct request strategy across to English. This finding was also supported by other researchers (Lee 2005, 2011; Lee-Wong 1998; Zhang 1995a,b) who found, even though Chinese speakers prefer to use direct requests in Chinese, they use conventional indirect requests in English, suggesting that learners did not transfer from L1 to L2 as their language proficiency increased.

The variability found between NSs and non-native speakers (NNSs) has been explained predominantly in terms of L2 learners' proficiency levels, assessment of the equivalence between learner's L1 and L2 (e.g., Takahashi 1992, 1996; Takahashi \& Roitblat 1994), and transferability features of learners' L1 to L2 features as an explanation (Takahashi 1990). Most research on request devices has found that learners' progress from direct to conventionally indirect request heads as they become more linguistically competent. The following section will discuss literature on how proficiency in using external request modification develops.

\subsubsection{External modifiers}

To date, a majority of ILP research on external supportive devices for requests have reported grounders as the most frequently used supportive move for requests amongst English NSs (House \& Kasper 1987; Trosborg 1995) and learners (Blum-Kulka \& Olshtain 1986; Færch \& Kasper 1989; Felix-Brasdefer 2005, 2009; Hassall 2001; Schauer 2007; Woodfield 2007, 2012; Woodfield \& Economidou-Kogetsidis 2010, 2012). Hassall (2001: 266) found that grounders are either used as negative politeness strategy (to convey an intention by the speaker not to impose), or positive politeness strategy (by assuming the hearer's cooperation).

Hassall's (2001) study of a group of 20 Australian English NSs learning Indonesian at a university revealed that these learners over-used grounders and were over-explicit in using external supportive moves compared to native Indonesian speakers in the oral role-play data. According to Hassall (2001: 266), learners over-used reasons/explanation, so they can explain to the hearer that they do not impose on him or her without a good reason, thus 
achieving negative politeness. It may also be that learners excessively use grounders because they do not have knowledge of the standard routines. This is labelled as the 'waffle phenomenon' (Edmondson \& House 1991: 274).

Other researchers (Barron 2005 in Barron 2007a, 2007a, 2008; Blum-Kulka \& Olshtain 1986; Economidou-Kogetsidis 2008; Economidou-Kogetsidis \& Woodfield 2008; Færch \& Kasper 1989, Hassall 2001, Schauer 2006b, 2007, 2008; Woodfield 2007, 2012) also found that grounders are the main external modifiers used by both by NSs and NNSs in English and across languages (Færch \& Kasper 1989; Hassall 2001, 2008). For example, EconomidouKogetsidis (2009) studied Greek learners at a university in Great Britain and a group of NSs of British English for an average of 2.8 years. Using Discourse Completion Tasks (DCTs) designed to elicit requests in writing and semi-structured interviews, it was found that learners generally underused apologies, but overused disarmers, preparators, and most of all grounders. While English NSs generally employed vague explanations, the learners provided much greater detail by providing specific reasons and explanations related to poor health and family emergencies. In terms of achieving B\&L's (1978) positive and negative politeness, Hassall (2001) pointed out that learners tended to use grounders as they can convey positive politeness by assuming the hearer's cooperation. The learners assumed that the hearer will respond positively to the request once s/he hears the reasons/explanation for it (B\&L 1978: 133).

Consistent with Economidou-Kogetsidis and Woodfield's (2008) findings, Woodfield \& Economidou-Kogetsidis (2010) conducted an investigation on status-unequal requests and use of modifications made by 89 advanced mixed-L1 English learners and 87 British English native speakers elicited by a written discourse completion task. Results showed that the learners used significantly fewer imposition minimisers and apologies than English NSs, but overused preparators. Though NSs and learners used grounders most frequently, there were qualitative differences. Learners tended to provide more detailed grounders than NSs. NSs were more likely to use modifiers interpersonally to signal shared knowledge, indicate common ground and to focus the topic of the request. The native speakers used grounders from a more impersonal perspective with a range of internal mitigation devices, and formulaic constructions. 
Similarly, Woodfield's (2012) recent investigation of the development of request modification devices showed that SALs also acquired external modification at different rates. The responses were collected using status equal and unequal open role-plays from eight SALs from Taiwan, China, Korea and Japan studying in a British university for eight months. Woodfield (2012) found the eight SALs had approximated English native speaker levels on using a range of request external modifications such as grounders, alerters, discourse orientation moves, preparators and imposition minimisers at the onset of graduate study in the target language community. However, these SALs took longer to acquire certain modification devices such as considerators and appreciators.

In general, it appears grounders are acquired by learners quite early in their development. One possible explanation for learners' reliance on grounders is that providing reasons is the usual way that requests are effectively justified in their L1 and L2 (Blum-Kulka 1991; Hassall 2001). It may be that offering explanations and/or justifications for a request does not require knowledge of idiomatic use and simply involves the construction of a syntactically simple clause (Hassall 2001: 274). Hassall (2001: 267) and Woodfield (2012) both explained the 'non-native effect' of providing redundant or over-explicit information and excessive repetition may be related to learners' concern for clarity (Kasper 1982) and so they used a 'playing it safe' strategy (Færch \& Kasper 1989). It may also be that learners lacked confidence in communicating meaning (Blum-Kulka \& Olshtain 1986).

Furthermore, Warga (2004, in Barron 2007b) and Edmondson and House (1991) suggested waffling may be more likely to occur amongst learners with intermediate grammatical proficiency. Blum-Kulka and Olshtain (1986) conducted a study of request realisations by American English L2 learners of Hebrew living in the target community (Israel) for different lengths of time. Data from DCTs suggested that waffling increased with increasing competence. Hassall (1997, in Hassall 2001) found that intermediate learners tended to waffle more than beginners and advanced learners. Both Blum-Kulka and Olshtain (1986) and Hassall (1997, in Hassall 2001) claimed it is plausible that beginners could not waffle due to linguistic constraints, as a result of limited linguistic competence, and advanced learners have the competence to use various supportive moves to mitigate impositions without lengthy justifications as they approach the native speaker norm. The intermediate learners, nevertheless, have enough linguistic knowledge to justify at length their speech acts, but are 
not quite competent enough to use different devices to mitigate speech acts, thus forming a U-shaped curve of development related to linguistic competence.

It appears that learners tend to use devices formulaic to them from their L1 to soften speech acts before their repertoire of pragmatic devices can grow with increasing linguistic competence. Subsequently, learners become more confident in their linguistic and pragmatic ability. If grounders are commonly used across languages, then it is not surprising that learners, especially those with low linguistic competence, over rely on this device before they use other softening devices like preparators and minimisers.

\subsubsection{Research on requests in Chinese \& Australian English}

The previous sections provided an overview of research on Cross-Cultural Pragmatics and Interlanguage Pragmatics. As this study aims to investigate Hong Kong learners' development of request devices during their nine-month sojourn in Australia, this section will define the types of direct, conventional indirect and non-conventional indirect requests in Australian English and Chinese, as well as the little research that has been conducted on external modifiers.

\subsection{Request heads}

\section{i. Direct requests:}

\section{Australian English}

Direct request devices are expressed as imperatives 'Pass me the salt (+ please)', performatives 'I am asking you to + VP', and want statements 'I want you to + VP'. For example, an Australian English imperative such as 'Please give me a beer' can be defined as a direct request (Blum-Kulka 1989a). Australian English speakers tend to use less direct forms, as direct requests would seem impolite, and prefer the more indirect form of requests.

\section{Chinese}

In Chinese, unlike Australian English, there are three forms of direct request which take distinct structural forms: imperatives, performatives and want statements. 


\section{Imperatives}

Direct requests are the most proper and efficient way of making requests in Chinese as this language does not have the range of modals that exist in English. Instead, it would be polite to make a direct request without markers in Chinese (see example below).

Dài nǐ érzi yìqǔ lái.

Bring you son together come. (Come with your son.)

Politeness can also be achieved by using q̌̃ng 'please', and tags such as kěyı̌ ma, kě bù kěy̌ are used to make a proper request (Lee-Wong 1994a). For example:

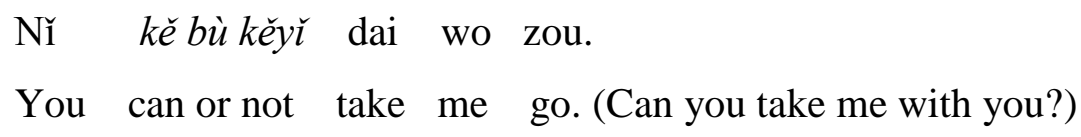

A more sincere query can also be acquired by other polite markers such as bāng 'help' and máfán nı̌ 'bother you'. For example:

máfán nǔ, qǔng nǐ bāng wŏ chá yì chá.

bother you, please you help me check one check.

(Sorry to bother you. Please help me check.)

\section{Performatives}

In Chinese, the performative verbs which convey request intent range from the explicit to more polite utterances. For example, in Chinese one can explicitly mark the utterance as an order (e.g., minglìng 'order', ràng 'let', jiào 'call' and yāoqiú 'ask'):

$\begin{array}{lcc}\text { Wŏ } & \text { ming lìng nì líkāi. } \\ \text { I } & \text { order } \quad \text { you leave. (I order you to leave.) }\end{array}$

The more polite marking of an utterance is a sincere plea, even to the extent of begging (e.g., 'please ask', kěnqiú 'sincerely ask', qiú 'beg/ask', qǔqiú 'pleadingly ask', qiúqiú 'beg'). Qiú is the most common basic form of performative as it does not require extra effort or a pleading with desperation. For example:

Wŏ qiú nǐ jiè diăn qián.

I beg/ask you borrow some money. 


\section{Want Statements}

Want statements are more direct. They include statements of speaker's needs, demands, wishes and desires. Unlike in English, these are not impolite. Want statements such as the one illustrated below shows a close relationship between the requester and the requestee and the level of directness which is appreciated in making a request.

$$
\begin{array}{llll}
\text { Wŏ } & x \bar{u} y a ̀ o & \text { yì běn } & \text { zìdiăn. } \\
\text { I } & \text { need one (classifier) } & \text { dictionary. }
\end{array}
$$

\section{ii. Conventional indirect requests:}

\section{Australian English}

CCSARP researchers identified suggestory formula (e.g., 'How about + VP?') and query preparatory ('Would you + VP?') in Australian English (Blum-Kulka 1989), as ways of expressing conventional indirect requests.

\section{Chinese}

Conventional indirect requests in Chinese use suggestory formulae and query preparatory. Suggestory formulae imply that the addressee should have done what was obviously the right thing for the speaker to do. Chinese speakers can also use 'politeness formulae' to request insistently that the addressee do something which benefits, and is appreciated by, the addressee in the Chinese culture. For example:

Gànma bú jìn lái?

do what not enter come (Why not come in?)

While English and Chinese have some equivalent forms, not all English query preparatory forms function as requests in Chinese. For example, when a basic interrogative form, such as, Will you close the door please?, is translated from English into Chinese, it is considered to be both the most polite and most common practice to add the word qing 'please' in making the request.

Unlike in English, however, pseudo-questions such as Would you do it?, Won't you do it?, Do you want to do it? or Would you like to do it? are not preferred in Chinese, since they are considered superficial. They seem to inquire into the addresser's desires, but should be 
interpreted as requests. In Chinese it is preferable for requests to be direct. Literal equivalents of sentences in the frame Why don't you as in Why don't you close the window? would be interpreted as a combination of a question and a criticism in Chinese.

Ní wèishénme bù guān shàng chuānghù?

you why not close up window

Why don't you close the window?

Such an utterance would appear unreasonable and stubborn to the Chinese addressee. It implies the speaker believes the addressee obviously did not do the right thing, but the same utterance in English may or may not be interpreted in this way.

Similarly, utterances with the frame Would you mind are seldom used to show politeness in Chinese. Only those speakers who are strongly influenced by the English language tend to use it. Instead, one could perform requests, or acts closely related to requests, by asking about the addressee's ability to do something, such as Nĩ néng ... ma? (Could you ... ?). When a speaker of Chinese gets angry with the hearer but wants to show it in a polite way, he/she will often avoid the imperative and resort to the device of interrogative forms. The interpretation of what is socially acceptable and how language functions clearly differs between cultures.

\section{iii. Nonconventional indirect requests:}

\section{Australian English}

In Australian English an utterance such as 'The kitchen is a bit untidy' may function as a hint, expressed by speakers in such a way as to let the addressees know that they are responsible for the performance of the act, but the speaker does not make the request explicit (Weizman 1989, 1993). The interpretations of these requests rely on context. In this study, statement hints are considered to be nonconventional indirect request devices.

\section{Chinese}

Hints are often used when speakers have power over the addressees, and when the speakers intend to question addressees' commitment, questioning feasibility, or starting potential grounders before they launch requests. Hints tend to be used when the speakers are in a close relationship and have good knowledge of the background situation. Such hints are also often 
used as adequate support for the more direct requests (Ye 1995). There are two commonlyused formulae in Chinese request hints. As in English, the interpretation of hints depends on the context. Request frames such as zài ma? (is/are ... ?) and $n \breve{\imath} . . . m a$ ? (are you ...?) are common Chinese hints. For instance, $n \breve{\imath}$... ma? signals there is a forthcoming request. As the hearer may be anxious to know what request it is, he or she can sometimes reply directly with a question instead of an answer: shénme shì ba? (literally: 'what matter?')

To date, a majority of studies that have examined Chinese request devices are conducted on Mandarin Chinese, not Cantonese. However, researchers have shown both Cantonese and Mandarin speakers are similarly direct when making requests (see for example, Lee-Wong 1994b, 1998, 2000 on Mandarin; Rose (2000) and Lee (2005, 2011) on Cantonese).

Zhang (1995a) found that Chinese NSs prefer query preparatory (54.2\%), accounting for more than half of the possible cases from all three levels of directness. Most prefer conventional indirect requests $(59.2 \%)$, followed by direct requests $(26.4 \%)$ and hints $(9.5 \%)$. Zhang (1995a) and Ye (1995) also reported identical conventional indirect request devices in Mandarin Chinese (ni neng...ma?). A significantly lower proportion of nonconventional indirect requests are used in Mandarin Chinese (data not exceeding 10\%, with over 50\% conventional indirect requests) (Blum-Kulka, House \& Kasper 1989b; Gu 1990; House \& Kasper 1987; Kasper 1989; Ye 1995; Zhang 1995a). Researchers (Blum-Kulka \& House 1989) also found that because English speakers avoided using imperatives in many situations, they were also reluctant to use the Chinese imperative/want statement + tag structure. In contrast, Chinese learners of English tended to transfer the Chinese structure into English by using imperative/want statements plus 'ok/all right'.

\subsection{External modifiers}

Færch and Kasper (1989) reported internal and external modification work independently from each other. While internal modification is important, external modification is optional in languages such as Australian and British English, German and Danish. Chinese is the opposite. While Chinese indirectness is realised as conventional indirect requests and exists in interaction, indirectness is not used without external modifications preceding the request. The formulation of the utterance itself and its internal modification do not constitute indirectness. 
Chinese indirectness seems to be linked with information sequence. Directness depends on whether the speaker's intended proposition precedes any small talk or supportive moves, and how the speaker intends to convey a communicative intention before explicitly bringing it up. The degree of indirectness is determined by the length of the supportive moves which do not contain explicitly the intended proposition. In Chinese, interrogative + negations $(0.6 \%)$ were used. Lexical and phrasal downgraders were displayed as follows-grounders (36.1\%), apologising (8.3\%), cost-minimising (6.4\%), sweetener (6.1\%), self-criticising $(5.7 \%)$, preparatory $(3.3 \%)$, advice-seeking $(2.7 \%)$, thanking $(2.5 \%)$, pre-commitment $(0.6 \%)$, promise $(0.6 \%)$, direct appeal $(0.6 \%)$, offer of help $(0.6 \%)$, reprimanding $(0.6 \%)$, moralising statement $(0.3 \%)$, threat $(0.3 \%)$, promise of reward $(0.3 \%)$, opt out $(2.2 \%)$ (Zhang 1995a: $64)$.

Thus, there are notable differences in the way Australian English and Chinese speakers use request modifications to mitigate the imposition of requests. Australian English speakers use internal modification to minimise the imposition of requests, while Chinese speakers employ a range of external modification to mitigate the imposition of requests.

In summary, this section has highlighted the contribution of cross-cultural pragmatics research in interlanguage pragmatics, particularly on Australian English and Chinese request heads and external modifiers. The CCSARP studies have established categories of conventional devices used to express politeness in a range of speech acts in numerous languages. Thus, differences between the conventional devices used to express politeness in language learners' L1 and L2 can help explain learners' errors in the acquisition of pragmatic skills in another language.

\subsection{Summary}

This chapter has reviewed the development of politeness theories from the work of B\&L to post-modern and neo-politeness approaches. It has highlighted how the premises of speech act, and politeness theories have laid the fundamental groundwork of cross-cultural and ILP research. The CCSARP research on different speech acts across different cultures and languages has led to the classifications of the requests heads and external modifiers. SLA researchers have used these classifications to advance research in ILP. However, most research conducted by the CCSARP project is on English; very little is known about Chinese. 



\section{Chapter 3 Environmental and affective dimensions of the study abroad experience}

\subsection{Introduction}

'Study Abroad' studies have come to the conclusion that a study abroad environment is more beneficial than 'At-Home' environment in developing learners' pragmatic competence. However, researchers have long rejected the idea that students in a target language community are guaranteed to gain greater cultural awareness and more linguistic opportunities than at-home students (e.g., Freed 1995; Rivers 1998; Segalowitz \& Freed 2004; Talburt \& Stewart 1999; Wilkinson 1998a,b, 2000). This chapter reviews literature on the factors that influence Study Abroad Learners' (SALs) pragmatic development. The first part discusses the process of acquiring L2 pragmatic competence, and the second focuses on environmental and affective dimensions of learners' study abroad experience.

\subsection{Process of acquiring $\mathrm{L} 2$ pragmatic competence}

This section describes processes that could affect learners' pragmatic competence. It begins with a definition of pragmatic competence and discusses whether learners' grammatical proficiency affects their pragmatic development. This is followed by a review of literature on two explanations of learners' process of pragmatic development—namely, language transfer and the Complexification Hypothesis; as well learners' acquisition of the relationship between social distance and speech behaviour in the Bulge Theory. 


\subsubsection{Definition of pragmatic competence}

Pragmatic competence may be defined as:

... the relationships between utterances and the acts of functions that the speakers intend to perform through these utterances... and the characteristics of the context of language use that determine the appropriateness of utterances. The notion of pragmatic competence...thus includes illocutionary competence, or the knowledge of the pragmatic conventions of performing acceptable language functions, and sociolinguistic competence, or knowledge of the sociolinguistic conventions for performing language functions appropriately in a given context. (Canale 1988: 90, in Hudson, Detmer \& Brown 1992: 4)

This is comparable to the notions of sociopragmatic and pragmalinguistic levels defined by Leech (1983) and Thomas (1983). Sociopragmatics is the level at which researchers focus on comparing how speech acts are used by NSs and L2 learners in particular contexts. Pragmalinguistics is the level at which researchers examine a variety of utterances which NSs and L2 learners use to convey speech acts.

For the purposes of this study, pragmatic competence is defined as the process of:

... acquiring knowledge of linguistic resources available in a given language necessary for realising particular illocutions, knowledge of sequential aspects of speech acts, and knowledge of appropriate contextual use of particular languages' linguistic resources $\ldots$ the process of establishing sociopragmatic and pragmalinguistic competence and the increasing ability to understand and produce sociopragmatic meanings with pragmalinguistic conventions. (Kasper \& Roever 2005: 318)

\subsubsection{Grammatical and pragmatic competence}

This section will examine the relationship between learners' grammatical and pragmatic proficiency. 
Research has established that grammatical and pragmatic competence are related in complex ways (e.g., Barron 2005 in Barron 2007a, 2007a, 2008; Blum-Kulka \& Olshtain 1986; Economidou-Kogetsidis 2008; Færch \& Kasper 1989; Hassall 2001; House \& Kasper 1987; Otçu \& Zeyrek 2008; Schauer 2006b, 2007, 2008; Woodfield \& Economidou-Kogetsidis 2010). However, the question as to whether learners need grammatical competence before acquiring L2 pragmatic functions remains unanswered.

On the one hand, researchers such as Bardovi-Harlig (1999: 686) propose grammatical competence is not a necessary condition for learners to develop interlanguage pragmatic competence. For instance, Schmidt (1983) found that his learner, Wes, made very little progress in his grammatical knowledge but improved his pragmatic and discourse pragmatic competence considerably over three years. He concluded that limited grammar does not prevent pragmatic and interactional competence from developing, and that grammar and pragmatic competence are independent of each other.

Koike (1989: 286) further pointed out that since learners' grammatical proficiency cannot develop as quickly as learners' pragmatic concepts, the pragmatic concepts can only be expressed at the level of syntax that learners know. Therefore, the pragmatic information may be added peripherally to the early-acquired basic command form through lexical options (e.g., imperative + porfavor 'please'). Likewise, Ahrenholz (2000) found a group of L1 Italian learners of German were still able to perform instructions in pragmatic mode before they had acquired the correct syntactic form. The learners expressed the instruction with incorrect syntax by using verbless directives or directives including formulaic, uninflected verb forms. Even lower competence learners already have pragmatic categories, but they lack the grammatical repertoire to express them (see Ahrenholz 2000; Geyer 2007; Kasper \& Rose 2002; Koike 1989; Salsbury \& Bardovi-Harlig 2001).

Likewise, Pearson's (2006) results also support the claim that learners' grammatical proficiency is not related to pragmatic development. The study examined the acquisition of Spanish directive devices by L1 university English learners in an AH context. Quantitative and qualitative analyses from questionnaires and role-plays for pre- and post-tests revealed learners who struggled with Spanish conjugations used formal verb forms to address friends and peers, and informal forms to address professors, shop clerks, and strangers. Learners' verbal accuracy increased after instructions were given but some learners continued to use 
earlier acquired forms (e.g., formal commands) as default forms to encode all commands, and present subjunctive forms were used for both informal and formal interactions. Pearson concluded that the learners with limited linguistic proficiency were still able to express pragmatic functions using the grammatical structures they know.

In contrast, other researchers claimed learners must know the linguistic structures before they are able to use them as pragmatic devices (e.g., Hassall 2008; House \& Kasper 1987; Kasper 1997; Kasper \& Rose 2002; Liu 2006, in Liu \& Jackson 2008; Niezgoda \& Rover 2001; Takahashi 2001; Xu, Case \& Wang 2009; Yamanaka 2003). Thus, the more proficient learners are better able to use a wider, and more complex, range of speech acts such as requests (Trosborg 1995).

Takahashi (2001), for example, showed learners' grammatical knowledge precedes pragmatic knowledge. Takahashi measured the ability of a group of advanced Japanese At-Home Learners (AHLs) of English in Japan to use request devices using DCTs and written retrospection. For example, learners rejected bi-clausals such as 'I was wondering if you could + VP' and 'Would it be possible for you to + VP' as requests. Instead, they opted for simpler, mono-clausal structures such as 'Would/could you (please) + VP' but they understood bi-clausal structures such as 'I was wondering if you could + VP' as requests. Takahashi (2001:173) concluded that the Japanese AHLs lacked the L2 pragmalinguistic knowledge required to mitigate an English request using more complex syntactic structures. They tended to transfer L1 semantic and syntactic features to make their requests when they lacked L2 grammatical knowledge.

Consistent with Yamanaka's (2003) findings, Xu, Case and Wang (2009) found that learners' overall L2 competence has a stronger impact on learners' L2 pragmatic development than other factors such as learners' length of residence in a target language community. A total of 126 international students at low and advanced English proficiency levels at a US university judged 20 scenarios on grammatical and pragmatic appropriateness. Results revealed no statistically significant difference between the severity of grammatical violations between learners with different lengths of residence abroad and proficiency levels. However, advanced learners who had been in the US longer were more sensitive towards pragmatic violations than those who had been in the US a shorter period. The low proficiency learners who had been in the US for a shorter time showed more sensitivity towards pragmatic 
infelicities than those who had been in the US longer. Xu, Case and Wang (2009) explained the lower competence learners were not able to map forms to functions, and were therefore less likely to understand speech acts than advanced learners. The researchers thought it possible the participants in the study were in an educational setting and received considerable English instruction each day. Further, participants in the study who were living abroad may have been more motivated to improve their skills in both English and their academic field of interest.

One plausible explanation for the effect noted by Xu, Case and Wang (2009) is that the input learners had received from their target language community and their high motivation to succeed enabled them to develop in both L2 pragmatics and grammar. This offers support for Bardovi-Harlig and Dörnyei's (1998) claim that learners' exposure to their L2 in the target language community promoted the development of pragmatic rules. The other possibility is that people can only attend to certain tasks due to their limited cognitive processing capacity (Krashen 1982; Meisel, Clahsen \& Pienemann 1981; Pienemann 1987, 1989). Thus, it is possible that learners with low linguistic proficiency were only able to attend to linguistic planning of speech within their capacity (Hassall 2008). On the other hand, learners with high proficiency were able to perform many low-level processing tasks automatically and free up more processing capacity to devote to other more cognitively-demanding tasks such as thinking about politeness and face-threatening speech acts.

As the above research has illustrated, even the low proficiency L2 learners are able to perform pragmatic devices, but they may rely on the simpler linguistic structures to make a request.

\subsubsection{Pragmatic transfer}

Researchers believe that one of the factors that may have an impact on learners' pragmatic development is their language transfer from L1 to L2. In this section, I will discuss how learners' grammatical proficiency could possibly influence their language transfer from L1 to L2 and, in turn, their pragmatic development.

Blum-Kulka (1982) found from her Hebrew NSs and English L2 learners of Hebrew that learners borrowed linguistic means from the L1 to interpret L2 pragmatic features. For 
example, L2 learners had no problems in acquiring the usage of 'Can you + VP?' in Hebrew as it also functions as a conventional indirect request strategy in English (positive transfer). This group of learners frequently used a willingness to form questions such as 'Would you + VP?' as requests in Hebrew. This form functions as a conventional indirect request in English, but it functions only as a question in Hebrew, thus resulting in negative transfer.

Other researchers have also found negative correlation between learners' transferability and proficiency (e.g., Ellis 1994; Koike 1996; Maeshiba, Yoshinaga, Kasper \& Ross 1996). For instance, Takahashi and DuFon (1989) examined whether Japanese learners of American English would transfer request devices from their L1 to L2 in various scenarios. The low proficiency learners proceeded from a less direct to a more direct approach. Not surprisingly, they were most like the native Japanese speakers' group. In contrast, the advanced learners did not transfer and opted for the more direct approach in using request devices, using the same types of request devices as the American NSs. Takahashi and DuFon (1989) concluded that the low proficiency learners relied more on transferring L1 conventional means and forms to L2 without realising the nonequivalence of pragmalinguistic meaning of these structures. Conversely, the high proficiency learners had sufficient linguistic and pragmatic knowledge to interpret the intended meaning of indirect request devices in the second language.

However, Takahashi and Beebe (1987) demonstrated advanced proficiency learners also transfer when they are unaware of the nonequivalence in meaning between learners' L1 and L2, possibly resulting in a skewed bell curve for the level of transfer against increased proficiency while transfer decreases as learners' proficiency increases. As Takahashi (2001, 2005) noted, other factors such as learners' familiarity with the situational context or learning environment may outweigh linguistic proficiency in determining the relationship between L1 to L2 transfer, language proficiency and pragmatic development.

It is possible that negative transfers of linguistic and pragmatic features from L1 to L2 occur when learners assess relevant situational factors (e.g., size of imposition, social distance, rights and obligations) on the basis of their L1 sociopragmatic norms. Learners have different perceptions of what constitutes appropriate linguistic behaviour (Thomas 1983: 99). To overcome this, learners have to acquire an understanding of different beliefs and value systems when learning an L2 (Jaworski 1994). 


\subsubsection{Complexification hypothesis and Bulge Theory}

Two theoretical models have also been proposed to explain learners' choice of pragmatic strategies in the mitigation of impositions of speech acts in terms of cognitive capacity and social distance.

In the Complexification Hypothesis, Meisel, Clahsen and Pienemann (1981) argued that the order of acquisition of L2 forms is dependent upon their syntactic structural complexity and the processing demands involved. That is, more syntactically complex structures are more cognitively demanding and are usually acquired after the simpler structures which require less processing capacity.

Trosborg (1995) used the Complexification Hypothesis to explain learners' acquisition of pragmatic functions in a developmental sequence. Trosborg found learners first master request heads, then syntactic structures (downgraders) and lexical/phrasal downgraders in their pragmatic development. Learners appeared to acquire internal modifiers later, and their use increases with linguistic proficiency. Trosborg showed that learners' acquisition of pragmatic devices also depends on how routinised these devices are. A highly routinised device is likely to be learned more easily than a device which has to be more creatively formulated or is less routinised. This explains why syntactic downgraders appear earlier in learner requests than lexical downgraders. Syntactic downgraders form part of a request strategy to a much higher degree than lexical/phrasal downgraders. In contrast, lexical/phrasal downgraders are generally optional to the request structure (e.g., markers of tentativeness 'perhaps' and 'possibly' and the consultative device 'would you mind'). The 'popular' conventions seem to be acquired as ritualised formulae first and modifiers like lexical/phrasal downgraders are acquired later in their pragmatic development. Furthermore, Trosborg (1995: 430) found learners do not acquire upgraders as easily as downgraders in complaints. It may be that the use of upgraders increased with increasing proficiency, but only after a certain degree of linguistic competence had been reached (Trosborg 1995: 358, 427). Barron (2007a) further explained that learners tended to employ different devices in different interactions, mostly using formulaic interactions with strangers. Learners' use of pragmatic routines decreased cognitive burden and, thus, frees capacity for upgrading. According to Barron (2007a), this suggests a slow rate of development in upgrader employment by learners in non-formulaic utterances. Therefore, Barron (2007a, 2008) 
suggests learners' first use and rely predominantly on the easier structures before developing more complex structures which demand a high level of cognitive complexity.

The different linguistic resources used by learners can also be accounted for by the Bulge Theory (Wolfson 1988). The Bulge Theory explains speech events in relation to speakers' social distance in interactions. Accordingly, people display similar speech behaviours at the extreme ends of the social distance continuum - minimum social distance (intimates, status equals) and maximum social distance (status unequals and strangers). The term bulge group comprises non-intimates, status-equal friends, co-workers and acquaintances. Wolfson's (1988) research on speech acts (e.g., invitations, compliments, thanking, apologising) demonstrated the similarities and differences between three groups lie in the certainty of the relationships, the status and predictability of the response. For example, Wolfson (1988: 7576) showed that because middle-class Americans at the two extremes (minimum and maximum distance) know more clearly where they stand in an interaction, they prefer a more direct, unambiguous invitation and disfavour negotiation (See Example 3.1). In contrast, people with more intimate relationship tend to avoid direct invitations in case their invitations are rejected (See Example 3.2). Speakers tend to negotiate with one another in a mutual backand-forth negotiation.

Example 3.1: The unambiguous invitation

A: Do you want to have lunch tomorrow?

B: Okay, as long as I'm back by 1.30 .

Example 3.2: The ambiguous invitation

A: You doing anything exciting this weekend?

B: No, I'll be around the pool here.

A: Ok. I'll see you.

Only a few researchers have adopted Wolfson's (1986) Bulge Theory to explain the effect of social distance on speakers' choice of pragmatic strategies (e.g. Barron 2007a; Cheng 2005; Kreutel 2007). To date, these studies have demonstrated that other factors such as familiarity 
between interlocutors, level of imposition, and the urgency of a situation may also influence speakers' pragmatic choice in minimizing the impositions of speech acts.

For instance, Kreutel (2007) found that both social distance and the urgency of a situation impacted on how the mitigation devices were used in disagreement. Participants in this study were collected from 27 adult native speakers and 27 adult second language learners of American English. Data from DCTs dealing with disagreement indicated that the learners used mitigation devices such as hedges or explanations less frequently than the native speakers. However, both groups were more blunt and used shorter responses in disagreement in minimum and maximum social distance situations than in those involving equal social distance. Kreutel (2007) explained that this may be because the speakers felt they did not need to soften their message in order to improve their social relationships with people who are either intimate or strangers to them, and can therefore be more direct. In addition, while social distance was the main factor that influenced learners' choice of pragmatic strategies in disagreement, the urgency of a situation also influenced the degree of mitigation used by native speakers of English but not by learners. Native speakers of English tended to use more direct strategies and were less likely to mitigate a disagreement in urgent situations. This suggests that the less time that is available and/or the more that is at stake in a given situation, the more direct and blunt the answer is.

In a study abroad context, similar results were found in Cheng's (2005) cross-sectional investigation into the number of words and types of strategies native English speakers and Chinese learners of English used to express gratitude. Eight DCTs were used to collect data from native English speakers in the United States, 'at-home' Chinese learners of English in Taiwan, and three groups of 'study abroad' Chinese learners of English with different lengths of residence in the United States (one semester, one year and four or more years). All participants were university students. Results showed that both the at-home and study abroad Chinese learners of English used significantly fewer strategies and shorter responses to express gratitude with interlocutors of minimal and maximum social distance than interlocutors with equal status. The native English speakers used significantly more words in the low-status situations than in the equal-status situations but a similar number of strategies regardless of the social distance between the interlocutors. Interestingly, the level of imposition also impacted on the length and types of strategies the five groups of participants used. All participants used more strategies and lengthier responses in the high-imposition 
situations than in the low-imposition situations. Cheng (2005) explained that the learners in situations with greater imposition were likely to feel especially indebted, and therefore used more devices and longer responses to mitigate an imposition. Familiarity was a third factor that was found to influence participants' responses. English native speakers used lengthier and more strategies when they were more familiar with the interlocutors.

In a third study testing the Bulge Theory (and also, in this case, the Complexification Hypothesis), Barron (2007a) investigated the use of upgraders in refusals of offers by adult native German speakers, and adult advanced Irish learners of German who were either in a study abroad context or an at-home in Ireland studying at a university. Her results showed that the types of upgrades used were influenced by social distance in ways congruent with the Bulge Theory. The native speakers of German and the study abroad learners of German mostly used formulaic utterances in interactions with strangers, and less formulaic and more complex utterances which may require negotiation in interactions with equal status interlocutors. Barron (2007a) also suggested that because upgrading appears to be overly cognitively demanding for learners, they reverted to pragmatic routines in interactions with strangers as this decreases the cognitive burden.

Overall, these three studies provide support for the Bulge Theory but also reveal other factors such as familiarity between interlocutors, level of imposition, and the urgency of a situation that contribute to the types and number of pragmatic strategies speakers use to mitigate the impositions of speech acts.

There is still much debate on whether, and the extent to which, interlanguage pragmatic development is constrained by grammatical competence as proposed in the complexification hypothesis. On the one hand, research shows learners with limited linguistic proficiency are still able to express a range of pragmatic functions using the grammatical structures they know (e.g. Ahrenholz 2000; Geyer 2007; Pearson 2005; Salsbury \& Bardovi-Harlig 2001). On the other hand, research has shown that learners' repertoire and complexity of pragmatic devices increases with increasing grammatical proficiency. Similarly, less linguistically proficient learners are not as able to map forms to functions as more proficient learners and so are less likely to correctly interpret the pragmatic force of speech acts (e.g., Hassall 2008; Xu, Case \& Wang 2009; Yamanaka 2003). It also appears that as learners' L2 proficiency increases, they rely less on transfer of sociopragmatic and pragmalinguistic features from L1 
(Takahashi 2001, 2005; Takahashi \& Beebe 1987). The next section will review external factors that could possibly affect L2 pragmatic competence.

\subsection{Environmental and affective dimensions of learners' experience abroad}

This section will provide an overview of the literature on the environmental and affective dimensions of learners' experience abroad, in particular it draws research on AHLs' and SALs' pragmatic performance on request devices. Firstly, it compares research on the differences between learners' pragmatic performance in an at-home versus a study abroad environment, and reviews literature on the extent to which SALs' length of residence in the target language community and opportunities for input and interactions influences learners' pragmatic performance of request devices. In addition, it examines research on the impact which affective factors such as SALs' self-perceived confidence and self-perceived proficiency, and perceptions of the target language learning environment have on SALs' pragmatic performance.

\subsubsection{At-Home vs study abroad environment}

While there is evidence to show pragmatic teaching can be effective, research has demonstrated learners' exposure to the target language environment is more beneficial than $\mathrm{AH}$ teaching programmes in promoting pragmatic development. Research has illustrated SALs are advantaged because they have more opportunities for richer and more authentic input in a target language community than learners in an $\mathrm{AH}$ context (Bardovi-Harlig \& Griffin 2005; Barron 2003, 2005 in Barron 2007a; Code \& Anderson 2001; Schauer 2006a,b).

In addition, researchers (e.g., Thomas 1983; Matsuda 1999, in Liu 2010: 467; Takahashi 2005) have questioned the authenticity of pragmatic rules taught in an $\mathrm{AH}$ environment. Thomas (1983), for instance, noted that language teachers' knowledge is often inadequate. Matsuda (1999, in Liu 2010) argued that in reality some teachers in AH programmes may be hesitant to teach pragmatics because it is a difficult and sensitive task which often requires a high degree of 'face threat', and pedagogical resources are often limited. Furthermore, Takahashi (2005) stated that Japanese AHLs were more likely to focus on discourse markers and idiomatic expressions than complex request head acts because these students were less 
likely to learn colloquial English. Also, AHLs have fewer opportunities in purely instructional settings to engage in longer stretches of NS discourse containing a larger number of discourse markers.

Numerous studies have shown that SALs were able to develop pragmatic awareness through exposure to the target language environment even without specific instructions (e.g., Soler 2005; Bardovi-Harlig \& Griffin 2005; Martínez-Flor \& Fukuya 2005). Substantial empirical findings have illustrated a sojourn abroad has an overall positive effect on learners' L2 pragmatic development (e.g., Barron 2003, 2005 in Barron 2007a, 2007a, 2008; Bouton 1988, 1994, 1996; Felix-Brasdefer 2004; Kinginger \& Belz 2005; Kinginger \& Farrell 2004; Matsumura 2003, 2007; Olshtain \& Blum-Kulka 1985; Schauer 2006a,b, 2007, 2008; Shardakova 2005; Takahashi 1996). SALs' gains in L2 have been attributed to the increase in opportunities for richer, more authentic input in the target language community than learners in AH contexts. As Kasper and Schmidt (1996:159-160) note:

Because pragmatic knowledge, by definition, is highly sensitive to social and cultural features of context, one would expect input that is richer in qualitative and quantitative terms to result in better learning outcomes. A second language environment is more likely to provide learners with the diverse and frequent input they need for pragmatic development than a foreign language learning context, especially if the instruction is precommunicative or noncommunicative.

From a pragmatic developmental perspective, studies into the acquisition of request devices which specifically compared the performance of AHLs and SALs have generally revealed that SALs are able to reach a higher level of pragmatic competence than AHLs in general discourses and in speech acts like request devices (e.g., Lörscher 1986; Lörscher \& Schulze 1988). For instance, Bardovi-Harlig and Dörnyei (1998: 233-62) compared American English NSs with two groups of learners for grammar ability and pragmatic awareness in requests, apologies, suggestions, and refusals. The SALs of English were in the US, and the AHLs in Hungary. The SALs were at the intermediate to advanced levels studying university intensive language programmes. The AHLs were studying at a Hungarian high school or university and had self-assessed their English as low-intermediate to advanced level. In the study, learners had to identify whether the 20 video scenarios of English conversations were error free or had pragmatic or grammatical errors. Results revealed that even though these learners had 
English intermediate-advanced proficiency, they had different levels of pragmatic and linguistic awareness. The US-based SALs identified more general pragmatic errors and rated them as more serious than grammatical errors, while the Hungarian-based AHLs identified more grammatical errors and judged them as more serious than pragmatic errors. BardoviHarlig and Dörnyei (1998) concluded that SALs were better able to identify pragmatic errors than AHLs because of their exposure to L2 in the target environment.

More recent research also consistently shows that SALs are able to improve on the use, types and varieties of request modifications during their sojourn abroad (Barron 2003, 2005 in Barron 2007a, 2007a; Schauer 2006a,b, 2007, 2008). This was illustrated by Barron's (2003, 2005 in Barron 2007a) investigations into the development of request devices and refusals of offers by advanced Irish English learners of German in an SA setting and their AH counterparts in Ireland. One of the findings showed that SALs made noticeable improvements in requests and refusals of offers after 10 months abroad. Though the SALs' pragmatic responses were not native-like in the role-plays, DCTs and interviews, their pragmatic knowledge of discourse structure of refusals of offers and requests improved over time. The SALs' use of routinised formulae increased with less negative L1 transfer and they were able to use mitigation in refusals and requests in different contexts with different levels of impositions. For example, Barron (2003) reported that this group of learners had initially overused 'bitte' (please) to mitigate their impositions of refusals and requests when their German was less proficient and they could not use other forms of downgraders to mitigate the impositions in the pre-test at the beginning of the learners' sojourn. However, the learners' syntactic downgrading employed at the end of the year abroad in the post-test was more complex in offer and request devices compared to the beginning of the year. The learners' use of 'bitte' decreased as their ability to use German downgraders increased.

Schauer's (2006a,b) comparative studies of German learners of English AH in Germany and SALs in Great Britain for one academic year revealed similar findings. Data was elicited from videos of English conversations between speakers of different status and levels of impositions of requests, questionnaires and interviews in pre- and post-tests. Results showed these SALs' pragmatic awareness increased significantly and productive pragmatic competence improved greatly in the post-test after one year in Great Britain. Schauer also found that SALs had a broader repertoire of request modifiers at the end of the SA period than AHLs. However, learners had developed internal modifiers prior to external modifiers. 
Schauer $(2006 a, b)$ concluded that the acquisitional sequence was linked to the length of stay in the target environment but found that individual learners developed the use of modifiers at different rates.

To date, substantial evidence shows exposure to the target language environment has an overall positive effect on learners' L2 pragmatic development. Whilst early SA research argued SALs' gains were because the target language environment could provide more opportunities for richer and more authentic input than AHLs, more recent research has suggested other factors are also important.

\subsubsection{Learners' length of residence abroad}

Previous studies (e.g., Bouton 1996; Bouton \& Kachru; 1994, Felix-Brasdefer 2004, 2005, 2007, 2009; Koike 1996; Olshtain \& Blum-Kulka 1985) which measured SALs' pragmatic development focussing only on the length of the learners' stay abroad were able to find a positive relationship between the length of the stay and pragmatic development. However, there is debate about the length of time learners require to develop pragmatic competence. For instance, Olshtain \& Blum-Kulka (1985: 321) found that a group of SALs of Hebrew in Israel for a stay shorter than two years rated the politeness of request devices differently to NSs, but those who spent more than ten years used similar devices to NSs. The SALs' pragmatic changes of non-native response patterns reflect a process of approximation of target language norms over time. Similarly, Felix-Brasdefer (2004) found pragmatic ability increased with learners' length of residence in the target community for six SA American learners of Mexican Spanish with advanced proficiency. Though this was a very small study, and results are speculative, data collected from role-plays and retrospective verbal reports showed that SALs who spent at least nine months in the L2 community were able to approximate NSs' interactional skills and degree of politeness in refusals. Learners made more attempts at negotiation of a refusal and higher degrees of politeness by employing more indirect devices (e.g., request for additional information, alternative, postponement, reason/explanation, and indefinite reply) than those who spent less than five months abroad.

Bouton $(1994,1996)$ also found learners' L2 proficiency and intensity of their interactions with NSs affected their pragmatic development. Bouton (1994) administered multiple choice questionnaires related to conversational implicatures to two groups of SALs at the target 
language community - one group for 17 months and the other for $4 \frac{1}{2}$ years in the US. The results showed SALs' interpretations of conversational implicatures correlated with their length of stay in the host environment but, more importantly, their developing proficiency led to learners being increasingly able to correctly interpret request utterances. The 17-month group significantly improved their understanding of conversational implicatures after 17 months, but were still unable to interpret types of implicatures they had difficulty with at the beginning of their stay. However, learners who spent $4 \frac{1}{2}$ years in the host environment were able to interpret implicatures that the 17-month learners could not, with no significant differences found between NSs and these SALs. It was concluded that learners gradually improved their ability to understand conversational implicatures as the length of residence in the US increased, but learners' proficiency and interactions with NSs enabled them to interpret better more complex request utterances (Bouton 1999: 277).

This parallels Barron's (2003) argument that even when Irish English learners of German spent one year abroad in Germany, they still did not acquire all the pragmatic features to which they should have been exposed to. Barron's (2003) research also demonstrated that singling out learners' different lengths of stay as a factor to explain learners' pragmatic development could not account for why learners acquire certain speech acts before others. It also failed to consider why some pragmatic elements did not appear in learners' knowledge until very late in their year abroad as well as learners' individual preferences for choosing modifiers (e.g., Kinginger \& Belz 2005; Matsumura 2003; Schauer 2006a,b, 2007, 2008).

Other researchers (e.g., Warga \& Schölmberger 2007) found no correlation between SALs' length of stay in the target language community and pragmatic development, while others found no difference between SA and AHLs' pragmatic development (Rodríguez 2001, in Cohen \& Shively 2005). For instance, some researchers (Bardovi-Harlig \& Hartford, 1996; Warga \& Schölmberger 2007) found learners tended to move towards non-native-like pragmatic development as they spent more time in the target environment. In another study, the DCT data from Warga and Schölmberger's (2007) 10-month study of a group of Austrian learners of French at the University of Montréal (Canada) revealed that the SALs' ability to use upgrades in apologies followed a non-L2-like development over time in the L2 speech community. The learners increasingly overgeneralised a non-L2-like intensifier 'très' ('very') and decreased using a L2-like intensifier vraiment ('really') in apologies over time in the target speech community. It was rationalised this may be due to learners' transferences from 
L1 and that the learners lacked the desire to stay or adapt to the L2 community. Warga and Schölmberger (2007) further argued that this nonlinear development phenomenon is because, initially, learners have a tendency to translate frequently occurring features from their L1 into the foreign language. The decrease in L1 non-native-like features by the fifth and about the seventh-eight month might be because learners take over chunks from the target language. By the tenth month, however, learners may begin to replace their adoption of chunks from the target language by developing a more controlled and creative pragmatic language usage. It is possible that learners are making errors in this process.

Martinsen (2008) further explained this non-linear relationship between length of residence and pragmatic gain in terms of interlanguage processes (Gass \& Selinker 2001). Accordingly, learners generate a hypothesis about how the language works during their interlanguage phrase. This hypothesis may cover some of the variation in the language and allow learners to produce a certain structure correctly a percentage of the time, but, as learners gain experience, they will realize the limitations of the hypothesis and give it up. Learners can be left without an alternate explanation for a period of time, or temporarily adopt another hypothesis that is less helpful than the first. This may result in a phenomenon called 'backsliding', in which students' skills temporarily decrease for a time because they reject one hypothesis while searching for another. Students in this process are making progress, but their visible skills may stagnate. This means that if students are tested while going through a period of backsliding, they may be unable to demonstrate the progress they have experienced.

Research to date suggests length of residence alone tells us very little about the nature of learners' pragmatic developmental patterns. The remainder of this chapter will critically examine other factors shown to influence L2 pragmatic development.

\subsubsection{Input and interactions in target language community}

In practice, SALs are believed to have many rich opportunities for native-like input and interactions in the target language community through activities such as social engagements, sports and recreation, service encounters and small talk with NSs. However, studies consistently reveal the SA context does not necessarily guarantee ample rich opportunities for native-like input and interactions for learners (e.g., Allen 2010a,b; Barron 2003, 2005 in Barron 2007a; Coleman 1998; Freed 1995; Martinsen 2008; Regan 1995, 2003; Segalowitz \& 
Freed 2004; Yager 1998). This section will discuss how input and interaction, as well as homestay environment, may affect learners' pragmatic development during their sojourn abroad.

\subsubsection{Input in the target language community}

Some researchers suggest that an ideal SA environment can offer a wide variety of ways to increase L2 input through, for example, watching television or films, reading newspapers, listening to music, and overhearing native-speaker conversations (Coleman 1998; Regan 1995, 2003). However, others have shown that, in reality, students spend a lot of time in front of the television set and have only limited exposure to native-speaker input, and this can be detrimental to learners' pragmatic development because it detracts from time talking with NSs (Gubbins \& Holt 2002; Rivers 1998).

Magnan and Back (2007), for instance, found even intermediate-level learners cannot participate as sufficiently proficient partners in L2 conversations and that two learners at this level tend to converse in minimal or fractured L2. They point out that it is essential for SALs to seek more fluent speakers as guides for language improvement and cultural growth (Magnan \& Back 2007: 56).

\subsubsection{Interactions in the target language community}

Some researchers have reported that relatively few interactions occur between SALs and NSs during their sojourn abroad (e.g., Long 1983; Maiworm, Steube \& Teichler 1993). In reality, SALs mostly interact with other same-L1 speakers. This is illustrated by Maiworm Steube and Teichler's (1993) study of L2 learners in the European Community Action Scheme for the Mobility of University Students (ERASMUS) programme. Maiworm, Steube and Teichler (1993) investigated the SA experience of 3,263 learners through questionnaires. The learners had different L1 (Spanish, Irish English, German, Greek, Italian, British English, Danish, Portuguese, Dutch and French) learning an L2 (Spanish, English, German, Greek, Italian, Danish, Portuguese, Dutch and French) for one year in one of the host countries: Spain, Ireland, Germany, Greece, Italy, Britain, Denmark, Portugal, Netherlands, France and Belgium. Maiworm, Steube and Teichler (1993: 60-61) found SALs generally had very limited contact with teachers and NSs outside the classroom and that opportunities to interact with NSs were scarce. Maiworm, Steube and Teichler (1993: 60-61) reported SALs' had too much contact with other L1 speakers. They argued that learners' contact with those of the 
same L1 can support learners to adapt to the target culture and reduce culture shock, but too much L1 talk amongst learners can potentially limit learners' L2 development. SALs typically experienced difficulties establishing contact with NSs and had very limited interactional input, especially at tertiary institutions. Like Barron's (2003:70-72, 246-7) finding, Maiworm, Steube and Teichler (1993) found learners ended up mixing with the same L1 speakers or with other international students in the same class.

Long (1983) compared NS-NS and NS-NNS interactions in a range of tasks such as informal conversations, vicarious narratives, giving instructions and research discussions. Results revealed that NS interlocutors often simplified the input for NNS learners. In the NS-NNS interactions, NSs tended to use less complex utterances and displayed different interactional styles. For instance, when interacting with NNSs, NSs used more confirmation and comprehension checks, clarifications of requests, as well as self- and other repetitions. This is further supported by Kasper and Zhang's (1995) study on NS-NNS interactions in giving compliments. Data collected from DCTs showed that Chinese NSs treat foreigners differently to the way they treat their fellow Chinese. Chinese speakers were found to compliment foreigners to a much greater extent than they would their fellow Chinese interlocutors. Therefore, learners' exposure to Chinese NS norms for complimenting behaviour may be limited if NSs simply use their speech too much, even if they had exposure to NSs.

Research shows that even when there are interactions between SALs and NSs, this contact may not necessarily be sufficient for learners' pragmatic development (Teichler 1991). Martinsen (2008) explained that there are several possible reasons why interaction with speakers of the target language was not significantly related to changes in students' oral skills. One possibility is that the interactions students have during study abroad can be repetitive or simple enough that these interactions do not push students to improve. Martinsen (2008: 516), for example, found students may request basic necessities or make specific transactions, such as purchasing a bus ticket or engaging in other brief and superficial exchanges, multiple times during their time abroad. Students are not often asked to perform linguistic tasks that reach beyond the intermediate level. If this is the case, then simply having more of these kinds of repetitive interactions will probably not provide the experiences students need to improve their skills. 
In Barron's (2003) study of request devices and refusals of offers by advanced Irish English learners of German in the SA setting, there was evidence for a positive effect of second language input on the development of learners' L2 pragmatic competence after ten months spent in the target language community. The learners used more L2-like pragmatic routines in discourse, especially in offer-refusal exchanges where they used more frequent and a wider array of internal mitigation as their time spent in the target language community increased. Learners had acquired some pragmatic routines in refusal (e.g., 'Es geht schon' meaning 'It's all right') but not others (e.g.,'Ich schaff'das schon' meaning 'I'll manage all right') over time. Barron (2003, 2005 in Barron 2007a) argues that these differences were a factor of the frequency of these forms in the input. In addition, even when learners receive input, it must be salient enough to be 'noticed' by learners in order for them to acquire the pragmatic feature (Barron 2003, 2005 in Barron 2007a; DeKeyser 1996; Schmidt 1983, 1992, 2001). In other words, the frequency of interaction may be important but the situations to which learners are exposed must lead them to notice gaps in their interlanguage production.

\subsubsection{Self-perceived confidence and self-perceived proficiency}

Some researchers have found learners' self-perceived proficiency and self-confidence are related (Clément 1986; Clément, Dörnyei \& Noels 2004; Clément, Smythe \& Gardner 1978; Li 2006; Magnan \& Back 2007). While researchers in the past found even SALs' sojourn abroad cannot increase their self-perceived proficiency and self-perceived confidence, more recent SA researchers have found SALs' self-perceived proficiency and self-perceived confidence is likely to increase in the target language community (e.g.,Clément 1986; Clément, Dörnyei \& Noels 2004; Magnan \& Back 2007).

Clément and his colleagues (Clément 1986; Clément, Dörnyei \& Noels 2004; Clément, Smythe \& Gardner 1978) note self-confidence is gained from the quantity and quality of contact with members of the target language community. However, after having sufficient contact with NSs in the target language community, some learners indicated that they still felt they lacked confidence in their speaking, especially aural understanding because they felt so overwhelmed by their difficulties. The learners claimed self-perception affects selfconfidence and that even quantity and quality social networks may not be sufficient in helping learners to increase self-confidence and L2 development. 
Conversely, there is evidence that SALs' self-perceived proficiency increases during their sojourn abroad which affects their self-confidence, and that self-perceived confidence affects learners' use of request modifiers (Li 2006). Li's (2006) extensive interview data from L2 Chinese learners of English in the UK revealed that learners' perceived difficulties with learning English lowered their self-confidence. However, evidence suggests learners' selfperceived confidence increased over time, particularly as English proficiency increased. In Li's (2006) study, low proficiency learners commonly reported their difficulties in understanding spoken English and that speaking English was more problematic at the start of the learners' sojourn. They felt inadequate and embarrassed expressing themselves in English due to a lack of fluency, phonological competence and useful vocabulary. Such difficulties consequently lowered the learners' self-confidence and inhibited them from speaking English, thus affecting their motivation to further practise spoken English in real life and participate in informal conversations. High proficiency learners were more confident in their English ability than the low proficiency learners. Even though learners reported difficulties in English aural understanding, and the hindrance of thinking in Chinese by the end of the study, at least some learners' self-confidence increased. They also felt more willing to take the initiative to talk with increasing confidence.

Researchers have also found a relationship between learners' self-perceived proficiency and self-perceived confidence and the types of request modifiers they use. Learners preferred to use external over internal modifiers (e.g., Færch \& Kasper 1989; Hassall 2001). Hassall (2001) and Economidou-Kogetsidis (2009) explained this may be because learners with limited L2 linguistic proficiency feel more confident using external modification. Perhaps it is because the politeness function is more explicit and learners can derive their politeness value directly from the illocutionary meaning from context (Blum-Kulka \& Olshtain 1986). House and Kasper (1987) suggest that learners' over-use of external modifications may be due to their insecurity about their social status in a foreign country.

Research into the relationship between self-perceived confidence and self-perceived proficiency and pragmatic development is still scarce. However, research so far indicates learners' self-perceived confidence/proficiency is vital to their pragmatic learning. 


\subsubsection{Perceptions of the target language learning environment}

\subsubsection{Attitude towards learning $\mathrm{L} 2$}

Research shows students' L2 development is highly related to their motivation. This section will highlight literature on the extent to which SALs' motivation impacts on their L2 pragmatic development. There is extensive research conducted on learners' motivation and their L2 development. There are numerous models of motivation. Some of the most influential ones are: Graham's (1984) notion of assimilative motivation; Gardner's (1985, 2001, 2005) socio-educational model of integrative/instrumental motivation; Brown's (1990, 2000) extrinsic/intrinsic dichotomy; Peirce's (1995) construct of investment; and Kouritzin, Piquemal and Renaud's (2009) proposal of social capital motivation.

Gardner $(1985,2001,2005)$ distinguished between integrative and instrumental motivation in a socio-educational model. Similar to Graham's concept of assimilative motivation, Gardner (1985, 2001, 2005) defined integrative motivation as learner's orientation to the goal of learning L2. It means that learner's positive attitudes towards the target language group and the desire to integrate into the target language community'. Instrumental motivation, on the other hand, refers to the need for learners to acquire a functional command of a language in order to gain some social or economic reward through L2 achievement (e.g., finding a job).

In a somewhat different motivation model, Brown (1990, 2000) distinguished between extrinsic and intrinsic motivation. Extrinsic motivation refers to the performance of an activity to gain a desired outcome (e.g., motivations are rewards like money and grades). Intrinsic (internal) motivation is driven by an interest or enjoyment in the task itself. According to Brown (1990, 2000) and Carreira (2005), students who are intrinsically motivated perform out of their own initiative and are more likely to engage in the task willingly, as well as to work to improve their skills, which will increase their capabilities.

In support of Brown's notion of intrinsic motivation, Takahashi (2005) found learners' pragmatic awareness of target features was correlated with intrinsic motivational factors such as whether learners enjoyed learning English, believed learning English was a challenge they enjoy, a hobby and if they wished they could learn English in an easier way. English learners who were intrinsically motivated were greatly interested in English and enjoyed learning activities for gaining skills for more successful L2 communication. They perceived these 
pragmalinguistic forms as ones that allowed them to achieve their language learning goals successfully, resulting in greater attention to these features. Li (2000) added learners' desire and attitude toward learning L2 are also particularly important in their pragmatic development because the attainment of L2 proficiency usually entails long-term effort. Learners' motivation may also be affected by factors such as personal relevance with respect to their learning goals, and expectancy of success in L2 learning could also influence how much attention L2 learners pay to pragmalinguistic features in L2 input.

Researchers (e.g., Gillette 1994; LoCastro 2001; Wesely 2009) found some students have greater instrumental rather than integrative motivation. Gillette (1994) found in a study even highly motivated AH L2 learners viewed only language skills as a valuable asset. They did not necessarily feel having native-like L2 competence was desirable (Gillette 1994). Furthermore, LoCastro (2001) found that learners' motivation and performance in English were related to whether they thought English was important, if they needed to use English in order to work abroad, or to live in or travel to a country where English is spoken, and whether they needed it for graduate school and to get good academic results. Very few students seemed motivated to acculturate to the target language culture or norms of communication (integrative motivation). While learners were willing to acquire proficiency in the use of L2 pragmatic norms, they were only willing to establish an L2 self-identity as long as it was compatible with their individual goals.

In addition to the socio-cultural motivation model, Gardner $(1985,2001,2005)$ also added that learners' self-identity may also influence and constrain the willingness to adopt NS standards for linguistic action. Many favour retaining their own identities when they feel it is inappropriate to accommodate the L2 pragmatic norms (Gardner 1985, 2001, 2005). As Celce-Murcia, Dörnyei and Thurrell (1995: 23) stated, 'Sociocultural rules and norms are so ingrained in our own identity that it is difficult to change behaviour based on a new set of assumptions.' Learners were not willing to establish or converge to such L2 norms if these conflicted with their self-identity or value system about how they should behave. The relationship between learners' motivation to learn an L2 and their willingness to use the L2 in pragmatically appropriate ways is best described by Pierce's (1995) notion of 'investment'. Pierce (1995: 17) claims it is more appropriate to view language learning as an 'investment' in relation to the changing social world. That is, learners 'invest' in learning an L2 in order to increase their cultural capital (Bourdieu 1991). Further, rather than viewing or assessing 
learners' motivation to acculturate to the L2 community, the notion of investment focuses on the individuals' self-identity as the locus of concern.

Kouritzin, Piquemal and Renaud (2009) reported in a survey of more than 6,000 university students in Canada, Japan, and France, differences in language learning beliefs, attitudes, and motivations in the three countries. Compared with Canadian students, Japanese and French students exhibited stronger additional forms of motivation. The French students showed more integrative motivation and more personal experiences with foreign languages (arguably also associated with intrinsic motivation) while the Japanese students demonstrated more social value consciousness. The English learners in Japan showed their motive to learn English was that having good knowledge of English was a valuable asset in Japan. This motivation is known as 'social capital motivation' (Kouritzin, Piquemal \& Renaud 2009). It may also be that because English is an international language, and English courses are mandatory in France and Japan, the French and Japanese students had the desire to learn a foreign language and thus to identify with the foreign language community, its speakers, literature, and culture.

\subsubsection{Attitude towards the target language learning environment}

Relatively little research has examined how learners' perception of their target language community influences their motivation and, ultimately, L2 achievement. More recent research has suggested there is a positive relationship between learners' cultural sensitivity of the target language community and L2 development.

Li (2006) found the L2 Chinese learners of English in the UK had positive attitudes towards learning English, compared to an $\mathrm{AH}$ learning environment in China. SALs generally perceived their English-learning environment with a positive attitude, especially in relation to improvement of oral/aural skills in English. Learners believed the host environment was good for learning English and it was the only place they were able to learn idiomatic English. Li (2006) stressed the importance of the interaction between the environment and the learner. He believed the initiative taken by the learner as well as the environmental influences weighed heavily on the learner's acquisition of the language. Nonetheless, a few learners felt they lacked opportunities to improve their English. 
Other studies (e.g., Martinsen 2008; Wesely 2009) suggest learners believed their success and failure in learning L2 is due to environmental factors. Sometimes learners perceived the host environment exerted pressure on them to use English in various situations. However, learners were more inclined to invoke personal failure when they made attributions about their failure, such as the lack of practice in relevant areas, which they believed to be the result of their lack of initiative to seek opportunities to use English with NSs. Some scholars (Horwitz, Horwitz \& Cope 1986; Twombly 1995; Wilkinson 1998a,b, 2010) have found L2 learners with low cultural sensitivity cannot adapt to L2 cultural differences and are likely to be anxious about learning L2 and its culture, which could decrease their ability to learn the target language while abroad. Furthermore, Martinsen (2008) also found a positive connection between cultural sensitivity and improved speaking skills. Martinsen's (2008) qualitative studies suggested students' progress in language learning was sometimes impeded by cultural differences and students who were most willing and able to adapt better to L2 and culture made the greatest gains. It is probable that students with greater cultural sensitivity are able to focus more on the language than students with lower levels of cultural sensitivity because the former are more able to understand and enjoy the cultural differences they encounter. It is also possible that the more culturally sensitive students interact more actively with NSs than those with less cultural sensitivity (Martinsen 2008: 517).

\subsubsection{Homestay}

It is clear that learners' sojourns abroad do not necessarily guarantee an increase of their input and interactions in the target language and culture. Learners' opportunities to interact with NSs and the types of interactions learners have do not automatically lead to pragmatic development. It is only when learners notice pragmatic features and see the gaps in their production of pragmatic features that interactions can possibly lead to improvement.

Some scholars (e.g., Rivers 1998; Schmidt-Rinehart \& Knight 2004: 261) believe in the 'homestay advantage' in that homestays are one of the ideal avenues for students to gain access to the target language and culture during their sojourn abroad. However, further studies have revealed there are mixed results on learners' homestay experiences abroad (Gutel 2008: 173). Some students reported they have only limited interactions with their host families, and even when learners do interact with host families, they are exposed to limited pragmatic features. Marriott (1995) observed that in a homestay environment the students were mostly exposed to the plain style usage among families and good friends. Students 
rarely received negative feedback on pragmatic devices since most feedback addressed grammatical errors or message content (Marriott 1995: 218). This suggests that it is possible learners do not get exposure to a range of pragmatic features that are used in the host environment.

Some researchers (e.g., Magnan \& Back 2007; Wilkinson 2000) have found some SALs have limited interaction with their host family. Wilkinson (2000), for instance, found a group of American learners of French studying in France had very limited interaction with their host family. One student quoted 'I was just so surprised that you could be in France for a month and really not speak French that often. I mean, I probably spoke about maybe three sentences a day in French with my family' (Wilkinson 2000: 39). In fact, Magnan and Back (2007) found students who lived with NSs, either in homestays or in apartments, would improve their speaking ability more than students who lived alone or with other Americans.

Other researchers (Knight \& Schmidt-Rinehart 2002; Schmidt-Rinehart \& Knight 2004) found that although the majority of students in sites in both Mexico and Spain felt very comfortable with their families at the end of their homestay experience, some were disappointed that their host families did not offer more linguistic and social interaction. In addition, the most frequent complaint from students in both countries during the personal interview was that they wanted to be more involved in family activities: 'They could have integrated me more into the real family life and activities; they could have invited me out more with the family when they went out; I feel more like a guest in a hotel than part of the family’ (Schmidt-Rinehart \& Knight 2004: 259).

In a more recent large-scale study, Gutel (2008) investigated a group of 3,545 SALs' homestay experiences, looking at male and female students from several countries who experienced stays of various lengths (one month, one summer, one semester and one year). Quantitative and qualitative data revealed that learners would recommend staying with a host family (Gutel 2008). The learners reported positive experiences when they were able to gain insights into the host culture, had an environment which fostered their language learning, and felt they had independence and freedom. However, the female students who had another student with a significantly higher or lower language level as roommate at the host family believed this impacted upon (hindered or helped) their ability to interact with the host family. The more proficient learners hindered lesser learners who relied on the more proficient 
learners to communicate. The lower proficiency learners did not speak to their host family due to limited English competence and shyness. As a result, interaction between students and hosts became very limited and, in turn, affected their learning outcomes (Tanaka 2004, in Ellis 2008).

This was elaborated by Jackson's (2008) ethnographic study on a group of native Hong Kong Cantonese learners of English who spent five weeks in the UK. Jackson's (2008) data, collected pre-, during and post-sojourn, revealed that learners in general found their time abroad to be a 'valuable and life-changing experience' (Jackson 2008:217). As for the more proficient learners, they suffered as they spent more time helping the lower-level learners which gave them less time to communicate with other proficient learners. The learners reported that living with a family in the host speech community enabled them to experience the culture firsthand and opened up new possibilities to use English in their daily lives. It expanded their view of English, to '...varying degrees, and sparked new interest in future forays into the English-speaking world' (Jackson 2008:217). In contrast, women who had difficulty adjusting to the L2 environment regretted not having spent more time with their host families. This means it is vital for homestay families to involve learners in interactions and expose them to the L2 culture (Knight \& Schmidt-Rinehart 2010). Knight and SchmidtRinehart (2010: 64) reported 'greater understanding of the family, increased language and cultural learning and increased interaction for learners'.

Research from learners' homestay experiences reveal, overall, one cannot assume that the host environment, even at homestays, can enrich SALs' language and culture during their sojourn abroad.

\subsection{Summary}

This chapter has provided an overview of research on the acquisition of L2 pragmatic competence in a study abroad context. It has addressed the important processes involved in learners' development of pragmatic competence by first examining how proficiency influences learners' pragmatic transfer from L1 to L2, then summarised how the Complexification Hypothesis and the Bulge Theory may be used to account for the differences in L2 learners' pragmatic development. Furthermore, it has provided a picture of research that compares learners in at-home and study abroad environments. To date, there is 
evidence to suggest learners' pragmatic gains are not purely attributable to their length of stay in the target language environment. Researchers have proposed that environmental factors such as opportunities for input and interactions and, more important, affective factors such as SALs' self-perceived confidence and self-perceived proficiency, and perceptions of the target language learning environment, all play a crucial role in learners' pragmatic performance. 



\section{Chapter 4 Methodology}

\subsection{Introduction}

This chapter describes the methodology of the present study. It begins with a summary of the research design, followed by details of participants and the recruitment process. The subsequent section provides an in-depth description of the instruments used in the pilot study and the main study, as well as the disadvantages and advantages of the instruments used. The final part of this chapter comprises the procedure section and an account of the data coding and analyses in order to address the five main research questions in this study.

RQ1: What effect did study abroad have on the students' engagement with English outside formal education settings?

RQ2: What effect did study abroad have on learners' self-rated proficiency and self-rated confidence in English?

RQ3: What effect did study abroad have on learners' attitude towards the target language community?

RQ4: What was the effect of study abroad on the learners' performance of requests in English?

RQ5: To what extent did environmental, affective or attitudinal factors in the study abroad experience correlate with the acquisition of more native-like request devices in English?

\subsection{Research Design}

This section describes the methodological design of the study.

Multiple data collection instruments were employed during this study. Each data collection method has its strengths and weaknesses and any one source of information can potentially be 
incomplete or partial (Beebe \& Cummings 1996; Nugraha 2002; Richards 2001). Furthermore, the request responses collected from oral Enhanced Discourse Completion Tasks (EDCTs) were not from spontaneous authentic interactions. Therefore, this study attempts to address these problems using multiple instruments to collect quantitative and qualitative data to yield more reliable and generalisable results in the request responses.

A quantitative approach was used to analyse request devices used by participants in the oral EDCTs. The statistical analyses provide information on AHLs' and SALs' pragmatic performances of request devices, and allow comparisons to be drawn between AHLs, SALs and Australian native speakers (ENGs).

Qualitative research allows the examination of learners' responses in-depth and provides explanations of the responses from oral EDCTs. This study includes interviews as they offer more explanatory power and reveal individual differences that may shed light on L2 learning, and provide results which may be missed if quantitative methods alone were used (Bailey \& Ochsner 1983).

By using multiple data gathering methods to measure pragmatic performance, one instrument can also compensate for the drawbacks of the other. The use of multiple methods to measure the same variables can increase the explanatory power of results and the generalisability of the research (Beebe \& Cummings 1996; Nugraha 2002; Richards 2001).

\subsection{Participants and recruitment}

This section provides an overview of the participants and the recruitment process that took place in this study.

\subsubsection{Participants}

Three groups of participants took part in this study: ENGs, AHLs, and SALs.

\subsubsection{ENGs}

All 30 ENGs were undergraduates at a university in Melbourne, Australia. The mean age of the ENGs was 21, 18 were males and 12 were females. Most of them learned a second 
language in high school, with basic to intermediate proficiency but reported they rarely used their L2.

\subsubsection{AHLs}

There were 30 AHLs in this group, 14 females and 16 males. They were first-year undergraduates studying at a university in Hong Kong. At the time of the study, they were enrolled in a 13-week oral English course, which focused on various aspects of spoken English such as pronunciation, fluency and accuracy. The average age of learners was 19. Sixteen learners took the Hong Kong Certificate Education Examination (HKCEE) after Form Five, and 14 learners had completed the Hong Kong Advanced Level (HKAL) examination after Form Seven prior to university. They all spoke Cantonese as their L1, and all had studied English as a foreign language at school since kindergarten (mean $=15$ years). None of the learners in this group had been on a holiday over one week or studied abroad in the past.

\subsubsection{SALs}

There were 21 SALs recruited in the study, 17 females and 4 males. It would have been ideal to recruit more female participants so as to provide a more gender-balance perspective of males' and females' study abroad experiences. Unfortunately, this was not possible as it was extremely difficult to recruit a sufficient number of participants in the same cohort with similar language and cultural backgrounds, studying the same university courses in Australia, and able to partake in nine-month longitudinal study. All 21 SALs were first-year foundation/diploma studies programme students at an Australian university. At the time of the study, the students were enrolled in a one-year compulsory academic study skills course. The course aimed to prepare students for the International English Language Testing System examination (IELTS), with very little focus on communication skills. The average age of learners was 18.5. They all spoke Cantonese as their mother-tongue, and all had studied English as a foreign language at school since kindergarten (mean $=15$ years); 13 learners undertook the HKCEE after completing Form Five and eight learners undertook HKAL examinations after completing Form Seven prior to going to Australia. None of these students had been on any study abroad programme. 


\subsection{SALs' attitude towards learning English}

Both groups of learners were motivated to learn English because they wanted to communicate better in English, improve their job prospects, for academic purposes and to become more native-like in their usage. Very few learners wanted to improve English purely because they liked to learn English.

Table 4.1 shows $72 \%$ of SALs agreed or strongly agreed that learning English was fun. A much lower rate ( $24 \%$ of learners) disagreed or strongly disagreed with the idea that learning English was fun and only $4 \%$ of learners had neutral feelings about learning English. However, despite the percentage of learners who disagreed with the notion that learning English was fun, learners had an average of 4 (standard deviation $=1.1$ ) reasons to learn English. The results from Table 4.2 indicate this group of SALs had good reasons to want to improve their English proficiency and pragmatic competence. Overall, more than $81 \%$ of SALs in this study wanted to learn English to enhance their future career prospects, cope with academic studies, and improve their communication skills. Only about $60 \%$ of learners wanted to learn English so they could speak native-like Australian English. A mere 15\% of learners wanted to learn English because it was fun.

Table 4.1: SALs' self-ratings on their view on whether learning English is fun

\begin{tabular}{lcl}
\hline Strongly agree & $2(10 \%)$ \\
Agree & $13(61 \%)$ \\
Neutral & 1 & $(5 \%)$ \\
Disagree & 3 & $(14 \%)$ \\
Strongly disagree & 2 & $(10 \%)$ \\
\hline Note: Figure in brackets = percentage &
\end{tabular}

Table 4.2: SALs' reasons for learning English

\begin{tabular}{lcrc}
\hline & Agreed & \multicolumn{2}{c}{ Disagreed } \\
\hline Job & $17(81 \%)$ & 4 & $(19 \%)$ \\
Further studies & $17(81 \%)$ & 4 & $(19 \%)$ \\
Become native-like & $12(57 \%)$ & 9 & $(43 \%)$ \\
Like learning English & $4(19 \%)$ & 17 & $(81 \%)$ \\
Communicate better & $18(86 \%)$ & 3 & $(14 \%)$ \\
To teach English & 0 & 0 & \\
\hline
\end{tabular}

Note: Figure in brackets $=$ percentage

\subsubsection{Recruitment}

The AHL participants were students at a Hong Kong university studying an English course. The activities were provided to the learners as in-class activities, so there was no formal 
recruitment process. However, the ENGs and SALs were recruited through advertisements. The participating institutions in Australia sent out advertisement for the recruitment of ENGs (See Appendix I) and SALs (See Appendix II).

In the initial meeting for the study, participants were informed the project was on English usage and given an introductory letter (Appendix III) and consent form (Appendix IV). The activities they would be involved in were outlined (interviews and role-plays and that they would be video- and audio-taped). Participants were also told that all results collected would be used anonymously for research purposes only and that their personal details would remain confidential. All the oral EDCTs and role-play data were video- and audio-taped. The files were transferred and stored on a secure computer.

In return for time spent on the study, participants were offered feedback on their written and spoken English. The SALs in particular took up this opportunity to submit their work for correction and feedback. Upon completion of the data collection, all participants were informed the study focused on request devices and provided with a summary of request devices in Australian English.

\subsection{Instruments}

This section provides details of instruments used in this project: the Language Contact Profile (LCP), oral EDCTs, as well as the instruments used in the open role-plays to elicit requests and interview questions used to gain more understanding of learners' responses. The advantages and disadvantages of these instruments will also be highlighted.

\subsubsection{Pilot study}

A pilot study was undertaken to ensure the appropriateness of the oral EDCTs and the roleplays. The participants involved were 10 ENGs and 20 AHLs. As a result of the pilot study, questions were either added or amended to suit the needs of this project. The changes will be discussed in the main study. 


\subsubsection{Oral EDCTs}

Two high, two mutual and two low social status situations selected from Billmyer \& Varghese's (2000) EDCTs were presented as the oral EDCTs to elicit request responses. The oral EDCT situations were read by an ENG and recorded onto a DVD to play back to participants. The participants were informed there was no right or wrong answer, no word limit and that they could listen to the situations again if necessary, and provide oral responses when they were ready.

Results of the pilot tests revealed that the ENGs and learners used greetings, said excuse me, introduced themselves, explained reasons for making requests, promised to return items borrowed or favour, used mostly conventional indirect requests, said thank you and showed appreciation. Learners made more apologies and frequently explained reasons for making requests but NSs tended to chat more and justify their requests to listeners more before making requests. NSs showed they were aware that it may be bad to make a request without using pre-request devices. For example, 'I normally wouldn't ask but...' and 'I understand if you can't but...' Interestingly, NSs justified requests, for example, 'I will be quick...', 'I live close to you so...' and 'I was in your class so...'. The pilot tests indicated the oral EDCTs were appropriate to elicit request responses and external request devices.

\subsubsection{Role-plays}

Five situations were designed in a way that set up a scenario in which participants have to negotiate with others to come up with a solution. Participants were put into groups of two to four. They were asked to go through the scenario and come up with a solution for the scenario. Participants were informed everyone in the group must speak. Participants were not asked specifically to make requests, but the situations provided opportunities for them to negotiate and make requests. The results from the role-plays indicated they provided opportunities for participants to negotiate and make requests. The same role-play scenarios were included in the main study.

\subsubsection{Main study}

Table 4.3 presents the tasks and testing time intervals for AHLs, SALs and ENGs in the preand post-tests. As can be seen from Table 4.3, this study included two written questionnaires, a diary, interview, role-play and oral EDCTs. 
Table 4.3: Questionnaires completed by three groups of participants in the study

\begin{tabular}{|l|l|l|l|l|l|}
\hline & $\begin{array}{l}\text { Written } \\
\text { LCP }\end{array}$ & $\begin{array}{l}\text { Written } \\
\text { Diary }\end{array}$ & Interview & $\begin{array}{l}\text { Oral } \\
\text { EDCT }\end{array}$ & Role-play \\
\hline SALs & $\checkmark$ & $\checkmark$ & $\checkmark$ & $\checkmark$ & $\checkmark$ \\
\hline AHLs & $\checkmark$ & & $\checkmark$ & $\checkmark$ & $\checkmark$ \\
\hline NSs & & & $\checkmark$ & $\checkmark$ & $\checkmark$ \\
\hline
\end{tabular}

$\checkmark=$ task performed

\subsubsection{Language Contact Profile (LCP)}

The LCP constructed by Freed, Dewey and Segalowitz (2004) was originally designed to elicit information about learners' exposure to English in a longitudinal study and offered both a pre- and a post-test. This questionnaire has been widely used in SA studies (e.g., Barron 2003, 2007a, 2008; Cohen 2005; Colletine \& Freed 2004; Schauer 2004, 2006a,b) to elicit information about learners' past experiences and exposure to English in an SA environment. For similar reasons, the LCP was used in this study because the pre- and post-questionnaires allowed learners to self-report their exposure to English before and during their sojourn abroad. Both the pre- and post-questionnaires consist of questions regarding learners' accommodation, and the amount of exposure to English they have in a day and per week for reading, writing, listening and speaking in a range of situations, both inside and outside the classroom. In this study, additional questions on learners' educational background, and a selfperceived proficiency and self-perceived confidence in reading, writing, listening, speaking, communication effectiveness and grammar were included as these scales relate to learners' development of request devices (See Appendix V for pre- and post- tests).

\subsubsection{Oral Enhanced Discourse Completion Tasks (Oral EDCTs)}

Discourse completion tasks (DCTs) typically consist of a situational description followed by a brief dialogue, with at least one open turn to be completed by the participant. For example, 'You missed class and need to borrow a friend's notes. What would you say?' The context is designed to constrain the open turns so that a specific communicative act is elicited-request devices in this case.

The major criticisms of DCTs are that the responses obtained in the DCTs do not adequately represent natural conversations in that speakers' DCT responses lack actual wording, emotions, a range of formulas and devices, and the number of repetitions and elaborations that occur in a real conversation. More importantly, the DCTs do not provide sufficient social 
and situational information in the prompt. They exclude the background information of the event, the relationship between interlocutors, the frequency of their interaction and details related to context and settings (Beebe \& Cummings, in Kasper \& Dahl 1991; Wolfson, Marmor \& Jones 1989).

Despite the shortcomings of DCTs, cross-cultural and interlanguage pragmatics (ILP) studies have continued to use DCTs to measure pragmatic knowledge as DCTs can be used to gather a large amount of data quickly. In recent years, DCTs are still frequently employed to collect data since they elicit respondents' knowledge of stereotypical responses that reflect the values of the native culture (e.g., Bataineh \& Bataineh 2006; Econmidou-Kogetsidis 2008a,b, 2009; Woodfield 2008). Therefore, by investigating what respondents know about routine and stereotypical ways of encoding speech acts in the target culture, DCTs indicate the extent to which speakers are familiar with the sociopragmatic norms of that culture. Hence, DCTs allow respondents to demonstrate what they know about socioculturally appropriate ways of responding to specific situations, and provide information about their ability to produce routine, planned responses (Beebe \& Cummings 1996). However, researchers such as Econmidou-Kogetsidis $(2008,2009)$ and Woodfield (2008) have pointed out that the DCT responses should not be interpreted as revealing how respondents would spontaneously respond.

In an attempt to provide more contextual information in a scenario, Billmyer and Varghese (2000) also provided lengthier versions of Rose (1992) and Rose and Ono (1995) Discourse Completion Tasks (DCTs) in their EDCTs. They constructed scenarios by examining the literature to identify the type of social and contextual information which critics of DCTs found lacking in the situations and which others in the field regarded as necessary and relevant (Wolfson, Marmor \& Jones 1989; Beebe \& Cummings 1996; Hymes 1972). Hyme's (1972) components of speech guided Billmyer and Varghese's (2000) design of situational prompts. These components include a description of the physical setting, including time and place; the participants, meaning interlocutor as well as audience; and the purpose of the speaker, specifically the request goal. Enhanced prompts specified these social factors by including the following information: the gender and name of the interlocutor; the role relationship, and by implication, social distance and social dominance; the length of the acquaintanceship; the frequency of the interaction; whether or not the relationship was optional; a description of the place the interaction happened and the time of the day; and 
familiarity with the situations. In this study, both the short and context-enriched scenarios of Billmyer and Varghese's (2000) questionnaire were included. By way of example, the context-enriched version of the music situation is shown below. Here, time and place are described, the interlocutor is given a name, and events leading up to the request are described, thus providing the speaker with motivation for the ensuing act. For example,

Music situation

It is $10.30 \mathrm{pm}$ on a Wednesday night and you have a paper due the next day. You are trying to finish the paper and you can't concentrate because you hear loud music coming from another student's room down the hall. You decide to ask her to turn the music down. The music has been on at this volume for half an hour. You have occasionally seen the student, Lucy Row, in the same dorm during the past six months. She is a student like you but you have never spoken to her. You have heard other people in the dorm complain about the volume of her music on several occasions, although you never have because you usually study in the library. However, today the library closed early. You are only half- way through and you know that the professor for this class is very strict and does not give extensions. What would you say?

The scenarios are designed with the expectation that the context-rich prompts will elicit a fuller range of request devices because they include time and place, more information about the situation, the interlocutors and the background, and longer, more elaborately modified, requests with greater degrees of supportive mitigation.

Like Billmyer and Varghese (2000), the six situations provide for combinations of social distance and social dominance (see Appendix VI pre- and post- oral EDCTs). The six scenarios provided were interactions of different social distance relationships defined by Wolfson (1988). The oral EDCTs and open roleplays aimed to elicit a range of request devices (request heads and external modifiers) in maximum social distance interactions (status unequals and strangers) and the middle distance social interactions (non-intimates, status equals friends) Wolfson (1988). The maximum social distance interactions included the participant being of a higher status than the interlocutor (participant as a professor requesting students to submit an assignment earlier than expected and participant as a professor requesting students to present work earlier than scheduled knowing they have a heavy 
workload), and a lower status than the interlocutors (participant as a student requesting an extension for an assignment and participant as a student requesting an assistant professor to give him/her a lift home in the snow). The middle distance group in this study is defined as mutual status friends (participant asking a friend to borrow lecture notes and asking a friend next door to turn down music).

In this study, the EDCTs were presented to participants in audio form as closed role-plays, read out by an Australian English native speaker. At the beginning of the oral EDCT, participants listened to the instructions recorded on a tape. They were asked to listen to ten situations carefully, then respond to each situation, after it was played, relying on their past experiences. It was explained that there were no right or wrong answers and there was no time or length limit. They could listen to the situations again if they did not understand them on the first listening. To ensure learners understood the instructions, the first situation was used as a training exercise. After the first situation was played, participants were asked to respond when they were ready. They were free to take as long as they needed to think about their answers before responding.

\subsubsection{Open role-plays}

It is not always possible to collect naturalistic data on a particular speech act because it is time-consuming. In addition, a very large dataset would be required in order to obtain sufficient data on a particular speech act as there is no instruction or direction that guides what the participants say (Kasper 2000). Consequently, researchers such as Hassall (1997, in Hassall 2001), Tateyama (2001) and Trosborg (1995) have used oral tasks or role-plays to collect spoken data in L2 developmental pragmatic studies. The advantage of role-plays is that they are capable of producing a wide array of interactional conducts through the role specifications and can simulate authentic situations. The respondents are free to control the conversation if given an opportunity to interact with the interlocutor freely (Sasaki 1998).

Open role-plays can provide more naturalistic data and capture features similar to naturally occurring conversations such as turn-taking, sequencing and hesitations. The other advantage is that role-plays are easy to administer, allow for comparisons across dyads, and make it possible to control extra-linguistic variables such as power, status and gender (Golato 2003). Some researchers (e.g., Duan \& Wannaruk 2008; Rintell \& Mitchell 1989; Morrison \& Holmes 2006) have compared the responses of closed oral (DCT) role-plays and written 
DCTs and examined the validity of role-plays in ILP. These researchers have found that speakers' responses from open role-plays display similar features to natural conversations. For instance, Edmondson and House (1991) found that NNSs produced longer and more verbose utterances than NSs on DCTs but not in role-plays in general. Eisenstein and Bodman's (1993) study compared the role of DCTs, open role-plays, and field notes of how NNSs and NSs expressed gratitude. They found all three types elicited the same words and expressions but differed in length and complexity. The authentic data provided the longest and most complex responses, followed by the role-plays data and the DCT data led to the shortest and least complex responses.

Similar to Sasaki (1998), Tsai (2007) compared the use of request devices and modality markers from apology speech act data collected from the two most popular speech act elicitation tasks, DCTs and role-plays. Twenty-four Chinese NSs and 40 Chinese AHLs participated in Tsai's study where results showed that all tended to use direct expressions of apology, acknowledge responsibility, and offer repairs as their main devices in apology situations both on DCTs and role-plays. However, the frequencies and distributions of apology devices and modalities differed. Role-plays elicited overall more apology devices and modalities than DCTs. The learners employed a narrower range of devices and modalities on DCT. Because of the feeling of insecurity in face-to-face encounters (Rintell \& Mitchell 1989), AHLs exhibited more 'play it safe' devices than NSs (Færch \& Kasper 1989; Trosborg 1987) by giving more direct apologies across four situations.

In this study, participants were asked to take part in open role-plays so the data could indicate not only how participants use request devices, but also how they lead up to and follow a request. Therefore, to ensure a good basis for comparison between the data obtained from the DCTs and the role-plays, the role-plays used in this study were closely related to situations participants were likely to encounter in their daily life. Like the oral EDCTs, participants were given three situations of maximum (unequal status) and middle distance (status equal friends). One of the maximum social distance interactions (unequal status) involved a situation where participants were of high status (Professor requesting for work earlier than scheduled) and lower status than the interlocutor (participant as a junior at school telling a senior student to return money s/he had borrowed). The middle distance group involved a situation where one of the participants had to borrow his/her only umbrella when it was raining outside (see Appendix VII for the role-plays used in this study). 
The situations used in this study required participants to negotiate the borrowing or lending of money, notes, books, assignments or a car. To reduce practice effects in the post-tests, social distance between the roles remained the same but names and scenarios were changed slightly. Here is an example of a role-play scenario with the instructions presented to the students. This scenario is about raining outside and aims to enable learners to elicit a request with her friend.

You just paid for your friends' coffee.

It's raining very heavily outside.

All of your friends have umbrellas except for you.

No one has offered to lend you an umbrella. Will you ask one of your friends to lend you an umbrella?

Most participants only used their preparation time to work out the theme and what they were likely to say and then rehearsed instead of writing down the whole dialogue. They began the role-play when they felt comfortable to start. The participants enjoyed performing in the reloplay. All role-plays were audio-recorded and video-taped.

The AHLs performed in a role-play during class time in the first week of the course. Both the SALs and NSs had pre-arranged a time to meet to perform in a role-play. Each group had three or four people who were given a situation which they were asked to solve in a conversation between all participants. They were given as much time as they required to work through the scenario, assign a role to each group member and work out the general theme, not necessarily the exact wording of the dialogue.

\subsubsection{Interviews}

Each interview began with an informal interaction to find out the students' well-being, followed by a list of questions focusing on the participants' experiences and attitudes towards learning English (Appendix VIII). Interviews ended with the oral EDCTs. Each interview lasted about 30 minutes. Again, the participants were asked to answer the questions to the best of their knowledge as there were no right or wrong answers. All questionnaires were collected during the interview. 
At the beginning of the interviews, the researcher's personal experiences of living and studying in Hong Kong and Australia were shared with learners. Items in the LCP, especially ratings on self-rated proficiency and confidence on reading, writing, speaking, listening, communicating, vocabulary (academic and social needs), and cultural knowledge were then discussed. Learners were asked to reflect on what they were good and not so good at in English and what they planned to do to improve on their weaknesses while they were in Australia. The reasons learners improved or did not improve on certain items were discussed along with what they could do in the post-tests that they could not do previously. Learners were also given feedback on their oral English, mostly focusing on fluency, pronunciation and grammar.

\subsubsection{Diary studies}

One of the main advantages of asking learners to keep a diary is that they can reflect on their entries and take steps to overcome their learning obstacles (Krishnan \& Hoon 2002). The SALs were asked to keep a diary during the nine-month period that they took part in this study. They were asked to think about situations where they communicated successfully and unsuccessfully in English, then try to work out the reasons why their communication was successful or unsuccessful and how they felt. Below is the list of topics suggested to the learners in this study:

1. Write down what you learn.

2. Write down the situations you face where you have to speak in English.

3. What was your conversation and discussion like?

4. How did you feel?

5. Did you have to ask someone to give you something or do something for you?

6. What did you say? How did your listener respond?

7. Did your listener(s) understand what you want — why or why not?

8. Feel free to write down anything else that you would like to share with me, or any questions you may have. 
The learners were asked to write in the diary in English at least once per week, with the written material collected at three data collection points. Although the learners wrote in the diary, a majority of them did not write in it once per week. The text was written in a combination of Chinese and informal English, and it provided insight into the learners' learning and general life experiences in Australia. At each meeting, situations and experiences that learners raised as problematic or enjoyable in the diary were discussed. Previous diary studies tended to specify the language that learners had to use in their diary entries - commonly in either their L1 or L2. One of the main disadvantages of constraining learners to report on their experiences in their L2 is that sometimes learners may not have the language skills to reflect on their own feelings, thinking and experiences. Similarly, by asking learners to reflect on their experiences only in their L1, they may not be given the opportunity to reflect on their experiences using what they have learned in their L2. It is possible that they can sometimes capture their thinking better with a vocabulary or a phrase that has no equivalence in their L1.

Learners in this study were free to choose to write in their diary entries using Chinese or English, so they were able to express their feelings and reflect on their experiences without a language barrier. Indeed, learners reported they felt more comfortable writing in Chinese at times as it was their L1 and they were able to express their thinking better. Interestingly, learners frequently used colloquial English and expletives to express their frustrations (See Appendix IX).

\subsubsection{Versions of instruments}

Three versions of questionnaires, oral EDCT and role-plays were required. To minimise practice effects, the three versions of written questionnaires differed in the order of questions presented and the names that appeared in the scenarios. More importantly, the time interval between each administration was 3.5-4 months to allow ample time to minimise practice effects. 


\subsection{Reflections on the procedure}

\subsubsection{Interviews}

The informal interactions at the beginning of the interviews in both the pre- and post-tests were a very good way to ensure participants were at ease before they had to answer questions about their educational background, experiences learning English, and life in Hong Kong and Australia. The video and audio recording equipment could have made some participants reluctant to talk during the interviews so the video camera was placed about a metre away from the participants. The NSs said they were comfortable being taped. None of the learners had any problems with the audio recording. Some learners, however, were a little anxious when they realised they were going to be video-taped. They were assured only the researcher would watch the videos. The learners were more comfortable about being taped during the post-tests.

\subsubsection{Oral EDCTs}

The oral EDCTs went very smoothly for the NSs. All participants understood the instructions and what they had to do. Sometimes learners asked to re-listen to some situations because they thought the speaker on the tape spoke too fast, the situations were too long and they could not remember the more intricate details, or they did not understand vocabulary or the pronunciation of a word. Participants were told not to respond when they did not feel comfortable asking for the favour as they would not do this in real life. This instruction was the opposite of the original study plan. In the Oral EDCT post-tests, participants were asked to reflect on their performance in the Oral EDCTs. They were asked if the length of the situations affected their responses, if they thought the mode of comprehension (reading or listening) affected their answers and which was easier. Some NSs and learners said they did not answer some scenarios where they felt uncomfortable in real life; namely, asking to borrow money. Some AHLs felt very bad asking for extensions from their professors; so they would not do this in real life unless they really had no choice.

\subsubsection{Role-plays}

All participants enjoyed working through and performing the role-plays very much. The participants took approximately 10-15 minutes to prepare for the role-play. Learners held 
discussions in Cantonese and English during their preparation time. Both NSs and learners worked through the situations without any difficulty. They assigned roles and only worked out generally how the role-play would begin, what would happen in the middle and at the end. The participants were comfortable enough to work out the lines they were going to use without writing any script, and some rehearsed once in some instances. All the participants commented on how much they enjoyed watching each other's performances. Each role-play lasted between three and four minutes.

\subsection{Procedure}

This section will outline the pre- and post-test time data collection intervals over nine months for the ENGs, SALs and AHLs. It will also describe the order in which tasks were given. The instructions for all three groups of participants and a synopsis of the meetings, the handout of written tasks, interviews, oral EDCTs and role-plays are provided in the appendix.

\subsubsection{Time Intervals}

Table 4.4 shows the data collection intervals for all three groups of participants in the study. As can be seen from the table below, data from SALs was collected three times over a ninemonth period, with each test held at 4-4.5 month intervals. Data from the AHLs was collected twice and data from the NSs was collected only once.

Table 4.4: Time intervals between data collection sessions

\begin{tabular}{|c|c|c|c|c|c|}
\hline \multirow{2}{*}{ Participants } & \multicolumn{3}{|c|}{ 4-4.5 months } & \multicolumn{2}{|c|}{ 4-4.5 months } \\
\hline & Time 1 & $\longleftrightarrow$ & Time 2 & $\longleftrightarrow$ & Time 3 \\
\hline SALs & $\checkmark$ & & $\checkmark$ & & $\checkmark$ \\
\hline AHLs & $\checkmark$ & & $\checkmark$ & & \\
\hline ENGs & $\checkmark$ & & & & \\
\hline
\end{tabular}

Prior to each meeting, participants were given questionnaires and appointments were made for interviews and role-plays (involving three or four people). The Language Contact Profile (LCP) was disseminated to AHLs and SALs in the initial meeting. NSs were given all questionnaires except the LCP. The LCP was not relevant for NSs as it contained questions about their educational background, their attitudes and experiences in learning English, and a self-rated proficiency and self-rated confidence in learning English. Participants were asked to fill in all questionnaires prior to the interview. All participants were asked to answer the 
questions in the questionnaires using only their knowledge and past experiences in the DCTs. As for all pragmatic questionnaires, there was no right or wrong answer. For the grammar section, the participants were asked not to use a dictionary and to use only their grammatical knowledge to answer all the questions.

\subsubsection{Meetings}

\subsubsection{Briefing the participants}

Two groups of participants (ENGs and SALs) were recruited through an advertisement from three universities in Melbourne, Australia. At the initial meeting, participants were informed the study focussed on English usage and that they would be asked to fill in questionnaires and complete listening-and-responding oral tasks (oral EDCTs) and interviews which would be video- and audio- taped. They were also given guidelines on the diary and were given an exercise book as a diary. At this initial meeting, they were also told that the data collected would remain strictly confidential and be used anonymously for academic and research purposes only. At the end of the study, all participants would be briefed about the nature of the study.

The NSs received an honorarium of AUD20 upon completion of all tasks. The AHLs were not paid as the tasks in this study were incorporated into class as part of their class activities, and the data were used to give them feedback on their oral English proficiency. The SALs were paid an honorarium of AUD90 upon the completion of all the tasks in the study.

It was not possible to recruit SALs who were first year undergraduates like the AHLs in this study. This was because of difficulty locating SALs who were studying in Melbourne at a similar level, and in courses that lasted for at least nine months (many university English language courses were only three months long).

\subsubsection{Debriefing the participants}

At the conclusion of the study, participants were informed this study was about the use of request devices. They were free to ask questions they had about the nature of the study. Learners were particularly keen to find out how they had performed and the progress they had made in the effectiveness of their requests. NSs were keen to find out more about the nature of the study and the differences between the use of request devices between NNSs and 
NSs. Further feedback was given to those who were keen to find out more about the study via msn or email. All participants were informed their final results or conclusions would be emailed to them along with any details of any publications. The SALs and NSs were paid and they signed and dated a receipt. Again, they were reminded the results of this project would remain confidential and be used for research purposes only.

\subsection{Data coding and analyses}

This section describes the way data were coded and analysed to answer the five main research questions related to the extent to which the environmental and affective dimensions affect this group of Hong Kong learners' pragmatic performance of request devices. The five research questions can be divided into three research areas.

The first section of analyses relates to the first three research questions on environmental and affective dimensions of SALs' study abroad experience.

RQ1: What effect did study abroad have on the students' engagement with English outside formal education settings?

To investigate if there were differences between the amount of Cantonese the SALs used in Australia, and the amount of English input and interactions they used during their sojourn in Australia between $T_{1}$ and $T_{3}$, ANOVA repeated measures, t-tests and post-hoc analyses for within-group comparisons were conducted between $T_{1}$ and $T_{3}$. The types of English listening input examined were from radio, television/movies, songs, conversations between ENGs and for academic purposes (e.g. lectures and tutorials). The types of interactions in this study are their contact in class, with English fluent/NSs, their living environment and NNSs outside school or home.

To reveal whether the SALs' amount of English listening input and interactions in Australia contribute to an increase in their use of external modifiers, Spearman's rho $r$ correlations were performed between SALs' amount of English input and interactions in Australia, and the number of external modifiers SALs' used in situations where learners were of mutual, higher and lower status than their interlocutor in $T_{1}$ and $T_{3}$. Listening input in English included input from radio, TV/Movies, songs, English fluent/NSs and English for academic 
purposes. Spearman's rho $r$ correlations were used because the values of external modifiers were on non-normal distributions. Additionally, Spearman's rho $r$ analyses were performed between SALs' listening input and interactions in English and self-rated proficiency and selfrated confidence scores in $T_{1}$ and $T_{3}$ to see if there was any relationship between the amount of listening input and learners' self-rated proficiency and self-rated confidence in $T_{1}$ and $T_{3}$.

RQ2: What effect did study abroad have on learners' self-rated proficiency and self-rated confidence in English?

SALs' development of self-rated proficiency and self-rated confidence scores, and the relationship between SALs' self-rated proficiency and self-rated confidence were correlated with the number of external modifiers they used between $T_{1}$ and $T_{3}$

To examine if the SALs' self-perceived confidence and self-perceived proficiency scores had increased from $T_{1}$ to $T_{3}$, ANOVA repeated measures, t-tests and post-hoc analyses for withingroup comparisons were conducted in learners' self-rated confidence and proficiency scales for speaking and ability to communicate effectively between $T_{1}$ and $T_{3}$. The scale was out of 5 , with $1=$ very poor, $2=$ poor, $3=$ average, $4=$ good and $5=$ very good.

To answer the question of whether the SALs self-rated proficiency and self-rated confidence scores for speaking, and ability to communicate effectively increase their use of external modifiers, Spearman's rho $r$ correlations were performed. These correlations measured SALs' self-perceived, self-rated proficiency and self-rated confidence scores for speaking, ability to communicate effectively, and grammar and the number of external modifiers they used in situations where learners of mutual, higher or lower status than their interlocutor in T1 and T3. Spearman's rho $r$ analyses were used because the self-perceived proficiency and self-rated confidence scores were ranked.

RQ3: What effect did study abroad have on learners' attitude towards the target language community?

Answers to the following questions from the interviews were analysed to examine whether SALs' attitude towards Australia influenced their pragmatic development: 
i. Can you tell me two or three things you like and dislike about Australia so far?

As for the question related to whether the types of accommodation (particularly homestays) can provide learners more opportunities to interact and learn more about the L2 culture and increase exposure to English listening input and interactions, the interview data on the following questions were examined:

i. Where are you staying? Does your living environment give you a chance to use English with NSs/NNSs?

ii. Homestay students: Do you speak to your host family? How often? Why/why not? How much time do you spend talking to your host family? Any outings? What is your relationship with your host family? Do you go out with your flatmates? Do you speak English or Cantonese? Does your family tell you about Australian customs or special events (like ANZAC day? Or how they celebrate Easter or Christmas?).

To explore whether the SALs' perceptions of the target language learning environment increased during their sojourn abroad, Spearman rho's $r$ was performed between $\mathrm{T}_{1}$ and $\mathrm{T}_{3}$. The scale was as follows: $0=$ no feeling, $1=$ very little, $2=$ little, $3=$ average, $4=$ quite a lot, $5=$ very much.

The second section of analyses relates to SALs' pragmatic performance on English request devices. This is dealt with in the fourth question:

RQ4: What was the effect of study abroad on the learners' performance of requests in English?

If learners develop pragmatic skills during their sojourn abroad, we should see an increase in their use of request devices measured in the oral EDCTs over time, and perhaps see some similarities between the devices used by ENGs and SALs. The role-plays were analysed using the same coding scheme as the oral EDCTs. The responses are used as supporting evidence for quantitative analyses.

The pragmatic skills data obtained from the oral EDCTs and role-plays were coded according to the CCSARP coding scheme (selected from the CCSARP Manual 1989; Economidou- 
Kogetsidis 2008, House \& Kasper 1989; Schauer 2005). In each low, high, and mutual status situation, data were coded as follows: request heads and pre- and post-request heads (external and internal modifiers). Because of the scope of this study, only low, high and mutual status situations were considered.

Request heads: To find out if learners develop an ability to use direct, conventional indirect to nonconventional indirect requests in this order, the request device used in each scenario was examined. There were three types of request heads possible for each situation-direct, conventional indirect and nonconventional indirect requests. To see what stage learners were at, the following codes were used: no answer $=0$, yes $=1$, don't want to answer $=77$, don't know answer $=99$, missing case $=999$, not applicable $=9999$.

Pre- and post-request devices: The pre- and post-request devices were coded on external and internal devices. The external request modifiers listed in Table 1.1 were analysed to see which devices this group of SALs had not acquired and which were acquired during their sojourn abroad. See Table 2.1 (adapted from Section 2.3.1.2, p. 35).

Table 2.1: Classifications of external modifiers, functions and examples

\begin{tabular}{|l|l|l|}
\hline $\begin{array}{l}\text { Types of external } \\
\text { modifiers }\end{array}$ & Function of devices & Examples \\
\hline Alerter & $\begin{array}{l}\text { Used to get interlocutor's } \\
\text { attention; precedes the Head. }\end{array}$ & Excuse me; hi; Professor/Jane \\
\hline Preparator & $\begin{array}{l}\text { Used to prepare the interlocutor } \\
\text { for the request; can follow or } \\
\text { substitute the alerter. }\end{array}$ & Can you do me a favour? \\
\hline $\begin{array}{l}\text { Getting a pre- } \\
\text { commitment }\end{array}$ & $\begin{array}{l}\text { Used to commit the hearer to the } \\
\text { request prior to the actual } \\
\text { request. }\end{array}$ & $\begin{array}{l}\text { Could you do me a favour? } \\
\text { from yesterday's class? }\end{array}$ \\
\hline $\begin{array}{l}\text { Acknowledging the } \\
\text { imposition of the } \\
\text { request }\end{array}$ & $\begin{array}{l}\text { Used to show awareness of the } \\
\text { inconvenience caused to the } \\
\text { hearer and acknowledges the } \\
\text { imposition created by the } \\
\text { requested action. }\end{array}$ & $\begin{array}{l}\text { I understand this is an } \\
\text { imposition. }\end{array}$ \\
\hline $\begin{array}{l}\text { Complimenting the } \\
\text { addressee }\end{array}$ & $\begin{array}{l}\text { Used to compliment the } \\
\text { addressee. }\end{array}$ & $\begin{array}{l}\text { My teacher said that you are the } \\
\text { top student in the class. }\end{array}$ \\
\hline Showing gratitude & $\begin{array}{l}\text { Used to thank the hearer for } \\
\text { his/her help. }\end{array}$ & Thank you for your help. \\
\hline
\end{tabular}




\begin{tabular}{|c|c|c|}
\hline $\begin{array}{l}\text { Pointing out the } \\
\text { importance of the } \\
\text { request }\end{array}$ & $\begin{array}{l}\text { Used to emphasise the } \\
\text { importance of making the } \\
\text { request. }\end{array}$ & $\begin{array}{l}\text { I must borrow your notes by } \\
\text { today. }\end{array}$ \\
\hline Apologising & $\begin{array}{l}\text { Used to apologise for an } \\
\text { inappropriate act or for the } \\
\text { inconvenience caused to the } \\
\text { addressee. }\end{array}$ & $\begin{array}{l}\text { I am very sorry you have to pay } \\
\text { for my lunch. }\end{array}$ \\
\hline $\begin{array}{l}\text { Offering } \\
\text { compensation }\end{array}$ & $\begin{array}{l}\text { Used as an offer to compensate } \\
\text { the hearer for the inconvenience } \\
\text { caused by the requested act. }\end{array}$ & $\begin{array}{l}\text { I can pay you interest on the } \\
\text { money you lend me. }\end{array}$ \\
\hline $\begin{array}{l}\text { Pointing out the } \\
\text { negative } \\
\text { consequences of } \\
\text { refusal to the } \\
\text { listener }\end{array}$ & $\begin{array}{l}\text { Used to point out the negative } \\
\text { consequences for the speaker if } \\
\text { the request is rejected. }\end{array}$ & $\begin{array}{l}\text { I will hand in my work late and } \\
\text { lose marks if you don't show me } \\
\text { how to finish it. }\end{array}$ \\
\hline $\begin{array}{l}\text { Pointing out the } \\
\text { benefits the author } \\
\text { would gain if the } \\
\text { request were } \\
\text { approved }\end{array}$ & $\begin{array}{l}\text { Used to point out the benefits for } \\
\text { the speaker if the request were } \\
\text { approved. }\end{array}$ & $\begin{array}{l}\text { You will get bonus marks if you } \\
\text { present your work today. }\end{array}$ \\
\hline Grounder & $\begin{array}{l}\text { Used as an explanation for the } \\
\text { request. }\end{array}$ & Please be quiet, I need to sleep. \\
\hline Disarmer & $\begin{array}{l}\text { Used to pre-empt the hearer's } \\
\text { potential objections. }\end{array}$ & $\begin{array}{l}\text { I know you are really busy but } \\
\text { could you hand in your } \\
\text { assignment earlier? }\end{array}$ \\
\hline $\begin{array}{l}\text { Imposition } \\
\text { minimizer }\end{array}$ & $\begin{array}{l}\text { Used to reduce the imposition of } \\
\text { the request. }\end{array}$ & $\begin{array}{l}\text { I will return them immediately, } \\
\text { the next day. }\end{array}$ \\
\hline Sweetener & $\begin{array}{l}\text { Used to flatter the hearer and to } \\
\text { put him/her into a positive } \\
\text { mood. }\end{array}$ & $\begin{array}{l}\text { I think you are the perfect } \\
\text { person to do it. }\end{array}$ \\
\hline $\begin{array}{l}\text { Promise of } \\
\text { Reward }\end{array}$ & $\begin{array}{l}\text { Used to offer the hearer a reward } \\
\text { for fulfilling the request. }\end{array}$ & $\begin{array}{l}\text { I will cook your dinner if you } \\
\text { clean the toilet. }\end{array}$ \\
\hline Small talk & $\begin{array}{l}\text { Used at the beginning of the } \\
\text { request as a way to establish a } \\
\text { positive atmosphere. }\end{array}$ & Good to see you. \\
\hline Appreciator & $\begin{array}{l}\text { Used at the end of the request to } \\
\text { positively reinforce the request. }\end{array}$ & $\begin{array}{l}\text { It would be wonderful if you } \\
\text { could hand in your work early. }\end{array}$ \\
\hline Considerator & $\begin{array}{l}\text { Used at the end of the request to } \\
\text { show consideration towards the } \\
\text { interlocutor's situation. }\end{array}$ & $\begin{array}{l}\text { Only if you've got the time of } \\
\text { course. }\end{array}$ \\
\hline $\begin{array}{l}\text { Asking for } \\
\text { forgiveness }\end{array}$ & $\begin{array}{l}\text { Used to ask for forgiveness for } \\
\text { what } s / \text { he has done. }\end{array}$ & Please forgive me. \\
\hline
\end{tabular}




\begin{tabular}{|l|l|l|}
\hline $\begin{array}{l}\text { Giving options to } \\
\text { the hearer }\end{array}$ & $\begin{array}{l}\text { Used to provide options to the } \\
\text { hearer as far as the details of } \\
\text { carrying out the request and the } \\
\text { possible rejection of the request } \\
\text { are concerned. }\end{array}$ & $\begin{array}{l}\text { You could choose the place and } \\
\text { the time for the interview. }\end{array}$ \\
\hline Showing sincerity & $\begin{array}{l}\text { Used to emphasise speaker's } \\
\text { desire to receive a positive reply. }\end{array}$ & $\begin{array}{l}\text { I sincerely hope that you can } \\
\text { help }\end{array}$ \\
\hline
\end{tabular}

The use by participants of internal and external devices per request was coded for the number of devices used.

The total number of external modifications per request was counted in pre- and postrequest devices and analysed for all three situations where learners were of mutual, higher and lower status than their interlocutor. Cross-group comparisons were analysed using ANOVA tests to compare differences between AHLs, SALs and ENGs in each round for all three statuses. Paired sample t-tests were performed within groups for comparison. The types of devices in each external and internal device participants used were counted and analysed to see if NSs and learners used different types of external and internal devices, and whether SALs and AHLs had developed different types of pre- and post-request devices.

\section{Inter-rater reliability}

An inter-rater reliability test was conducted to verify the reliability and validity of coding categories and decisions of the three main components of responses (pre-request, request and post-request devices), their functions, and to ensure request devices were coded in accordance with the CCSARP coding request categories (1989). A second rater and I studied the definitions and examples of request devices, as well as external and internal request devices. The second rater had conducted extensive research on L2 learners' development on request devices in the past. Therefore, four examples were discussed together before independent practice on two examples; after this coding was discussed and agreed upon. There were 36 responses and each had a request as well as pre- and post- request devices (for a total of 108 request components).

Of the 108 request components, there was disagreement on $13(12 \%)$ responses. The disagreements arose because of a query on whether to code the modal 'can/could' based on its literal meaning (question) or function (request) in, for example, 'Can you give me an 
extension because I've difficulties to finish the paper?' After discussion, it was agreed to code these modals based on the functions of willingness.

Finally, the third main area analysed investigates the effect of environmental and affective factors on SALs' performance of English request devices

RQ5: To what extent did environmental, affective or attitudinal factors in the study abroad experience correlate with the acquisition of more native-like request devices in English?

In order to examine the effect of environmental and affective dimensions on SALs' pragmatic performance to use English request devices, the last section uses Spearman's rho $r$ correlations to analyse the relationship between the number of external modifiers SALs with the following factors: self-rated proficiency and self-rated confidence scores on speaking, communication and grammar; as well as SALs' listening input and interaction in English. Furthermore, since living environment has been suggested in the literature as a factor which promotes learners' pragmatic development, ANOVA repeated measures t-tests and post-hoc analyses were performed to see if there were differences between the number of external modifiers the SALs in different types of accommodation used across the three statuses between $T_{1}$ and $T_{3}$. In addition, one-way ANOVA analyses of variance and post-hoc analyses were performed between the type of accommodation SALs had and their self-rated proficiency and self-rated confidence scores in speaking, ability to communicate and grammar in $\mathrm{T}_{1}$ and $\mathrm{T}_{3}$.

\subsection{Summary}

This chapter has described the methodologies used to collect and analyse data addressing the five main research questions which relate to the extent to which the environmental and affective dimensions of learners' experience abroad and its effect on their pragmatic performance of request devices. The use of multiple methods is designed to collect both quantitative and qualitative data and aims to increase the reliability and generalisability of the request responses. Quantitative analyses of learners' self-report data from the LCP provided details of the environmental and affective dimensions of learners' study abroad experience. Additionally, quantitative and qualitative analyses of the EDCTs and qualitative analyses of role-play responses from the ENGs, AHLs and SALs provided across-group performance of 
request devices used by the three groups, and within groups analyses of the SALs' pragmatic performance over their nine-month sojourn abroad. Finally, correlations were used to analyse the relationship between study abroad learners' pragmatic performance and the affective and environmental dimensions of their experience. Qualitative data in the form on interview data and student entries in introspective diaries was collected to provide in-depth explanations for responses to the oral EDCTs and role-plays, and their experience abroad. 



\section{Chapter 5 Environmental and affective dimensions of Hong Kong learners' study abroad experience}

\subsection{Introduction}

Previous research suggests that living in the target language community should, in practice, offer a wide variety of ways to increase learners' exposure to the target language (Coleman 1998; Regan 1995, 2003). However, in reality, the amount of L2 authentic listening input and interaction SALs have in the target language community largely depends on both environmental and affective factors. This chapter provides results pertaining to the first research question:

RQ 1: What are the environmental and affective dimensions of SALs' study abroad experience?

The first section of this chapter analyses the environmental dimensions of learners' experience during their sojourn in Australia. It focuses on the number of hours SALs reported that they listened and interacted face-to-face in English, and whether they reported using less Cantonese during their sojourn in Australia. Furthermore, it analyses results of the effect of SALs' living arrangement on their input and interaction. The second section focuses on the affective dimensions of SALs' experience abroad. Analyses will be performed to compare SALs' perception of the target language community and self-perceived proficiency and selfperceived confidence. Quantitative and qualitative data from this section are from the LCP questionnaire and interviews. Both descriptive and inferential statistics will be presented.

\subsection{Environmental factors}

This section reports on the analyses of the number of hours SALs had English listening input and face-to-face interaction, and the number of hours they used Cantonese during their sojourn abroad. It also presents and discusses data on the relationship between SALs' living arrangement and the number of hours SALs listened and interacted face-to-face in English. 


\subsubsection{Listening input and interaction in target language community}

Researchers have proposed that the target language environment is more beneficial than the 'at-home' environment because learners would have more native-like input and interactions (e.g., Bardovi-Harlig \& Griffin 2005; Barron 2003, 2005 in Barron 2007a, 2007; Code \& Anderson 2001; Schauer 2006a,b). This section reveals results related to SALs' English listening input and interaction in the target language community.

\subsubsection{SALs' English listening input in the target language community}

Table 5.1 and Figure 5.1 show the average number of hours per week SALs listened and interacted face-to-face in English from $T_{0}$ to $T_{3}$ in Australia. The general trend shows, with the exception of listening in academic settings, the number of hours SALs listened in English was low in Hong Kong $\left(\mathrm{T}_{0}\right)$ and immediately after they arrived in Australia $\left(\mathrm{T}_{1}\right)$. However, the number of hours this group of SALs listened in English increased dramatically in total. This includes all listening sources such as radio, TV/movies, songs, overhearing English conversations and in academic settings by the third and fourth months $\left(\mathrm{T}_{2}\right)$. It plateaued at this level through to the ninth month $\left(\mathrm{T}_{3}\right)$.

Table 5.1: Average number of hours per week SALs listened in English from $T_{0}$ and $T_{3}$

\begin{tabular}{|c|c|c|c|c|c|c|c|c|}
\hline \multirow[t]{2}{*}{ Listening input } & \multicolumn{2}{|l|}{$\mathrm{T}_{0}$} & \multicolumn{2}{|l|}{$\mathrm{T}_{1}$} & \multicolumn{2}{|l|}{$\mathrm{T}_{2}$} & \multicolumn{2}{|l|}{$\mathrm{T}_{3}$} \\
\hline & Mean & SD & Mean & SD & Mean & SD & Mean & SD \\
\hline Radio & 1.45 & 1.92 & 1.45 & 1.92 & 6.43 & 8.61 & 8.60 & 10.33 \\
\hline TV/Movies & 1.07 & 1.94 & 1.07 & 1.94 & 6.74 & 9.25 & 8.21 & 9.73 \\
\hline Songs & 2.83 & 5.05 & 2.83 & 5.05 & 9.45 & 9.80 & 11.62 & 11.60 \\
\hline Conv. Eng. & 1 & 2.25 & .52 & .56 & 8.86 & 9.26 & 10.12 & 10.32 \\
\hline Acad. settings & 16.43 & 2.54 & 27.81 & 3.84 & 27.43 & 3.79 & 27.38 & 3.77 \\
\hline Total & 22.79 & 8.89 & 33.69 & 9.36 & 58.90 & 33.04 & 65.93 & 39.18 \\
\hline
\end{tabular}

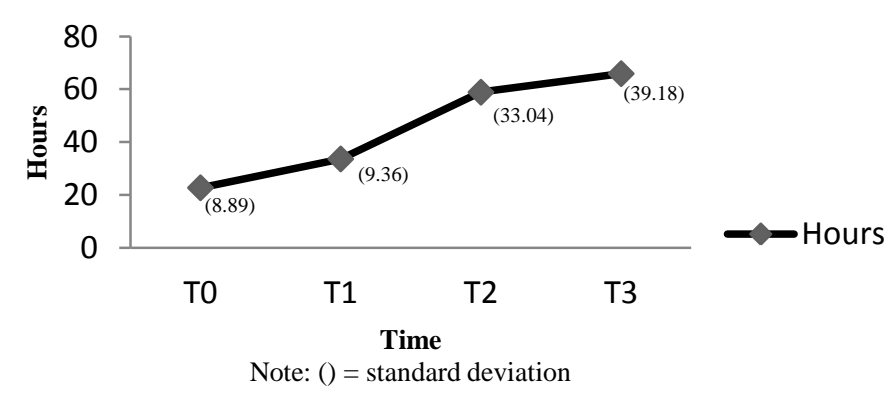

Figure 5.1. Average of the total number of hours per week SALs' listened in English from $\mathbf{T}_{0}$ to $\mathbf{T}_{3}$ 
Repeated measures ANOVA analyses revealed the main effects were statistically significant in the total number of listening hours in English between T0 and T4 F $(3,18)=35.08$, p<.01, as well as other sources of input measured such as radio $F(2,19)=4.59, \mathrm{p}<.02, \mathrm{~T} / \mathrm{V}$ and movies $F(2,19)=4.91, \mathrm{p}<.02$, songs $F(2,19)=4.78, p<.03$, NS English conversations $F(3,18)$ $=7.33, \mathrm{p}<.003$, and lectures $F(3,18)=38.48, \mathrm{p}<.002$. Posthoc analyses revealed the total number of hours SALs listened in English, as well as the hours they watched TV, listened to the radio, songs and overheard English speakers' conversations were not significantly different between $T_{0}$ and $T_{1}$. Statistically significant differences were found between $T_{0}$ and $T_{2}$, and $T_{0}$ and $T_{3}$, as well as $T_{1}$ and $T_{2}$, and $T_{1}$ and $T_{3}$ in total and for radio input, $T V / m o v i e s$, songs, listening to NS English conversations and input related to academic purposes.

\subsubsection{SALs' interaction in the target language community}

As can be seen from Table 5.2, there were big contrasts between the average number of hours per week SALs interacted from $\mathrm{T}_{0}$ and $\mathrm{T}_{1}$. The interaction hours then increased drastically from $\mathrm{T}_{1}$ to $\mathrm{T}_{2}$ and $\mathrm{T}_{3}$.

Table 5.2: Average number of hours per week SALs used English in different types of interactions from $\mathbf{T}_{0}$ and $\mathbf{T}_{3}$

\begin{tabular}{lcrrrrrrr}
\hline Types of interactions & \multicolumn{1}{l}{ T0 } & & \multicolumn{1}{c}{$\mathrm{T}_{1}$} & & $\mathrm{~T}_{2}$ & \multicolumn{2}{c}{$\mathrm{T}_{3}$} \\
& Mean & \multicolumn{1}{c}{$\mathrm{SD}$} & Mean & \multicolumn{1}{c}{$\mathrm{SD}$} & Mean & \multicolumn{1}{c}{$\mathrm{SD}$} & \multicolumn{1}{c}{ Mean } & \multicolumn{1}{c}{$\mathrm{SD}$} \\
\cline { 2 - 9 } Class hours & 1.33 & 2.16 & 7.86 & 8.83 & 7.86 & 8.83 & 8.24 & 6.88 \\
English speakers & 1 & 2.22 & 6.33 & 8.28 & 6.71 & 8.26 & 8.02 & 10.22 \\
Living arrangement & .17 & .46 & 8.50 & 11.48 & 9.79 & 12.06 & 10.26 & 11.98 \\
NNSs out school/home & .64 & .45 & 7.10 & 9.40 & 7.10 & 9.40 & 7.60 & 7.55 \\
Total & 3.14 & 3.84 & 41.69 & 34.90 & 46.12 & 39.15 & 49.14 & 36.61 \\
\hline
\end{tabular}

Repeated measures ANOVA analyses revealed there were significant increases in the total number of hours SALs interacted in English from T0 to T3 $(\mathrm{F}(3,18)=10.68, \mathrm{p}<.01)$. Likewise, there were also significant increases from T0 to T3 in the number of hours SALs interacted using English in class $(F(2,19)=11.40, \mathrm{p}<.01)$, with English speakers $(F(3,18)=$ $4.05, \mathrm{p}<.05)$, at home $(F(3,18)=4.99, \mathrm{p}<.05)$, and with NNSs outside school or home $(F(2,19)=11.20, \mathrm{p}<.01)$.

Posthoc analyses revealed the number of hours SALs interacted in English during class, at the living arrangement, and with other NNSs outside school or home as significantly greater between $T_{1}$ and $T_{0}, T_{2}$ and $T_{0}$ as well as $T_{3}$ and $T_{0}$. The SALs' interactions with NSs/fluent English speakers were not significantly different between $\mathrm{T}_{1}$ and $\mathrm{T}_{0}$; however, as with other types of interactions, the increases from $T_{0}$ and $T_{2}$ as well as $T_{0}$ and $T_{3}$ were significantly 
different. In all types of interactions, however, the small increases between $T_{1}, T_{2}$ and $T_{3}$ were not significantly different. Overall, there were no significant differences between $T_{1}$ and $T_{2}, T_{1}$ and $T_{3}$, and $T_{2}$ and $T_{3}$. The increases were only significant between $T_{0}$ and $T_{1}, T_{0}$ and $\mathrm{T}_{2}$ and $\mathrm{T}_{0}$ and $\mathrm{T}_{3}$.

Overall, the results showed a significant increase in the total number of hours that SALS listened and interacted in English during their sojourn abroad.

\subsubsection{Number of hours that SALs spoke in L1 (Cantonese)}

Data was also collected on the use of L1 (Cantonese by the SAL students while in Australia) to examine if learners had less contact with L1 speakers of Cantonese as they used more Australian English.

As can be seen from Figure 5.2, there was a dramatic decrease in the number of hours SALs used Cantonese since their departure from Hong Kong (T0) and after arrival in Australia (T1). However, the number of hours SALs used Cantonese remained at a constant of 16-18 hours per week between $\mathrm{T} 1$ and $\mathrm{T} 3$. There was significant increase in the amount of Cantonese spoken over time between T0 (in Hong Kong) and in T1, T2 and T3 (F(2, 40) = 18.9, $\mathrm{p}<.05)$. Post-hoc pairwise comparisons revealed there was no statistical significance between T1, T2 and T3. However, the number of hours the SALs used Cantonese in Hong Kong $\left(\mathrm{T}_{0}\right)$ was significantly higher than $\mathrm{T}_{1}, \mathrm{~T}_{2}$ and $\mathrm{T}_{3}$.

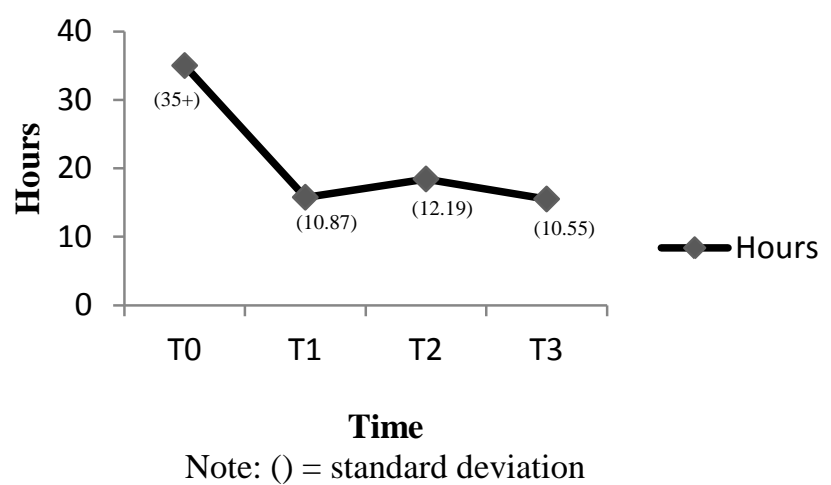

Figure 5.2. Average number of hours per week SALs used Cantonese with friends from Hong Kong from $T_{0}$ and $T_{3}$ 


\subsubsection{Discussion of listening input and interaction in target language community}

SALs are believed to have many rich opportunities for native-like input and interaction in the target language community through activities such as social engagements, sports and recreation, service encounters and small talk with NSs (Coleman 1998; Regan 1995, 2003). The results of this study support this claim to the extent that this group of SALs had significantly greater L2 listening input in total via radio, TV/movies, songs, overhearing fluent/native English speaker conversations, and for academic purposes during their sojourn abroad compared to when they were in Hong Kong. Additionally, this group of SALs had significantly greater interaction using English in Australia compared to when they were in Hong Kong. Nonetheless, the predominant interactions learners had in English were with NNSs who were their classmates, flat mates or friends through the Hong Kong Association at the university. The only source of English speakers for a majority of these SALs was their class instructor. Therefore, this study supports previous research which found that study abroad did not necessarily provide the opportunities for native-like input and interactions that was expected (for example Allen \& Herron 2003; Barron 2003, 2005 in Barron 2007a; Coleman 1998; Martinsen 2008; Regan 1995, 2003; Segalowitz \& Freed 2004).

This study also showed that the level of engagement with the wider community and with the target language appeared to stabilize early in the period of study abroad rather than continue to increase throughout the period. As mentioned above, the SALs listened and interacted face-to-face in English. This was something which they did not have much opportunity for in Hong Kong $\left(\mathrm{T}_{0}\right)$ or immediately after they first arrived in Australia before they had established a network $\left(T_{1}\right)$. The biggest difference occurred between learners' immediate arrival in Australia $\left(\mathrm{T}_{1}\right)$ and the first four months of their stay $\left(\mathrm{T}_{2}\right)$. After that point, there were only small increases in the number of hours SALs listened and interacted face-to-face in English between three to four months $\left(\mathrm{T}_{2}\right)$ and nine months $\left(\mathrm{T}_{3}\right)$ in Australia. It is also interesting to see a similar pattern in the number of hours the SALs used Cantonese. There was a sharp decrease from $T_{0}$ to $T_{1}$, and the number of hours remained steady from $T_{2}$ to $T_{3}$.

There are several possibilities for this plateau effect in the number of hours SALs listened and interacted face-to-face in English. It is plausible that the learners did not have additional time to spend on listening activities in English or to meet new people due to heavy university workload. Another very likely possibility is that the SALs had established their main network 
shortly after they arrived in Australia. This is the circle of friends that is most important to them during their sojourn in Australia as they offer support at a time that the SALS are at their most vulnerable: a time they most missed friends and family in Hong Kong, they felt isolated in a new environment, faced similar challenges in an unfamiliar setting, and had the same goal of studying overseas so they can better their career prospects. The tendency is for these learners to stay within a network they feel most comfortable with during their sojourn abroad, and perhaps they may extend more friendships within that circle. Naturally, the most convenient and quickest way for the SALs to establish friends upon their arrival in Australia is with Hong Kong or international students from the same cohort in the university foundation studies.

Therefore, it is possible that the number of hours of interaction learners had could be either due to learners' unwillingness to extend beyond the circle of friends or because learners found it difficult to find English speaker friends. As can be seen from Figures 5.1 and 5.2, the standard deviations of the number of hours this group of SALs used English and Cantonese was quite large in both $\mathrm{T}_{1}$ and $\mathrm{T}_{3}$. It is possible that the learners' network of friends influenced the number of hours they spoke English (Figure 5.1) and Cantonese (Figure 5.2). For instance, a learner, Masaya, reported she was not confident in speaking English in the interview and in the LCP said she had mostly Hong Kong friends in both $\mathrm{T}_{1}$ and $\mathrm{T}_{3}$, spoke very little English $\left(\mathrm{T}_{1}=13.5 ; \mathrm{T}_{3}=38.5\right.$ hours per week respectively) and a lot of Cantonese $\left(\mathrm{T}_{1}=3.5\right.$ hours; $\mathrm{T}_{3}=31.5$ hours per week respectively) in the first nine months of her stay in Australia. The notable increase in the number of hours Masaya spoke Cantonese indicates her network of Hong Kong friends increased during her sojourn abroad. Masaya reported that she used English mostly with other foreign students at school and at her dormitory.

Conversely, Prudence was determined not to befriend other Hong Kong learners and had expressed strong desire to socialise mainly with fluent/native English speakers from $T_{1}$. She reported she spoke a lot of English with fluent/native English speakers $\left(\mathrm{T}_{1}=82.5\right.$ hours; $\mathrm{T}_{3}=$ 124.5 hours per week respectively) ${ }^{4}$ and very little Cantonese with other Hong Kong learners $\left(\mathrm{T}_{1}=1\right.$ hour; $\mathrm{T}_{3}=3.5$ hours per week respectively). Therefore, it appears that learners' willingness to integrate into the target language community and their network of friends

\footnotetext{
${ }^{4}$ The number of hours Prudence reported she had spoken in English with fluent/native English speakers should be interpreted with caution. It is possible that Prudence may have exaggerated on the number of hours she spoke English every week. During the interviews in all three rounds of data collection, Prudence claimed she frequently spoke English with native/fluent Australian English speaking service providers and friends outside school and at the dormitory every week.
} 
influence the amount of face-to-face interaction they have and the amount of Cantonese used during their sojourn abroad.

\subsubsection{Relationship between SALs' living arrangement and the amount of listening and face-to-face interaction in English}

Some scholars (e.g., Rivers 1998; Schmidt-Rinehart \& Knight 2004: 261) who believe in the 'homestay advantage' suggest homestays is another ideal way for students to gain access to the target language and culture during their sojourn abroad, while others (e.g., Gutel 2008) have found in reality that learners have only scarce opportunities to interact with their host family and have limited exposure to the target language and culture. This section reports the results of the relationships between SALs' living arrangement and the number of hours they listened and interacted face-to-face in English.

\subsubsection{Relationship between SALs' living arrangement and amount of English listening input}

Results reveal the SALs who lived with a host family did not always have more English listening input than those who lived in a dormitory or alone/with other NNSs in $\mathrm{T}_{1}$ (See Table 5.3). In $T_{1}$, those in dormitories had slightly higher total number of hours of English listening input and in academic settings than those with a host family and living with NNSs/alone. While the SALs at homestay had greater hours of listening to English speakers' conversations, the SALs living alone had the highest listening input from listening to the radio and songs, and watching $\mathrm{TV}$.

Table 5.3: SALs' mean number of hours of English listening input in different types of living arrangements in $\mathbf{T}_{1}$

\begin{tabular}{|c|c|c|c|c|c|c|c|c|c|c|c|c|}
\hline \multirow[t]{2}{*}{$\begin{array}{l}\text { Living } \\
\text { arrangements }\end{array}$} & \multicolumn{2}{|l|}{ Radio } & \multicolumn{2}{|c|}{ Movies } & \multicolumn{2}{|l|}{ Songs } & \multicolumn{2}{|c|}{$\begin{array}{l}\text { English } \\
\text { speakers }\end{array}$} & \multicolumn{2}{|c|}{$\begin{array}{l}\text { Acad. } \\
\text { Settings }\end{array}$} & \multicolumn{2}{|l|}{ Total } \\
\hline & Mean & SD & Mean & SD & Mean & SD & Mean & SD & Mean & SD & Mean & SD \\
\hline Homestay & 1.25 & 1.04 & .63 & .75 & 1.13 & .75 & .75 & .38 & 28.5 & 4.43 & 31.88 & 5.48 \\
\hline Dormitory & .90 & .96 & .80 & .84 & 3.90 & 7.62 & .40 & .42 & 30 & 2 & 36 & 10.72 \\
\hline alone/NNSs & 1.75 & 2.42 & 1.33 & 2.51 & 2.96 & 4.84 & .63 & .57 & 26.67 & 4.03 & 33.33 & 10.32 \\
\hline
\end{tabular}




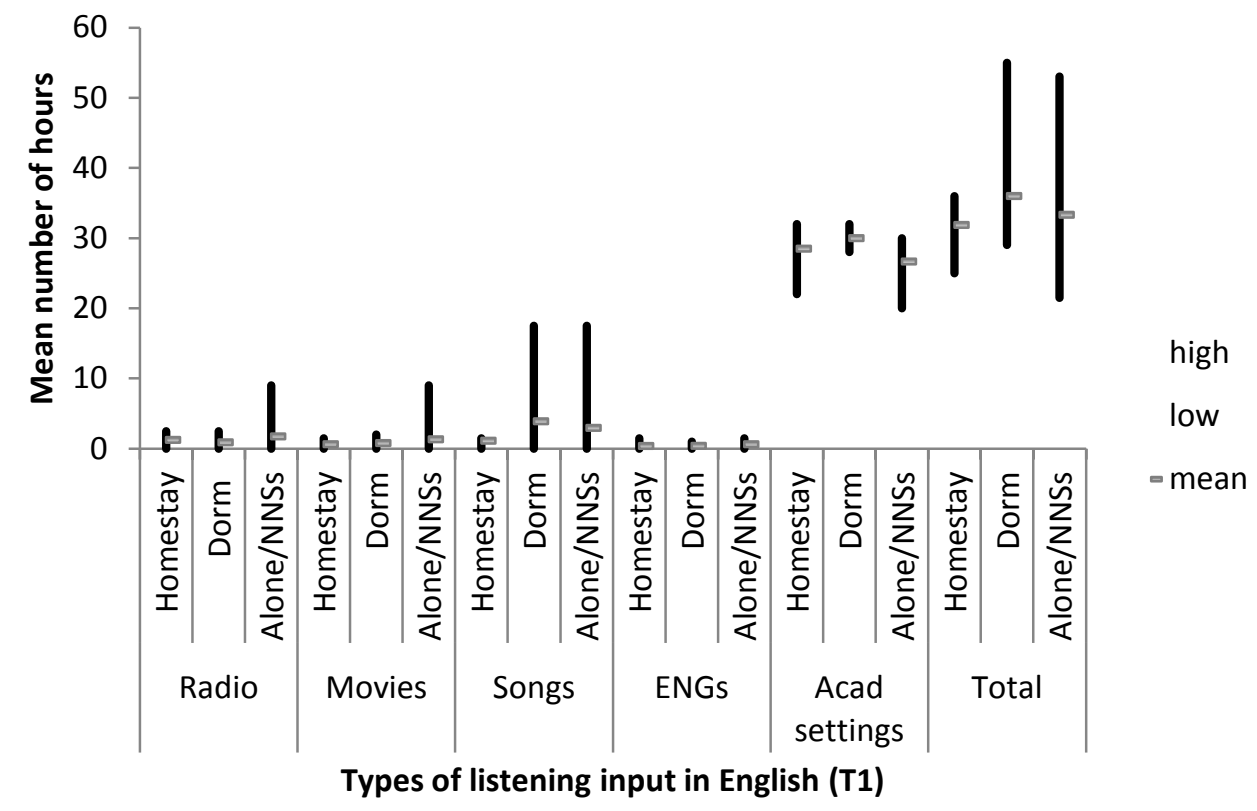

Figure 5.3. SALs' living arrangements and mean number of hours of English listening input in $\mathbf{T}_{1}$

Table 5.4 shows that by $\mathrm{T}_{3}$, SALs living in dormitories generally had much more English listening input than those living alone/with other NNSs and homestay in listening mediums measured: radio, movies and songs. What is most surprising is that even the SALs who lived in dormitories had more input from English speakers than those living with homestay families.

Table 5.4: SALs' mean number of hours of English listening input in different types of living arrangements in $T_{3}$

\begin{tabular}{|c|c|c|c|c|c|c|c|c|c|c|c|c|}
\hline \multirow[t]{2}{*}{$\begin{array}{l}\text { Living } \\
\text { arrangements }\end{array}$} & \multicolumn{2}{|l|}{ Radio } & \multicolumn{2}{|c|}{ Movies } & \multicolumn{2}{|l|}{ Songs } & \multicolumn{2}{|c|}{$\begin{array}{l}\text { English } \\
\text { speakers }\end{array}$} & \multicolumn{2}{|c|}{ Acad settings } & \multicolumn{2}{|l|}{ Total } \\
\hline & Mean & SD & Mean & SD & Mean & SD & Mean & SD & Mean & SD & Mean & $\mathrm{SD}$ \\
\hline Homestay & 6.06 & 6.63 & 5.63 & 4.16 & 9.44 & 8.30 & 10 & 6.25 & 28.25 & 4.06 & 59.38 & 19.31 \\
\hline Dormitory & 23.75 & 13.62 & 21.75 & 15.64 & 19 & 18.48 & 19.50 & 18.12 & 29.50 & 1.91 & 113.5 & 64.19 \\
\hline alone/NNSs & 4.11 & 3.85 & 4.50 & 4.02 & 10.28 & 10.69 & 6.06 & 6.79 & 25.67 & 3.67 & 50.61 & 50.61 \\
\hline
\end{tabular}




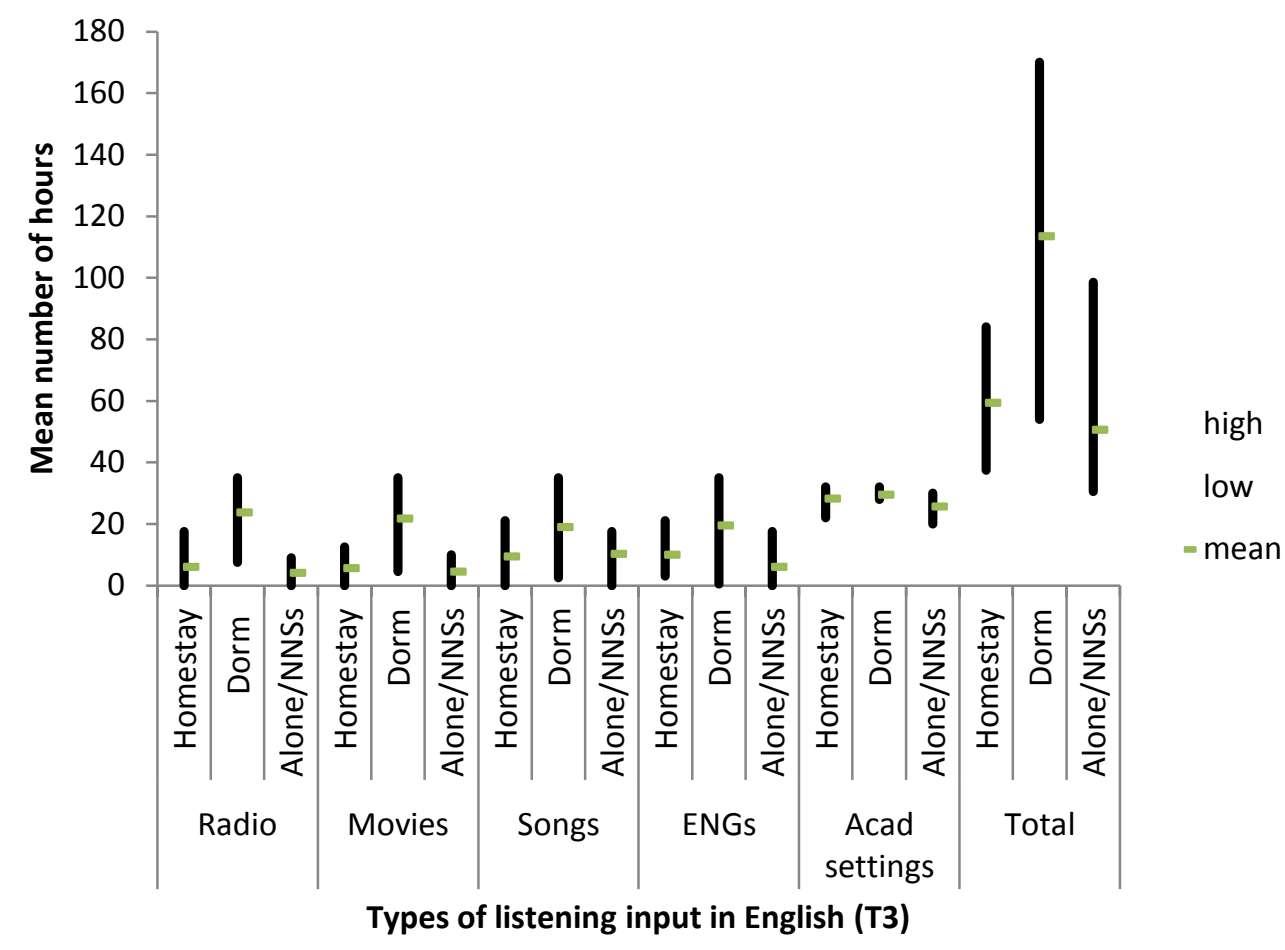

\section{Figure 5.4. SALs' living arrangements and mean number of hours of English listening input in $\mathbf{T}_{3}$}

Figures 5.3 and 5.4 illustrate the maximum, minimum and mean scores of the number of hours of English listening input in T1 and T3 respectively. As can be seen from Figures 5.3 and 5.4, there were generally big differences between learners' maximum and minimum scores in all listening types. It suggests that there were learners who were more pro-active in getting more listening input than others regardless of their living arrangement.

Table 5.5 shows that in $\mathrm{T} 1$, there was no significant difference between the number of hours SALs living with a homestay family, dormitory and alone/other NNSs received different types of listening input in English. In fact, the greatest difference between the total number of listening hours was found amongst those with a homestay family. Some students reported they received only 37.5 hours per week and maximum was 64 hours in total. This was 54-170 hours for the student dormitory group and 30.5-98.5 hours for the alone/with NNSs groups (see Figures 5.3 and 5.4). 
Table 5.5: ANOVA analyses of SALs' mean number of hours of English listening input in different types of living arrangement in $T_{1}$ and $T_{3}$

\begin{tabular}{|c|c|c|c|c|}
\hline \multirow[t]{2}{*}{ Types of listening input } & \multicolumn{2}{|l|}{$\mathrm{T}_{1}$} & \multicolumn{2}{|l|}{$\mathrm{T}_{3}$} \\
\hline & $\mathrm{F}$ & Exact Sig. & $\mathrm{F}$ & Exact Sig. \\
\hline \multirow[t]{4}{*}{ Radio } & .35 & $.711, \mathrm{df}=2,18$ & 6.20 & $.05^{*}, \mathrm{df}=2,5^{(\mathrm{x})}$ \\
\hline & & & \multirow{3}{*}{\multicolumn{2}{|c|}{$\begin{array}{l}\text { Posthoc analyses: } \\
\text { Homestay > dormitory at } .001 * * \\
\text { Homestay }=\text { alone at } .593 \\
\text { dormitory }>\text { live alone at } .000^{* *}\end{array}$}} \\
\hline & & & & \\
\hline & & & & \\
\hline Movies & .24 & $.787, \mathrm{df}=2,18$ & 4.18 & $.115, \mathrm{df}=2,4^{(\mathrm{x})}$ \\
\hline Songs & .32 & $.729, \mathrm{df}=2,18$ & .71 & $.532, \mathrm{df}=2,6^{(\mathrm{x})}$ \\
\hline English speakers & .44 & $.653, \mathrm{df}=2,18$ & 1.58 & $.307, \mathrm{df}=2,4^{(\mathrm{x})}$ \\
\hline Acad. Settings & 1.48 & $.255, \mathrm{df}=2,18$ & .19 & $.173, \mathrm{df}=2,18$ \\
\hline
\end{tabular}

\subsubsection{Relationship between SALs' living arrangements and amount of interaction}

Tables 5.6 and 5.7 provide the statistics and analyses of the number of hours of different types of interactions from SALs living with homestay family, students living in dormitories or alone/other NNSs of English in $\mathrm{T}_{1}$ and $\mathrm{T}_{3}$. As Tables 5.7 and 5.8 show, in $\mathrm{T}_{1}$ and $\mathrm{T}_{3} \mathrm{SALs}$ who lived with a homestay family did not necessarily have more interaction with English speakers at home and outside home/class than students who stayed in a dormitory or lived alone/with other NNSs. In fact, students living in dormitories had greater number of hours of interaction with classmates, and with English speakers at the dormitory and outside home/class, at home or with other NNSs outside school/home than those who lived in student dormitories or alone/with other NNSs in $\mathrm{T}_{1}$ and $\mathrm{T}_{3}$ (see Tables 5.7 and 5.8 respectively).

Table 5.6: SALs' mean number of hours of interactions in different types of living arrangement in $\mathrm{T}_{1}$

\begin{tabular}{|c|c|c|c|c|c|c|c|c|c|c|}
\hline \multirow[t]{2}{*}{$\begin{array}{l}\text { Types of living } \\
\text { arrangement }\end{array}$} & \multicolumn{2}{|l|}{ Class } & \multicolumn{2}{|c|}{$\begin{array}{l}\text { English speakers (out } \\
\text { school/home) }\end{array}$} & \multicolumn{2}{|l|}{ Home } & \multicolumn{2}{|c|}{$\begin{array}{l}\text { NNSs (out school or } \\
\text { home) }\end{array}$} & \multicolumn{2}{|l|}{ Total } \\
\hline & Mean & SD & Mean & SD & Mean & SD & Mean & $\mathrm{SD}$ & Mean & $\mathrm{SD}$ \\
\hline Homestay & 3.63 & 5.95 & 7.88 & 7.63 & 13.25 & 14.61 & 12.50 & 15.92 & 45.63 & 33.36 \\
\hline Dormitory & 15.10 & 13.38 & 12.30 & 13.64 & 16 & 16.22 & 2.50 & 2.00 & 59.8 & 51.40 \\
\hline Alone/NNSs & 6.25 & 5.81 & 3.33 & 3.78 & 3.79 & 5.28 & 7.21 & 8.35 & 32.83 & 26.64 \\
\hline
\end{tabular}


Table 5.7: SALs' mean number of hours of interactions in different types of living arrangement in $T_{3}$

\begin{tabular}{|c|c|c|c|c|c|c|c|c|c|c|}
\hline \multirow[t]{2}{*}{$\begin{array}{l}\text { Types of living } \\
\text { arrangement }\end{array}$} & \multicolumn{2}{|l|}{ Class } & \multicolumn{2}{|c|}{$\begin{array}{l}\text { English speakers (out } \\
\text { school/ home) }\end{array}$} & \multicolumn{2}{|l|}{ Home } & \multicolumn{2}{|c|}{$\begin{array}{l}\text { NNSs (out school/ } \\
\text { home) }\end{array}$} & \multicolumn{2}{|l|}{ Total } \\
\hline & Mean & $\mathrm{SD}$ & Mean & $\mathrm{SD}$ & Mean & SD & Mean & $\mathrm{SD}$ & Mean & SD \\
\hline Homestay & 8.06 & 6.16 & 9.13 & 7.52 & 15.25 & 10.78 & 7.56 & 5.95 & 54.38 & 30.67 \\
\hline Dormitory & 7.50 & 10.06 & 17.13 & 18.68 & 19.50 & 16.40 & 13.38 & 14.10 & 74.13 & 57.88 \\
\hline Alone/ NNSs & 8.72 & 6.84 & 3 & 3.14 & 1.72 & 2.58 & 5.06 & 3.62 & 33.39 & 25.55 \\
\hline
\end{tabular}

As can be seen from Figures 5.5 and 5.6, the minimum and maximum number of hours of interaction the SALs had varied drastically in each type of living arrangement. Typically students in a dormitory spent more time in interaction using English than those living with homestay and alone/with other NNSs. Again, those living alone/with other NNSs had the least mean hours of interaction. The greatest difference between the total number of listening hours was found amongst those with a homestay family. Some students reported they had only 37.5 listening hours per week and the maximum was 64 hours in total; the student dormitory group had 54-170 hours and the alone/with NNSs groups had 30.5-98.5 hours.

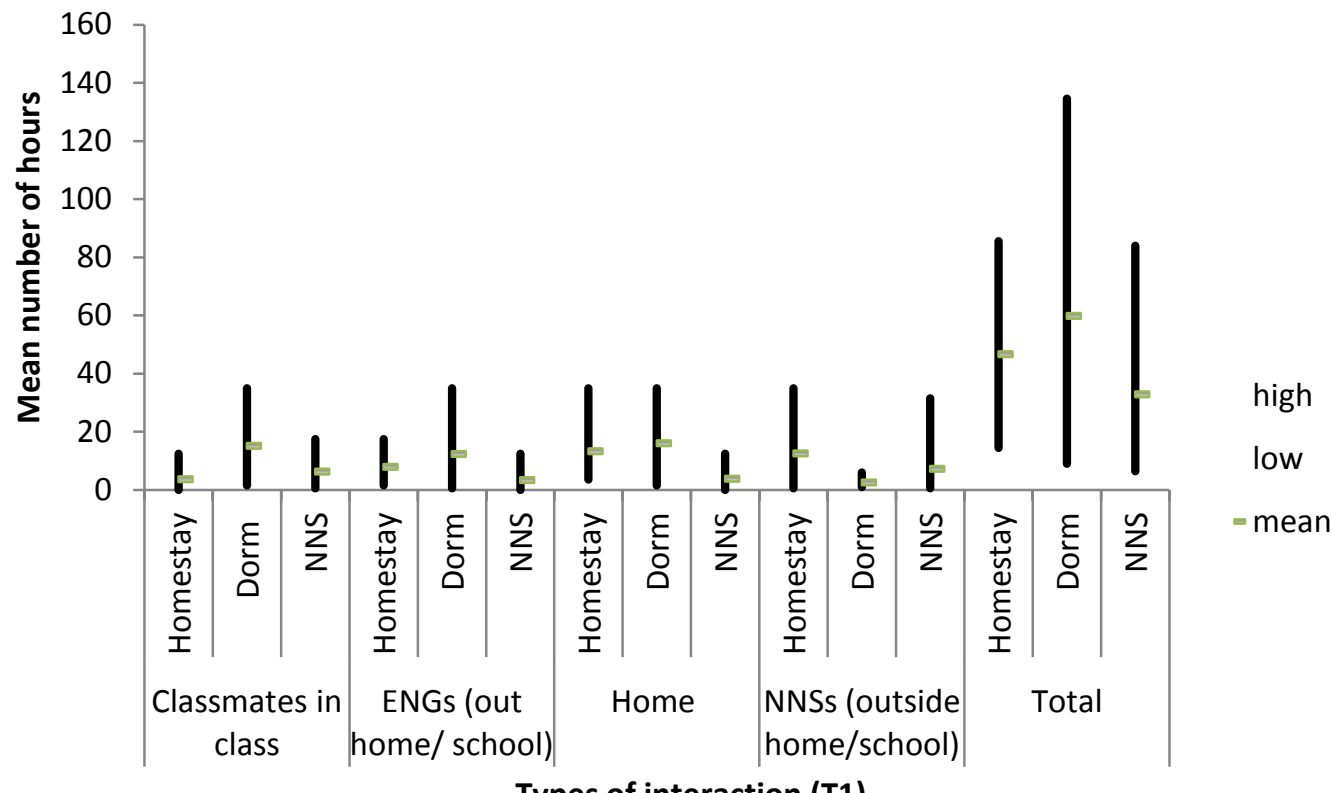

Types of interaction (T1)

Note. Homestay $\left(T_{1} n=4, T_{3} n=8\right)$, dormitory $\left(T_{1} n=5, T_{3} n=4\right)$, NNSs/living alone $\left(T_{1}\right.$ $\mathrm{n}=12, \mathrm{~T}_{3} \mathrm{n}=9$ )

Figure 5.5. SALs' living arrangement and types of interaction in $\mathbf{T}_{1}$ 


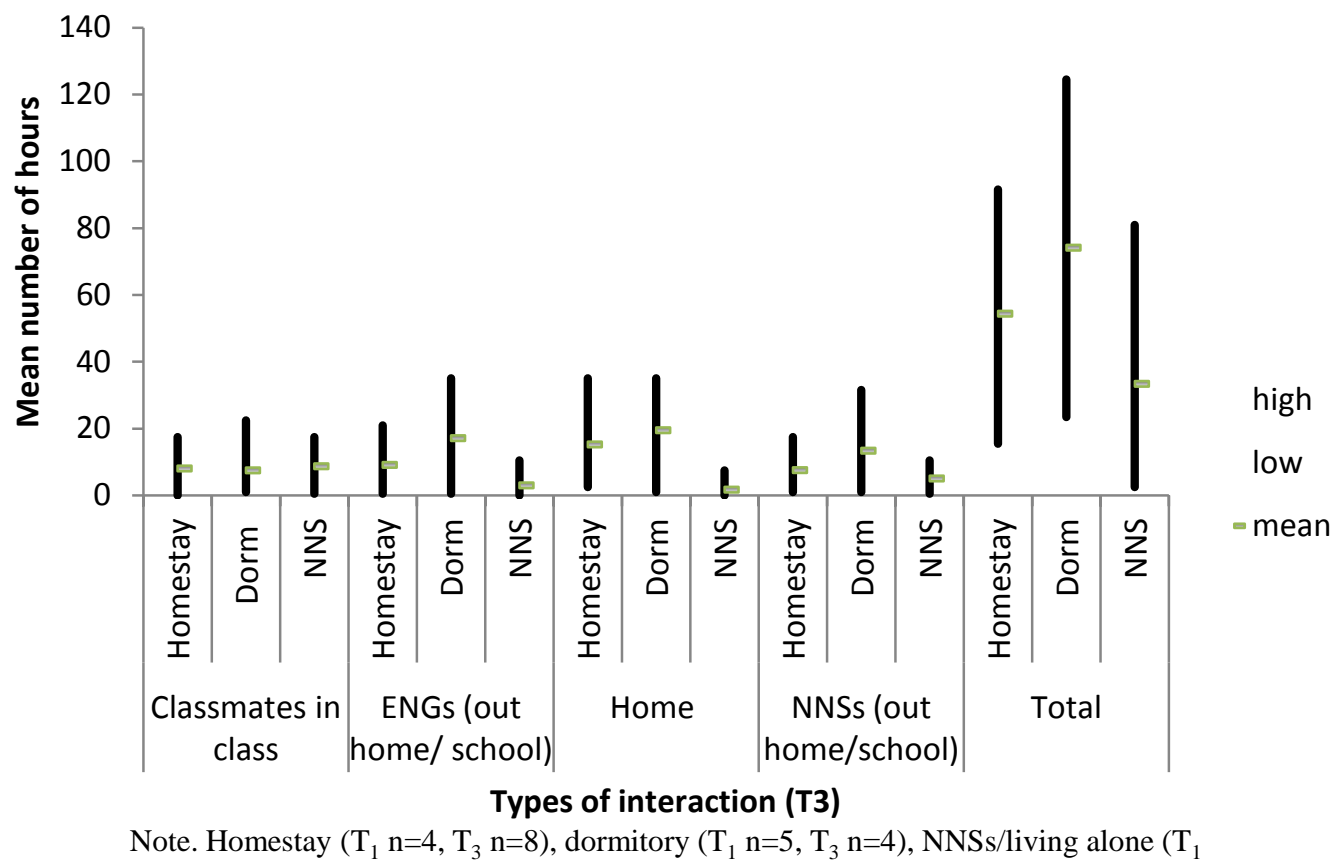

Note. Homestay $\left(T_{1} n=4, T_{3} n=8\right)$, dormitory $\left(T_{1} n=5, T_{3} n=4\right)$, NNSs/living alone $\left(T_{1}\right.$ $\mathrm{n}=12, \mathrm{~T}_{3} \mathrm{n}=9$ )

\section{Figure 5.6. SALs' living arrangement and types of interaction in $\mathbf{T}_{3}$}

One-way ANOVA analysis of variance revealed there was no main effect on the SALs' living arrangements and the mean total number of hours per week they used English in interaction in $\mathrm{T}_{1}$ and $\mathrm{T}_{3}$ (See Table 5.8).

Table 5.8: ANOVA analyses of SALs' mean number of hours of English listening input in different types of living arrangement in $T_{1}$ and $T_{3}$

\begin{tabular}{|c|c|c|c|c|}
\hline \multirow[t]{2}{*}{ Types of listening input } & \multicolumn{2}{|l|}{$\mathrm{T}_{1}$} & \multicolumn{2}{|l|}{$\mathrm{T}_{3}$} \\
\hline & $\mathrm{F}$ & Exact Sig. & $\mathrm{F}$ & Exact Sig. \\
\hline Class & 2.75 & $.091, \mathrm{df}=2,18$ & .043 & $.958, \mathrm{df}=2,18$ \\
\hline English speakers & 2.47 & $.113, \mathrm{df}=2,18$ & 1.76 & $.286, \mathrm{df}=2,4$ \\
\hline Living arrangement & 1.66 & $.254, \mathrm{df}=2,7$ & 4.08 & $.086, \mathrm{df}=2,5$ \\
\hline NNSs outside school or home & 1.30 & $.297, \mathrm{df}=2,18$ & 1.01 & $.440, \mathrm{df}=2,4$ \\
\hline
\end{tabular}

\subsubsection{Discussion of living arrangements}

The results indicate that overall there was no 'homestay advantage' effect in terms of learners receiving native-like listening input and interaction with English speakers during their first 
nine months in Australia. Consistent with previous findings (Maiworm, Steube \& Teichler 1993), SA learners generally had very limited contact with English speakers other than their teachers in an academic context.

The results showed SALs who lived alone/shared an apartment with other Hong Kong learners/NNSs had less listening input and interaction in English than those who lived in a dormitory and homestay, especially by $\mathrm{T}_{3}$. In $\mathrm{T}_{1}$, for example, the SALs who lived with other Hong Kong learners/NNSs actually had heard more English speakers' conversations than the other two groups. However, by T3, those who lived in a dormitory had heard more native English input from English speakers' conversations and had more interaction with English speakers in and out of their homes. There was a clear trend that those who lived alone/with Hong Kong learners and with other NNSs had very scarce opportunities to interact with English speakers in/out of their homes.

Despite the low number of hours SALs (particularly those who lived alone/with Hong Kong learners and with other NNSs) received listening input and interacted with English speakers, there was a vast difference between this group's minimum and maximum scores in interaction with English speakers.

The large variation between the minimum and maximum number of hours SALs listened and interacted face-to-face in English suggests SALs' living arrangement alone cannot fully account for the amount of listening input and interaction they had. Several factors such as SALs' self-proficiency and their willingness to integrate into the community could also play a critical role in the amount of input and interaction with English speakers. Additionally, the 'homestay advantage' does not happen automatically. The SALs must initiate and actively take part in communication. According to the interview data from the SALs, this is also heavily dependent on their perception of whether the host family welcomes them into the family.

Qualitative data will be included in the discussion below in an attempt to shed light on the possible factors related to the big variations in the number of hours SALs listened and interacted face-to-face in English with English speakers. 


\subsection{Apartment living}

The results showed SALs who lived alone/shared an apartment with other Hong Kong learners consistently had the least listening input and face-to-face interaction with NSs/fluent speakers of English compared to those SALs who lived in a dormitory or with a host family. Students had very limited opportunity to use English at home, so if they did not make an effort to meet other people, they would not have the chance to meet with people to interact in English. A majority of the students had established a very good network with other Hong Kong students and, at most, were only able to befriend and use English with other NNSs. They would only use English with NSs/fluent English speakers through service counters during their sojourn abroad.

For instance, a student, Terry, who shared an apartment with two other Hong Kong students had disliked being in Australia when he first arrived in Melbourne because he missed his family, friends and, most of all, his girlfriend. He felt isolated and did not have friends in $\mathrm{T}_{1}$. By $\mathrm{T}_{2}$ he was very happy as he had built a very good social network of Hong Kong friends through his course and the Hong Kong Students Association at the same university. He reported he was content and it was unnecessary for him to befriend other NNSs or NSs/fluent English speakers. He spoke very little English outside class, except in requesting services over the phone or at service counters which was not frequent. This resulted in Terry having only a low number of hours of overall input per week $\left(\mathrm{T}_{1}=25.5\right.$ and $\left.\mathrm{T}_{3}=38.5\right)$ and from overhearing English speakers conversations per week $\left(\mathrm{T}_{1}=0\right.$ and $\left.\mathrm{T}_{1}=3\right)$. A similar pattern can be observed in SALs' interaction $\left(\mathrm{T}_{1}=13\right.$ and $\left.\mathrm{T}_{3}=6.5\right)$ with English speakers outside school or home during the first nine months in Australia. The comparatively higher number of hours of interaction Terry had in $\mathrm{T}_{1}$ was due to the time he spent requesting information or services such as contacting real estate agents to look for a place, negotiating his lease, getting the phone, Internet and electricity connected, and asking for directions. In their living environment in Australia, there was no such chance for most SALs to interact with English speakers.

The large gap between the high number of hours of input and interaction of SALs in this group with English speakers could be attributed to Onnie and Sophia. Both Onnie and Sophia shared an apartment with other Hong Kong learners. However, they both got part-time jobs at a Chinese restaurant to earn pocket money and to find a chance to communicate with people using English. Both Onnie and Sophia reported a substantial increase in total number of hours 
of listening input $\left(\mathrm{T}_{1}=30.5\right.$ and $\mathrm{T}_{3}=98.5 ; \mathrm{T}_{1}=31$ and $\mathrm{T}_{3}=70$ respectively $)$ and interaction ( $\mathrm{T}_{1}=22$ and $\mathrm{T}_{3}=48 ; \mathrm{T}_{1}=26$ and $\mathrm{T}_{3}=81$ respectively). In addition, the number of hours both Onnie and Sophia listened in English $\left(\mathrm{T}_{1}=0\right.$ and $\mathrm{T}_{3}=17.5 ; \mathrm{T}_{1}=0.5$ and $\mathrm{T}_{3}=17.5$ respectively) and interacted $\left(\mathrm{T}_{1}=8.5\right.$ and $\mathrm{T}_{3}=32 ; \mathrm{T}_{1}=12.5$ and $\mathrm{T}_{3}=53.5$ respectively $)$ increased dramatically. Though they spoke Cantonese or Mandarin with other staff at the restaurant, they had many English speaker customers who spoke to them in English. Accordingly, in addition to using English for work tasks such as taking orders and asking customers if they needed things, the customers (especially regular customers) would often chat to them about school and life in Australia and tell them about the way people lived in Australia.

\subsection{Dormitory living}

The situation that SALs faced in dormitories was similar to those who lived alone/with other NNSs in that these SALs in general also had fewer opportunities to interact with English speakers than those living with a host family. However, unlike most who lived alone/with other Hong Kong learners/NNSs, learners in a dormitory at least had exposure to more NNSs. What is important, though, is how willing the learners are to take up opportunities to listen and engage in face-to-face interactions in English.

For instance, Masaya was a student who lived in a dormitory. She mostly spoke with other Hong Kong learners and studied in her room. She worked hard to improve her English by increasing her listening input overall $\left(\mathrm{T}_{1}=32\right.$ and $\left.\mathrm{T}_{3}=63\right)$ but still had very limited chances to listen to English speakers' conversations $\left(T_{1}=0\right.$ and $\left.T_{3}=7.5\right)$ per week. The 32 hours of overall listening input in $\mathrm{T}_{1}$ was from listening in academic settings (e.g., lectures and seminars), while the increase to 63 hours in $T_{3}$ was attributed to Masaya's determination to improve her English by listening to the radio/music and watching movies/TV programmes. Masaya reported that the increase of 7.5 hours of listening to English speakers' conversations in T3 came from listening to other students in the dormitory. However, Masaya rarely had interaction with English speakers. The total number of hours of interaction she had was $T_{1}=$ 13.5 and $\mathrm{T}_{3}=24.5$, but very little time was spent talking to English speakers $\left(\mathrm{T}_{1}=5.5\right.$ and $\mathrm{T}_{3}$ =3). At the dormitory, there was no chance to interact with English speakers. Masaya reported she only interacted with English speakers when it was necessary and her friends were not free to help her. Masaya reported she had relied on her friend Gloria, whom Masaya 
perceived as having better English, to help her to request for information or at service counters outside the classroom.

In contrast, another student, Prudence, who also lived at a dormitory had a very outgoing personality and was very confident. Prudence said from $T_{1}$ that she was determined not to mix so much with other Hong Kong students but wanted to make friends with other international students and English speakers to practise her English and learn about Australian culture.

Indeed, through Prudence's sojourn abroad, she spent time to increase her listening input and was able to build a good social network of English speakers and NNSs of English. This is reflected in the high number of hours Prudence received English listening input in total and listened to English speakers' conversations $\left(T_{1}=29\right.$ and $T_{3}=98 ; T_{1}=.05$ and $T_{3}=35$ respectively). Unlike other participants in this study, Prudence had regular interactions with English speakers. Thus, the total number of hours of face-to-face interaction remained high and face-to-face interaction with native/fluent English speakers increased greatly $\left(\mathrm{T}_{1}=99.5\right.$ and $\mathrm{T}_{3}=95.5 ; \mathrm{T}_{1}=53$ and $\mathrm{T}_{3}=81.5$ respectively). At the dormitory, Prudence was able to establish contact and interact with English speakers on regular bases $\left(\mathrm{T}_{1}=5\right.$ and $\left.\mathrm{T}_{3}=7\right)$.

In $T_{1}$ Prudence said living in Australia was boring but still liked it. She liked to watch American movies and listen to American songs. In the first week she had already met a Swedish neighbour and the neighbour took her shopping for food. Prudence frequently spoke to her in English for about 3-4 hours every day in addition to her other English speaker friends. Again she said she did not sit with Chinese people as she wanted to speak in English. By $\mathrm{T}_{2}$ she said her best friend was a Singaporean student at the dormitory and she had met several other English speaker friends outside the university whom she spent time with regularly. By $\mathrm{T}_{3}$, Prudence still had frequent contact with her friends, but did not meet up every day because she had to complete many assignments and she was busy preparing for exams. However, Prudence claimed she was losing her American accent (she said she acquired her American accent from exposure to a lot of American TV programmes in Hong Kong). Prudence had access to NNSs and English speakers the same way other SA learners had, but she made the most of those opportunities to build friendships with these people. 


\subsection{Homestay}

More interesting, and somewhat unexpected, results can be observed in students living with a host family. Despite the common belief that study abroad learners in a host family have many more opportunities to use English and learn more about the target culture than students with other living arrangements, this study suggests SALs' amount of input and interaction also heavily depends on factors such as the compatibility between the learner and the host family, the family's willingness to include the student as part of their family and, also, the student's desire to be part of the family. The SALs in this study had mixed feelings and experiences with their homestay families.

Queenie and Tiffany are good examples of students who stayed with good host families. Both their families were very willing to integrate them into the family and spent a lot of time talking to both of them. Both students were also very willing to interact with the families. However, both students did not establish a social network with other NNSs of English outside their home. So they did not use English outside their home except during service encounters.

In $T_{1}$ Queenie reported her host family looked after her very well. She stayed with the same family during the whole 10 months of her study. She stayed with an Australian lady and four other Singaporean international students. The host mother's children were grown-up. Queenie had a good relationship with the host family, and particularly enjoyed chatting to the host mum and her children very often and sometimes to other students. She had learned to joke in English, and became confident enough to talk to the host family and other NNSs. Queenie spent an increased number of hours chatting to the English speakers at home $\left(\mathrm{T}_{1}=3.5\right.$ and $\mathrm{T}_{3}$ $=17.5$ ) and with other English speakers outside the home environment. In the beginning, Queenie spoke little English with her host family, and used English only when requesting for information and services $\left(T_{1}=1.5\right.$ and $\left.T_{3}=21\right)$. As Queenie became more confident, she spoke more to the host family's friends when they took her to their friends' place for social gatherings on some weekends. Hence, there was still an overall increase in the number of hours of interaction $\left(\mathrm{T}_{1}=14.5\right.$ and $\left.\mathrm{T}_{3}=84.5\right)$. Queenie also put in an effort to increase her English input overall and in attempting to listen to English speakers' conversations $\left(\mathrm{T}_{1}=36\right.$ and $\mathrm{T}_{3}=84 ; \mathrm{T}_{1}=1.5$ and $\mathrm{T}_{3}=21$ respectively).

Similarly, Tiffany had a very good host family, and she spent a lot of time interacting with her host family at home. Like most other SALs in this study, Tiffany also put in an effort to 
increase her listening input overall and in conversations with English speakers $\left(\mathrm{T}_{1}=39\right.$ and $\mathrm{T}_{3}=81.5 ; \mathrm{T}_{1}=1.5$ and $\mathrm{T}_{3}=14$ respectively). Tiffany's host family made a tremendous effort to integrate her into the family and expose her to Australian culture and lifestyle. There were steady increases in the total number of hours of interaction and interaction with English speakers at home and outside home $\left(\mathrm{T}_{1}=69\right.$ and $\mathrm{T}_{3}=80 ; \mathrm{T}_{1}=22.5$ and $\mathrm{T}_{3}=35 ; \mathrm{T}_{1}=15$ and $\mathrm{T}_{3}=20.5$ respectively).

The family frequently took Tiffany out to socialise with their friends and family. Tiffany built a very good relationship with the host family and their friends throughout her stay. She liked talking to them very often. She had learned to joke in English, and became confident about her exchanges with her host and other English speakers and NNSs. Tiffany said in $\mathrm{T}_{3}$ :

...They [homestay family] are perfect, I think...they are very nice to me because I think normally they will bring me to some occasion for some gathering even though I'm not really their family member but still they will bring me to see friends or if they got a party or something they bring me to go together...I just do it on the day before because they got their son and their daughter got a birthday and they brought me to the restaurant and eat together ... I talk to them every day ...maybe after school once I get home I will talk to the homestay mother until we go to bed...they taught me some Australian accent and it's fun (laughs)... normally because all the kids and the homestay mum have got the partner on Friday and I will go out on Friday or on the weekends I see my friends...I talk to them for 5 hours at least every day...normally we will share the time to watch TV on TV programme and then they will talk about maybe talk about the show and what I feel or something ...

As mentioned by Gutel (2008) and Jackson (2008), learners who reported positive experiences are able to gain better insight into the host culture and environment which fostered their language learning. The learners reported that living with a family in the host speech community enabled them to experience the culture firsthand and opened up new possibilities for their lives, as Queenie and Tiffany were fortunate to experience.

In contrast, this study shows that, one cannot assume, even in the case of a homestay living arrangement, that learners are provided with an enriched experience vis-à-vis the target 
language and culture. Similarly, in Jackson's (2008) study, some learners actually had bad experiences with their host family and, in turn, led to learners feeling stressed. Learners in this study reported they had bad experiences with their host family for numerous reasons.

For instance, Sally stayed with a family with a couple and their two-year-old son and at the beginning with three other international students from Japan and China. She reported at T1 that she used English at meal times (breakfast and dinner) and frequently mixed with the homestay family because they had not met other Hong Kong students before. At the beginning, she was very happy with the host family. Sally said in T1:

When I'm arrived two days she brought me to the shopping centres, and she showed me how to go to the school and she brought me to the city for a drive and go to see the sea beach to see the sea but because I'm lucky but I don't like swimming but she pulled me in because she want me to enjoy it but I wear trousers I don't want to get wet...just want me to enjoy and I know her kindness I know...

However, by $\mathrm{T}_{2}$ Sally was asked to look after the family's two-year-old son very frequently. When she did not want to play with the child, the host mother was not happy. This prevented Sally from going out of her room to talk to other students and the family. $\operatorname{In}_{2}$, Sally said:

I talk to my family after dinner and sometimes I look after her children because the boy just two years old...the boy just two years old...[the boy] a little bit annoy...but she will feel bad but at the end of the class if I don't play with her son and the housemate will feel not so good because her face go bad because I have refused for once didn't play with her son and she just (pulls a face) but I am studying here I can't just play with him every day...we have a lot of stress in foundation studies... and you know that I have a lot to do so I can't play with him you know. If I play with him it's one to two hours and I can...I can go back to my room I can go back to my room after the night and if I go to go back home sometimes her son will beg me and she just ask me that is that ok but I can't refuse her I can't say no I just say it's ok but she just reading books or talking to her husband or play with her home computer and leave her son to me or on their own... 
Sally's situation deteriorated further by $\mathrm{T}_{3}$ :

...homestay still...so so feeling about homestay. They have a little boy, he's just 2 years old he's very cute but sometimes he's very annoying...very annoying when I study he's very noisy very always screaming and crying oh very noisy.

This situation worsened by $\mathrm{T}_{3}$. The host mother was very moody for personal reasons. This limited Sally to her room and avoided interactions with the host mother. She was still expected to play with the son for three to four hours at a time. She only interacted with the host dad after dinner when they cleaned the kitchen. It appears Sally was no longer in a happy environment. She was planning to move into a dormitory as she felt the host mum had caused a lot of tension in the house. Sally said in $\mathrm{T}_{3}$ :

Sometimes so so so so because sometimes hmm something happened to my house mum and she has bad temper and something like that...the mood is not very good when it's eating dinner...always sick... because she has pregnant...but she has lost the baby...she is very very sad...it seems not very well...so bad temper...I don't feel happy...you can't always treat very bad and I know you are...sometimes is not always...still talking...at home still feel very normal...before this happened because the homestay mum mood sometimes very good sometimes very bad...House dad is much better...talk to him much more we usually talk when we are having dinner and after dinner I go back to my room to study because this semester I have many things to study so didn't have time...weekends...hmm just the same I like staying in my room because when I go out and his son want to want me to play with him and for three to four hours sometimes...two to three hours is very tiring and after that I didn't do anything...I better not play and stay in my room...

I spend one hour talking but not every day but sometimes on the weekends...because he sometimes taught me how to cook and I will help and set the table and something like that and we will have a lot of communication...that's fine. Better than the house mum because house mum always like like that (pulls sad face) and house dad always smiling and talk many things and he taught me how to do my English comprehension so this time in comprehension I'm ok because I use his methods and it works. 
This experience led Sally to feel very stressed, and affected her interaction with the host. The total number of Sally's listening input and English speakers' conversations increased slightly from $T_{1}$ to $T_{3}\left(T_{1}=31\right.$ and $T_{3}=37.5 ; T_{1}=0$ and $T_{3}=3$ respectively $)$ in the nine months of the study. The total number of hours of interaction, interaction with the host family and out of home remained unchanged from $\mathrm{T}_{1}$ to $\mathrm{T}_{3}\left(\mathrm{~T}_{1}\right.$ and $\mathrm{T}_{3}=15.5 ; \mathrm{T}_{1}$ and $\mathrm{T}_{3}=10.5 ; \mathrm{T}_{1}$ and $\mathrm{T}_{3}=0.5$ respectively). There was very little quality interaction between Sally and her host family. By T3, Sally mostly spoke to the other international students at home.

Similarly, Ruby's host mother expected her to do a lot of house cleaning and, subsequently, she had very little quality interaction with the host family. A lot of talks between Ruby and her host mother were instructions for Ruby. Ruby wanted an opportunity to talk to the host mother but the host mother did not provide such opportunities. Ruby said in $\mathrm{T}_{3}$ :

... hmm not really [learner didn't enjoy staying at homestay]...I think she make a lot of rules in...umm actually I...I don't. I don't know if it's good or not. She needs me do more cleaning in the house every week or every night I need to clean all the dishes after the dinner...but I want to study more or I want to do my things...but she make the rule to say it's my job...before I would help her but not every night... but now she give me a rule list and say I need to clean my own clothes and I need to clean the toilet and I need to clean the house...my room and I need to clean the dishes that's my job something like that and blah blah blah blah lots of rules...I get along with her...actually I like her I think she's good sometimes but I don't like the rules...I think too many rules...too much...usually I have job work so I don't have time...

And one week day night she said you want to clean something first I need to clean the toilet and something first something but I just think I live in homestay that's why I want to someone to take care of me

...not really a lot of time [to talk] because she need to work and I need to study and usually she has time just at dinner time. After dinner she will go in to work on her computer and I go back to my room and Saturday or Sunday I will be not in home I am going to church or work so we didn't have a lot of time to talk...ummm I can learn from her but not a lot of time. Sometimes I will say one 
sentence she will say not complete. She will teach me. She will say it is not complete but not a lot of time to talk

There was a decrease in the total number of hours Ruby received listening input in English but a slight increase in the number of hours she heard English speakers' conversations during her stay abroad $\left(\mathrm{T}_{1}=53\right.$ and $\mathrm{T}_{3}=45 ; \mathrm{T}_{1}=0.5$ and $\mathrm{T}_{3}=4.5$ respectively). Unfortunately, there was also a decrease in the total number of hours interaction with her host family and with English speakers outside her home from $T_{1}$ to $T_{3}\left(T_{1}=54\right.$ and $T_{3}=41 ; T_{1}=10$ and $T_{3}=4.5$ respectively). However, the time spent outside the home remained unchanged $\left(T_{1}\right.$ and $T_{3}=$ 7.5).

Ruby explained she did not want to interact with her host mother unless it was necessary and she had less time to listen to music and watch English TV programmes/movies and interact as she needed more time to complete assignments and study for exams.

Janice had similar experiences with her host mother. Janice's host mother was rude to her and appeared to be very impatient while listening to Janice's complaints. In $T_{3}$, the host mother had one international student from Macau. The host mother and the student relied on Janice to translate for them because of the student's low English proficiency. Janice's host mother was very impatient when Janice spoke to the student in Mandarin and Cantonese during translation. This situation not only prevented Janice from learning the target language and culture at home, but also made her use more Mandarin and Cantonese. Outside the classroom and the homestay, Janice mainly stayed with people from Hong Kong and spent a lot of time with her boyfriend from Hong Kong for the previous three months.

Not now...but I'm not enjoy [homestay]. Usually I think maybe hmm when I eat dinner I need to face her and I think she is just not social. Not like a relationship between friend and friend it's not social...worse than before because many people told me that a homestay mum is like your mum and so they take care of you and when I come to this homestay she is bad...maybe because her education and the manner he she is a little bit rude always rude to me...it is not meaningful she say it's just crap and it's stupid...she use many rude words... and sometimes like maybe yesterday usually I will ask her how are you today and she will give me a feedback and ask me how are you today also and I said that it is so boring 
and she just said that 'arr' I try to explain to her how boring it is and...she didn't want to know she just suddenly said eat dinner the feeling is very very different between my feeling and her feeling...actually we can end this topic already I don't understand what you are talking...it's ok it's not important...I try to explain to her because she said she didn't understand. Actually I told her it's boring and I explain to her and it so clear I think it's clear. Maybe not so but clear enough maybe just too long and she didn't want to know.... Didn't listen to my story...I feel a little bit upset...not like friend to friend or mother to daughter.

The host mother disliked Janice speaking to the other student in Cantonese all the time. Janice was also expected to translate conversations between herself and the other student for the host mother. Janice reported the host mother swore at her and was rude to her especially when the host mother got frustrated as she did not know what was said in Cantonese. Janice said the host mother sometimes just asked the other student a question in English, and wanted Janice to translate and then give her an answer quickly.

The host mother did not understand why sometimes it took so long for Janice to translate. She did not understand that Janice had to provide some background information and negotiate the meaning to ensure the student understood what was being asked before answering the question, or that what could be said in one sentence in English requires more than a one sentence translation into Cantonese. On top of this problem, Janice and her host mother had trouble with the laundry arrangement.

In contrast, women who had difficulty adjusting to the L2 environment regretted not having spent more time with their host families. They had a weak relationship with the host families. This is similar to what Jackson (2008) found with communication between high and low proficiency learners. The more proficient learners like Janice are more likely to suffer as they spend more time helping the lower proficiency learners which gave them less time to communicate with other proficient learners.

This study shows that, in reality, some SALs experienced difficulties establishing contact with NSs and had very limited chances for interaction with English speakers. Learners ended up mixing with the same L1 speakers or with other international students in the same course. Unless learners were very pro-active in establishing a network with fluent or English 
speakers, they would only use English with instructors or administrators who are English speakers outside school. This was especially so for those who lived alone or shared an apartment with other NNSs. Thus, one cannot assume that the target language community can automatically provide learners opportunities for interaction with English speakers and enrichment to the target language and culture, even for those who lived with a host family. Interview and diary data showed that some students did not speak to their host family due to limited English competence, others due to incompatibility between the host family and the learner. However, those who had a positive experience from their host family found the experience valuable, learned about the Australian lifestyle, and had more opportunities to interact with English speakers.

\subsection{Affective factors}

This section examines the affective dimensions of SALs' experience during their sojourn abroad. It draws on analyses of SALs' perceptions of the target language learning environment and on their self-perceived proficiency and self-perceived confidence levels at $\mathrm{T}_{1}$ and $\mathrm{T}_{3}$. In addition, it examines the correlations between SALs' environmental and affective dimensions to see whether these factors are interrelated.

\subsubsection{Perceptions of the target language learning environment}

Little research has been conducted on how SALs' perception of the target language community influences their learning. This section discusses results of SALs' perception of the target language community during their sojourn abroad.

This group of SALs wanted to further their studies in Australia. Thus it is perhaps not surprising that they on average liked it as the 'average' level in T1, and this level increased to 'quite a lot' in T3 (See Table 5.9) with some even liking it 'very much'. The mean score of their attitude for Australia increased steadily throughout their sojourn abroad. Wilcoxon analysis revealed learners' rating of how they liked Australia in $\mathrm{T}_{3}$ was statistically significantly higher than $\mathrm{T}_{1}(\mathrm{z}=3.03, \mathrm{p}<.01)$. 
Table 5.9: Degree to which SALs liked Australia

\begin{tabular}{llccccc}
\hline & $\mathrm{T}_{1}$ & & $\mathrm{~T}_{2}$ & & $\mathrm{~T}_{3}$ & \\
& Mean & $\mathrm{SD}$ & Mean & $\mathrm{SD}$ & Mean & $\mathrm{SD}$ \\
\cline { 2 - 8 } scale & 2.95 & 1.1 & 3.3 & 1.2 & 3.8 & 1.2 \\
\hline
\end{tabular}

Note: Scale: $0=$ no feeling, $1=$ very little, $2=$ little, $3=$ average, $4=$ quite a lot, $5=$ very much

All the learners in this study reported they liked Australia. Either the learners reported they liked it as 'average' right from the beginning and continued to like it a little more throughout the study, or they disliked Australia initially or only liked it a little then began to like it more by $\mathrm{T} 2$ and began to like it a lot in $\mathrm{T}_{3}$.

Although the SALs reported there were disadvantages, they reported the benefits of being able to study in Australia far out-weighed the disadvantages. The commonly perceived disadvantages were that Australia was too quiet, the shopping malls shut too early and the public transport system was inconvenient. Nonetheless, the SALs reported they liked Australia because the people were very friendly and helpful, the environment was relaxing and the air was clean, and more importantly, all learners reported they liked the less stressful and interactive approach to learning English in Australia. According to previous research (Gardner 1985, 2001, 2005; Graham 1984; Kouritzin, Piquemal \& Renaud 2009; Peirce 1995; Xu, Case \& Wang 2009; Li 2006), the SALs' positive attitude tends to lead to motivation, attitude and willingness to learn and use English. Additionally, positive perception of the target language environment influences students' willingness to participate in the host environment, which in turn affects their L2 achievement. This will be discussed further in chapter 6.

\subsubsection{SALs' self-perceived proficiency and self-perceived confidence}

This section describes and discusses changes in SALs' self-perceived proficiency and confidence scores over the duration of their study abroad.

\subsubsection{SALs' self-perceived proficiency and self-perceived confidence}

As can be seen from Tables 5.10 and 5.11, this group of SALs' self-perceived proficiency and confidence in speaking (pronunciation and fluency), communication (conversing with others) and grammar scores were higher in T3 than in T1. On average the learners rated their proficiency and confidence across speaking, communication and grammar as between little to average (2-2.5 on the scale) to about average to quite a lot (3-3.5 on the scale). Wilcoxon 
tests revealed SALs' self-perceived scores were statistically significantly higher in T3 than in $\mathrm{T} 1$ for proficiency in speaking $\mathrm{z}=3.86, \mathrm{p}<.01$, proficiency in communication $\mathrm{z}=3.67, \mathrm{p}<$ .01 ; proficiency in grammar $\mathrm{z}=3.03, \mathrm{p}<.01$, confidence in speaking $\mathrm{z}=3.75, \mathrm{p}<.01$, confidence in communication $\mathrm{z}=3.78, \mathrm{p}<.01$; confidence in grammar $\mathrm{z}=2.59, \mathrm{p}<.01$.

Table 5.10: SALs' self-perceived proficiency scores in $T_{1}$ and $T_{3}(n=21)$

\begin{tabular}{lcccc}
\hline $\begin{array}{l}\text { Self-perceived } \\
\text { proficiency scores }\end{array}$ & $\mathrm{T}_{1}$ & \multicolumn{2}{c}{$\mathrm{T}_{3}$} & \\
Speaking & Mean & $\mathrm{SD}$ & Mean & \multicolumn{1}{c}{$\mathrm{SD}$} \\
\cline { 2 - 5 } Communication & 2.19 & .75 & 3.36 & .98 \\
Grammar & 2.24 & .70 & 3.38 & 1.05 \\
\hline
\end{tabular}

Table 5.11: SALs' self-perceived confidence scores in $T_{1}$ and $T_{3}(n=21)$

\begin{tabular}{|c|c|c|c|c|}
\hline \multirow{2}{*}{$\begin{array}{l}\text { Self-perceived } \\
\text { confidence scores }\end{array}$} & \multicolumn{2}{|l|}{$\mathrm{T}_{1}$} & \multicolumn{2}{|l|}{$\mathrm{T}_{3}$} \\
\hline & Mean & SD & Mean & SD \\
\hline Speaking & 2.19 & .75 & 3.54 & 1.08 \\
\hline Communication & 2.33 & .73 & 3.50 & 1.11 \\
\hline Grammar & 2.52 & .51 & 3.14 & .87 \\
\hline
\end{tabular}

\subsubsection{Correlations between SALs' self-perceived proficiency and self-perceived confidence scores}

As can be seen from Table 5.12, Spearman's rho correlations revealed there were significant correlations between the SALs' self-perceived proficiency and self-perceived confidence in speaking, communication and grammar in $\mathrm{T}_{1}(r=.88, p<.01 ; r=.75, p<.01 ; r=.75 ., p<$ .01 respectively $)$ and $\mathrm{T}_{3}(r=.80, p<.01 ; r=.81, p<.01 ; r=.59, p<.01$ respectively).

Table 5.12: Correlations between SALs' self-perceived proficiency and self-perceived confidence scores in $T_{1}$ and $T_{3}$

\begin{tabular}{|c|c|c|c|c|c|c|}
\hline Types of interactions & $\mathrm{T}_{1}$ & & & $\mathrm{~T}_{3}$ & & \\
\hline & $\begin{array}{l}\text { Conf } \\
\text { speak }\end{array}$ & $\begin{array}{l}\text { Conf } \\
\text { comm }\end{array}$ & $\begin{array}{l}\text { Conf } \\
\text { gram }\end{array}$ & $\begin{array}{l}\text { Conf } \\
\text { speak }\end{array}$ & $\begin{array}{l}\text { Conf } \\
\text { comm }\end{array}$ & $\begin{array}{l}\text { Conf } \\
\text { gram }\end{array}$ \\
\hline \multicolumn{7}{|l|}{$\mathrm{T}_{1}$} \\
\hline Prof speak & $.88^{*}$ & & & & & \\
\hline Prof comm & & $.75^{* *}$ & & & & \\
\hline Prof gram & & & $.75^{* *}$ & & & \\
\hline \multicolumn{7}{|l|}{$\mathrm{T}_{3}$} \\
\hline Prof speak & & & & $.80 * *$ & & \\
\hline Prof comm & & & & & $.81 * *$ & \\
\hline Prof gram & & & & & & $.59 * *$ \\
\hline
\end{tabular}

Note: Spearman's rho correlation: **p <.01, *p <.05 (2 tailed) 


\subsubsection{Correlations between SALs' English listening input in English and self-perceived proficiency and self-perceived confidence scores}

As can be seen from Table 5.13, the correlations between SALs' listening input and their self-perceived proficiency and confidence scores were very weak in $\mathrm{T}_{1}$. Spearman's rho correlations revealed there were no statistically significant correlations between the total number of hours of listening per week with learners' self-perceived proficiency in speaking, communication and grammar, as well as self-perceived confidence in speaking, communication and grammar.

Table 5.13: Correlations between SALs' amount of listening in English and selfperceived proficiency and self-perceived confidence in $T_{1}$

\begin{tabular}{lcccccc}
\hline $\begin{array}{l}\text { Types of } \\
\text { listening input }\end{array}$ & $\begin{array}{l}\text { Prof } \\
\text { Speak }\end{array}$ & $\begin{array}{l}\text { Prof } \\
\text { Comm }\end{array}$ & $\begin{array}{l}\text { Prof } \\
\text { Gram }\end{array}$ & $\begin{array}{l}\text { Conf } \\
\text { speak }\end{array}$ & $\begin{array}{l}\text { Conf } \\
\text { comm }\end{array}$ & $\begin{array}{l}\text { Conf } \\
\text { gram }\end{array}$ \\
\cline { 2 - 7 } Radio & .20 & .11 & .07 & .08 & .05 & .12 \\
TV/Movies & .03 & .07 & .15 & .11 & .01 & .03 \\
Songs & .18 & .09 & .07 & .10 & .06 & .03 \\
English speakers conversations & .01 & .08 & .21 & .01 & .04 & .13 \\
Acad. settings & .23 & .14 & .08 & .16 & .02 & .22 \\
Total & .09 & .08 & .07 & .11 & .04 & .06 \\
\hline
\end{tabular}

Note: Spearman's rho correlation: $* * p<.01, * \mathrm{p}<.05$ (2 tailed)

As can be seen from Table 5.14, in $\mathrm{T}_{3}$ the only significant correlation found was between the number of hours SALs' spent listening to English speakers' conversations and their selfperceived proficiency in communication $(r=.48, p<.05)$. There were more significant correlations between SALs' self-perceived confidence scores and types of listening input. There were significant correlations between the SALs' self-perceived confidence scores in speaking, communication and grammar with the number of hours they listened to radio ( $r=$ $.48, p<.05 ; r=.55, p<.01 ; r=.45, p<.05$ respectively $)$, songs $(r=.63, p<.01 ; r=.64, p<$ $.01 ; r=.45, p<.05$ respectively) and time spent listening to NS/fluent English speaker conversations $(r=.66, p<.01 ; r=.68, p<.01 ; r=.56, p<.01$ respectively). There were significant correlations between listening to English from TV/movies and SALs' selfperceived confidence scores in speaking $(r=.47, p<.05)$ and communication $(r=.57, p<$ $.01)$. 
Table 5.14: Correlations between SALs' listening input in English and self-perceived proficiency and self-perceived confidence in $\mathbf{T}_{3}$

\begin{tabular}{lcccccc}
\hline $\begin{array}{l}\text { Types of } \\
\text { listening input }\end{array}$ & $\begin{array}{l}\text { Prof } \\
\text { Speak }\end{array}$ & $\begin{array}{l}\text { Prof } \\
\text { Comm }\end{array}$ & $\begin{array}{l}\text { Prof } \\
\text { gram }\end{array}$ & $\begin{array}{l}\text { Conf } \\
\text { Speak }\end{array}$ & $\begin{array}{l}\text { Conf } \\
\text { Comm }\end{array}$ & $\begin{array}{l}\text { Conf } \\
\text { gram }\end{array}$ \\
\hline Radio & .38 & .27 & .40 & $.48^{*}$ & $.55^{* *}$ & $.45^{*}$ \\
TV/Movies & .30 & .39 & .19 & $.47^{*}$ & $.57^{* *}$ & .36 \\
Songs & .42 & .35 & .37 & $.63^{* *}$ & $.64^{* *}$ & $.45^{*}$ \\
English speakers' conversations & .38 & $.48^{*}$ & .10 & $.66^{* *}$ & $.68^{* *}$ & $.56^{* *}$ \\
Acad settings & .17 & .01 & .07 & .03 & .02 & .238 \\
Total & .37 & .40 & .28 & $.61^{* *}$ & $.66^{* *}$ & $.60^{* *}$ \\
\hline
\end{tabular}

Note: Spearman's rho correlation: $* * \mathrm{p}<.01,{ }^{*} \mathrm{p}<.05$ ( 2 tailed $)$

\subsubsection{Correlations between SALs' interaction in English and self-perceived proficiency and self-perceived confidence scores}

As can be seen from Table 5.15, Spearman's rho correlation tests reveal that in $\mathrm{T}_{1}$ the only significant correlation is between SALs' interaction at home (at a dormitory and homestay) and their confidence in grammar $(r=.47, p<.05)$.

Table 5.15: Correlations between types of interactions and SALs' self-perceived proficiency and self-perceived confidence scores $\mathbf{T} 1$

\begin{tabular}{lcccccr}
\hline Types of interactions & $\begin{array}{l}\text { Prof } \\
\text { speak }\end{array}$ & $\begin{array}{l}\text { Prof } \\
\text { comm }\end{array}$ & $\begin{array}{l}\text { Prof } \\
\text { gram }\end{array}$ & $\begin{array}{l}\text { Conf } \\
\text { speak }\end{array}$ & $\begin{array}{l}\text { Conf } \\
\text { comm }\end{array}$ & $\begin{array}{l}\text { Conf } \\
\text { gram }\end{array}$ \\
\cline { 2 - 7 } Classmates in class & .34 & .35 & .24 & .31 & .41 & .28 \\
English speakers(out home/school) & .29 & .31 & .33 & .36 & .42 & .38 \\
Home & .21 & .200 & .34 & .16 & .24 & $.47 *$ \\
NNSs(out home/school) & .10 & .18 & .15 & .13 & .11 & .11 \\
Total & .38 & .33 & .31 & .39 & .42 & .39 \\
\hline
\end{tabular}

Note: Spearman's rho correlation: **p <.01, *p <.05 (2 tailed)

Table 5.16 shows that, in T3, the relationship between the types of interactions that SALs had and their self-perceived proficiency and self-perceived confidence scores were stronger. Although Spearman's rho correlation tests revealed SALs' interaction with classmates in class and with NNSs (outside home/school) were only statistically significant with confidence in speaking $(\mathrm{r}=.51, \mathrm{p}<.05$ and $\mathrm{r}=.45, p<.01$ respectively), there were also statistically significant correlations between SALs' interaction with English speakers(outside home/ school) with their self-perceived proficiency and confidence scores in speaking ( $r=$ $.64, p<.01$ and $r=.74, p<.01$ respectively), communication $(r=.51, p<.05$ and $r=.71, p$ $<.01$ respectively) and grammar $(r=.50, p<.05$ and $r=.57, p<.01$ respectively). 
Table 5.16: Correlations between types of interactions and SALs' self-perceived proficiency and self-perceived confidence scores $\mathbf{T}_{3}$

\begin{tabular}{llllccr}
\hline Types of interactions & $\begin{array}{l}\text { Prof } \\
\text { speak }\end{array}$ & $\begin{array}{l}\text { Prof } \\
\text { comm }\end{array}$ & $\begin{array}{l}\text { Prof } \\
\text { Gram }\end{array}$ & $\begin{array}{l}\text { Conf } \\
\text { speak }\end{array}$ & $\begin{array}{l}\text { Conf } \\
\text { comm }\end{array}$ & $\begin{array}{l}\text { Conf } \\
\text { gram }\end{array}$ \\
\cline { 2 - 7 } Classmates in class & .29 & .18 & .19 & $.51^{* *}$ & $.47^{*}$ & .24 \\
English speakers (out home/school) & $.64^{* *}$ & $.51^{*}$ & $.50^{*}$ & $.74^{* *}$ & $.71^{* *}$ & $.57^{* *}$ \\
Home & $.56^{* *}$ & $.61^{* *}$ & .07 & $.56^{* *}$ & $.64^{* *}$ & $.44^{*}$ \\
NNSs(out home/school) & .15 & .35 & .04 & $.45^{*}$ & .42 & .30 \\
Total & $.55^{* *}$ & $.60^{* *}$ & .25 & $.74^{* *}$ & $.73^{* *}$ & $.49^{*}$ \\
\hline Note: Spearman's rho correlation: **p <.01, *p <.05 (2 tailed) & & & &
\end{tabular}

\subsubsection{Living arrangement and self-perceived proficiency and self-perceived confidence}

As can be seen from Table 5.18, in $\mathrm{T}_{1}$ SALs' self-perceived proficiency and self-perceived confidence scores were similar amongst those who lived with homestay families, student dormitory and alone/with other NNSs. One-way ANOVA analyses of variance revealed there was no statistical significance between the type of living arrangement SALs had and their self-proficiency and self-confidence scores in speaking, communication and grammar (see Table 5.17).

Table 5.17: SALs' self-perceived proficiency and self-perceived confidence scores in different types of living arrangement in $\mathbf{T}_{1}$

\begin{tabular}{|c|c|c|c|c|c|c|c|c|c|c|c|c|}
\hline \multirow{3}{*}{$\begin{array}{l}\text { Types of } \\
\text { living } \\
\text { arrangement }\end{array}$} & \multicolumn{6}{|c|}{ Self-perceived Proficiency } & \multicolumn{6}{|c|}{ Self-perceived Confidence } \\
\hline & \multicolumn{2}{|c|}{ Speaking } & \multicolumn{2}{|c|}{ Communication } & \multicolumn{2}{|c|}{ Grammar } & \multicolumn{2}{|c|}{ Speaking } & \multicolumn{2}{|c|}{ Communication } & \multicolumn{2}{|c|}{ Grammar } \\
\hline & Mean & $\mathrm{SD}$ & Mean & SD & Mean & SD & Mean & $\mathrm{SD}$ & Mean & $\mathrm{SD}$ & Mean & $\mathrm{SD}$ \\
\hline Homestay & 2 & 0 & 2 & 0 & 2.6 & .55 & 2.3 & .50 & 2.3 & .50 & 2.75 & .50 \\
\hline Dormitory & 2.2 & 1.30 & 2.4 & 1.14 & 2.3 & .45 & 2.20 & 1.30 & 2.60 & 1.14 & 2.80 & .45 \\
\hline Alone/NNSs & 2.3 & .62 & 2.3 & .62 & 2.4 & .50 & 2.17 & .58 & 2.3 & .62 & 2.33 & .49 \\
\hline
\end{tabular}

Table 5.18 shows that by $\mathrm{T}_{3}$, there were more variations amongst SALs' self-perceived proficiency and self-perceived confidence scores depending on the type of living arrangement they had. Those who stayed with homestay families were more likely to rate their proficiency and confidence levels higher in speaking, communication and grammar than those in a student dormitory and those who lived alone/with other NNSs. In addition, those SALs in both these groups had higher self-perceived proficiency and self-perceived confidence levels than those living alone/with other NNSs. 
Table 5.18: SALs' self-perceived proficiency and self-perceived confidence scores in different types of living arrangement in $T_{3}$

\begin{tabular}{|c|c|c|c|c|c|c|c|c|c|c|c|c|}
\hline \multirow{3}{*}{$\begin{array}{l}\text { Types of living } \\
\text { arrangement }\end{array}$} & \multicolumn{6}{|c|}{ Self-perceived Proficiency } & \multicolumn{6}{|c|}{ Self-perceived Confidence } \\
\hline & \multicolumn{2}{|c|}{ Speaking } & \multicolumn{2}{|c|}{ Communication } & \multicolumn{2}{|c|}{ Grammar } & \multicolumn{2}{|c|}{ Speaking } & \multicolumn{2}{|c|}{ Communication } & \multicolumn{2}{|c|}{ Grammar } \\
\hline & Mean & SD & Mean & SD & Mean & SD & Mean & SD & Mean & SD & Mean & SD \\
\hline Homestay & 4.06 & .82 & 4.13 & .79 & 3.13 & .83 & 4.19 & .88 & 4.13 & .92 & 3.44 & .98 \\
\hline Dormitory & 3.13 & 1.03 & 3.25 & 1.26 & 3.13 & .25 & 3.50 & 1.22 & 3.63 & 1.38 & 3.38 & .48 \\
\hline Alone/NNSs & 2.83 & .75 & 2.78 & .79 & 2.89 & .60 & 3 & .97 & 2.89 & .89 & 2.78 & .83 \\
\hline
\end{tabular}

Note: Scale: $0=$ no feeling, $1=$ very little, $2=$ little, $3=$ average, $4=$ quite a lot, $5=$ very much

\subsubsection{ANOVA analyses of SALs' self-perceived proficiency and self-perceived confidence scores in different arrangements in $T_{1}$ and $T_{3}$}

One-way ANOVA analyses of variance in Table 5.19 revealed there were no significant differences between SALs' living arrangement and self-perceived proficiency and selfperceived confidence scores in $\mathrm{T}_{1}$. In $\mathrm{T} 3$, there were also no significant differences between SALs' living arrangements and self-perceived proficiency and self-perceived confidence in grammar and self-perceived confidence score. There were significant differences between the types of living arrangement SALs had and their self-perceived proficiency scores in speaking $(F(2,18)=4.84, p<.05)$ and communication $(F(2,18)=4.93, p<.05)$, as well as their selfperceived confidence score in communication $(F(2,18)=3.28, p<.05)$. Posthoc pairwise comparisons revealed the differences were significant between the SALs who lived with a homestay family and those who lived alone/with other NNSs $(\mathrm{p}<.05)$.

Table 5.19: ANOVA analyses between SALs' self-perceived proficiency and selfperceived confidence with living arrangements in $T_{1}$ and $T_{3}$

\begin{tabular}{|c|c|c|c|c|}
\hline \multirow[t]{2}{*}{ Self-perceived scores } & \multirow{2}{*}{$\begin{array}{r}\mathrm{T}_{1} \\
\mathrm{~F}\end{array}$} & \multicolumn{3}{|c|}{$\mathrm{T}_{3}$} \\
\hline & & Exact Sig. & $\mathrm{F}$ & Exact Sig. \\
\hline Proficiency speaking & .15 & $.859, \mathrm{df}=2,18$ & $\begin{array}{l}4.84 \\
\text { Postho } \\
\text { Home } \\
\text { Home } \\
\text { dormit }\end{array}$ & $\begin{array}{l}.021 *, \mathrm{df}=2,18 \\
\text { nitory at } .082 \\
\text { e at } .007 * * \\
\text { alone at } .57\end{array}$ \\
\hline Proficiency communication & .342 & $.715, \mathrm{df}=2,18$ & $\begin{array}{l}4.93 \\
\text { Posthe } \\
\text { Home } \\
\text { Home } \\
\text { dormit }\end{array}$ & $\begin{array}{l}\quad .02 *, \mathrm{df}=2,18 \\
\text { nitory at } .125 \\
\text { e at } .006 * * \\
\text { alone at } .388\end{array}$ \\
\hline Proficiency grammar & 1.02 & $.382, \mathrm{df}=2,18$ & .33 & $.73, \mathrm{df}=2,18$ \\
\hline Confidence speaking & $.01(\mathrm{~B}-\mathrm{F})$ & $.99, \mathrm{df}=2,6$ & 3.08 & $.07, \mathrm{df}=2,18$ \\
\hline Confidence communication & .41 & $.67, \mathrm{df}=2,18$ & $\begin{array}{l}3.28 \\
\text { Postho } \\
\text { Home } \\
\text { Home } \\
\text { dormit }\end{array}$ & $\begin{array}{l}\quad .05^{*}, \mathrm{df}=2,18 \\
\text { nitory at } .424 \\
\text { e at } .02 * \\
\text { alone at } .236\end{array}$ \\
\hline Confidence grammar & 2.18 & $.142, \mathrm{df}=2,18$ & 1.47 & $.26, \mathrm{df}=2,18$ \\
\hline
\end{tabular}

Notes: $0=$ no feeling, $1=$ very little, $2=$ little, $3=$ average, $4=$ quite a lot, $5=$ very much

1. F stats if it meets the homogeneity of variances (Levene tests), otherwise used the robust tests of equality means test values from Brown-Forsythe(B-F)

2. Statistical significance: $* *$ p <.01, *p <.05 (2 tailed). 3. (x)=equality not assumed. 


\subsubsection{Discussion of affective factors}

To date, very little is known about how study abroad affects language learners' self-perceived proficiency and self-perceived confidence. The limited research that has been conducted so far suggests learners' self-perceived proficiency is related to self-confidence (Clément 1986; Clément, Dörnyei \& Noels 2004; Clément, Smythe \& Gardner 1978; Li 2006; Magnan \& Back 2007). Consistent with Li's (2006) findings, the results of this study indeed indicate there were strong correlations between SALs' self-perceived proficiency and self-perceived confidence scores in both $\mathrm{T}_{1}$ and $\mathrm{T}_{3}$ in the target language community. Moreover, the results showed there were significant increases between SALs' self-perceived proficiency and selfperceived confidence in speaking, communication and grammar from $\mathrm{T}_{1}$ to $\mathrm{T}_{3}$.

The results above suggest that a number of factors could contribute to learners' overall increase in self-perceived proficiency and self-perceived confidence. Consistent with Clément's (1986) finding that learners' self-confidence is gained from the quantity and quality of contact with members of the target language community, the results of this study showed that by $T_{3}$ there were significant correlations between learners' listened and face-toface interaction and self-perceived confidence in speaking, communication and grammar. It is difficult to define what 'quality' contact is here. In this study not all learners had much interaction with English speakers. Most had contact with NNSs, but generally those who lived in a dormitory or host family had more opportunities to listen to and interact with English speakers. Chapter 6 will discuss results on whether the amount of input in English and the contact learners had with English speakers and NNSs were sufficient to promote pragmatic development.

The results also showed the types of living arrangements correlated to self-perceived proficiency in speaking and communication as well as self-perceived confidence in communication by $\mathrm{T}_{3}$. Those students with a host family and the dormitory had significantly higher self-perceived proficiency and, self-perceived confidence scores in speaking and communication than those who lived alone/with other NNSs/English speakers. This might be partially due to the greater amount of interaction that learners in a dormitory and homestay had with English speakers and NNSs. Such opportunities were important in making students more confident to initiate interaction. 
As Li (2006) also found, even though learners reported their English was weak, their selfperceived confidence increased. They were also more willing to take the initiative to talk with increasing confidence. The results indicate the importance of environmental dimensions on the learners' self-perceived proficiency and self-perceived confidence in study abroad contexts. With the exception of Prudence in this study, learners were somewhat hesitant in using English at the beginning of their sojourn in Australia. They particularly worried about their vocabulary and fluency. They always thought in Chinese and they had very rare opportunities to speak with English speakers. So they were uncertain and not confident with their communication skills. Consequently, these difficulties may have lowered the learners' self-confidence and inhibited them from speaking English, thus affecting their willingness to further practise spoken English in real life and participate in informal conversations. The most proficient learner was more confident in their English ability than the other SALs. Even though Prudence acknowledged her English was far from perfect, she was confident interacting with English learners and fluent/native English speakers. Although learners reported they had difficulties in English aural understanding and the hindrance of thinking in Chinese by the end of the study, at least some learners' self-confidence increased.

\subsection{Summary}

This chapter addressed the environmental and affective dimensions of SALs' study abroad experience. The results illustrated that the target language environment provides learners with more opportunities to listen and have face-to-face interaction in English overall than when they were in Hong Kong. Though learners had comparatively more native-like English listening input and face-to-face interactions with English speakers in Australia than when they were in Hong Kong, a majority of students mostly interacted with other Hong Kong learners and NNSs in the first nine months of their sojourn abroad. The drastic increase in the SALs' English listening input and interaction occurred from the beginning to about the fourth to fifth month, after which there appears to be a plateau effect where the hours remained steady. This suggests that learners may have established their main network of important and close friends early on in their sojourn abroad and it was difficult for them to go beyond their comfort zone to meet other friends. In addition, the most distinctive benefit of homestay in general is that learners can have more opportunities to interact with English speakers. However, as this study illustrated, the 'homestay advantage' is not always guaranteed. The 
SALs had a mixed experience. The SALs must initiate and actively take part in communication. According to the interview data from the SALs, this is also heavily dependent on SALs' perception of whether the host family welcomes them into the family.

Even though the results presented here are based on learners' self-report data, they also add to our understanding of the affective dimension of SALs' experience abroad. This study showed learners' self-perceived proficiency and self-perceived confidence in speaking, communication and grammar increased from $\mathrm{T} 1$ to $\mathrm{T} 3$, and there were strong correlations between SALs' self-perceived proficiency and self-perceived confidence scores in both T1 and T3 in the target language community. It also suggests the environment and affective dimensions are related. The results showed that, overall, SALs' self-perceived proficiency and self-perceived confidence in speaking, communication and grammar are related to the number of hours SALs listened and interacted face-to-face in English as well as their living environment. It appears those who lived in dormitories and homestay families had higher self-perceived proficiency and self-perceived confidence than those who lived alone/with other Hong Kong learners and NNSs. This may be partially due to the greater amount of interaction that learners in dormitories and homestays had with English speakers and NNSs. Such opportunities were important in making students more confident to initiate interaction. Chapter 6 will discuss whether SALs' environment and affective experience are sufficient to promote pragmatic development. 



\section{Chapter 6 Effect of study abroad on SALs' pragmatic performance of English request devices}

\subsection{Introduction}

This chapter presents the results of the analysis of the data addressing the fourth research question related to whether a group of Hong Kong learners studying in Australia developed pragmatic competence to use request devices over their nine-month sojourn abroad. The research question is:

RQ4: What was the effect of study abroad on the learners' performance of requests in English?

This chapter presents data on SALs' use of requests and request external modifiers on DCTs and roleplays performed prior to, during and at the end of their first nine months in Australia. Data from ENGs and AHLs who performed the same tests will be used in across group comparisons. Data used for this study were from participants' oral responses for three oral EDCTs where the participants had mutual, higher or lower status than the interlocutor in a given scenario.

\subsection{Request heads and request softeners}

This section presents descriptive and inferential statistics for cross-group comparisons of request heads and request softeners used by ENGs, AHLs and SALs. As the focus of this study is on SALs, it also describes results from longitudinal analyses of request heads and softeners produced by the SALs prior to, during and at the end of their nine-month stay in Australia. Data from ENGs will be used in the within-group comparisons. Data from AHLs were not included in the within-group comparisons if results from the cross-group comparisons show there were no changes in the SALs' use of request devices from $T_{1}$ to $T_{2}$. 


\subsubsection{Request heads}

This section presents cross-group comparisons on the types of request heads used by AHLs, SALs and ENGs, followed by analyses of longitudinal data on the SALs.

\section{i Cross-group comparisons of request heads}

Table 6.1 shows the three different types of request heads used by ENGs, AHLs and SALs. As can be seen from Table 6.1, a higher number of ENGs and AHLs used conventional indirect requests rather than direct and non-conventional indirect requests regardless of the interlocutor's status. Even though more AHLs and SALs used conventional indirect than direct requests when they had mutual status as their interlocutor in all three rounds, more learners from both groups used direct requests, especially by $\mathrm{T}_{3}$. Only a very small number of ENGs used nonconventional indirect requests, and no learner used nonconventional indirect requests. As shown in Table 6.1, the AHLs used a similar number of direct, conventional and nonconventional indirect requests in $\mathrm{T} 1$ and $\mathrm{T} 2$, so they were excluded from the within-group comparisons.

Table 6.1: Descriptive statistics for the number of request heads used by ENGs, AHLs and SALs (\%)

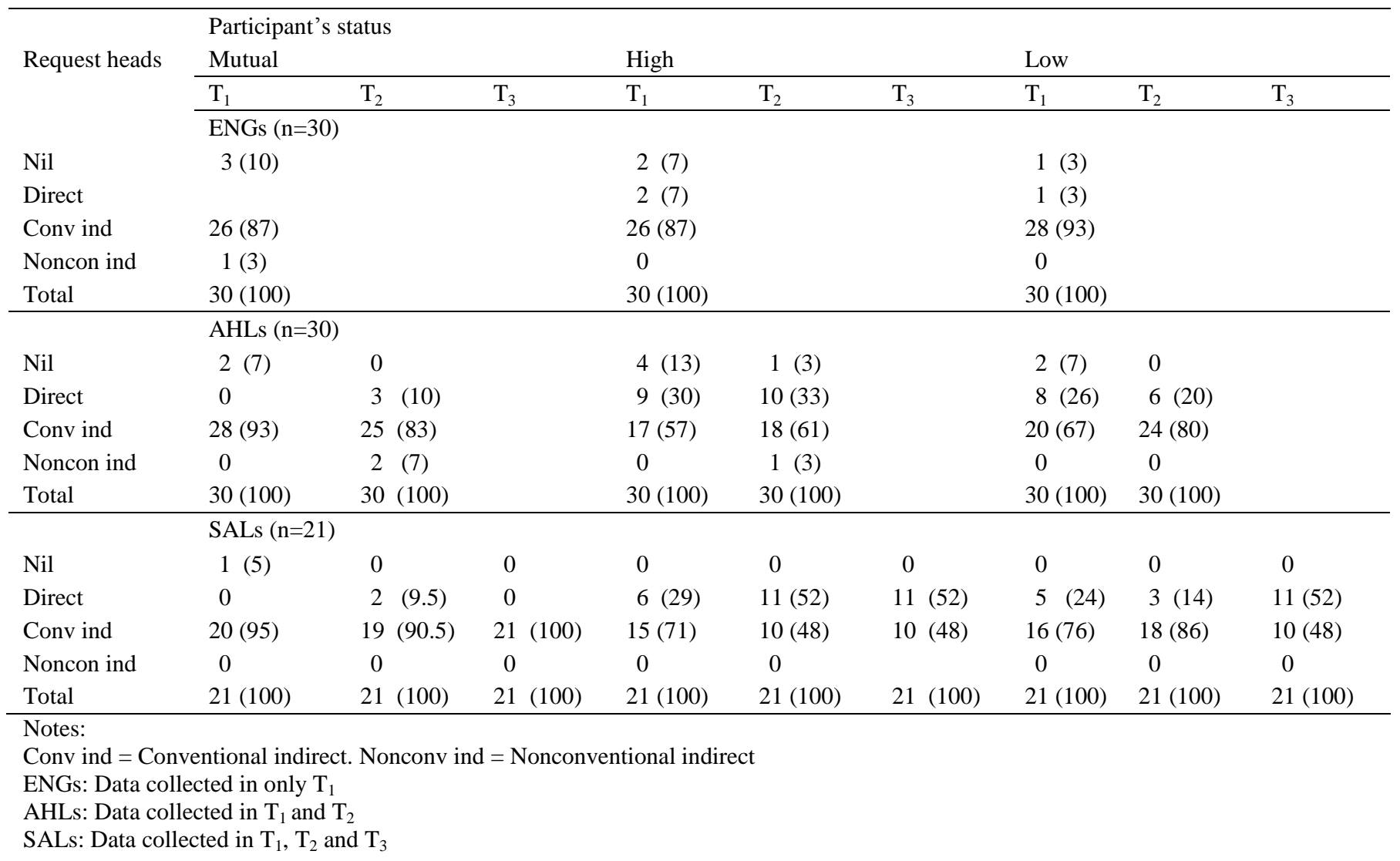


The chi-square analyses in Table 6.2 revealed that in $T_{1}$ and $T_{2}$ the differences between the number of direct, conventional indirect and nonconventional indirect requests used by ENGs, AHLs and SALs were not significant regardless of the interlocutor's status. However, in $\mathrm{T}_{3}$ a significantly higher number of SALs used direct requests than ENGs when their status was higher $\left(\chi^{2}=7.32, \mathrm{df}=1, p<.01\right)$ and lower $\left(\chi^{2}=7.32, \mathrm{df}=2, p<.01\right)$ than their interlocutor's. Additionally, a significantly higher number of ENGs used conventional indirect requests than SALs when their status was higher $\left(\chi^{2}=4.56, \mathrm{df}=1, p<.05\right)$ and lower $\left(\chi^{2}=4.56, \mathrm{df}=1\right.$, $p<.05)$ than their interlocutor's.

Table 6.2: Chi-square tests for cross-group comparisons of request heads used by AHLs, SALs and ENGs

\begin{tabular}{|c|c|c|c|c|c|c|c|}
\hline \multirow[b]{2}{*}{$\begin{array}{l}\text { Participant's } \\
\text { status }\end{array}$} & \multirow[b]{2}{*}{ Request heads } & \multicolumn{2}{|c|}{$\begin{array}{l}\mathrm{T}_{1} \\
\text { (Engs vs AHLs } \\
\text { vs SALs) }\end{array}$} & \multicolumn{2}{|c|}{$\begin{array}{l}\mathrm{T}_{2} \\
\text { (Engs vs AHLs } \\
\text { vs SALs) }\end{array}$} & \multicolumn{2}{|c|}{$\begin{array}{l}\mathrm{T}_{3} \\
\text { (Engs vs AHLs } \\
\text { vs SALs) }\end{array}$} \\
\hline & & $\chi^{2}$ & Exact Sig. & $\chi^{2}$ & Exact Sig. & $\chi^{2}$ & Exact Sig. \\
\hline \multirow[t]{3}{*}{ Mutual } & Direct & $2.34^{(\mathrm{F})}$ & .33 & $.43^{(\mathrm{F})}$ & 1 & $.23^{(\mathrm{F})}$ & .51 \\
\hline & Conv ind & $3.25^{(\mathrm{F})}$ & .24 & $.98^{(\mathrm{F})}$ & .69 & $4.8^{(\mathrm{F})}$ & .07 \\
\hline & Noncon ind & $1.67^{(\mathrm{F})}$ & 1 & $1.29^{(\mathrm{F})}$ & .78 & $.71^{(\mathrm{F})}$ & 1 \\
\hline \multirow[t]{3}{*}{ High } & Direct & $1.66^{(\mathrm{p})}$ & .52 & 4.26 & .08 & $7.32^{(\mathrm{p})}$ & $.01 * *$ \\
\hline & Conv ind & $2.82^{(\mathrm{p})}$ & .26 & $4.65^{(p)}$ & .10 & $4.56^{(p)}$ & $.04 *$ \\
\hline & Noncon ind & 0 & 0 & $1.67^{(\mathrm{F})}$ & 1.0 & 0 & 0 \\
\hline \multirow[t]{3}{*}{ Low } & Direct & $.91^{(\mathrm{p})}$ & .71 & $.30^{(\mathrm{p})}$ & .93 & $7.32^{(\mathrm{p})}$ & $.01 * *$ \\
\hline & Conv ind & $.92\left({ }^{\mathrm{p}}\right)$ & .69 & $.64^{(\mathrm{p})}$ & .73 & $4.56^{(p)}$ & $.04 *$ \\
\hline & Noncon ind & 0 & 0 & 0 & 0 & 0 & 0 \\
\hline
\end{tabular}

1. Conv ind $=$ Conventional indirect. Nonconv ind $=$ Nonconventional indirect

2. Pearson's chi-square values ${ }^{(\mathrm{P})}=<20$ of expected cells is 5. Fisher's exact test values ${ }^{(\mathrm{F})}=20>$ of expected cells is 5 .

3. $\chi^{2}$ statistical significance: $* * p<.01, * p<.05$ ( 2 tailed).

\section{ii. Within-group comparisons of request heads}

The chi-square analyses in Table 6.3 show there were no significant differences between the number of direct, conventional indirect and nonconventional indirect requests SALs used between $T_{1}$ and $T_{3}$ when they had mutual status with their interlocutor. However, a significantly greater number of SALs used direct requests in $T_{3}$ than $T_{1}$ when their status was lower than their interlocutor $\left(\chi^{2}=3.64, \mathrm{df}=1, p<.05\right.$ respectively). In addition, a significantly lower number of SALs used conventional indirect requests in $\mathrm{T}_{3}$ than $\mathrm{T}_{1}\left(\chi^{2}=3.64\right.$, df $=1$, $p<.05)$. 
Table 6.3: Chi-square tests for comparisons of request heads used by SALs in $T_{1}$ and $T_{3}$

\begin{tabular}{llll}
\hline Participant's & Request heads & $\chi^{2}$ & Exact Sig. \\
\cline { 3 - 3 } status & & $0^{(\mathrm{F})}$ & 0 \\
Mutual & Direct & $1.02^{(\mathrm{F})}$ & 1 \\
& Conv ind & $0^{(\mathrm{F})}$ & 0 \\
High & Noncon ind & $2.47^{(\mathrm{p})}$ & .21 \\
& Direct & $2.47^{(\mathrm{p})}$ & .21 \\
Low & Conv ind & 0 & 0 \\
& Noncon ind & $3.64^{(\mathrm{p})}$ & $.05^{*}$ \\
& Direct & $3.64^{(\mathrm{p})}$ & $.05^{*}$ \\
\hline
\end{tabular}

Notes:

1. Conv ind $=$ Conventional indirect. Nonconv ind $=$ Nonconventional indirect

2. Pearson's chi-square values $(\mathrm{P})=\langle 20$ of expected cells is 5 . Fisher's exact test values $(\mathrm{F})=20>$ of expected cells is 5 .

3. $\chi^{2}$ statistical significance: $* * p<.01, * \mathrm{p}<.05$ (2 tailed).

\subsubsection{Request softeners}

This section presents the descriptive and inferential statistics on the types of request softeners used by AHLs, SALs and ENGs. It begins with comparisons across the three groups, followed by longitudinal data for the SALs.

\section{i. Cross-group comparisons of request softeners}

As can be seen from Table 6.4, ENGs used softeners more frequently than both AHLs and SALs in all situations in all rounds. Somewhat unexpectedly, the AHLs also used more softeners than the SALs in $T_{1}$ and $T_{2}$. The biggest contrast between the number of request softeners between ENGs and SALs occurred when their status was lower than their interlocutor. The SALs used the least number of softeners when their status was lower than the interlocutor, and it decreased dramatically from $T_{1}$ to $T_{3}$.

Table 6.4: Descriptive statistics for the number of request softeners used by AHLs, SALs and ENGs (\%)

\begin{tabular}{|c|c|c|c|c|c|c|c|c|c|}
\hline \multicolumn{10}{|c|}{ Participant's status } \\
\hline \multirow{3}{*}{$\begin{array}{l}\text { Use of } \\
\text { softeners }\end{array}$} & \multicolumn{3}{|l|}{ Mutual } & \multicolumn{3}{|l|}{ High } & \multicolumn{3}{|l|}{ Low } \\
\hline & $\mathrm{T}_{1}$ & $\mathrm{~T}_{2}$ & $\mathrm{~T}_{3}$ & $\mathrm{~T}_{1}$ & $\mathrm{~T}_{2}$ & $\mathrm{~T}_{3}$ & $\mathrm{~T}_{1}$ & $\mathrm{~T}_{2}$ & $\mathrm{~T}_{3}$ \\
\hline & \multicolumn{9}{|c|}{ ENGs $(n=30)$} \\
\hline Not used & $12(40)$ & & & $18(60)$ & & & $16 \quad(53)$ & & \\
\hline \multirow[t]{2}{*}{ Used } & $18(60)$ & & & $12(40)$ & & & $14 \quad(47)$ & & \\
\hline & \multicolumn{9}{|c|}{ AHLs $\quad(n=30)$} \\
\hline Not used & $19(63)$ & $17(57)$ & & $24(80)$ & $19(63)$ & & $26(87)$ & $19(63)$ & \\
\hline \multirow[t]{2}{*}{ Used } & $11(37)$ & $13(43)$ & & $6 \quad(20)$ & $11(37)$ & & $4 \quad(13)$ & $11(37)$ & \\
\hline & \multicolumn{9}{|c|}{ SALs $\quad(n=21)$} \\
\hline Not used & $18(86)$ & $18(86)$ & $16(76)$ & $19(91)$ & $17(81)$ & $16(76)$ & $20(95)$ & 4 (19) & 3 (14) \\
\hline Used & $3 \quad(14)$ & $3 \quad(14)$ & $5(24)$ & $2(19)$ & $4 \quad(19)$ & $5 \quad(24)$ & $1 \quad(5)$ & $17(81)$ & $18 \quad(86)$ \\
\hline
\end{tabular}


The chi-square analyses in Table 6.5 show that in $T_{1}$ significant differences were found between the number of ENGs, AHLs and SALs who used request softeners when they had mutual $\left(\chi^{2}=10.96, \mathrm{df}=2, p<.01\right)$, lower $\left(\chi^{2}=8.51, \mathrm{df}=2, p<.05\right)$ and higher $\left(\chi^{2}=15.44\right.$, df $=2, p<.01)$ status than their interlocutors. Further chi-square analyses revealed a significantly higher number of ENGs used more request softeners than AHLs when they had lower status than their interlocutor in $\mathrm{T}_{2}\left(\chi^{2}=8.01\right.$, df $\left.=1, p<.01\right)$. Additionally, a significantly higher number of ENGs used request softeners as compared to SALs when they had mutual $\left(\chi^{2}=10.66, \mathrm{df}=1, p<.01\right)$, higher $\left(\chi^{2}=5.76, \mathrm{df}=1, p<.01\right)$ and lower $\left(\chi^{2}=\right.$ $12.35, \mathrm{df}=1, p<.01)$ status than their interlocutor.

Similarly, in $\mathrm{T}_{2}$, there was a significant difference between the number of ENGs, AHLs and SALs who used softeners when they had a mutual status interlocutor $\left(\chi^{2}=12.86, \mathrm{df}=2, p<\right.$ $.01)$. Further chi-square tests showed significantly more ENGs used request softeners than the AHLs $\left(\chi^{2}=6.76, \mathrm{df}=1, p<.05\right)$ and SALs $\left(\chi^{2}=9.46, \mathrm{df}=1, p<.01\right)$.

Compared to ENGs, a significantly lower number of SALs used softeners when they had mutual $\left(\chi^{2}=7.79, \mathrm{df}=1, p<.01\right)$, higher $\left(\chi^{2}=6.64, \mathrm{df}=1, p<.05\right)$ and lower $\left(\chi^{2}=5.12\right.$, df $=1, p<.05)$ status than their interlocutor even by $\mathrm{T}_{3}$.

Table 6.5: Chi-square tests for cross-group comparisons of request softeners used by AHLs, SALs and ENGs

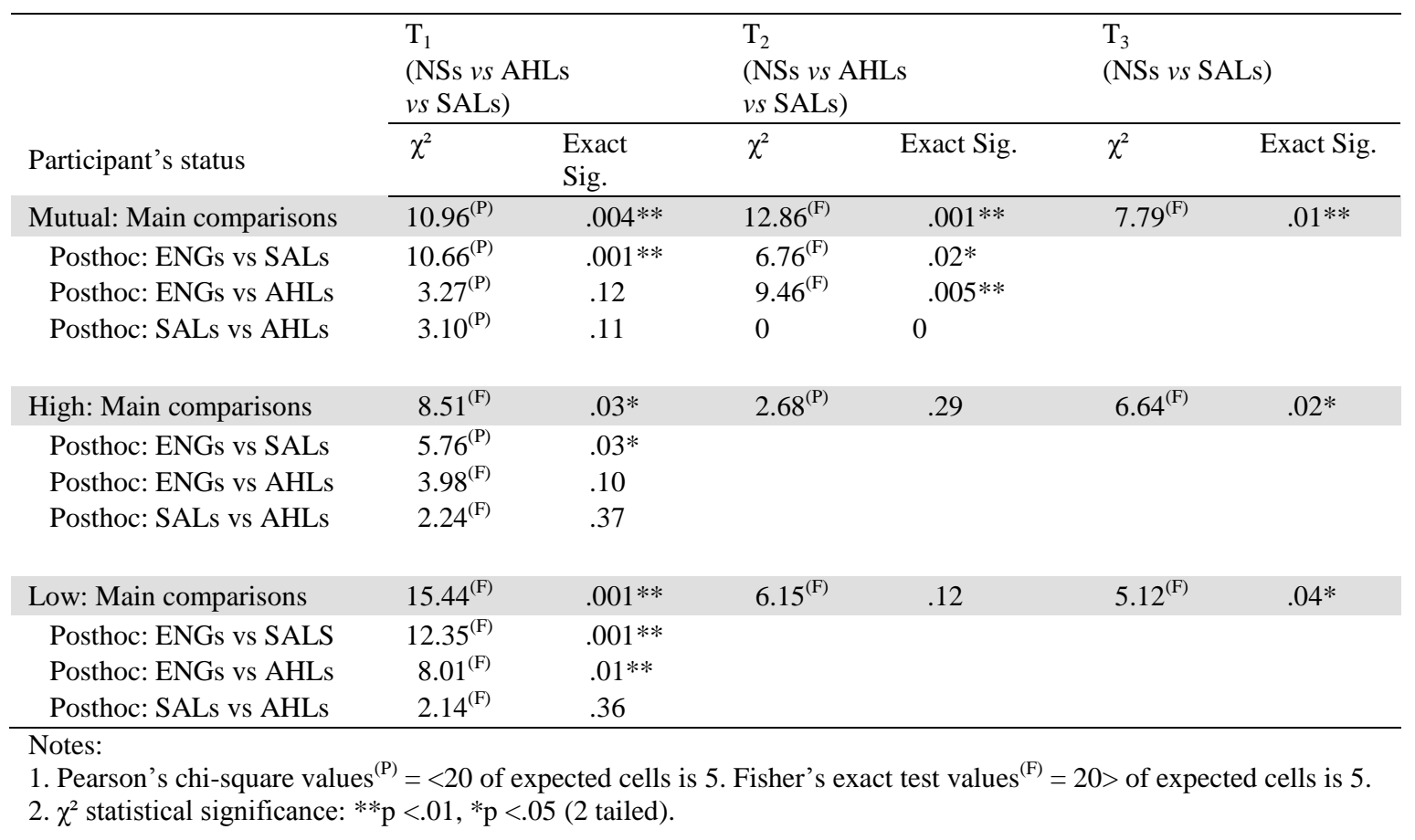




\section{ii. Within-group comparisons of request softeners}

\section{ENGs}

As can be seen from Table 6.6, a high number of ENGs used 'Would/Do you mind/like', especially when they had mutual status interlocutor. Interestingly, the ENGs who used request softeners to lessen the impact of requests preferred to use 'I was wondering' regardless of whether they had the same, higher or lower status as their interlocutor.

Table 6.6: Descriptive statistics for the types the request softeners used by ENGs $(n=30)$ $(\%)$

\begin{tabular}{lccc}
\hline Softener types & Mutual & High & Low \\
\cline { 2 - 4 } I was wondering & $8(27)$ & $6(20)$ & 7 (24) \\
Would/Do you mind/like & $9(30)$ & $3(10)$ & 1 (3) \\
Do you reckon & & $1 \quad(3)$ & $6(20)$ \\
Is it possible & & $2(7)$ & \\
Do you think & $1(3)$ & & $14(47)$ \\
Total ENGs used softeners & $18(60)$ & $12(40)$ & $16(53)$ \\
Total ENGs not used softeners & $12(40)$ & $18(60)$ & \\
\hline
\end{tabular}

Here, the within-group request softener results for AHLs were also provided so that we can see the types of request softeners they used in T1 and T2 compared to ENGs and AHLs. As can be seen from Table 6.7, there appears to be almost no increase between the number of learners who used softeners regardless of the interlocutor's status. In the mutual-status situations, a low number of AHLs used softeners. Similarly in the low-status situations, there was a slight increase in AHLs' use of softeners. There was very little change between the number of AHLs who used softeners in $\mathrm{T}_{1}$ and $\mathrm{T}_{2}$ when they had higher status. Fisher's Exact Test revealed there was no statistical significance between AHLs' use of softeners in $T_{1}$ and $\mathrm{T}_{2}$ when their status were of mutual $\left(\mathrm{X}^{2}=.62, \mathrm{df}=1, \mathrm{~ns}\right)$, lower $($ Fisher $=.86, \mathrm{df}=2, \mathrm{~ns})$ and higher $($ Fisher $=.63, \mathrm{df}=2, \mathrm{~ns})$ than their interlocutors.

Table 6.7: Descriptive statistics for the types the request softeners used by AHLs (n=30) $(\%)$

\begin{tabular}{|c|c|c|c|c|c|c|}
\hline \multirow[t]{2}{*}{ Types of softeners } & \multicolumn{2}{|l|}{ Mutual } & \multicolumn{2}{|l|}{ High } & \multicolumn{2}{|l|}{ Low } \\
\hline & $\mathrm{T}_{1}$ & $\mathrm{~T}_{2}$ & $\mathrm{~T}_{1}$ & $\mathrm{~T}_{2}$ & $\mathrm{~T}_{1}$ & $\mathrm{~T}_{2}$ \\
\hline I was wondering & & & $1(3.3)$ & $1(3)$ & & $1 \quad(3)$ \\
\hline Would/Do you mind/like & $11(37)$ & $12(40)$ & $5(16.7)$ & $9 \quad(30)$ & 4 (13) & $10(33)$ \\
\hline Do you reckon & & 1 (3) & & & & \\
\hline Is it possible & & & & $1(3)$ & & \\
\hline Do you think & & & & & & \\
\hline Total AHLs used softeners & $11(37)$ & $13(43)$ & $6 \quad(20)$ & $11(37)$ & 4 (13) & $11(37)$ \\
\hline Total AHLs not used softeners & $19(63)$ & $17(57)$ & $24(80)$ & $19(63)$ & $26(87)$ & $19(63)$ \\
\hline
\end{tabular}




\section{SALs}

Though the number of SALs who used request softeners increased steadily from $T_{1}$ to $T_{3}$ when they had mutual and higher status than their interlocutor, it remained low throughout this period (See Table 6.7). Chi-square tests revealed there were no statistical significant differences between the number of softeners SALs used when they had mutual and higher than their interlocutor in $\mathrm{T}_{1}$ and $\mathrm{T}_{3}\left(\chi^{2}=1.07, \mathrm{df}=1, \mathrm{~ns} ; \chi^{2}=1.72, \mathrm{df}=1\right.$, ns respectively). The only significant increase between the number of softeners SALs used from $T_{1}$ to $T_{3}$ was when they had lower status than their interlocutor $\left(\chi^{2}=7.30, \mathrm{df}=1, p<.05\right)$.

\section{Table 6.8: Descriptive statistics for the distribution of request softeners used by SALs} $(\mathbf{n}=21)(\%)$

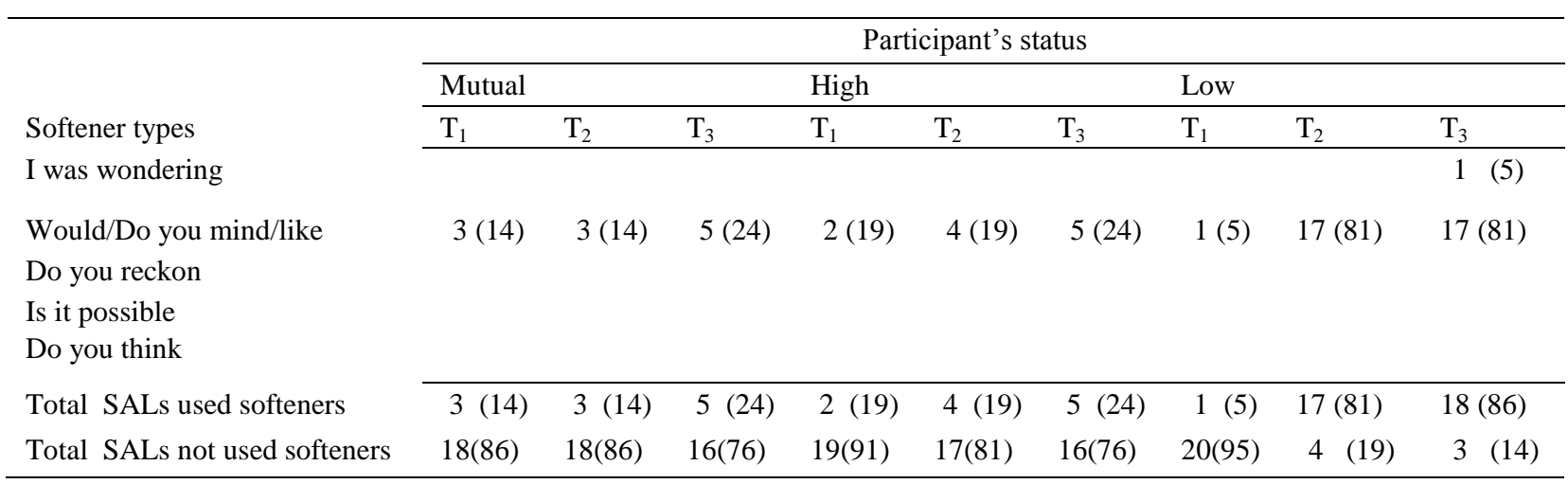

\subsubsection{Discussion of request heads and request softeners}

This research uncovered three main findings which will be discussed in this section. Firstly, as expected, a much higher number of ENGs used conventional indirect requests over direct and nonconventional indirect requests irrespective of the interlocutor's status. Secondly, even though a majority of the AHLs and SALs used conventional indirect requests when they were of mutual status with their interlocutor, more learners from both groups used direct requests when their status were higher or lower than their interlocutor's. Thirdly, what is more surprising is that the number of SALs who used direct requests increased from $T_{1}$ to $T_{3}$ in requests to either higher or lower status interlocutors.

The first point is that direct request devices are expressed as imperatives, performatives and want statements in Australian English. Previous research has shown ENGs tend to prefer the more indirect form of requests (Blum-Kulka 1989; Blum-Kulka \& House 1989). This study supports previous findings that showed that no ENGs used direct requests when they had 
mutual status and only very few used direct requests when their status were higher and lower than their interlocutors (See Examples 1-2).

As can be seen from these examples, even though ENGs used direct requests, they used external modifiers to minimise the imposition of a request.

Example 1: Asher (high status)

Rose (.) that (.) class that I asked you to teach in three week:::s (.) I know this is going to be a hu:::ge problem (.) but (.) I need you to teach it next week (.) and I know you're up to::: (.) the fact that (.) you can handle (.) the amount work you are doing (.) and teaching this (.) I've prepared some of the class for you (.) but (.) I really need you to teach next week (.) and I've got full faith in the fact that you can do it (.) so if you can give me an answer tomorrow that'd be fantastic

Example 2: Janet (low status)

uhm I haven’t finish my assign:ment (.) and ar:: (.) I need another week (.) would I be able to get an extension for it

Consistent with previous findings (Blum-Kulka \& House 1989), ENGs predominantly used requests defined as Australian conventional indirect requests regardless of their status. The conventional indirect forms of requests in Australian English reference to addressees' ability 'Can/could you + VP?'. Approximately only half the ENGs used this form (60 in mutual, 50 in high and only 40 in low status). Similar to previous research (Blum-Kulka 1989), the ENGs frequently employed softeners with the willingness structure 'Do/Would you mind/like to + VP?' and 'I was wondering + VP.' regardless of their status vis-à-vis the interlocutor.

Examples 3-8 illustrate learners using both the addressees' ability 'Can/Could you + VP?' and the 'would you mind + VP?' structure interchangeably in situations when they were of mutual, higher and lower status than their interlocutor; that is, they did not distinguish these structures. 
Example 3, Sam (mutual status)

uhm (.) could you please turn down the music it's (.) 2am in the morning (.) why are you watching it (.) at (.) such a loud volume when you know that other people are studying and trying to sleep (.) thanks (.) it just (.) defies all logic at this hour of the morning (.) just turn it down [chuckles] (.) I've got headphones if you want to borrow them

Example 4, Christina (mutual status)

hey:: I'm from (.) the:: room (.) just ar (.) cross there (.) would you mind turning the music (.) TV down(laugh) just a bit

Example 5, Katie (high status)

Hi (.) I was wondering (.) could you:: please (.) present (.) ar:: (.) one week earlier than I've asked you to (.) I'm sorry it's it's not a great big task so don't worry and (.) uhm (.) you are not going to lose a whole heap of marks if it's not perfect so:: (.) if you could do that earlier that would be great thanks.

Example 6, Christina (high status)

u::hm (.) would you mind:: submitting your work (.) a week earlier than schedule

Example 7, Whitney (low status)

Hi Mr Wilson uhm (.) I have a really really big favour to ask you (.) uhm:: (.) could I get an exten::sion (.) for:: my:: uhm (.) paper because (.) I just need a little bit more time to work on it and (.) uhm it would be really good if I could get this extra time

Example 8, Bethany (low status)

excuse me u::hm (.) I am sorry but in regards to:: our:: final ar:: ess::ay for the seaso- semester (.) I've been having some problems (.) like (whatever the excuse is going to be::??) and therefore couldn't submit it would you mind if I submit it a week after the due date please 
In addition to using 'Would you mind+VP?', ENGs would often use 'I was wondering+VP.' regardless of their status (See Examples 9-11).

Example 9: Katie (mutual status)

hey anita (.) uhm:: (.) I was just wondering if you could (.) turn down the TV a bit I mean it's $2 \mathrm{am}$ (.) uhm (.) I've (.) I've got my exam at 8 o'clock tomorrow morning and I've got a really strict (.) marker I mean (.) usually wouldn't ask you to turn it down coz I sleep pretty late (.) but:: uhm (.) do you reckon you could turn it down just a little bit (.) coz:: you know (.) yeah that'll be great

Example 10: Christina (low status)

Uhm (.) excuse me Mr Wilson but I've just had (.) ar uhm (.) quite a few problems with (.) with the:: ar concepts ar around this (.) assignment and (.) uhm (.) I (.) found I was doing a lot of work that wasn't that productive (.) and (.) uhm (.) I really feel like I'm back on track now (.) but (.) uhm (.) I won't be able to hand in (.) the assignment in any kind of finished form (.) uhm (.) when it's due (.) I I'll need an extra week (.) uhm (.) I I was uhm (.) I was hoping that I'd be able to do a really good job on (.) on this assignment and uhm (.) I just think it'd be a bit of a shame if I (.) if I did hand it in tomorrow (.) or when it's due then (.) uhm (.) I I won't be able to do that (.) and ar (.) so I was just wondering if there was a chance of getting an extension for a week-low.

Example 11: Katie (high status)

hi (.) rose (.) uhm::: (.) I've got a (.) favour to ask you (.) ar::: (.) I know that you have (.) your (.) presentation in three weeks time (.) I was wondering if you could (.) maybe do it next week instead (.) listen I know that you're really busy with major exams so if you can't do it (.) that's ok:: it's just that (.) uhm the topic you are presenting on (.) is actually a lot more relevant to next week (.) uhm:: ar:: I was just wondering if you could (.) ar:: teach the students how to write an essay (.) that'd be all thanks 
Curl and Drew's (2008) claim that different syntactic forms have different levels of impositions in English and that ENGs tended to use 'I was wondering+VP' when they were unsure whether the request conditions could be met or when they perceived themselves as potentially lacking entitlement through their use of these forms. Although the results here support Curl and Drew's (2008) finding that ENGs employed this form, the results differ in that the ENGs used the 'I was wondering+VP.' to express politeness irrespective of their interlocutor's status. In fact, more ENGs used 'I was wondering+VP' than the 'Could/would you mind+VP?' conventional indirect request structure. Moreover, the ENGs did not use nonconventional indirect requests regardless of interlocutor's status. However, even though the 'I was wondering+VP' request is used by more ENGs, the results show that this structure was not acquired by learners.

The second point is that most AHLs who used the 'Can/Could you+VP' request structure and softeners 'Would you like/mind+VP?' and only two learners in all rounds used the 'I was wondering+VP.' Likewise, about $80 \%$ of the SALs' used the 'Can/Could you+VP?' structure but only a small minority (14\%-24\%) used softeners such as 'Do/Would you like/mind+VP?' regardless of their status in all rounds, and only one used 'I was wondering+VP' in $\mathrm{T}_{3}$ with higher status interlocutor.

The results showed the SALs frequently employed the 'Can/Could you+VP?' in their requests irrespective of the interlocutor's status in all rounds (Examples 12-14).

Example 12: Ivan ( $\mathrm{T}_{2}$, mutual status)

Uhm (.) can you:: (.) turn off the music (.) or turn it (.) ar (.) lower (.) because (.) I only have (.) few hour to sleep

Example 13: Masaya $\mathrm{T}_{1}$ (low status)

professor:: (.) could you (.) err:: (.) could you give me (.) a:: extent (.) extent (.) err::: (.) extensive (.) extension day:: (.) to::: (.) to::: hand in my::: (.) my paper (.) I need to (.) finish it (.) err: (.) err:: (.) uhm (.) extra (.) extra day (.) extra time (.) yeah 
Example 14: Terry $\mathrm{T}_{3}$ (high status)

arr::: (.) could you::: (.) hand in your work (.) one week earlier

As Zhang (1995a,b) suggests, English conventional indirect request formulas such as query preparatory 'Can/Could you/I (please)+VP?' are not used to express politeness in Chinese, and learners who are able to use these forms are those who have been influenced and acquired this from the English language. Like ENGs, in $\mathrm{T}_{1}$, a majority of learners from both groups used these forms without grammatical errors to express politeness irrespective of their interlocutor's status. In other words, this group of learners had acquired these English request forms to express politeness in English prior to their arrival in Australia.

However, not all SALs used English request softeners. Most of the SALs who used request softeners used the 'Would/Do you mind + NP' structure regardless of whether they had mutual, higher or lower status interlocutors and did so in all three rounds (as seen in examples 15-17).

Example 15: Ivan ( $\mathrm{T}_{1}$, mutual status)

uhm (.) excuse me (.) would you mind to::: (.) turn the volume::: (.) of the music down

Example 16: Tiffany ( $\mathrm{T}_{1}$, high status)

Uhm:::: (.) actually I know (.) you are having a very (.) uhm (.) hardworking (.) this week (.) but: (.) uhm:: (.) I know you are the only one (.) who can help my class to::: (.) to (.) the only one who can teach the class (.) to (.) solve some problem (.) so::: (.) would you mind to take a few (.) uhm:: (.) to:: (.) maybe one hour (.) to:: teach (.) them (.) for extra class (.) uhm:::: (.) and:::::::

Example 17: Ronald ( $\mathrm{T}_{1}$, low status)

arr (.) sorry professor (.) but (.) uhm::: (.) I got (.) some (.) I got my essay (.) not yet done (.) and I (.) got (.) so many ideas to write inside (.) but (.) uhm (.) I couldn't finish it within this week (.) arr (.) would you mind if I hand to you (.) hand it in to you (.) maybe next week (.) and I promise it will (.) be a great job 
Examples 15-17 show some learners had acquired and used the 'Would/Do you mind+NP' structure in $\mathrm{T}_{1}$, though a majority of these learners made an error by latching 'Would/Do you mind' to an to-infinitive after the word 'mind' instead of using a gerund. This suggests learners had learned and used the overall structure as a formulaic sequence, but had not attended to the grammar of the overall syntactic structure of 'Would/Do you mind+NP', even after nine months in the target language community. It may be that SALs did not get feedback on their grammatical errors when they used this form as a request in the target language community, or that learners did not have sufficient exposure and input to English to hear this form during their sojourn abroad.

It is likely that the learners had used the 'Would/Do you mind' request softener in the same way they used to-infinitive in the verb phrase in the 'Can/could you+VP' structure without noticing the need to change the to-infinitive to a gerund in the "Would/Do you mind'.

Additionally, learners' limited exposure to English from ENGs may be the reason they did not have enough opportunities to acquire the use of the 'I was wondering+VP' structure even by $\mathrm{T}_{3}$ irrespective of interlocutor's status.

The only SAL who used the 'I was wondering+VP' structure was Tiffany when she had a higher status interlocutor in $\mathrm{T}_{3}$, where she requested for an extension from her professor (see Example 18).

Example 18: Tiffany in $\mathrm{T}_{3}$ (mutual status)

ar:: (.) hi (.) Jane:: (.) I'm (.) I'm sorry I can't (.) uhm (.) ar (.) I did finish my essay (.) but (.) I think if I have another (.) week to (.) uhm (.) to:: (.) check or (.) to do with my essay (.) I think I could do better (.) but (.) uhm (.) just wondering if you can give me an extension (.) because (.) uhm (.) I ju- (.) I have (.) $\mathrm{uhm}$ (.) pretty much (.) uhm (.) difficulty in this subject (.) but I want to (.) have uhm (.) satisfying result

The 'I wonder + VP' structure does not exist as a request in Chinese. This may explain why the learners in this study did not use this as a request. Learners are more likely to rely on a direct request form and the simpler form 'Can/Could you/I (please)+VP?' because it is the form they are most familiar with using to express politeness in requests. The SALs have 
reported even when they talk to Australian English NSs, they tend to use the simplified and reduced form. Further evidence that learners had little exposure to the more complex forms of request ' $\mathrm{I}$ was wondering+PP' is seen in the interpretation of requests tasks in the oral EDCTs.

Thirdly, the results show, similar to ENGs, even in $T_{1}$ the SALs illustrated they used conventional indirect requests irrespective of the interlocutor's status. However, what is more surprising is that the number of SALs who used direct requests increased from $T_{1}$ to $T_{3}$ when their status was higher and lower than their interlocutor. By $\mathrm{T}_{3}$, many SALs chose to use direct requests in preference to conventional indirect requests when they were of a higher and lower status than their interlocutor. Examples 19-22 illustrate the SALs' preference for conventional indirect requests when their status was higher and lower than their interlocutor in $\mathrm{T}_{1}$, which changed to an inclination for direct requests in $\mathrm{T}_{3}$.

Example 19: Heyman $\mathrm{T}_{1}$ (low status)

hmm:: (.) could I have (.) an:: (.) extension: to::: the:::: homework (.) err::: (.) because (.) arr (.) uhm (.) I'm::: (.) I have so many works (.) these days

Example 20: Heyman $\mathrm{T}_{3}$ (low status)

uhm (.) professor (.) I want to (.) extend (.) arr (.) the date (.) of handing in (.) my essay (.) because (.) I am so busy these days

Example 21: Heyman $\mathrm{T}_{1}$ (high status)

hmm:::: (.) could you help me to teach my class for::: (.) a week (.) or::: (.) when (.) err (.) could you help me (.) because I'm (.) I have some other works (.) and:: I can't (.) teach (.) my students

Example 22: Heyman $\mathrm{T}_{3}$ (high status)

hmm (.) I know you are having (.) exam next (.) next week (.) but (.) I want (.) you to present your (.) article (.) next week (.) err::: (.) can you:: (.) please 
It is perhaps not surprising to see SALs using direct requests because they are considered polite in Chinese, but it is somewhat unexpected to see the change in learners' use of conventional to direct requests from $T_{1}$ to $T_{3}$ in situations where their status were higher and lower than their interlocutor.

It is unlikely SALs used direct requests without awareness of the non-equivalence of imperatives and performatives in terms of politeness they express in English and Chinese. Although direct requests are considered polite in Chinese, the learners had learned the appropriate way of requesting in English is the conventional indirect request ' $\mathrm{Can} / \mathrm{Could}$ you+VP?', and that direct requests may be less polite in English. However, and importantly, learners frequently employed external modifiers to minimise the imposition of a request. For instance, a SAL, Janice, used apologies, grounders, and stated desire to do better when she employed a direct request when their status was lower than the interlocutor (See Examples 23-24).

Example 23: Tiffany $\mathrm{T}_{1}$ (high status)

uhm:::: (.) attention please (.) uhm::: (.) actually got something (.) some changes (.) for your (.) uhm (.) assignment (.) and:: (.) I want you to hand it (.) to me:: by:::: (.) next week (.) that (.) means (.) ear (.) it's a bit early (.) than schedule (.) but (.) I want it next week

Example 24: Janice $\mathrm{T}_{2}$ (low status)

uhm:::: (.) sorry professor (.) I want to do it better (.) if I err (.) just only give (.) the assignment to you (.) err (.) I need to be (.) so hurry (.) and (.) I would like to do well (.) so (.) if you want me to do well (.) you need to give me more time

As Færch and Kasper (1989) reported, the formulation of the utterance itself and its internal modification do not constitute indirectness. Chinese indirectness seems to be linked with information sequence. The SALs' use of conventional indirect requests along with request external modifiers from $T_{1}$ to $T_{3}$ suggests that it is necessary to express a higher level of politeness with those who have closer or equal relationship than those of higher or lower status than their interlocutor. This suggests for Chinese learners of English that negative politeness is more salient in relation to social distance than status. 
Previous researchers have found a negative correlation between learners' L1-L2 transferability and proficiency (e.g., Ellis 1994; Koike 1996; Maeshiba, Yoshinaga, Kasper \& Ross 1996). However, it is unlikely that the SALs in this study had increased the use of direct requests by $\mathrm{T}_{3}$ because of their low linguistic proficiency or that they were unaware of the non-equivalence in meaning between learners' L1 and L2 since they used conventional indirect requests in $T_{1}$. It was only in $T_{3}$ that learners chose direct requests with higher and lower status interlocutors, but not with equal status interlocutor.

Instead, it may be that as SALs spent more time in the target language community they found the use of a simpler and more direct way of requesting which was still socially acceptable and, more importantly, could be understood more easily-especially amongst other NNSs. It may also be plausible that the SALs were fully aware that direct requests were less polite than conventional indirect requests in English, and so they expressed politeness with a range of external modifiers whether they were in situations of higher or lower status than their interlocutor (see Examples 25-26).

Example 25, Suki $\mathrm{T}_{1}$ (high status):

uhm::::: (.) I want you:: all to:::: (.) hand in the homework (.) uhm (.) earlier (.) in (.) this (.) week.

Example 26, Suki $\mathrm{T}_{3}$ (high status):

hmm::: (.) I need you to help because I want (.) I::: (.) I hope you can::: (.) hmm (.) you can:::: (.) teach my class (.) ar:: (.) just one hour (.) ar:: to teach the (.) how to::

There is evidence that learners used external modifiers in $T_{3}$ which they did not use in $T_{1}$ (see Examples 25 and 26). Perhaps with the influence of Australian culture, Suki used postrequest devices to mitigate the imposition of the request after launching the direct request (See Example 26). It may be that the SALs influenced by improved linguistic and cultural knowledge. The use of external modifiers will be discussed in the next section of this chapter. 


\subsection{External modifiers}

This section presents the descriptive and inferential statistics of the number and the types of external modifiers used by ENGs, AHLs and SALs. Section 6.3.1 provides the analyses of cross-group and within-group comparisons of the total mean number of external modifiers used by ENGs, AHLs and SALs. Section 6.3.2 presents the results of the acquisition of preand post-request external modifiers which show SALs did not acquire the use of these devices. Section 6.3.3 presents the correlations between the total number of external modifiers used during their sojourn abroad and affective and environmental factors. Data from ENGs will be used as comparisons.

\subsubsection{Total number of external modifiers}

This section presents the total number of external modifiers used by ENGs, AHLs and SALs. It provides cross-group analyses of the number of external modifiers and within-group comparisons of the development of the number of external modifiers used by AHLs and SALs.

\section{i. Cross-group comparisons for total number of external modifiers}

As can be seen from Table 6.9, on average ENGs used more external modifiers per request than AHLs and SALs regardless of the interlocutor's status. Overall, the AHLs used a slightly higher number of external modifiers per request when they had lower than mutual and higher status interlocutor. Interestingly, on average the SALs used external modifiers in $T_{3}$ rather than in $T_{1}$ when they had the same status as their interlocutor; but there appears to be an increase in the average number of external modifiers in $T_{3}$ rather than $T_{1}$ when they had higher and lower status than the interlocutor. Despite this increasing trend, the ENGs still used more external modifiers than SALs by $\mathrm{T}_{3}$. 
Table 6.9: Descriptive statistics for the total number of external modifiers per request used by ENGs, AHLs and SALs

\begin{tabular}{|c|c|c|c|c|c|c|c|}
\hline & & \multicolumn{6}{|c|}{ Participant's status } \\
\hline & & \multicolumn{2}{|c|}{ Mutual } & \multicolumn{2}{|l|}{ High } & \multicolumn{2}{|l|}{ Low } \\
\hline & & Mean & SD & Mean & SD & Mean & $\mathrm{SD}$ \\
\hline ENGs $(n=30)$ & $\mathrm{T}_{1}$ & 4.47 & 1.68 & 5.03 & 1.22 & 7.07 & 1.66 \\
\hline \multirow{3}{*}{ AHLs $(n=30)$} & $\mathrm{T}_{1}$ & 2.63 & 0.93 & 2.37 & 1.19 & 2.67 & .99 \\
\hline & $\mathrm{T}_{2}$ & 2.60 & 1.07 & 2.37 & 1.22 & 2.9 & 1.06 \\
\hline & $\mathrm{T}_{1}$ & 2.43 & 1.03 & 2.42 & 1.66 & 2.62 & .97 \\
\hline \multirow[t]{2}{*}{ SALs $(\mathrm{n}=21)$} & $\mathrm{T}_{2}$ & 2.29 & 1.10 & 2.48 & 1.17 & 3.29 & 1.59 \\
\hline & $\mathrm{T}_{3}$ & 2.1 & .88 & 2.81 & 1.21 & 3.86 & 1.59 \\
\hline
\end{tabular}

The ANOVA analyses in Table 6.10 revealed that in $T_{1}$ and $T_{2}$ there were significant differences between mean number of external modifiers between ENGs, AHLs and SALs when speakers had mutual $(F(2,64)=22.62, p<.001 ; F(2,65)=21.47, p<.001$ respectively $)$, higher $(F(2,78)=36.96, p<.001 ; F(2,78)=44, p<.001$ respectively $)$ and lower $(2 F(2,66)=$ $120.65, p<.001 ; F(2,78)=73.10, p<.001$ respectively) status than their interlocutor. Post-hoc analyses revealed ENGs used significantly more external modifiers than both AHLs and SALs, but the differences between AHLs and SALs were not statistically significant across the three statuses in $T_{1}$ and $T_{2}$. By $T_{3}$, the ENGs still used considerably more external modifiers than SALs irrespective of the interlocutor's status. Analysis by independent samples t-test revealed these differences were statistically significant when they were of a mutual, higher and lower status than the interlocutor $(t(46)=6.55, p<.001, t(49)=6.44, p<$ .001 and $(t(49)=6.91, p<.001$ respectively). 
Table 6.10: ANOVA tests for cross-group comparisons of request external modifiers used by AHLs, SALs and ENGs

\begin{tabular}{|c|c|c|c|c|c|c|}
\hline \multirow[t]{2}{*}{ Status of speaker } & \multicolumn{2}{|c|}{$\begin{array}{l}\mathrm{T}_{1} \\
\text { (NSs vs AHLs vs SALs) }\end{array}$} & \multicolumn{2}{|c|}{$\begin{array}{l}\mathrm{T}_{2} \\
\text { (NSs vs AHLs vs SALs) }\end{array}$} & \multicolumn{2}{|c|}{$\begin{array}{l}\mathrm{T}_{3} \\
\text { (NSs vs SALs) }\end{array}$} \\
\hline & $\mathrm{F}$ & Exact Sig. & $\mathrm{F}$ & Exact Sig. & $\mathrm{F}$ & Exact Sig. \\
\hline Mutual: Main comparisons & $22.62^{(\mathrm{B}-\mathrm{F})}$ & $.000 * *$ & $21.47^{(\mathrm{F})}$ & $.000 * *$ & $6.55^{(\mathrm{F})}$ & $.000 * *(\mathrm{x})$ \\
\hline $\begin{array}{l}\text { Posthoc: ENGs vs SALs } \\
\text { Posthoc: ENGs vs AHLs } \\
\text { Posthoc: SALs vs AHLs }\end{array}$ & & $\begin{array}{l}.000^{* *} \\
.000^{* *} \\
.58\end{array}$ & & $\begin{array}{l}.000 * * \\
.000 * * \\
.41\end{array}$ & & \\
\hline High: Main comparisons & $36.96^{(\mathrm{F})}$ & $.000 * *$ & $44^{(\mathrm{F})}$ & $.000 * *$ & $6.44^{(\mathrm{F})}$ & $.000 * *$ \\
\hline $\begin{array}{l}\text { Posthoc: ENGs vs SALs } \\
\text { Posthoc: ENGs vs AHLs } \\
\text { Posthoc: SALs vs AHLs }\end{array}$ & & $\begin{array}{l}.000 * * \\
.000 * * \\
.87\end{array}$ & & $\begin{array}{l}.000 * * \\
.000 * * \\
.83\end{array}$ & & \\
\hline $\begin{array}{l}\text { Low: Main comparisons } \\
\text { Posthoc: ENGs vs SALs } \\
\text { Posthoc: ENGs vs AHLs } \\
\text { Posthoc: SALs vs AHLs }\end{array}$ & $120.65^{(\mathrm{B}-\mathrm{F})}$ & $\begin{array}{l}.000 * * \\
.000^{* *} \\
.000^{* *} \\
.90\end{array}$ & $73.10^{(\mathrm{F})}$ & $\begin{array}{l}.000^{* *} \\
.000^{* *} \\
.000^{* *} \\
.35\end{array}$ & $6.91^{(\mathrm{F})}$ & $.000 * *$ \\
\hline \multicolumn{7}{|c|}{$\begin{array}{l}\text { Notes: } \\
\text { 1. F stats if it meets the homogeneity of variances (Levene tests), otherwise used the robust tests of equality means test } \\
\text { values from Brown-Forsythe(B-F)) }\end{array}$} \\
\hline
\end{tabular}

\section{ii. Within-group comparisons for total number of external modifiers}

\section{AHLs}

The AHLs used a similar number of external modifiers in $T_{1}$ and $T_{2}$ regardless of the interlocutor's status. This was expected as the AHLs were not in an environment where they interact or receive input from NSs that could potentially promote pragmatic learning in $T_{1}$ and $\mathrm{T}_{2}$. Pair samples t-test revealed there was nothing statistically significant between the number of external modifiers used in $\mathrm{T}_{1}$ and $\mathrm{T}_{2}$ when they had mutual, higher and lower status than their interlocutor, $t(29)=.80, p=$ n.s., $t(29)=.11, p=$ n.s. and $(t(29)=.87, p=$ n.s. respectively.

\section{SALs}

As can be seen from Table 6.11, the only significant increases between the number of external modifiers used by SALs between $T_{1}, T_{2}$ and $T_{3}$ were found when their status was lower than their interlocutor $(\mathrm{F}=5.10, \mathrm{df}=2,40, \mathrm{p}<.01)$. Posthoc analyses revealed there was significant difference between $\mathrm{T}_{1}$ and $\mathrm{T}_{3}$ at $\mathrm{p}<.01$. 
Table 6.11: ANOVA repeated measures t-tests for the comparisons of request external modifiers used by SALs between $T_{1}, T_{2}$ and $T_{3}$

\begin{tabular}{l} 
Mutual \\
\cline { 2 - 2 } \\
\cline { 2 - 2 } High
\end{tabular}

\subsubsection{Total number of external modifiers in pre-requests}

The first section provides cross-group comparisons of the total number of external modifiers in pre-requests used by ENGs, AHLs and SALs, and within-group comparisons of the number of pre-request external modifiers used by AHLs and SALs. Data from ENGs will be used as points of comparison.

\section{i. Cross-group comparisons for total number of external modifiers in pre-requests}

As can be seen from Table 6.12, in general the ENGs used a greater number of external modifiers per request than both groups of learners and used a greater number of external modifiers in the pre-requests. The AHLs used a similar number of external modifiers in $\mathrm{T}_{1}$ and $\mathrm{T}_{2}$ regardless of the interlocutor's status, while the SALs used a similar number of external modifiers when they had mutual and higher status than their interlocutor between $\mathrm{T}_{1}$ and $\mathrm{T}_{3}$. The biggest increase occurred when the SALs had a lower status than the interlocutor. By $\mathrm{T}_{3}$, the number of external modifiers the SALs used when they were of lower status was similar to the ENGs; but the number of external modifiers SALs used when they had mutual and lower status interlocutors remained lower than the ENGs. 
Table 6.12: Descriptive statistics for cross-group comparisons between the number of pre-request external modifiers used by AHLs, SALs and ENGs

\begin{tabular}{|c|c|c|c|c|c|c|c|}
\hline & & \multicolumn{6}{|c|}{ Participant's status } \\
\hline & & \multicolumn{2}{|c|}{ Mutual } & \multicolumn{2}{|l|}{ High } & \multicolumn{2}{|l|}{ Low } \\
\hline & & Mean & $\mathrm{SD}$ & Mean & $\mathrm{SD}$ & Mean & $\mathrm{SD}$ \\
\hline ENGs $(n=30)$ & $\mathrm{T}_{1}$ & 3.23 & 1.65 & 3.23 & 1.30 & 1.87 & .86 \\
\hline \multirow[t]{2}{*}{ AHLs $(n=30)$} & $\mathrm{T}_{1}$ & 1.3 & .53 & 1.1 & .83 & 1.3 & .75 \\
\hline & $\mathrm{T}_{2}$ & 1.47 & 1.10 & 1.37 & 1.02 & 1.67 & .84 \\
\hline \multirow[t]{3}{*}{ SALs $(n=21)$} & $\mathrm{T}_{1}$ & 1.1 & 1.05 & 1.33 & 1.58 & 1.1 & .77 \\
\hline & $\mathrm{T}_{2}$ & 1.29 & 1.10 & 1.14 & .73 & 2.19 & 1.21 \\
\hline & $\mathrm{T}_{3}$ & 1.1 & .89 & 1.52 & .81 & 1.95 & 1.40 \\
\hline
\end{tabular}

The ANOVA analyses in Table 6.13 revealed there were significant differences between the number of external modifiers used by ENGs, AHLs and SALs regardless of whether they had mutual $(F(2,64)=28.55, p<.01)$, high $(F(2,58)=30.99, p<.01)$ or low $(F(2,78)=112.8$, $p<.01)$ status as their interlocutor in $T_{1}$. The differences between the three groups were also statistically significant in $\mathrm{T}_{2}$ in mutual $(F(2,78)=18.06, p<.001)$ and higher status $(F(2,73)=$ $34.93, p<.001)$ but not lower status than their interlocutor $(F(2,78)=1.86, p=\mathrm{n} . \mathrm{s})$. Post-hoc analyses revealed ENGs used significantly more external modifiers than both AHLs and SALs, but the differences between AHLs and SALs were not statistically significant irrespective of their status in $\mathrm{T}_{1}$ and $\mathrm{T}_{2}$. By $\mathrm{T}_{3}$, the ENGs still used more external modifiers than SALs when they had mutual or higher status than their interlocutor. Analyses by independent samples t-test revealed these differences were statistically significant when they had mutual and higher status $(t(46)=5.96, p<.001 ; t(48)=5.75, p<.001$ respectively) but not when they had a lower status than their interlocutor $(t(31)=.25, p=n . s$.$) .$ 


\subsubsection{Total number of external modifiers in post-requests}

The first section provides cross-group comparisons of the total number of external modifiers in post-requests used by ENGs, AHLs and SALs, and within-group comparisons of the number of post-request external modifiers used by AHLs and SALs. Data from ENGs will be used as a point of comparison.

\section{i. Cross-group comparisons for total number of external modifiers in post-requests}

As can be seen from Table 6.15, the ENGs, AHLs and SALs tended to use a greater number of external modifiers when they had higher status interlocutors than lower and mutual status interlocutors. In general, the ENGs used only a slightly higher number of external modifiers as post-requests than both groups of learners when they had mutual and lower status interlocutors. The ENGs used more external modifiers per request than both groups of learners when they had lower status than their interlocutors, even compared to SALs in $\mathrm{T}_{3}$.

Table 6.15: Descriptive statistics for cross-group comparisons between the number of post-request external modifiers used by AHLs, SALs and ENGs

\begin{tabular}{lccccccc}
\hline & \multicolumn{3}{l}{\begin{tabular}{l}
\multicolumn{2}{l}{ Participant's status } \\
Mutual
\end{tabular}} & \multicolumn{2}{c}{ High } & \multicolumn{2}{c}{ Low } \\
\cline { 3 - 8 } & & Mean & SD & Mean & SD & Mean & SD \\
\cline { 3 - 8 } ENGs (n=30) & $\mathrm{T}_{1}$ & 1.23 & .57 & 1.87 & .86 & 5.2 & 1.30 \\
AHLs (n=30) & $\mathrm{T}_{1}$ & 1.33 & .76 & 1.27 & .69 & 1.37 & .67 \\
& $\mathrm{~T}_{2}$ & 1.13 & .43 & 1.07 & .52 & 1.23 & .50 \\
SALs (n=21) & $\mathrm{T}_{1}$ & 1.24 & .48 & 1.43 & .68 & 1.52 & .60 \\
& $\mathrm{~T}_{2}$ & 1 & .31 & 1.33 & .73 & 1.1 & .89 \\
& $\mathrm{~T}_{3}$ & 1 & .45 & 1.29 & .56 & 1.9 & 1.14 \\
\hline
\end{tabular}

The ANOVA analyses in Table 6.16 revealed that in $T_{1}$ and $T_{2}$ there were significant differences between the number of external modifiers used by ENGs, AHLs and SALs when the participants were at a higher $(F(2,78)=4.99, p<.01 ; F(2,65)=9.57, p<.01$ respectively $)$ and lower status than their interlocutor $(F(2,78)=166.91, p<.01 ; F(2,57)=169.54, p<.01$ respectively). Post-hoc analyses revealed ENGs used significantly higher number of external modifiers as post-requests than AHLs and SALs in higher and lower status interactions than the interlocutor in both $\mathrm{T}_{1}$ and $\mathrm{T}_{2}$.

By $T_{3}$, the SALs used more external modifiers per request when their status was lower than the interlocutor than $\mathrm{T}_{1}$, but used fewer external modifiers per request with mutual and lower status interlocutors (See Table 6.15). Overall, the number of external modifiers SALs used as 
post-requests was still lower than ENGs, especially when their status was lower than their interlocutor. As can be seen from Table 6.16, analyses by independent samples t-test revealed these differences are statistically significant in interactions with higher and lower status interlocutors $(t(48)=9.39, p<.001 ; t(48)=2.92, p<.01$ respectively).

Table 6.16: ANOVA tests for cross-group comparisons of the number of post-request external modifiers used by AHLs, SALs and ENGs

\begin{tabular}{|c|c|c|c|c|c|c|}
\hline \multirow[t]{2}{*}{ Status of speaker } & \multicolumn{2}{|c|}{$\begin{array}{l}\mathrm{T}_{1} \\
\text { (NSs vs AHLs } \\
\text { vs SALs) }\end{array}$} & \multicolumn{2}{|c|}{$\begin{array}{l}\mathrm{T}_{2} \\
\text { (NSs vs AHLs } \\
\text { vs SALs) }\end{array}$} & \multicolumn{2}{|c|}{$\begin{array}{l}\mathrm{T}_{3} \\
\text { (NSs } v s \text { SALs) }\end{array}$} \\
\hline & $\mathrm{F}$ & Exact Sig. & $\mathrm{F}$ & $\begin{array}{l}\text { Exact } \\
\text { Sig. }\end{array}$ & $\mathrm{F}$ & Exact Sig. \\
\hline Mutual: Main comparisons & $.26^{(\mathrm{B}-\mathrm{F})}$ & .78 & $1.70^{(\mathrm{B}-\mathrm{F})}$ & .19 & $1.64^{(\mathrm{F})}$ & .11 \\
\hline Posthoc: ENGs vs SALs & ns & .58 & sign & .08 & & \\
\hline Posthoc: ENGs vs AHLs & ns & .54 & $\mathrm{~ns}$ & .41 & & \\
\hline Posthoc: SALs vs AHLs & ns & 1 & ns & .32 & & \\
\hline High: Main comparisons & $4.99\left(^{\mathrm{F})}\right.$ & $.009 * *$ & $9.57^{(\mathrm{B}-\mathrm{F})}$ & $.000 * *$ & 2.92 & $.005^{* *}$ \\
\hline Posthoc: ENGs vs SALs & ns & .045 & sign & .01 & & \\
\hline Posthoc: ENGs vs AHLs & sign & .003 & sign & .000 & & \\
\hline Posthoc: SALs vs AHLs & ns & .453 & ns & .19 & & \\
\hline Low & $166.91^{(\mathrm{B}-\mathrm{F})}$ & $.000 * *$ & $169.54^{(\mathrm{B}-\mathrm{F})}$ & $.000 * *$ & 9.39 & $.000 * *$ \\
\hline Posthoc: ENGs vs SALs & sign & .000 & sign & .000 & & \\
\hline Posthoc: ENGs vs AHLs & sign & .000 & sign & .000 & & \\
\hline Posthoc: SALs vs AHLs & $\mathrm{ns}$ & .56 & $\mathrm{~ns}$ & .62 & & \\
\hline \multicolumn{7}{|c|}{$\begin{array}{l}\text { Notes: } \\
\text { 1. F stats if it meets the homogeneity of variances (Lev } \\
\text { values from Brown-Forsythe(B-F)) } \\
\text { 2. Statistical significance: } * * p<.01,{ }^{*} p<.05 \text { ( } 2 \text { tailed). } \\
\text { 3. (x)=equality not assumed. }\end{array}$} \\
\hline
\end{tabular}

\section{ii. within-group comparisons for total number of external modifiers in post-requests}

The analyses in Table 6.17 show there was a significant increase in the number of external modifiers used by SALs between $\mathrm{T}_{1}$ and $\mathrm{T}_{3}$ when they had mutual and lower status than their interlocutor $(F(2,40)=4.83, p<.05 ; F(2,40)=4.34, p<.05$ respectively). Posthoc analyses revealed the significant increase occurred between $T_{1}$ and $T_{2}$ and $T_{1}$ and $T_{3}$ at $p<.01$ when the SALs were of mutual status as the interlocutor, but there were significant differences between $\mathrm{T}_{1}$ and $\mathrm{T}_{3}(\mathrm{p}<.05)$ only when the learners were of lower status than the interlocutor. 
Table 6.17: ANOVA repeated measures t-tests for comparisons of post-request external modifiers used by SALs in $T_{1}, T_{2}$ and $T_{3}$

\begin{tabular}{|c|c|c|}
\hline & F & Exact Sig. \\
\hline Mutual & 4.83 & $.013 *$ \\
\hline \multicolumn{3}{|l|}{ Posthoc: } \\
\hline 1 vs 2 & & $.047 *$ \\
\hline 1vs 3 & & $.047 *$ \\
\hline 2 vs 3 & & 1 \\
\hline High & .27 & .765 \\
\hline Low & 4.34 & $.02 *$ \\
\hline \multicolumn{3}{|l|}{ Posthoc: } \\
\hline 1 vs 2 & & ns \\
\hline 1vs 3 & & $.045^{*}$ \\
\hline 2 vs 3 & & 1 \\
\hline
\end{tabular}

Notes.

1. F stats if it meets the homogeneity of variances (Levene tests), otherwise used the robust tests of equality means test values from Brown-Forsythe(B-F))

2. Statistical significance: **p <.01, *p <.05 (2 tailed).

3. $(\mathrm{x})=$ equality not assumed.

\subsubsection{Acquisition of external modifiers by SALs}

As the focus of this study is on the development of SALs' pragmatic competence during their sojourn abroad, the sections below will focus on SALs' use of request devices in pre- and post-requests. In particular, the sections below will provide within-group analyses of the types of pre-request external modifiers that were not acquired by SALs and those that the SALs had acquired. It also draws on cross-group comparison analyses between ENGs and SALs.

\subsubsection{Types of external modifiers not acquired by SALs}

This section provides within-group analyses of the types of external modifiers used as preand post-requests.

\section{i. Within-group of the types of external modifiers not acquired by SALs in pre-requests}

As can be seen from Tables 6.18-6.20, the ENGs and the SALs used very few cajolers, selfintroductions, compliments, minimal impositions, consequences and apologies regardless of the interlocutor's status in all rounds. 
Table 6.18: Descriptive statistics for the average number of external modifiers used by ENGs and SALs as pre-requests (speaker at mutual status with interlocutor)

\begin{tabular}{|c|c|c|c|c|c|c|c|c|}
\hline \multicolumn{9}{|l|}{ Participants } \\
\hline & \multicolumn{2}{|l|}{ NSs } & \multicolumn{6}{|l|}{ SALs } \\
\hline & & & $\mathrm{T}_{1}$ & & $\mathrm{~T}_{2}$ & & $\mathrm{~T}_{3}$ & \\
\hline & Mean & $\mathrm{SD}$ & Mean & $\mathrm{SD}$ & Mean & $\mathrm{SD}$ & Mean & SD \\
\hline Cajolers & .13 & .35 & 0 & 0 & 0 & 0 & 0 & 0 \\
\hline Self-introductions & .47 & .51 & .05 & .30 & 0 & 0 & 0 & 0 \\
\hline Compliments & .47 & .51 & 0 & 0 & .05 & .22 & 0 & 0 \\
\hline Minimal imposition & .05 & 0 & 0 & 0 & .05 & .22 & 0 & 0 \\
\hline Consequences & .03 & .43 & 0 & 0 & .05 & .22 & .10 & .28 \\
\hline Apologies & .20 & .41 & .17 & .37 & .33 & .48 & .24 & .44 \\
\hline Greetings & .47 & .51 & 0 & 0 & 0 & 0 & 0 & 0 \\
\hline
\end{tabular}

Table 6.19: Descriptive statistics for the average number of external modifiers used by ENGs and SALs as pre-requests (speaker at higher status than interlocutor)

Cajolers

Self-introductions

Compliments

Minimal imposition

Consequences

Apologies

Greetings

\begin{tabular}{|c|c|c|c|c|c|c|c|}
\hline \multicolumn{2}{|c|}{ NSs } & \multicolumn{6}{|l|}{ SALs } \\
\hline Mean & SD & $\begin{array}{l}\mathrm{T}_{1} \\
\text { Mean }\end{array}$ & SD & $\begin{array}{l}\mathrm{T}_{2} \\
\text { Mean }\end{array}$ & SD & $\begin{array}{l}\mathrm{T}_{3} \\
\text { Mean }\end{array}$ & SD \\
\hline .30 & .47 & 0 & 0 & 0 & 0 & 0 & 0 \\
\hline .30 & .35 & 0 & 0 & 0 & 0 & 0 & 0 \\
\hline .13 & .35 & 0 & 0 & .10 & .30 & .05 & .22 \\
\hline .07 & .25 & 0 & 0 & 0 & 0 & 0 & 0 \\
\hline 0 & 0 & 0 & 0 & 0 & 0 & 0 & 0 \\
\hline .03 & .18 & .14 & .36 & .19 & .40 & 0 & 0 \\
\hline .60 & .49 & .05 & .22 & 0 & 0 & .10 & .30 \\
\hline
\end{tabular}

Table 6.20: Descriptive statistics for the average number of external modifiers used by ENGs and SALs as pre-requests (speaker at lower status than interlocutor)

\begin{tabular}{|c|c|c|c|c|c|c|c|c|}
\hline \multicolumn{9}{|l|}{ Participants } \\
\hline & \multicolumn{2}{|l|}{ NSs } & \multicolumn{6}{|l|}{ SALs } \\
\hline & & & $\mathrm{T}_{1}$ & & $\mathrm{~T}_{2}$ & & $\mathrm{~T}_{3}$ & \\
\hline & Mean & SD & Mean & SD & Mean & SD & Mean & SD \\
\hline Cajolers & .20 & .41 & 0 & 0 & 0 & 0 & 0 & 0 \\
\hline Self-introductions & .20 & .28 & 0 & 0 & .05 & .22 & 0 & 0 \\
\hline Compliments & .37 & .49 & .05 & .22 & 0 & 0 & 0 & 0 \\
\hline Minimal imposition & .20 & .41 & 0 & 0 & 0 & 0 & 0 & 0 \\
\hline Consequences & .20 & .29 & 0 & 0 & .05 & .22 & .10 & .30 \\
\hline Apologies & .07 & .25 & 0.24 & .44 & 0 & 0 & .14 & .30 \\
\hline Greetings & .47 & .51 & .05 & .22 & 0.24 & .44 & .05 & .15 \\
\hline
\end{tabular}

As can be seen from Table 6.21, there were no significant differences in the number of cajolers, self-introductions, compliments, minimal impositions, consequences and apologies used by the SALs between $\mathrm{T}_{1}, \mathrm{~T}_{2}$ and $\mathrm{T}_{3}$. 
Table 6.21: Repeated measures for comparisons of pre-request external modifiers used by SALs in $T_{1}, T_{2}$ and $T_{3}$

\begin{tabular}{|c|c|c|}
\hline & $\mathrm{F}$ & Exact Sig. \\
\hline \multicolumn{3}{|l|}{ Mutual } \\
\hline Cajolers & 0 & \\
\hline Self-introduction & 1 & .33 \\
\hline Compliments & 0 & \\
\hline Consequences & 0 & \\
\hline Apologies & .66 & .43 \\
\hline Greetings & 0 & \\
\hline \multicolumn{3}{|l|}{ High } \\
\hline Cajolers & 0 & .16 \\
\hline Self-introduction & 2.11 & .33 \\
\hline Compliments & 1 & 0 \\
\hline Consequences & 0 & .33 \\
\hline Apologies & 1 & .58 \\
\hline Greetings & 1 & .33 \\
\hline Low & 0 & \\
\hline Cajolers & 1 & .33 \\
\hline Self-introduction & 1 & .33 \\
\hline Compliments & 0 & \\
\hline Consequences & 1.30 & .27 \\
\hline Apologies & 1 & .33 \\
\hline Greetings & 0 & \\
\hline
\end{tabular}

\section{Notes.}

1. F stats if it meets the homogeneity of variances (Levene tests), otherwise used the robust tests of equality means test values from Brown-Forsythe(B-F)

2. Statistical significance: $* * \mathrm{p}<.01, * \mathrm{p}<.05$ (2 tailed).

3. $(x)=$ equality not assumed.

\section{ii. Cross-group comparisons of types of external modifiers not acquired by SALs in pre-} requests

In order to investigate whether SALs acquired more external modifiers similar to those ENGs used, ANOVA tests were conducted between ENGs and SALs in $\mathrm{T}_{1}$ and $\mathrm{T}_{3}$ regardless of the interlocutor's status. As can be seen from Table 6.22, in $\mathrm{T}_{1}$ the ENGs used significantly more cajolers $(t(1,29)=2.11, p<.05)$, self-introductions $(t(1,42)=4.02, p<.01)$, consequences $(t(1,29)=2.97, p<.01)$ and greetings $(t(1,29)=5.04, p<.01)$ when they had the same status as the interlocutor. The ENGs also used significantly more greetings than the SALs when they had higher $(t(1,49)=12.95, p<.01)$ and lower $(t(1,42)=16.18, p<.01)$ status vis-à-vis the interlocutor. 
Table 6.22: ANOVA tests for cross-group comparisons of the number of pre-request external modifiers used by ENGs and SALs

\begin{tabular}{|c|c|c|c|c|}
\hline \multirow[t]{2}{*}{ Status of speakers } & \multicolumn{2}{|l|}{$\mathrm{T}_{1}$} & \multicolumn{2}{|l|}{$T_{3}$} \\
\hline & $\mathrm{F}$ & Exact Sig. & $\mathrm{F}$ & Exact Sig. \\
\hline \multicolumn{5}{|c|}{ Mutual: Main comparisons } \\
\hline Cajolers & 2.11 & $.04 *$ & .77 & .38 \\
\hline Self-introductions & 4.02 & $.000 * *$ & .98 & .33 \\
\hline Compliments & 0 & & .70 & .41 \\
\hline Minimal imposition & .83 & .41 & .71 & .40 \\
\hline Consequences & 2.97 & $.006 * *$ & .83 & .37 \\
\hline Apologies & .52 & .61 & .68 & .41 \\
\hline Greetings & 5.04 & $.000 * *$ & .95 & .22 \\
\hline \multicolumn{5}{|c|}{ High: Main comparisons } \\
\hline Cajolers & 0 & & 0 & \\
\hline Self-introductions & 0 & & 0 & \\
\hline Compliments & .009 & .92 & 1.18 & .28 \\
\hline Minimal imposition & .08 & .78 & 0 & \\
\hline Consequences & 0 & & 0 & \\
\hline Apologies & .06 & .81 & .70 & .41 \\
\hline Greetings & 12.95 & $.001 * *$ & .65 & .48 \\
\hline \multicolumn{5}{|c|}{ Low: Main comparisons } \\
\hline Cajolers & 0 & & .81 & .37 \\
\hline Self-introductions & .70 & .41 & .69 & .41 \\
\hline Compliments & 0 & & .92 & .34 \\
\hline Minimal imposition & 0 & & .78 & .38 \\
\hline Consequences & 0 & & .73 & .40 \\
\hline Apologies & 2.62 & .12 & .68 & .41 \\
\hline Greetings & 16.18 & $.000 * *$ & .89 & .35 \\
\hline
\end{tabular}

Notes.

1. F stats if it meets the homogeneity of variances (Levene tests), otherwise used the robust tests of equality means test values from Brown-Forsythe(B-F)

2. Statistical significance: $* * \mathrm{p}<.01, * \mathrm{p}<.05$ (2 tailed).

3. $(\mathrm{x})=$ equality not assumed.

\section{iii. Within-group of the types of external modifiers not acquired by SALs in post- requests}

As can be seen from Tables 6.23-6.25, the ENGs and the SALs rarely made apologies, gave compliments, said 'thank you' and stated consequences as post-request devices irrespective of the interlocutor's status in all rounds.

Table 6.23: Descriptive statistics for the average number of external modifiers used by ENGs and SALs as post-requests (speaker of mutual status as the interlocutor)

\begin{tabular}{|c|c|c|c|c|c|c|c|c|}
\hline \multicolumn{9}{|l|}{ Participants } \\
\hline & \multicolumn{2}{|l|}{ NSs } & \multicolumn{6}{|l|}{ SALs } \\
\hline & & & $\mathrm{T}_{1}$ & & $\mathrm{~T}_{2}$ & & $\mathrm{~T}_{3}$ & \\
\hline & Mean & $\mathrm{SD}$ & Mean & $\mathrm{SD}$ & Mean & $\mathrm{SD}$ & Mean & $\mathrm{SD}$ \\
\hline Apologies & 0 & 0 & .05 & .22 & 0 & 0 & .05 & .22 \\
\hline Compliments & 0 & 0 & 0 & 0 & 0 & 0 & 0 & 0 \\
\hline Thank you & .13 & .35 & .10 & .31 & .10 & .30 & .05 & .22 \\
\hline Consequences & .27 & .45 & .10 & .30 & 0 & 0 & .10 & .30 \\
\hline
\end{tabular}


Table 6.24: Descriptive statistics for the average number of external modifiers used by ENGs and SALs as post-requests (speaker at higher status than interlocutor)

\begin{tabular}{|c|c|c|c|c|c|c|c|c|}
\hline \multicolumn{9}{|l|}{ Participants } \\
\hline & \multicolumn{2}{|l|}{ NSs } & \multicolumn{6}{|l|}{ SALs } \\
\hline & & & $\mathrm{T}_{1}$ & & $\mathrm{~T}_{2}$ & & $\mathrm{~T}_{3}$ & \\
\hline & Mean & SD & Mean & SD & Mean & SD & Mean & SD \\
\hline Apologies & .07 & .25 & 0 & 0 & 0 & 0 & 0 & 0 \\
\hline Compliments & .30 & .47 & .05 & .22 & 0.14 & .36 & .10 & .30 \\
\hline Thank you & .03 & .18 & .05 & .22 & 0 & 0 & .05 & .22 \\
\hline Consequences & .47 & .51 & .10 & .30 & 0 & 0 & 0 & 0 \\
\hline
\end{tabular}

Table 6.25: Descriptive statistics for the average number of external modifiers used by ENGs and SALs as post-requests (speaker at lower status than interlocutor)

\begin{tabular}{|c|c|c|c|c|c|c|c|c|}
\hline \multicolumn{9}{|l|}{ Participants } \\
\hline & \multicolumn{2}{|l|}{ NSs } & \multicolumn{6}{|l|}{ SALs } \\
\hline & & & $\mathrm{T}_{1}$ & & $\mathrm{~T}_{2}$ & & $\mathrm{~T}_{3}$ & \\
\hline & Mean & SD & Mean & SD & Mean & SD & Mean & SD \\
\hline Apologies & 0 & 0 & 0 & 0 & 0 & 0 & 0 & 0 \\
\hline Compliments & .13 & .35 & .05 & .22 & 0 & 0 & 0 & 0 \\
\hline Thank you & .03 & .18 & .05 & .22 & .05 & .22 & 0 & 0 \\
\hline Consequences & .97 & .93 & .62 & .67 & .48 & .68 & .24 & .44 \\
\hline
\end{tabular}

As can be seen from Table 6.26, there were no significant differences in the number of apologies, compliments, expressions of thanks and consequences made by the SALs between $\mathrm{T}_{1}, \mathrm{~T}_{2}$ and $\mathrm{T}_{3}$.

Table 6.26: Repeated measures for comparisons of post-requests external modifiers used by SALs in $T_{1} T_{2}$ and $T_{3}$

\begin{tabular}{|c|c|c|}
\hline & $\mathrm{F}$ & Exact Sig. \\
\hline \multicolumn{3}{|l|}{ Mutual } \\
\hline Apologies & 1 & $.39, \mathrm{df}=2,19$ \\
\hline Compliments & 0 & 0 \\
\hline Thank you & .49 & .62 \\
\hline Consequences & 0 & 0 \\
\hline \multicolumn{3}{|l|}{ High } \\
\hline Apologies & 0 & 0 \\
\hline Compliments & .74 & $.48, \mathrm{df}=2,40$ \\
\hline Thank you & 1 & $.39, \mathrm{df}=2,19$ \\
\hline Consequences & 2.11 & $.162, \mathrm{df}=1,20$ \\
\hline \multicolumn{3}{|l|}{ Low } \\
\hline Apologies & 0 & 0 \\
\hline Compliments & 1 & $.33, \mathrm{df}=1,20$ \\
\hline Thank you & 1 & $.39, \mathrm{df}=2,19$ \\
\hline Consequences & 0 & 0 \\
\hline
\end{tabular}

Notes.

1. F stats if it meets the homogeneity of variances (Levene tests), otherwise used the robust tests of equality means test values from Brown-Forsythe(B-F)

2. Statistical significance: $* * \mathrm{p}<.01, * \mathrm{p}<.05$ ( 2 tailed).

3. $(\mathrm{x})=$ equality not assumed. 
iv cross-group comparisons of types of external modifiers not acquired by SALs in prerequests

In order to investigate whether SALs developed the ability to use post-request external modifiers similar to those ENGs used, ANOVA tests were conducted between ENGs and SALs in $T_{1}$ and $T_{3}$ irrespective of the interlocutor's status. As can be seen from Table 6.27, the ENGs used a significantly higher number of consequences than the SALs in $\mathrm{T}_{1}(F(1,48)=$ $10.70, \mathrm{p}<.01)$.

Table 6.27: ANOVA tests for cross-group comparisons of the number of post-request external modifiers used by ENGs and SALs

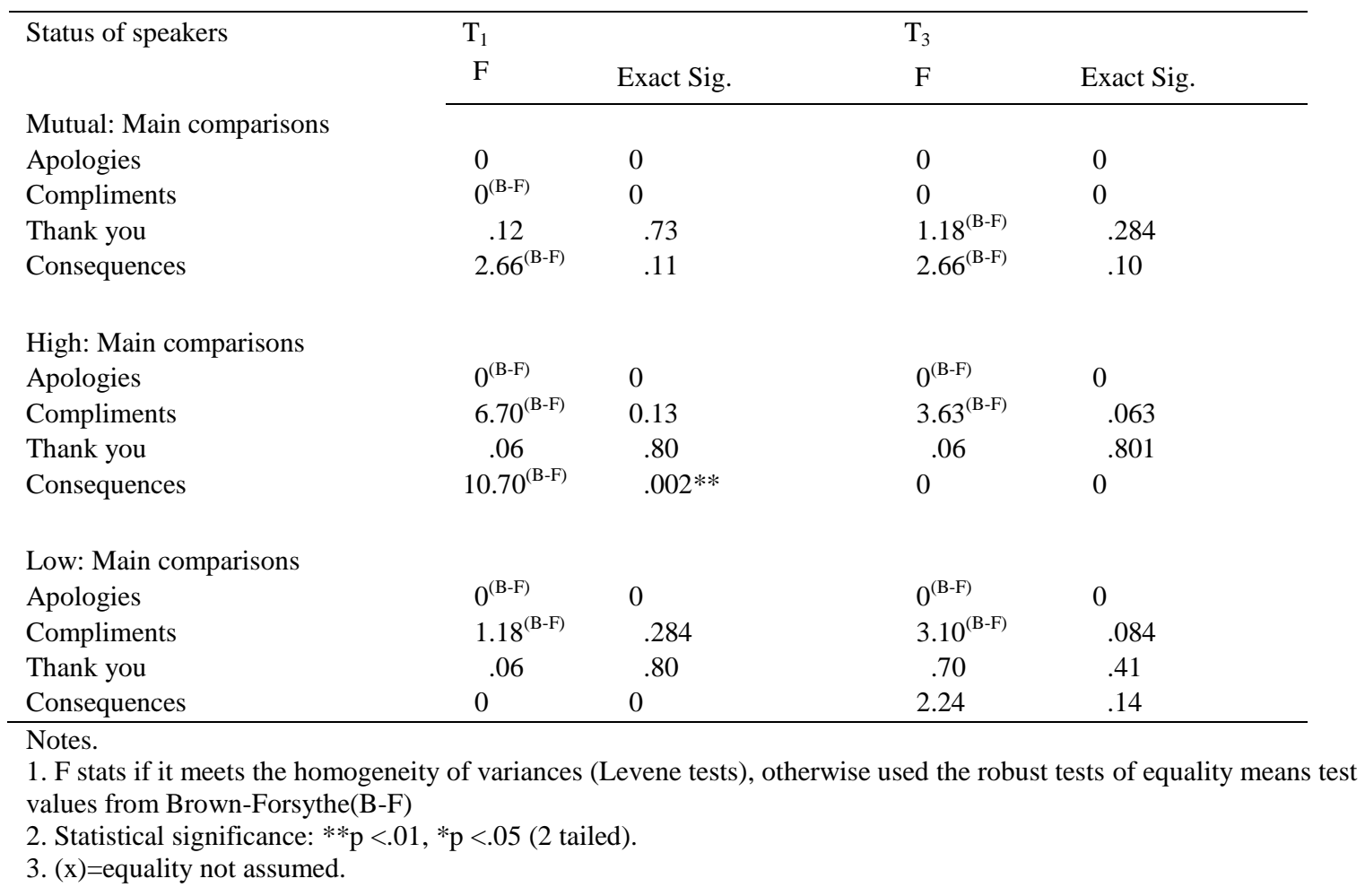

\subsubsection{Types of external modifiers acquired by SALs}

\section{i. Within-group of the types of external modifiers acquired by SALs in pre-requests}

As can be seen from Tables 6.28-6.30, the ENGs and SALs used devices such as addressing the interlocutor, making pre-warnings and stating grounders. More importantly, there were notable differences in the number of these devices used by SALs between $T_{1}, T_{2}$ and $T_{3}$. 
Table 6.28: Descriptive statistics for the average number of external modifiers used by ENGs and SALs as pre-requests (speaker at mutual status than interlocutor)

\begin{tabular}{|c|c|c|c|c|c|c|c|c|}
\hline \multicolumn{9}{|l|}{ Participants } \\
\hline & \multicolumn{2}{|l|}{ NSs } & \multicolumn{6}{|l|}{ SALs } \\
\hline & & & $\mathrm{T}_{1}$ & & $\mathrm{~T}_{2}$ & & $\mathrm{~T}_{3}$ & \\
\hline & Mean & SD & Mean & SD & Mean & SD & Mean & SD \\
\hline Address & .70 & .47 & .29 & .46 & .14 & .36 & .14 & .36 \\
\hline Pre-warnings & .23 & .43 & .05 & .22 & .19 & .40 & .38 & .49 \\
\hline Grounders & 1.27 & 1.12 & .48 & .51 & .62 & .49 & .48 & .51 \\
\hline
\end{tabular}

Table 6.29: Descriptive statistics for the average number of external modifiers used by ENGs and SALs as pre-requests (speaker at higher status than interlocutor)

\begin{tabular}{|c|c|c|c|c|c|c|c|c|}
\hline \multicolumn{9}{|l|}{ Participants } \\
\hline & \multicolumn{2}{|l|}{ NSs } & \multicolumn{6}{|l|}{ SALs } \\
\hline & & & $\mathrm{T}_{1}$ & & $\mathrm{~T}_{2}$ & & $\mathrm{~T}_{3}$ & \\
\hline & Mean & SD & Mean & SD & Mean & SD & Mean & SD \\
\hline Address & .77 & .43 & .24 & .44 & .19 & .40 & .38 & .50 \\
\hline Pre-warnings & .87 & .35 & .10 & .30 & .29 & .46 & .38 & .49 \\
\hline Grounders & .40 & .50 & .76 & .22 & .57 & .65 & .48 & .55 \\
\hline
\end{tabular}

Table 6.30: Descriptive statistics for the average number of external modifiers used by ENGs and SALs as pre-requests (speaker at lower status than interlocutor)

\begin{tabular}{|c|c|c|c|c|c|c|c|c|}
\hline \multicolumn{9}{|l|}{ Participants } \\
\hline & \multicolumn{2}{|l|}{ NSs } & \multicolumn{6}{|l|}{ SALs } \\
\hline & & & $\mathrm{T}_{1}$ & & $\mathrm{~T}_{2}$ & & $\mathrm{~T}_{3}$ & \\
\hline & Mean & $\mathrm{SD}$ & Mean & $\mathrm{SD}$ & Mean & $\mathrm{SD}$ & Mean & SD \\
\hline Address & .77 & .43 & .57 & .51 & .76 & .44 & .52 & .51 \\
\hline Pre-warnings & .87 & .35 & .05 & .22 & .38 & .50 & .57 & .51 \\
\hline Grounders & .40 & .50 & .62 & .49 & .71 & .46 & .43 & .51 \\
\hline
\end{tabular}

Though there was a slight increase in the mean number of times SALs addressed interlocutors, repeated measures analyses indicated the increase from $T_{1}, T_{2}$ and $T_{3}$ was not statistically significant regardless of the interlocutor's status (see Table 6.30).

As can be seen from Tables 6.28-6.30, the SALs used a similar number of grounders in $T_{1}, T_{2}$ and $\mathrm{T}_{3}$ when they had the same status as their interlocutor. However, the number of grounders decreased as the SALs stayed longer in Australia when the learners were of higher or lower status than the interlocutor. Repeated measures analyses in Table 28 shows the decrease in the number of grounders SALs used across time was statistically significant when they had higher and lower status than the interlocutor, $F(2,40)=6.25, p<.05$ and $F(2,40)=4.75, p<.05$ respectively. Post-hoc analyses revealed the decrease between $T_{1}$ and $T_{3}$ as well as $T_{2}$ and $T_{3}$ at $\mathrm{p}<.05$ were statistically significant when learners had higher status than the interlocutor. However, when the SALs had lower status than their interlocutor, post-hoc analyses revealed 
the SALs used significantly more grounders between $T_{1}$ and $T_{2}$ as well as between $T_{2}$ and $T_{3}$ at $\mathrm{p}<.05$.

The results revealed the most notable development of SALs' pragmatic competence was the increase in the number of pre-warnings these learners used in $\mathrm{T}_{1}, \mathrm{~T}_{2}$ and $\mathrm{T}_{3}$ across all three status differentiated interactions (See Tables 6.28-6.30). The biggest increases from $T_{1}$ to $T_{3}$ occurred when learners had mutual and lower status than the interlocutor. The repeated measures analyses presented in Table 6.31 revealed there was statistical significance between the number of pre-warnings SALs used across time when they had mutual, higher and lower status than the interlocutor $(F(2,19)=6.28, p<.01 ; F(2,40)=5.71, p<.01 ; F(2,40)=13.48$, $p<.001$ respectively). Posthoc analyses revealed the overall increase of pre-warnings SALs used between $T_{1}$ and $T_{3}$ was significantly different regardless of the interlocutor's status.

Table 6.31: Repeated measures for comparisons of request external modifiers used by SALs in $T_{1}, T_{2}$ and $T_{3}$

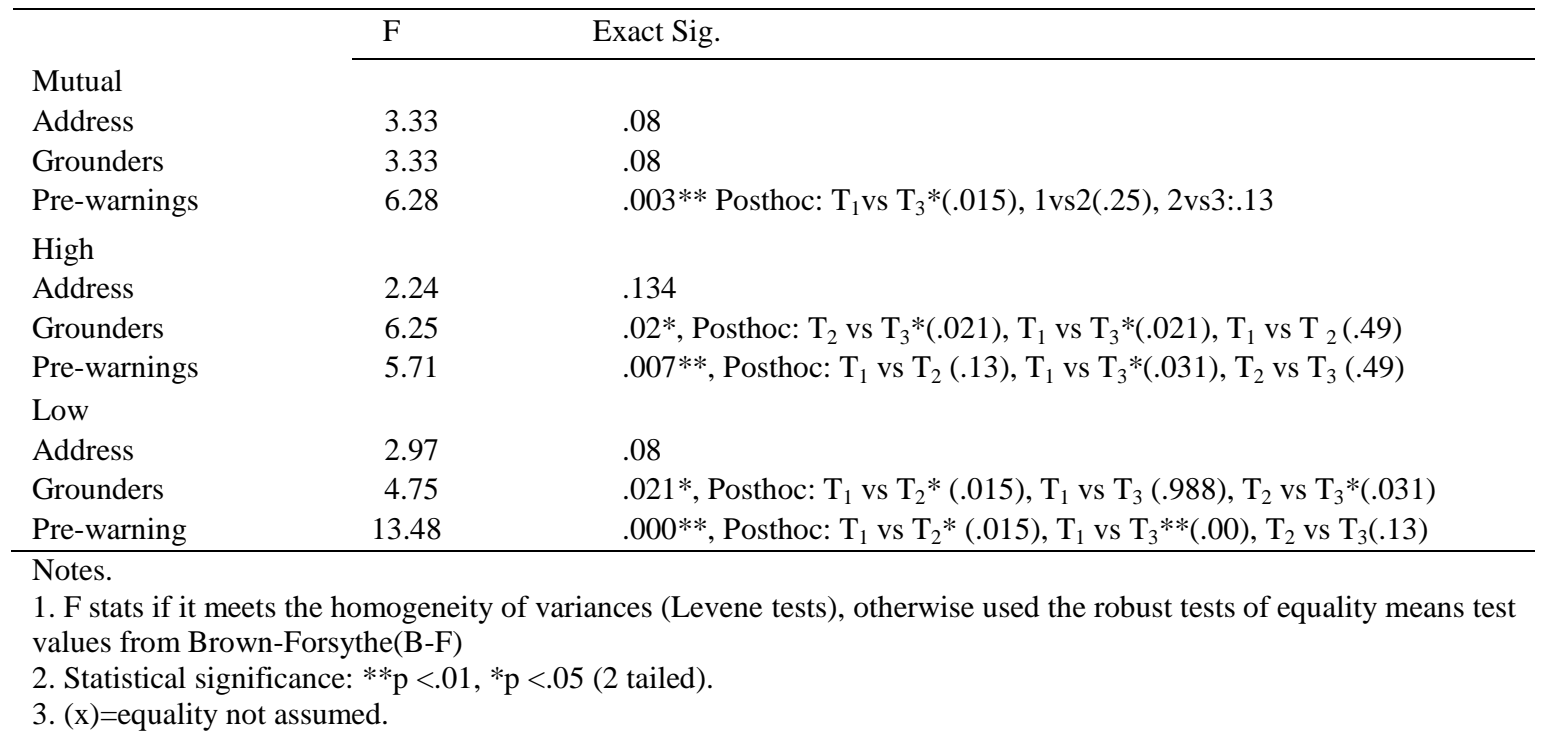

As can be seen from the distribution of pre-warning devices used by SALs presented in Table 6.32, a majority of the SALs who used pre-warnings tended to use disarmers and preparators, and precommitments. In fact, in situations where the SALs were of a higher and lower status than the interlocutor, a small percentage used two warnings prior to launching their request. This is illustrated by a SAL student, Masaya in $\mathrm{T}_{3}$, in Examples 27-28. 
Table 6.32: Distribution of pre-warning devices used by SALs (n=21) (\%)

\begin{tabular}{|c|c|c|c|c|c|c|c|c|c|}
\hline \multirow[b]{3}{*}{ Pre-warning devices } & \multicolumn{9}{|c|}{ articipant's status } \\
\hline & \multicolumn{3}{|l|}{ Mutual } & \multicolumn{3}{|l|}{ High } & \multicolumn{3}{|l|}{ Low } \\
\hline & $\mathrm{T}_{1}$ & $\mathrm{~T}_{2}$ & $\mathrm{~T}_{3}$ & $\mathrm{~T}_{1}$ & $\mathrm{~T}_{2}$ & $\mathrm{~T}_{3}$ & $\mathrm{~T}_{1}$ & $\mathrm{~T}_{2}$ & $\mathrm{~T}_{3}$ \\
\hline No & $20(95)$ & $17(81)$ & $20(95)$ & $15(71)$ & $12(57)$ & $11(52)$ & $20(95)$ & $13(62)$ & $14(67)$ \\
\hline Precommitment & & & & $1 \quad(5)$ & $1 \quad(5)$ & & & $2(10)$ & \\
\hline Preparator & & & & & $1(5)$ & 4 (19) & & $5 \quad(23)$ & $5 \quad(23)$ \\
\hline Disarmer & $1 \quad(5)$ & $4 \quad(19)$ & $1(5)$ & $3(14)$ & $5 \quad(23)$ & 4 (19) & $1 \quad(5)$ & & $1 \quad(5)$ \\
\hline 2 devices & & & & $2(10)$ & $2(10)$ & $2(10)$ & & $1 \quad(5)$ & $1 \quad(5)$ \\
\hline
\end{tabular}

As can be seen, in Example 27, Masaya used several pre-request devices such as warnings:

'I know the due (.) of the essay is: coming' and preparator 'I have no (.) arr:: (.) I have not finish my (.) essay (.) but I think (.) arr (.) because I have (.) I got many (.) problems about:: (.) arr::: (.) about::: (.) the essay writing because you know (.) arr (.) English is (.) my second language (.)...' before launching a request 'could you:: (.) give me a (.) extension...'

Example 27 (Masaya, $\mathrm{T}_{3}$, lower status)

mr james sir (.) uhm (.) I::: (.) have (.) arr::: (.) I know the due (.) of the essay is: coming (.) but (.) I have no (.) arr:: (.) I have not finish my (.) essay (.) but I think (.) $\operatorname{arr}$ (.) because I have (.) I got many (.) problems about:: (.) arr::: (.) about::: (.) the essay writing (.) because you know (.) arr (.) English is (.) my second language (.) so arr::: (.) could you:: (.) give me a (.) extension (.) so (.) I- I think I can:: (.) arr:: (.) do mu- (.) I can do my:: essay better

Similarly, in Example 28, before launching a request Masaya used a range of pre-warnings such as preparator 'how's your paper (.) have you finished it' and disarmer with grounders 'I know that (.) time will be tight if I request you to: (.) hand it in (.) arr (.) next week (.) because (.) arr (.) two weeks before (.) the scheduled time (.) because I know that mid-term (.) exam is coming (.) so::' before launching the request 'it would be nice (.) for you (.) if you hand it in (.) next week'. 
Example 28 (Masaya, $\mathrm{T}_{3}$, higher status)

hey (.) how's your paper (.) have you finished it (.) yet (.) uhm: (.) I know that (.) time will be tight if I request you to: (.) hand it in (.) arr (.) next week (.) because (.) arr (.) two weeks before (.) the scheduled time (.) because I know that midterm (.) exam is coming (.) so:: (.) it would be nice (.) for you (.) if you hand it in (.) next week (.) as I:: really wish (.) you can (.) teach (.) the others how to (.) write a good (.) essay (.) and I know that (.) you (.) are (.) pretty good (.) at (.) writing essay (.) so (.) it would be nice if you can (.) arr (.) lend a hand to me

Example 29 illustrates learners by $\mathrm{T}_{3}$ have also acquired the use of disarmers 'I know::: (.) uhm::: (.) you've been very busy lately' and appreciators 'I really (.) appreciate if you could do me a favour' before launching a request 'could you please give me arr:: (.) can you please (.) give (.) give your presentation (.) one week earlier (.) than the schedule'.

Example 29 (Prudence, $\mathrm{T}_{3}$, higher status)

uhm::: (.) I know::: (.) uhm::: (.) you've been very busy lately (.) but (.) arr:: (.) I really (.) appreciate if you could do me a favour (.) arr::: (.) could you please give me arr:: (.) can you please (.) give (.) give your presentation (.) one week earlier (.) than the schedule (.) coz (.) uhm::: (.) arr:: I know you can do it

Another SAL student, Ronald, was one of the very few SALs who used precommitment such as 'I just want to ask you to do me a favour' and a preparator 'I am not free for my class...' before launching a request 'I hope you can...teaching my students how to write an essay for just around a lesson'.

\section{ii. Cross-group comparisons of types of external modifiers acquired by SALs in pre- requests}

As can be seen from Table 6.33, there was no significant difference between the number of pre-request external modifiers used by ENGs and SALs irrespective of the interlocutor's status. 
Table 6.33: ANOVA tests for cross-group comparisons of the number of pre-request external modifiers used by SALs and ENGs

\begin{tabular}{|c|c|c|c|c|}
\hline \multirow[t]{2}{*}{ Status of speakers } & \multirow{2}{*}{$\begin{array}{r}\mathrm{T}_{1} \\
\mathrm{~F}\end{array}$} & \multicolumn{3}{|c|}{$\mathrm{T}_{3}$} \\
\hline & & Exact Sig. & $\mathrm{F}$ & Exact Sig. \\
\hline \multicolumn{5}{|c|}{ Mutual: Main comparisons } \\
\hline Address & 31.67 & $.000, \mathrm{df}=1,49$ & 1.05 & $.311, \mathrm{df}=1,49$ \\
\hline Pre-warnings & 4.09 & $.049, \mathrm{df}=1,45$ & .723 & $.40, \mathrm{df}=1,49$ \\
\hline Grounders & 8.12 & $.006, \mathrm{df}=1,49$ & 1.02 & $.32, \mathrm{df}=1,49$ \\
\hline \multicolumn{5}{|c|}{ High: Main comparisons } \\
\hline Address & 43.03 & $.000, \mathrm{df}=1,49$ & 23.35 & $.000, \mathrm{df}=1,49$ \\
\hline Pre-warnings & 18.84 & $.000, \mathrm{df}=1,49$ & 9.27 & $.005, \mathrm{df}=1,32$ \\
\hline Grounders & 7.7.38 & $.009, \mathrm{df}=1,49$ & 5.35 & $.025, \mathrm{df}=1,46$ \\
\hline \multicolumn{5}{|c|}{ Low: Main comparisons } \\
\hline Address & 1.213 & $.28, \mathrm{df}=1,39$ & .74 & $.394, \mathrm{df}=1,49$ \\
\hline Pre-warnings & 61.29 & $.000, \mathrm{df}=1,45$ & .97 & $.33, \mathrm{df}=1,49$ \\
\hline Grounders & 3.93 & $.053, \mathrm{df}=1,49$ & 2.86 & $.10, \mathrm{df}=1,49$ \\
\hline
\end{tabular}

\section{iii. Within-group comparison of the types of external modifiers used by SALs in post- requests}

As can be seen from Tables 6.33-6.35, both ENGs and SALs tended to use post-request external modifiers such as making promises, repeating the request and stating grounders. Interestingly, the ENGs tended to use more such devices when their status was higher and lower than the interlocutors than when they had mutual status interlocutors, particularly when making promises and grounders. Some interesting changes can be observed in the way SALs used grounders, repeating the requests and making promises between $T_{1}, T_{2}$ and $T_{3}$ regardless of the interlocutor's status.

As can be seen from Tables 6.34-6.36, the mean number of request repetitions that the SALs used was higher than the ENGs irrespective of the interlocutor's status across all rounds. The SALs tended to repeat requests when their status was higher and lower than their interlocutor compared to when they were of mutual status. Interestingly, however, the number of request repetitions these learners used decreased from $T_{1}$ to $T_{2}$ and $T_{3}$, especially when their status was higher and lower than their interlocutor. The repeated measures analyses in Tables 6.346.36 revealed the decrease in mean number of request repetition in $T_{1}, T_{2}$ and $T_{3}$ was statistically significant when their status was higher and lower than their interlocutor $(F(2,40)$ $=49.44, \mathrm{p}<.01 ; F(2,40)=59.15, \mathrm{p}<.01$ respectively $)$. Posthoc analyses revealed the decrease from $T_{1}$ to $T_{2}, T_{1}$ to $T_{3}$ and even $T_{2}$ to $T_{3}$ was significant $(\mathrm{p}<.01)$. 
Table 6.34: Descriptive statistics for the average number of external modifiers used by ENGs and SALs as post-requests (speaker of mutual status as the interlocutor)

\begin{tabular}{|c|c|c|c|c|c|c|c|c|}
\hline \multicolumn{9}{|l|}{ Participants } \\
\hline & \multicolumn{2}{|l|}{ NSs } & \multicolumn{6}{|l|}{ SALs } \\
\hline & & & $\mathrm{T}_{1}$ & & $\mathrm{~T}_{2}$ & & $\mathrm{~T}_{3}$ & \\
\hline & Mean & SD & Mean & SD & Mean & SD & Mean & SD \\
\hline Promise & 0 & 0 & 0 & 0 & 0 & 0 & 0 & 0 \\
\hline Repeat & 1.23 & .57 & 1 & .32 & .10 & .44 & 1.10 & .44 \\
\hline Grounders & 1 & 1.08 & .76 & .77 & .69 & .40 & 1.05 & .87 \\
\hline
\end{tabular}

Table 6.35: Descriptive statistics for the average number of external modifiers used by ENGs and SALs as post-requests (speaker at higher status than interlocutor)

\begin{tabular}{|c|c|c|c|c|c|c|c|c|}
\hline \multicolumn{9}{|l|}{ Participants } \\
\hline & \multicolumn{2}{|l|}{ NSs } & \multicolumn{6}{|l|}{ SALs } \\
\hline & & & $\mathrm{T}_{1}$ & & $\mathrm{~T}_{2}$ & & $\mathrm{~T}_{3}$ & \\
\hline & Mean & SD & Mean & $\mathrm{SD}$ & Mean & SD & Mean & SD \\
\hline Promise & .07 & .25 & 0 & 0 & 0 & 0 & .05 & .22 \\
\hline Repeat & 1.87 & .86 & 1.43 & .68 & .90 & .44 & 1 & 0 \\
\hline Grounders & .77 & .68 & .33 & .66 & .19 & .40 & .24 & .54 \\
\hline
\end{tabular}

Table 6.36: Descriptive statistics for the average number of external modifiers used by ENGs and SALs as post-requests (speaker at lower status than interlocutor)

\begin{tabular}{|c|c|c|c|c|c|c|c|c|}
\hline \multicolumn{9}{|l|}{ Participants } \\
\hline & NSs & & SALs & & & & & \\
\hline & Mean & SD & $\begin{array}{l}\mathrm{T}_{1} \\
\text { Mean }\end{array}$ & SD & $\begin{array}{l}\mathrm{T}_{2} \\
\text { Mean }\end{array}$ & SD & $\begin{array}{l}\mathrm{T}_{3} \\
\text { Mean }\end{array}$ & SD \\
\hline Promise & .60 & .22 & .05 & .51 & 0 & 0 & .57 & .50 \\
\hline Repeat & 1.69 & .71 & 1.67 & .58 & .14 & .48 & .95 & .22 \\
\hline Grounders & .97 & .93 & .24 & .44 & .48 & .68 & .62 & .67 \\
\hline
\end{tabular}

As can be seen from Table 6.37, the SALs continued to use a similar number of grounders from $T_{1}$ to $T_{3}$. With the exception of the increase in the number of grounders used by SALs from $T_{1}$ to $T_{3}$ with mutual status interlocutors, they used fewer grounders in $T_{3}$ than in $T_{1}$ when their status was higher and lower than their interlocutor.

Furthermore, the SALs generally made more promises after launching requests when their status was lower than their interlocutor than when their status was mutual and higher than the interlocutor. Repeated measures revealed the increase in the number of promises these learners used increased significantly from $T_{1}$ to $T_{3}$ when they had lower status than the interlocutor, $F(1,20)=12.67, p<.01$. Post-hoc analyses revealed the increase from $\mathrm{T}_{2}$ and $\mathrm{T}_{3}$ was statistically significantly greater than $\mathrm{T}_{1}(\mathrm{p}<.01)$. 
Table 6.37: Repeated measures for comparisons of post-request used by SALs in $\mathbf{T}_{1}, \mathbf{T}_{2}$ and $\mathbf{T}_{3}$

\begin{tabular}{|c|c|c|}
\hline & F & Exact Sig. \\
\hline \multicolumn{3}{|l|}{ Mutual } \\
\hline Promise & 0 & 0 \\
\hline Repeat & 2.24 & $.12, \mathrm{df}=2,40$ \\
\hline Grounders & .79 & $.463, \mathrm{df}=2,40$ \\
\hline \multicolumn{3}{|l|}{ High } \\
\hline Promise & 0 & 0 \\
\hline Repeat & 49.44 & $.000, \mathrm{df}=2,40$. Posthoc: $\mathrm{T}_{1}$ vs $\mathrm{T}_{2} * *(.000), \mathrm{T}_{1}$ vs $\mathrm{T}_{3} * *(.009), \mathrm{T}_{2}$ vs $\mathrm{T}_{3} * *(.000)$ \\
\hline Grounders & .526 & $.595, \mathrm{df}=2,40$ \\
\hline \multicolumn{3}{|l|}{ Low } \\
\hline Promise & 12.67 & $.00^{* *}, \mathrm{df}=2,19$. Posthoc: $\mathrm{T}_{1}$ vs $\mathrm{T}_{2} * *(.000), \mathrm{T}_{1}$ vs $\mathrm{T}_{3} * *(.000), \mathrm{T}_{2}$ vs $\mathrm{T}_{3}(.329)$ \\
\hline Repeat & 59.15 & $.000, \mathrm{df}=2,40$. Posthoc: $\mathrm{T}_{1}$ vs $\mathrm{T}_{2} * *(.000), \mathrm{T}_{1}$ vs $\mathrm{T}_{3} * *(.000), \mathrm{T}_{2}$ vs $\mathrm{T}_{3} * *(.000)$ \\
\hline Grounders & 2.98 & .06 \\
\hline
\end{tabular}

\section{Notes:}

1. F stats if it meets the homogeneity of variances (Levene tests), otherwise used the robust tests of equality means test values from Brown-Forsythe)

2. Statistical significance: $* * p<.01, * p<.05$ (2 tailed).

\section{iv. Cross-group comparisons of types of external modifiers acquired by SALs in pre- requests}

The ANOVA analyses presented in Table 6.38 revealed that in $T_{1}$ the ENGs used a significantly higher number of request repetition $(F(1,49)=3.80, p<.05)$ and grounders $(F(1,49)=5.16, p<.05)$ than the SALs when the participants had a higher status than their interlocutor. Furthermore, in the situation where the participants were of lower status than the interlocutor, the ENGs made more promises than the SALs in $\mathrm{T}_{1}(F(1,42)=28.94, p<.01)$. By T3, the SALs had used significantly fewer request repetitions and grounders than the ENGs when they had lower status than the interlocutor $(F(1,49)=27.5, p<.01 ; F(1,49=$ $11.17, p<.01$ respectively). 
Table 6.38: ANOVA tests for cross-group comparisons of the number of post-request external modifiers used by SALs and ENGs

\begin{tabular}{|c|c|c|c|c|}
\hline Status of speakers & $\begin{array}{l}\mathrm{T}_{1} \\
\mathrm{~F}\end{array}$ & Exact Sig. & $\begin{array}{r}\mathrm{T}_{3} \\
\mathrm{~F}\end{array}$ & Exact Sig. \\
\hline \multicolumn{5}{|c|}{ Mutual: Main comparisons } \\
\hline Promise & 0 & 0 & 0 & 0 \\
\hline Repeat & .001 & $.97, \mathrm{df}=1,49$ & .88 & $.354, \mathrm{df}=1,49$ \\
\hline Grounders & .11 & $.75, \mathrm{df}=1,49$ & .028 & $.868, \mathrm{df}=1,49$ \\
\hline \multicolumn{5}{|c|}{ High: Main comparisons } \\
\hline Promise & 1.44 & $.236, \mathrm{df}=1,49$ & .02 & $.87, \mathrm{df}=1,49$ \\
\hline Repeat & 3.80 & $.05^{*}, \mathrm{df}=1,49$ & 4.56 & $.04, \mathrm{df}=1,49$ \\
\hline Grounders & 5.16 & $.028^{*}, \mathrm{df}=1,49$ & 6.80 & $.033, \mathrm{df}=1,49$ \\
\hline \multicolumn{5}{|c|}{ Low: Main comparisons } \\
\hline Promise & $28.94_{(\mathrm{B}-\mathrm{F})}$ & $.000 * *, \mathrm{df}=1,35 * *$ & 0 & 0 \\
\hline Repeat & .02 & $.90, \mathrm{df}=1,49$ & $27.5_{(\mathrm{B}-\mathrm{F})}$ & $.000^{* *}, \mathrm{df}=1,49$ \\
\hline Grounders & 2.16 & $.15, \mathrm{df}=1,49$ & 11.17 & $.002 * *, \mathrm{df}=1,49$ \\
\hline $\begin{array}{l}\text { Notes. } \\
\text { 1. F stats if it meets } \\
\text { values from Brown } \\
\text { 2. Statistical signifi } \\
\text { 3. }(x)=\text { equality not }\end{array}$ & $\begin{array}{l}\text { ity of varia } \\
1, * \mathrm{p}<.05\end{array}$ & $\begin{array}{l}\text { (Levene tests), othe } \\
\text { iled). }\end{array}$ & ed the ro & ests of equality mear \\
\hline
\end{tabular}

\subsubsection{Discussion of modifiers}

This section has presented results of types of request external modifiers that were used by ENGs but were and were not acquired by SALs by the end of the nine-month stay abroad. The following discussion compares the use of the types of pre- and post-requests by ENGs and SALs, and offers explanations for these differences.

The results presented above showed that overall the ENGs used more and a wider range of external modifiers as pre- and post-requests than both AHLs and SALs across all rounds and in situations irrespective of the interlocutor's status. As expected, the AHLs continued to use very few request external modifiers between T1 and T2. However, SALs used overall more request external modifiers as pre- and post- reqgreuests in T3 than in T1. The data also suggest that although this group of SALs did not acquire all the pre- and post-request external modifiers measured, there is evidence to show they learned to use a number of pre- and postexternal modifiers including 'please' in their first nine months in Australia.

\subsubsection{Devices not commonly used by ENGs, AHLs and SALs}

Some of the external devices such as apologies, thank you and minimal impositions have been reported in the literature as being used by ENGs (e.g., Economidou-Kogetsidis \& Woodfield 2008; 2010). However, these devices were not commonly used amongst the ENGs 
and the learners in this study. It is possible that the learners may not have associated these devices as strategies to minimise the impositions of requests.

\subsubsection{Devices commonly used by ENGs, AHLs and SALs}

Grounders are frequently employed by ENGs, AHLs and SALs to justify their requests. The results from this study support previous findings that perhaps grounders are acquired early in learners' interlanguage (e.g., Færch \& Kasper 1989; Hassall 2001, 2006). The results in this study illustrate that AHLs and SALs learned this device prior to $\mathrm{T}_{1}$. As pointed out by numerous researchers (e.g., Færch \& Kasper 1989; Hassall 2001, 2006), grounders are a common feature which learners, even at a lower proficiency level, are able to use to justify and mitigate the imposition of their request. The learners in this study did in fact employ grounders most frequently before and after their direct and conventional indirect requests to justify their requests. Nonetheless, it is surprising the ENGs used more grounders than the SALs with mutual-status interlocutors in $T_{1}, T_{2}$ and $T_{3}$ as literature has reported the learners tended to over-use grounders due to their low linguistic proficiency and limited range of request external modifiers (Hassall 2001).

Hassall (2001) claimed that the lower proficiency learners tended to over-use grounders to explain and justify to the hearer that they are not imposing on him or her without a good reason, thus achieving negative politeness. The results revealed a greater number of SALs used grounders than the ENGs in $T_{1}, T_{2}$ and $T_{3}$ when their status was higher and lower than their interlocutor. This may be because ENGs have a wider range of request external modifiers and are less reliant on using grounders to minimise the imposition of their requests. Further support comes from the result that the SALs used fewer grounders in $T_{3}$ than in $T_{1}$. It is plausible that as the SALs spent more time in Australia, they used fewer grounders as they acquired other request external modifiers to justify their requests.

\subsubsection{Devices used by ENGs, but not yet acquired by AHLs and SALs}

Overall, there was very little change in the types of request external modifiers used by AHLs. This is not surprising as there were no changes in the environment of their learning at home. Interestingly though, there was a slight increase in the number of SALs who used prerequests. Some of the pre-request devices frequently used by this group of ENGs, but not acquired by SALs include cajolers, compliments, self-introductions and alerts. One plausible explanation is that learners did not have exposure to these devices as they had limited contact 
with ENGs, or that these features were not 'noticed' by the learners. A more likely possibility is cajolers, self-introductions, alerts and compliments are features of 'small talk' which native English speakers commonly use in conversations, and as indicated in this study used as part of request external devices. However, even if the SALs heard these devices, they may not realise they are used to minimise the imposition of a request and to express politeness in English. Thus, they did not make use of them in this context.

\subsection{Cajolers}

One of the most interesting features of pre-request devices in Australian English is the use of cajolers such as 'you know' and 'you see'. Although the use of cajolers by ENGs was not as high as some of the other pre-request devices they used in this study, it was still higher than both groups of learners. In addition, more ENGs used cajolers when they had higher status than their interlocutor compared to when their interlocutor's status was mutal or lower. No SALs used cajolers at all even by $\mathrm{T}_{3}$.

\subsection{Compliments}

Although very few compliments were used, all ENGs who used this device complimented their listener's ability and appearance when their status was lower than the interlocutor, and few used compliments when their status was higher than the interlocutor in both pre- and post- requests. The few learners who used compliments used them to comment on their listener's ability mostly in the high-status situations. Few learners used compliments when their status was lower than the interlocutor. No speakers used compliments in a mutual-status situation.

\subsection{Self-introductions}

Similarly, the usage of self-introductions was low amongst ENGs, AHLs and SALs, but about half of the ENGs introduced themselves in the mutual situations with ' $\mathrm{I}$ am/I am from/I live' and used two phrases such as 'I am...I' after they greet and/or address the listener.

\subsection{Alerts by name}

ENGs had the highest number for alerting speakers about a forthcoming request or a turn to talk by addressing people by name in situations regardless of the interlocutor's status. The AHLs most frequently alerted speakers by using their name in situations where they had 
lower status than their interlocutor. The mean number of alerts used by AHLs increased in the mutual and high status interactions. However, there appeared to be no change in how the SALs used them. The SALs who used alerts by names increased when they had lower status than the interlocutor and remained low in both the mutual status situations, but increased slightly when they had higher status than their interlocutor from $T_{1}$ to $T_{3}$. A very low number of SALs used address terms in mutual and high statuses in all three rounds. In the low status situations, speakers either used title or title and surname, but the number of learners who used title and surname together decreased from $T_{1}$ to $T_{3}$. Only a very low number used first name.

\subsection{Alerts by using 'excuse me'}

The mean number of ENGs using 'excuse me' was quite low across regardless of the interlocutor's status, but highest in mutual status interaction, compared to when their status were higher and lower than their interlocutor. Interestingly, the mean number of 'excuse me' used by AHLs and SALs decreased in mutual status interlocutor interaction, but increased when their status was higher than the interlocutor; it decreased again when their status was lower than their interlocutor.

\subsubsection{Devices acquired by SALs}

SALs increased usage of a number of devices including greetings and pre-warnings (precommitments, preparators and disarmers) before launching the request, and post-request devices such as making promises, consequences and repetition of the request. Thus, this supports the claim that learners do, in fact, gain pragmatic devices in a study abroad context, but at different rates.

\subsection{Greetings}

Greetings were used by approximately half of the ENGs. For example, in Australian English, speakers frequently begin a conversation by greeting their interlocutor with 'hi Rose' followed by asking their interlocutor how s/he is. In the example below the speaker asked 'how's everything going with ar with that presentation'. This functions not just as a greeting; it is also a preparatory device that warns the interlocutor of a forthcoming request (See Example 29).

Not surprisingly, there was no change in the AHLs. However, even though fewer SALs used greetings than ENGs, more SALs used greetings in $\mathrm{T}_{3}$ irrespective of their status. Greeting is 
not necessary in Chinese, but was used by some SALs in $\mathrm{T}_{3}$. However, only one SAL who had a lot of exposure asked how their interlocutor was using 'how are you?' which is a common greeting device used by ENGs. The others only said 'hello'.

Example 29, Obie ENGs (high status)

hi rose (.) how's everything going with (.) ar with that (.) presentation that I asked you for (.) uhm (.) I asked you for it about three (.) in about three weeks wasn't it (.) Yeah (.) uhm (.) well (.) it's just that (.) I'll be handing out the topics for the major essay next week as well (.) so I was kinda hoping (.) you know (.) ar that you'd be ready to maybe present it as well next week (.) I (.) I realize this this is kinda short notice (.) ar and you are really busy but (.) you know I mean (.) I've seen that you're a really capable student and if (.) if it'd be at all possible (.) that you can do this for me (.) that'll be (.) that'll be really great (.) and I'm sure (.) I'm sure the students would appreciate this to no end

While Chinese speakers do not normally use greetings, they also would not start a conversation or a request with 'excuse me'. They normally just launch a request straight away without any pre-request, or they would use pre-request devices such as apologies as an attention-seeking device to indicate to their listener that they are about to speak or a grounder to justify their request. For example, Tiffany still apologised at the beginning in one example by $\mathrm{T}_{3}$ (see Example 30), but in another example she greeted her interlocutor with 'Hi neighbour' before the request. Perhaps it is only learners who had more exposure to English that began to use additional features that are not necessarily the core features of a request (see Example 31). Tiffany, who reported frequent interaction with her host family, was a learner who used greetings prior to launching a request in $\mathrm{T}_{3}$.

Example 30, Tiffany $\mathrm{T}_{3}$ (mutual status)

uhm (.) sorry for:: (.) interrupt you (.) listen to your music (.) but (.) uhm (.) can you please (.) put it (.) down (.) a little bit because (.) I (.) people are (.) now (.) need to be in bed:: (.) and (.) you still dis(.)turbing them to be (.) uhm (.) having a test (.) tomorrow (.) so (.) please (.) turn the volume down (.) thanks 
Example 31, Tiffany $\mathrm{T}_{3}$ (mutual status)

hmm (.) hi neighbour (.) uhm (.) uhm (.) I:: think (.) ar (.) can you help ar (.) please (.) do this favour (.) because (.) I am in a hurry (.) because I am late (.) for (.) meeting somebody (.) so would you mind to (.) drop me off

Only one learner used a greeting feature which is uncommon for Chinese speakers. A learner, Sharon, was excluded from the main statistical analyses because she was in Australia for two years prior to the commencement of this study. However, she presents an interesting case because she had a homestay family whom she got on very well with. The family spent a lot of time with her, and Sharon had only native Australian English speaking friends during those two years. By the time I met Sharon, she was very confident in speaking English, though she was fully aware her speech had many grammatical errors. Sharon's requests displayed similar features to those of ENGs. For example, the greeting with 'hey Michelle (.) how are you doing?' (see Example 32).

Example 32, Sharon $\mathrm{T}_{1}$ (mutual status)

Hey michelle (.) how are you doing (.) uhm (.) I got a (.) test later (.) would you mind to lend me your notes (.) please

\subsection{Warnings (precommitment, preparators and disarmers)}

A much higher number of ENGs used warnings (precommitment, preparators and disarmers) when they had higher and lower status than mutual status interlocutors. Few AHLs used warnings throughout the study. Although there was no change in the number of warnings used by SALs in mutual status interlocutor interaction, there was an overall increase of warnings when their status was higher and lower than the interlocutors (See Examples 33$35)$.

Example 33, Tiffany $\mathrm{T}_{3}$ (mutual status)

uhm:::: (.) uhm (.) excuse (.) me: (.) uhm: (.) I'm:: (.) I'm (.) studying the same subject (.) but (.) just (.) uhm (.) in a (.) lower (.) level (.) and:: (.) I would like to (.) like you to (.) uhm (.) speak with our class (.) uhm (.) because (.) next week (.) or (.) we will have (.) exam soo::n (.) so maybe (.) if you (.) if you can (.) take (.) 
a bit (.) of your spare time (.) to talk about (.) some of the relevant subject of (.) this (.) uhm (.) it would be better for us (.) thanks

Example 34, Gloria $\mathrm{T}_{3}$ (high status)

hey (.) how's your paper (.) have you finished it (.) yet (.) uhm: (.) I know that (.) time will be tight if I request you to: (.) hand it in (.) arr (.) next week (.) because (.) arr (.) two weeks before (.) the scheduled time (.) because I know that midterm (.) exam is coming (.) so:: (.) it would be nice (.) for you (.) if you hand it in (.) next week (.) as I:: really wish (.) you can (.) teach (.) the others how to (.) write a good (.) essay (.) and I know that (.) you (.) are (.) pretty good (.) at (.) writing essay (.) so (.) it would be nice if you can (.) arr (.) lend a hand to me

Example 35, Ruby $\mathrm{T}_{3}$ (low status)

hmm::: (.) I know you got the: (.) ar: exam for next week (.) but (.) uhm:::: (.) I got the problem (.) can you help me for (.) teaching (.) ar:: (.) the class (.) uhm::: (.) I think I just (.) spend::: you:: (.) a few times for that (.) and I think you got enough (.) time for (.) ar (.) for prepare for exam (.) can you help me for that

\subsection{Making promises as a post-request}

Results showed no ENGs made a promise not to have to make a similar request again after launching a request in the mutual status interaction with an interlocutor, and only a very low number made a promise where their status was higher than their interlocutor. Nonetheless, a high number of ENGs made such a promise when their status was lower than their interlocutor. AHLs rarely used these devices in any situation throughout the study. No SALs made promises with a mutual status interlocutor, and only a few made promises when their status was higher than their interlocutor. Importantly, there was a statistically significant increase in the mean number of SALs who made a promise from $T_{1}$ to $T_{3}$ when their status was lower than their interlocutor (See Examples 36-38).

Example 36, Gloria $\mathrm{T}_{3}$ (low status)

$\mathrm{mr}$ Wilson (.) arr (.) can I (.) request for (.) an extension (.) for my assignment (.) actually I have (.) uhm (.) I- I'm nearly finish (.) the assignment (.) but (.) arr::: (.) 
it will be (.) better if I can have (.) one more week's time (.) to finish it (.) and:: (.) I (.) promise that (.) I can hand (.) in (.) uhm (.) ar (.) hand it qualify (.) work to you (.) could you (.) please (.) give me an extension

Example 37, Bonnie $\mathrm{T}_{3}$ (low status)

I am sorry (.) er (.) I do not have time to finish the: final exam (.) could you give me er more time (.) I will promise you (.) er (.) give you one week later (.) er (.) er:: (.) for example one week I will give you

Example 38, Taffy $\mathrm{T}_{3}$ (low status)

hmm:: (.) can you give an extension because (.) I (.) haven't (.) had enough time to do it (.) to finish it (.) and (.) I promise I will (.) do my best (.) and (.) got (.) the (.) give the good (.) effort to you

\subsection{Consequences as a post-request}

A low number of ENGs pointed out either the positive and negative consequences of their listener not complying/complying with the request after launching it. The mean number of AHLs used consequences when their status were mutual or higher than their interlocutor; but not when their status was lower than their interlocutor. Like the ENGs and AHLs, virtually no one stated the consequences in $T_{1}$, but there was a notable increase from $T_{1}$ and $T_{3}$ in the mean of positive consequences of the requests if complied with, especially when they had higher and lower status than their interlocutor (See Examples 39-41).

Example 39, Tiffany T3 (high status)

uhm:::: (.) uhm (.) excuse (.) me: (.) uhm: (.) I'm:: (.) I'm (.) studying the same subject (.) but (.) just (.) uhm (.) in a (.) lower (.) level (.) and:: (.) I would like to (.) like you to (.) uhm (.) speak with our class (.) uhm (.) because (.) next week (.) or (.) we will have (.) exam soo::n (.) so maybe (.) if you (.) if you can (.) take (.) a bit (.) of your spare time (.) to talk about (.) some of the relevant subject of (.) this (.) uhm (.) it would be better for us (.) thanks 
Example 40, Janice $\mathrm{T}_{2}$ (low status)

uhm:::: (.) sorry professor (.) I want to do it better (.) if I err (.) just only give (.) the assignment to you (.) err (.) I need to be (.) so hurry (.) and (.) I would like to do well (.) so (.) if you want me to do well (.) you need to give me more time

Example 41, Jackie $\mathrm{T}_{3}$ (low status)

uhm::: (.) mr Wilson (.) excuse me: (.) uhm (.) I think (.) arr (.) ng hai (.) no no no (.) arr (.) yep (.) can I hand in:: my:: (.) project (.) project (.) a week later (.) arr (.) because I (.) can find my:: (.) because (.) I find (.) some information (.) ${ }^{\circ}$ is that it $^{\circ}$ (.) information for my project (.) and did (.) I did (.) did not have time to:: (.) work (.) put them up (.) and I (.) need (.) if I (.) if I can (.) have more (.) a more (.) a week more (.) uhm (.) so:: I can:: (.) do a better work

\subsection{Repetition of requests}

The ENGs frequently repeated a request after launching their request when their status was mutual and higher than their interlocutor. However, this was less when they were in low status situations. The results showed the number of SALs who repeated requests dropped from $T_{1}$ to $T_{3}$. Similar to ENGs, the SALs repeated their request in when they had lower status than their interlocutor. As can be seen from Examples 42-44, the SALs repeated their requests with direct and conventional indirect requests.

Example 42 Queenie, T3 (high status)

ar I would like you to present (.) the:: (.) article next (.) week (.) ar: (.) because your (.) I think your article is (.) related to the:: (.) my topic (.) uhm (.) and:: (.) I know (.) you have a lot of work to do (.) but (.) I really want you to (.) (laughs)present next week

Example 43 Ronald, T3 (high status)

uhm (.) hello (.) uhm:: (.) uhm::: (.) I know you are (.) just having your (.) exam in few weeks (.) but (.) would you please do me a favour (.) I got a class (.) for:: 
(.) teaching (.) and (.) I:: (.) I really need your help (.) can you just (.) spare me some time please

Example 44 Ruby, T3 (high status)

hello sir:: (.) uhm: (.) I got some problem about the:: (.) essay (.) uhm:: (.) I know::: (.) uhm (.) I shouldn't (.) ask you for the extension (.) but (.) ar::: (.) I will (.) if I got the (.) one more week extension (. ) uhm (.) I could do it (.) do it better (.) and I hope you can help me for that (.) and (.) if you:: (.) if you can give me an extension (.) I can do it (.) for the best (.) ar:: (.) can you give me an extension

It is likely that ENGs and SALs repeated requests in lower and higher status interactions than the interlocutor to emphasise the need for the listener to comply with the request. The decrease in the number of request repetitions may be because the SALs wanted to ensure their interlocutor understood the meaning of the request. Hence, as the learners gained more confidence in their communication ability, it appears that they did not think it necessary to repeat the request to ensure their listener understood their intention.

\subsection{Use of 'please'}

Previous studies have shown 'please' functions as a politeness marker (e.g., House 1989; Lee-Wong 1994a; Pedlow, Wales \& Sanson 2001). However, the data of most research were based on requests made by children rather than that found in naturally occurring interactions (e.g., House 1989; Pedlow, Wales \& Sanson 2001). In this study, data collected from roleplay was also collected as a point of comparison. However, the results from this study show 'please' has more functions than showing politeness. These are several ways in which SALs in this study have used 'please'. Unfortunately, I could not find ENGs using 'please' in the role-play data.

\section{i. Where is 'please' used?}

Previous studies found 'please' is frequently used by English learners to mitigate imposition of requests, and is mostly used as the end of the request (Lee-Wong 1994a; Martinez-Flor 2009; Pedlow, Wales \& Sanson 2001; Sato 2008). Previous research revealed 'please' falls into the group of external modification (Martinez-Flor 2009) while others argued before that it was an internal lexical or phrasal modification (Achiba 2003; House \& Kasper 1981; 
Trosborg 1995). As can be seen from the examples below, it appears that both ENGs and NNSs used 'please' in a number of places. ENGs and NNSs used 'please' inside a request, as well as at the beginning and at the end of a request (See Example 45-50).

\section{i.a Beginning of the request}

\section{Example 45, ENGs}

Uhm (.) excuse me Anita (.) my name is Jo (.) I live down the hall from you (.) uhm I've got a really early exam in the morning I need my rest (.) please would you be able to turn the television down (.) thanks

Example 46, SALs

a::: (.) please turn off your television because I have to sleep

\section{i.b End of the request}

Example 47, ENGs

hi is your name anita (light laughter) (.) yeah I think I've seen you around I'm:: really sorry to do this to you (.) but I've got this rea:lly big exam tomorrow and my tutor and lecturer they're all really strict (.) uhm (.) would you mind just turning it down a little bit please

Example 48, SALs

uhm:: (.) please give me some more time:: (.) I will () do more good in this essay

\section{i.c Inside the request}

Example 49, ENGs

Excuse me (.) I really need to sleep (.) could you please turn the music off or down 
Example 50

NNSs: 10. uhm:: (.) arr (.) hi mate (.) but (.) would you please (.) hand (.) your: work (.) a:: (.) week earlier (.) arr:: (.) because (.) arr (.) next week I got no free time (.) and you cannot (.) collect your (.) work (.) would you please (.) if it's possible (.) please (.) hand it to me (.) this week

\section{ii. How is 'please' used?}

Please is used with mostly direct requests (imperatives and want statements), but it is also used with conventional indirect requests (See Examples 51-52).

Example 51, direct request

ar::: (.) please (.) turn off your:: (.) television (.) because I have to sleep

Example 52, conventional indirect request

teacher can you:: (.) extend (.) one week (.) more to me:: (.) for my essay (.)

please

\section{iii. What are the functions of 'please'?}

Martinez-Flor (2009) reports that previous research states that 'please' is used to soften imposition of the request (Sifianou 1999). Researchers (Martinez-Flor 2009; Sifianou 1999) claim that the first and main primary function of 'please' is as a mitigating device used by the requested to sound courteous and polite. Secondly, adding 'please' to an utterance explicitly and literally marks the primary illocutionary point of the utterance as a directive (Searle 1975). Thus it is a request marker, so that the interlocutor does not interpret it as a question of ability. E.g. Can you lift the parcel? The third function is to use 'please' to plead for cooperative behaviour from the addressee. In this sense, 'please' has an empathetic function, since it is used as an emotionally loaded expression before seeking the addressee's cooperative assistance. The fourth function is to reinforce what the speaker says.

The results of this study revealed that both ENGs and NNSs used 'please' at different places of a request, and their functions appear to be different. 


\section{iii.a 'Please' as a softener-please used inside a request as a post-request device}

In the SALs example provided below, it is possible that 'please' functions as a softener to mitigate the imposition when it is used in the middle of a request because the learner felt bad for having to launch the request (see Example 53).

\section{Example 53, SALs}

uhm::: (.) uhm::: (.) uhm::: (.) err:: (.) can you help me (.) to teach the (.) err:: (.) teach (.) my class (.) because err (.) I know (.) err (.) at that time I'll be busy and I know (.) err (.) your (.) your:: English is (.) quite good (.) so:: err (.) I think (.) err (.) the student will have err (.) good (.) err (.) experience with you (.) so err (.) can you (.) please (.) help me (.) please

In the example above, the speaker initially made the request without external devices to mitigate the request 'you help me (.) to teach the (.) err:: (.) teach (.) my class'. The speaker only used a few post-request devices like justifications for the request and compliments to the listener and pointed out the advantages if the request was made before repeating the request to ask the listener for help. The speaker later repeated the request at the end 'so err (.) can you (.) please (.) help me (.) please' as part of a post-request device. The speaker used 'please' in the middle of the request and after the request. It is likely that the first 'please' used in the middle of the request was used for mitigation, having used one 'please' already, it was likely that the second 'please' placed at the end of the request is more likely to function as a booster rather than a polite marker to reinforce the coercive force.

This is further illustrated by the use of 'please' in SALs' role-play data. The learner in this case agreed to lend her book to the requester, but then asked the requester to return the book to her when she needs it. In the request, the speaker used 'please' in the middle of a conventional request to mitigate the imposition (see Example 54). 
Example 54 (Role-play script from SALs):

$\begin{array}{ll}\text { S } & \text { Hi Queenie } \\ \text { Q } & \text { Hi } \\ \text { Q } & \text { Yessignment (.) ok (.) uhm (.) I can borrow to you } \\ \text { S } & \text { Alright when } \\ \text { Q } & \text { But (.) uhm (.) when ar (.) maybe ar (.) uhm (.) I need it in two } \\ \text { Sonths (.) so (.) when I need it (.) can you please (.) return to me } \\ \text { O }\end{array}$

\section{iii.b 'Please' as a booster-please used at the beginning or the end of a request as a post- request device:}

In the example below, the speaker did not use 'please' in the first request 'can you borrow your notes to me'. The speaker only used external mitigation devices 'I real (.) I really don't want (.) to (.) uhm (.) make a trouble' to minimise the imposition of the first request. The speaker then used a post-request device to justify the request made 'this is the last time', followed by repeating the request 'please help me'. Instead, the learner used the 'please' as a booster in the second request 'please help me'. It is very likely that the second 'please' was used with a direct request as an additional booster to reinforce the speaker's desire to have the listener comply with the request (See Example 55).

\section{Example 55, SALs}

uhm:: (.) excuse me (.) I real (.) I really don't want (.) to (.) uhm (.) make a trouble (.) make (.) coz (.) I'm going to (.) we are going have (.) exam (.) uhm:: (.) can you (.) can you borrow your notes to me (.) and this is the last time (.) please help me 
Similarly, in the example below the speaker made a request initially without using 'please' 'can I hand it (.) err (.) hand in:: the (.) homework to you (.) later (.)'. The speaker then used grounders to justify the request, then repeated the request and used 'please' twice. The first 'please' was a booster for the request and the second 'please' was used as an additional booster, again to reinforce the speaker's desire to have the listener comply with the request (See Example 56).

Example 56, SALs

hello professor (.) can I hand it (.) err (.) hand in:: the (.) homework to you (.) later (.) because I want to (.) think more (.) and more and more (.) about that (.) and (.) I want to (.) err:: (.) err:::: (.) just (.) write it down (.) then return to you (.) so please (.) err (.) please give me one more week

There is also evidence from role-play_-beginning of a request (See Example 57).

Example 57: SALsG3T 1 .Role-play performed by Janice, Heyman and Tiffany

J

Hey tiffany (.) tomorrow I need to:: hand in my English essay (.) please (.) lend it to me

$\mathrm{H} \quad$ I need to do my essay

$\mathrm{H} \quad$ Hey (.) wait (.) wait (as $\mathrm{J}$ and $\mathrm{H}$ fought over essay, tearing it up)

$\mathrm{T} \quad$ Calm down (.) you guys are just ridiculous (.) you (.) you are always taking my (.) homework away (.) and (.) copy it (.) I always (.) be silent (.) but this time (.) you are all going (.) you all (.) you already torn my (.) homework to half (.) so (.) I don't know what can I hand to my teacher

$\mathrm{H} \quad$ That's fine (.) let's stick it with the stickers

Likewise, the data below collected from the oral EDCT and the role-play illustrates the use of 'please' at the end of a request. In the oral EDCT, the learner used a pre-request followed by a direct request, then ended with a conventional indirect request with 'please' tagged onto the 
end. It is likely that 'please' in this case is used to increase illocutionary force rather than serve a softening or mitigating function as the request immediately before this was direct and contained no softening device (see Example 58).

Example 58 (SALs):

hmm (.) I know you are having (.) exam next (.) next week (.) but (.) I want (.) you to present your (.) article (.) next week (.) err::: (.) can you:: (.) please

Likewise, the role-play data showed speaker $\mathrm{T}$ made a direct request again after the initial request 'Let me pay for you', to reinforce speaker T's desire to pay. Speaker T made another direct request and tagged 'please' at the end to boost the strength of the request (See Example 59).

\section{iii.c End of requests}

Example 59: Role-play between Terry and Masaya — end of a request

$\mathrm{T}$

$\mathrm{M}$

$\mathrm{T}$

M

$\mathrm{T}$

M

$\mathrm{T}$

M

$\mathrm{T}$
Hi:: Masaya (.) how- (.) no long time no see= how are you=

$=$ long time no see (.)

fine thank you and what about you (.) I heard that you just came to Australia

Yeah (.) one week ago (.) almost one week (.) but it's really boring in here (.) ar::: (.) let's forget it (.) get a drink first ok

Ok:: good idea

Yeah (.) Coffee (.) do you like it

Oh: I like it

Then let me pay for you

Oh:: no no no I will pay by myself

Just this time please::: (.) ok::: [booster] 


\subsection{Development of 'please'}

SALs used 'please' less as they elaborated on the request statements in $\mathrm{T}_{3}$. For example, Vicki used more complex devices to set up and justify requests by $T_{3}$. In $T_{1}$, Vicki used 'please' inside requests with mutual and higher status interlocutors but did not use 'please' with more external devices to support the request in $\mathrm{T}_{3}$.

As shown in Example 60, Vicki made a request with 'please' inside, then offered explanation and promised good results if the request was complied with (see Example 60).

Example 60, Vicki, $\mathrm{T}_{1}$, low status

arr::: (.) could you please give (.) me:: (.) few more days (.) to:: finish my work (.) I will do it (.) much better: (.) if I get (.) few more days

By $\mathrm{T}_{3}$, Vicki, in lower status position than their interlocutor, set the request more elaborately with post-request devices. Vicki started with a request, followed by grounders, then promised good results and ended by repeating the request again (see Example 61).

Example 61, Vicki, $\mathrm{T}_{3}$, low status

arr::: (.) can I have (.) a few days for (.) for (.) extension (.) coz (.) I really need time to::: (.) arr::: (.) fix (.) the writing (.) coz I have some problem in it (.) I'll get it really good:: (.) I just need the time:: (.) to:: do:: the work (.) yep ((laughs))

ENGs also used very few instances of 'please' in the data. In fact, 'please' was not used in the role-play data. It appears that the examples illustrated above showed learners often used the request at the end of the request statement, as part of their post-request devices to reiterate the speaker's desire for the listener to comply with the request. This contradicts results of previous findings (e.g., Barron 2003; Færch \& Kasper 1989; House 1989), which showed learners overused 'please' as an illocutionary force indicator and as an imposition mitigator. As Economidou-Kogetsidis and Woodfield (2007) suggested, 'please' could be used by learners as a bald-on-record (direct) device, especially with direct questions and want statements (Economidou-Kogetsidis 2005, 2008a,b). It is possible that the SALs felt when they used conventionally indirect requests instead of direct requests, they did not need to use 
'please' to mitigate the imposition. It is, however, important to note that the intonation of learners' speech was not considered in the interpretation.

\subsubsection{Discussion of SALs' pragmatic performance}

Firstly, the results from SALs illustrate they were able to use the 'Could/Would you + VP' conventional indirect request, and had incorporated softeners 'Do/Would you mind + VP?' into conventional indirect request structures prior to their arrival in Australia, but did not acquire the more complex softener 'I was wondering + VP' which was frequently used by ENGs even after nine months in Australia. In addition, even though this group of SALs frequently employed conventional indirect requests irrespective of their interlocutor's status in $\mathrm{T}_{1}$ in the way ENGs did, they diverged from native speaker norm and employed direct requests when their status was higher and lower than the interlocutors in $T_{3}$.

The differences in learners' pragmatic performance of request heads when they had higher and lower status than their interlocutor compared with mutual status interlocutor can also be explained by the Complexification Hypothesis, together with Wolfson's (1988) account of relationship between speech and social distance in the Bulge Theory. Though this study compared only the middle distance group (non-intimates, status equals friends, co-workers and acquaintances) and the socially distance group (status unequals and strangers), the results in learners' speech can be explained by the basic premise that speakers used different speech with those with different social distance offered by the Bulge Theory.

Since learners have limited capacity according to the Complexification Hypothesis (Wolfson 1988), the more complex (and ad hoc) interactions are more cognitively demanding than interactions between friends. It is likely that the SALs had assessed and decided it was socially acceptable to use direct requests among their higher and lower status interlocutors in the first nine months of their stay, so by $\mathrm{T}_{3}$ the learners used direct requests to decrease their cognitive burden as they required more processing capacity for using the external modifiers they acquired during the first nine months abroad. It appears that learners used this strategy to avoid misunderstanding and minimise negotiation with a higher status interlocutor (professor) and a lower status interlocutor (student). 
However, in $\mathrm{T}_{3}$, the SALs continued to use conventional indirect requests with mutual status interlocutors (friends). It is likely the SALs chose to use conventional indirect requests with those of closer social distance (mutual status friends) than those of maximum social distance (unequal status acquaintance and professor) as they can more comfortably negotiate and clarify any misunderstandings in interactions with friends in $\mathrm{T}_{3}$.

Secondly, although learners had used some request external devices prior to their arrival in Australia and there were devices that were not acquired, they had learned to use several more request external modifiers such as pre-warnings, promises and decrease the number of times they repeated requests in the first nine months in Australia. This may suggest learners were aware of the importance of learning and using English devices to mitigate their requests. As Zhang $(1995 a, b)$ pointed out, Chinese speakers tend to use external devices and lexical modifiers are generally optional to the request structures. Therefore, it is not surprising to see learners using more external modifiers than using softeners as part of the request head.

Previous studies have consistently shown grounders are the most commonly used external request modifier (e.g., Blum-Kulka \& Olshtain 1986; Færch \& Kasper 1989; Felix-Brasdefer 2005, 2009; Hassall 2001; Schauer 2007; Woodfield 2007, 2012; Woodfield \& EconomidouKogetsidis 2010, 2012). In a more recent study, Woodfield (2012) found SALs had approximated English native speaker levels on using a range of request external modifications such as grounders, alerters, discourse orientation moves, preparators and imposition minimisers earlier than other devices such as considerators and appreciators.

Like Woodfield (2012), the results of this study showed that the more routinised devices such as grounders were frequently employed by ENGs, and the SALs prior to their sojourn abroad to minimise the imposition of requests. Interestingly, the mean number of grounders SALs used decreased from $T_{1}$ to $T_{3}$, as they learned to use other request external modifiers.

The results of this study, however, differed somewhat to Woodfield (2012). The results of this study showed request external modifiers such as apologies, 'thank you', and minimal impositions were not commonly used by ENGs and were also not used SLAs. External modifiers such as cajolers, compliments, self-introductions and alerts were frequently employed by ENGs but were not used by SALs in $T_{3}$. Perhaps these devices were not seen by learners as request devices to help minimise the imposition of requests. More importantly, 
though, the SALs used a range of request external devices which ENGs frequently employed by the end of the first nine months in Australia. They were pre-request devices such as greetings and pre-warnings and post-request devices such as making promises and consequences. Additionally, the ENGs used more request repetition than SALs. The SALs in this study repeated requests, but the mean number of times they repeated their requests decreased from $T_{1}$ to $T_{3}$.

It is possible that SALs frequently used grounders because they heavily relied on providing reasons to justify in their requests (Blum-Kulka 1991; Hassall 2001), and that they were concerned about the clarity of their speech, so they provided redundant or over-explicit information and excessive repetition may related to learners' concern for clarity (Kasper 1982). Consequently, they used a 'playing it safe' strategy (Færch \& Kasper 1989). Then, as the learners became more confident and acquired the use of other external request modifiers, the number of grounders they used decreased (Blum-Kulka \& Olshtain 1986).

More importantly, the results indicate the SALs had acquired some request external modifiers at different rates. The differences in learners' pragmatic performance can be explained from a cognitive perspective in the Trosborg's (1995) Complexification Hypothesis. As Trosborg (1995) explained with the Complexification Hypothesis, learners acquired pragmatic devices at different rates and what is acquired first depends on how routinised the device is. A highly routinised device is likely to be learned more easily than a device which has to be more creatively formulated or less routinised.

Furthermore, consistent with Barron's (2007a,b, 2008) findings, learners first used and relied predominantly on the easier structures before developing more complex structures which demand a high level of cognitive complexity. Thus, learners tended to employ different devices in different interactions. They used mostly formulae with strangers and nonformulaic utterances with people they knew in interactions. This is because pragmatic routines lessen the cognitive burden and, thus, free up capacity for using modifiers. By $\mathrm{T}_{3}$, the SALs in this study had used a simpler and more direct request but increased in the use of request external modifiers when they had higher and lower status than their interlocutor. It is plausible that during the nine months the SALs spent in Australia, learners had assessed it was socially appropriate and easier to be understood if they use direct and conventional indirect requests, particularly for those who had contact with other NNS students who may or 
may not be as proficient in English. A direct request is a more familiar pragmatic routine and would decrease the cognitive burden to free up capacity for using request external modifiers. This may explain SALs' decrease in repeating requests and increase in the usage of request external modifiers by $\mathrm{T}_{3}$.

\subsection{Summary}

This chapter has addressed the fourth research question related to the effect of study abroad on the learners' performance of requests in English. It has provided a detailed account of the SALs pragmatic performance of English request heads, request softeners and request external modifiers during their nine-month sojourn abroad. It also explains how existing theories can account for the variation in the SALs' pragmatic performance.

Firstly, the results show ENGs, AHLs and SALs used conventional indirect requests 'Can/Could/Would you +VP?' irrespective of their status vis-à-vis the interlocutor. However, somewhat unexpectedly, the SALs used direct requests with an increase of request external modifiers when they had higher and lower status than their interlocutor in $\mathrm{T}_{3}$. Previous researchers would explain SALs' greater use of direct requests in $T_{3}$ as a non-nativeness feature as learners spent more time in the target language environment, and only explained this phenomenon as 'a process of approximation of target language norms over time' (Olshtain \& Blum-Kulka 1985: 321). As we have seen from the results in this chapter, the learners' increased use of direct requests occurred with the increase of external modifiers. It is possible that the SALs indeed tested the appropriateness of using direct requests in the first few months in Australia, and found it was easier to be understood and still socially acceptable to use direct requests. At the same time, it was likely the SALs may have realised direct requests were not as polite as conventional indirect requests, and therefore used request external modifiers to express politeness.

Further support for the Bulge Theory and Complexification Hypothesis is that in $\mathrm{T}_{3}$ learners continued to use conventional indirect requests with mutual status interlocutors but they used direct requests with external modifiers with higher and lower status interlocutors. This supports the claim that with closer social relationship speakers, such as with friends, learners would use a less familiar conventional indirect request. In more distant interactions between 
higher and lower status interlocutors, learners employed direct requests to lessen the cognitive burden and to free more capacity for using external modifiers.

More importantly, the Complexification Hypothesis can account for the differences between pragmatic performances and the rate of development of request devices. This study lends more support for the Complexification Hypothesis, which holds that learners first use and rely predominantly on the easier structures before developing more complex structures that demand a high level of cognitive complexity. Thus the more rountinised features are acquired before the non-formulaic features. More routinised devices such as grounders were frequently employed by ENGs as well as SALs prior to their sojourn abroad. The SALs did not acquire the more complex, but frequently used by ENGs 'I was wondering + VP.' structure in this study and other request external devices such as cajolers, compliments, self-introductions and alerts. However, the mean number of grounders SALs used decreased from $\mathrm{T}_{1}$ to $\mathrm{T}_{3}$, as they learned to use other request external modifiers. In $\mathrm{T}_{3}$, the SALs used a range of request external devices which ENGs frequently employed, including pre-request devices such as greetings and pre-warnings and post-request devices such as making promises and consequences. Additionally, the ENGs used more request repetition than SALs. The SALs in this study repeated requests, but the mean number of times they repeated their requests decreased from $\mathrm{T}_{1}$ to $\mathrm{T}_{3}$.

Overall, the results presented in this chapter show this group of SALs chose to use different request forms with different status interlocutors and acquired request external devices at different rates. These findings can be adequately explained by the Bulge Theory and Complexification Hypothesis. 



\section{Chapter 7 Effect of affective and environmental factors on SALs' performance of request external modifiers}

\subsection{Introduction}

This chapter presents results of the analysis of the data addressing the fifth research question related to the extent to which affective and environmental factors affect SALs' pragmatic performance of request external modifiers during their sojourn abroad. The fifth research question is:

RQ5: To what extent did environmental, affective or attitudinal factors in the study abroad experience correlate with the acquisition of more native-like request devices in English?

This section examines the relationship between the number of request external modifiers used by SALs and affective and environment factors. It begins with analyses of the correlations between the number of request external modifiers SALs used and their self-rated proficiency and self-rated confidence scores on speaking, communication and grammar, as well as environmental factors such as listening input and interaction in English and living environment in $\mathrm{T}_{1}$ and $\mathrm{T}_{3}$.

\subsection{Correlations between SALs' self-rated proficiency and self-rated confidence and the number of request external modifiers in $T_{1}$ and $T_{3}$}

As can be seen from Table 7.1, there were only very weak correlations between SALs' selfproficiency and self-confidence scores and the total number of request external modifiers in mutual, high and low statuses in $T_{1}$. The only statistically significant correlation in $T_{1}$ was found between SALs' confidence in grammar and the total number of request external modifiers $r(19)=.49, p<.05$. 
Table 7.1: Correlations between SALs' self-rated proficiency and self-rated confidence and the number of request external modifiers in mutual, high and low statuses $\left(T_{1}\right)$

\begin{tabular}{lccc}
\hline Self-rated scores in $\mathrm{T}_{1}$ & Mutual & \multicolumn{1}{l}{ High } & Low \\
\cline { 2 - 4 } Proficiency speaking & .280 & .024 & .330 \\
Proficiency communication & .256 & .076 & .322 \\
Proficiency grammar & .201 & .290 & .216 \\
Confidence speaking in & .203 & .132 & .114 \\
Confidence communication & .156 & .321 & .109 \\
Confidence grammar & .163 & $.489^{*}$ & .105 \\
\hline
\end{tabular}

Note. Spearman's rho correlation: **p <.01, *p <.05 (2 tailed)

The results in $\mathrm{T}_{3}$ show there were generally stronger correlations between SALs' selfproficiency and self-confidence in speaking and communication and the mean total number of request external modifiers used. As can be seen from Table 7.2, there were statistically significant correlations between SALs' self-proficiency and self-confidence scores in speaking and the total number of request external modifiers in situations where learners had mutual $(r(19)=.44, p<.05$ and $r(19)=.44, p<.05$ respectively $)$, higher $(r(19)=.60, p<.01$ and $r(19)=.45, p<.05$ respectively) and lower status than their interlocutor $(r(19)=.47, p<$ .05 and $r(19)=.46, p<.05$ respectively). Similarly, there were statistically significant relationships between SALs' self-proficiency and self-confidence scores in communicating and the total number of request external modifiers in the case of mutual $(r(19)=.50, p<.05$ and $r(19)=.45, p<.05$ respectively), high $(r(19)=.61, p<.01$ and $r(19)=.44, p<.05$ respectively) and low statuses $(r(19)=.55, p<.05$ and $r(19)=.46, p<.05$ respectively). The correlation between SALs' self-proficiency and self-confidence scores in grammar and the mean number of request external modifiers used were weak. The only statistical correlation found was between SALs' self-confidence score in grammar and the number of request external modifiers used when their status was higher than their interlocutor, $r(19)=.44, p<$ .05 . 
Table 7.2: Correlations between SALs' self-rated proficiency and self-rated confidence and the number of request external modifiers in mutual, high and low statuses $\left(T_{3}\right)$

\begin{tabular}{llll}
\hline Self-rated scores in $\mathrm{T}_{3}$ & Mutual & High & \multicolumn{1}{l}{ Low } \\
\cline { 2 - 4 } & & & \\
\cline { 2 - 4 } Proficiency speaking & $.443^{*}$ & $.601^{* *}$ & $.469^{*}$ \\
Proficiency communication & $.500^{*}$ & $.611^{* *}$ & $.545^{*}$ \\
Proficiency grammar & .047 & .239 & .016 \\
Confidence speaking in & $.443^{*}$ & $.454^{*}$ & $.46^{*}$ \\
Confidence communication & $.45^{*}$ & $.443^{*}$ & $.455^{*}$ \\
Confidence grammar & .080 & $.437^{*}$ & .343 \\
\hline
\end{tabular}

Note. Spearman's rho correlation: **p <.01, *p <.05 (2 tailed)

\subsection{Correlations between SALs' English listening input in the target language community and the number of request external modifiers}

As can be seen from Table 7.3, the correlations between any listening input and the number of external modifiers SALs used in $\mathrm{T}_{1}$ were very weak. There is only a significant correlation between the amount that SALs listened to English for academic purposes and the number of external modifiers they used was when their status was higher than the interlocutor.

Table 7.3: Correlations between SALs' English listening input and the number of request external modifiers in mutual, high and low statuses in $\mathbf{T}_{1}$

\begin{tabular}{|c|c|c|c|}
\hline Types of Input in $\mathrm{T}_{1}$ & Mutual & High & Low \\
\hline Radio & .392 & .069 & .382 \\
\hline TV/Movies & .214 & -.117 & .087 \\
\hline Songs & .287 & .014 & .384 \\
\hline NS English conversation & .180 & .117 & .108 \\
\hline Academic purposes & .051 & $.441^{*}$ & .089 \\
\hline English Total & .089 & .334 & .062 \\
\hline
\end{tabular}

Note. Spearman's rho correlation: $* * p<.01, * \mathrm{p}<.05$ ( 2 tailed)

Table 7.4 shows that, in $T_{3}$, there were significant correlations between the total number of request external modifiers used when learners had lower status than the interlocutor and the amount of English learners listened to in total $(r=.48, p<.05)$ and the amount of time they listened to NS English conversation $(r=.49, p<.05)$. 
Table 7.4: Correlations between SALs' English listening input and the total number of request external modifiers in mutual, high and low statuses in $\mathbf{T}_{3}$

\begin{tabular}{lccc}
\hline Types of Input in $\mathrm{T}_{3}$ & Mutual & High & \multicolumn{1}{l}{ Low } \\
\cline { 2 - 4 } Radio & .107 & .202 & .260 \\
TV/Movies & .133 & .180 & .428 \\
Songs & -.076 & .002 & .101 \\
NS English conversation & .282 & .339 & $.490^{*}$ \\
Academic purposes & .324 & .412 & .423 \\
English Total & .169 & .317 & $.475^{*}$ \\
\hline
\end{tabular}

Note. Spearman's rho correlation: **p <.01, *p <.05 (2 tailed)

\subsection{Correlation between SALs' English interaction with ENGs and NNSs in the target language community and the total number of request external modifiers}

Tables 7.5 and 7.6 show there is no significant correlation between any face-to-face interactions and the total number of external modifiers used in $T_{1}$. However, in $T_{3}$ results revealed there were significant correlations between SALs' interaction with NSs/fluent English speakers and the total number of request external modifiers used when they had higher and lower status than the interlocutor $(r=.557, p<.01 ; r=.572, p<.01$ respectively).

Table 7.5: Correlations between SALs' types of interaction in English and total number of request external modifiers in mutual, high and low statuses in $T_{1}$

\begin{tabular}{lccc}
\hline Types of interaction in $\mathrm{T}_{1}$ & Mutual & High & Low \\
\cline { 2 - 4 } & & & \\
\cline { 2 - 4 } In class & .123 & .039 & .208 \\
NSs/fluent English speakers outside home & .143 & .185 & .298 \\
At home & .109 & .277 & .299 \\
NNSs outside class & .175 & .153 & .194 \\
Total input & .099 & .245 & .355 \\
\hline
\end{tabular}

Note. Spearman's rho correlation: **p <.01, *p <.05 (2 tailed) 
Table 7.6: Correlations between SALs' types of interaction in English and total number of request external modifiers in mutual, high and low statuses in $\mathbf{T}_{3}$

\begin{tabular}{llll}
\hline Types of interaction in $\mathrm{T}_{3}$ & Mutual & High & Low \\
\cline { 2 - 4 } & & & \\
\cline { 2 - 4 } In class & .107 & .097 & .023 \\
NSs/fluent English speakers outside home & .341 & .425 & .384 \\
At home & .314 & $.557^{* *}$ & $.572^{* *}$ \\
NNSs outside class & .225 & .125 & .271 \\
Total input & .313 & .313 & .416 \\
\hline
\end{tabular}

Note. Spearman's rho correlation: **p <.01, *p <.05 (2 tailed)

\subsection{Living environment}

The living environment has been reported in the literature as a factor which promotes learners' pragmatic development (e.g., Rivers 1998; Schmidt-Rinehart \& Knight 2004: 261). As can be seen from Table 7.7, in $\mathrm{T}_{1}$ there was very little difference between the number of request external modifiers used by SALs in homestay, student dormitories and those living alone/NNSs in all three statuses. By $\mathrm{T}_{3}$ the trend shows that in general SALs who lived with a homestay family used more request external modifiers than those in student dormitories, and both groups used more request external modifiers than those who lived alone or with other NNSs (See Table 7.8).

Table 7.7: Average number of request external modifiers used by SALs at homestay, a student dormitory and alone/other NNSs living environment across three statuses in $\mathbf{T}_{1}$

\begin{tabular}{lcccccc}
\hline $\begin{array}{l}\text { Types of living } \\
\text { environment }\end{array}$ & $\begin{array}{l}\text { Mutual } \\
\text { Mean }\end{array}$ & SD & $\begin{array}{l}\text { Migh } \\
\text { Mean }\end{array}$ & SD & Mean & SD \\
\cline { 2 - 7 } Homestay & 2.75 & .96 & 3 & 1.14 & 1.71 & .85 \\
Student dormitory & 2.40 & .89 & 3.40 & 2.88 & 1.22 & .55 \\
Live alone/NNSs & 2.33 & 1.37 & 2 & 1.28 & 1.56 & .45 \\
\hline
\end{tabular}

Table 7.8: Average number of request external modifiers used by SALs at homestay, a student dormitory and alone/other NNSs living environment across three statuses in $\mathbf{T}_{3}$

\begin{tabular}{llrrrrr}
\hline $\begin{array}{l}\text { Types of living } \\
\text { environment }\end{array}$ & $\begin{array}{l}\text { Mutual } \\
\text { Mean }\end{array}$ & \multicolumn{1}{c}{ SD } & $\begin{array}{l}\text { High } \\
\text { Mean }\end{array}$ & \multicolumn{1}{c}{ SD } & Mean & SD \\
\cline { 2 - 7 } Homestay & 2.63 & 1.19 & 4.50 & 1.19 & 6 & 2.14 \\
Student dormitory & 2 & 1.54 & 2.75 & .50 & 4.50 & 1.29 \\
Live alone/NNSs & 1.44 & .35 & 1.67 & .71 & 2.44 & 1.33 \\
\hline
\end{tabular}


As can be seen in Table 7.9, there was no significant difference between the average number of request external modifiers used by SALs living with homestay, student dormitories and living alone or with other NNSs in T1. However, in T3 there was no main effect between the type of living environment and the number of request external modifiers used in mutual status but there was a significant difference between the types of living environment learners had and number of request external modifiers used when their status was higher and lower than their interlocutor $(F(2,14)=24.92, p<.01 ; F(2,18)=9.49, p<.01$ respectively). Post-hoc analyses revealed that in $\mathrm{T}_{3}$ when the SALs had higher status than their interlocutor, the SALs in homestay used a significantly higher number of request external modifiers than those in dormitories and those living alone/with other NNSs. However, there was no difference between those living in student dormitories and those living alone/with other NNSs $(\mathrm{p}<.01)$. In situations where SALs were of lower status than their interlocutor in $\mathrm{T}_{3}$, only the SALs in homestay used significantly more request external modifiers than those who lived alone/with other NNSs $(\mathrm{p}<.01)$.

Table 7.9: ANOVA tests for the number of request external modifiers used by SALs in three different types of living environment in the target language community across the three statuses in $\mathbf{T}_{1}$ and $\mathbf{T}_{3}$

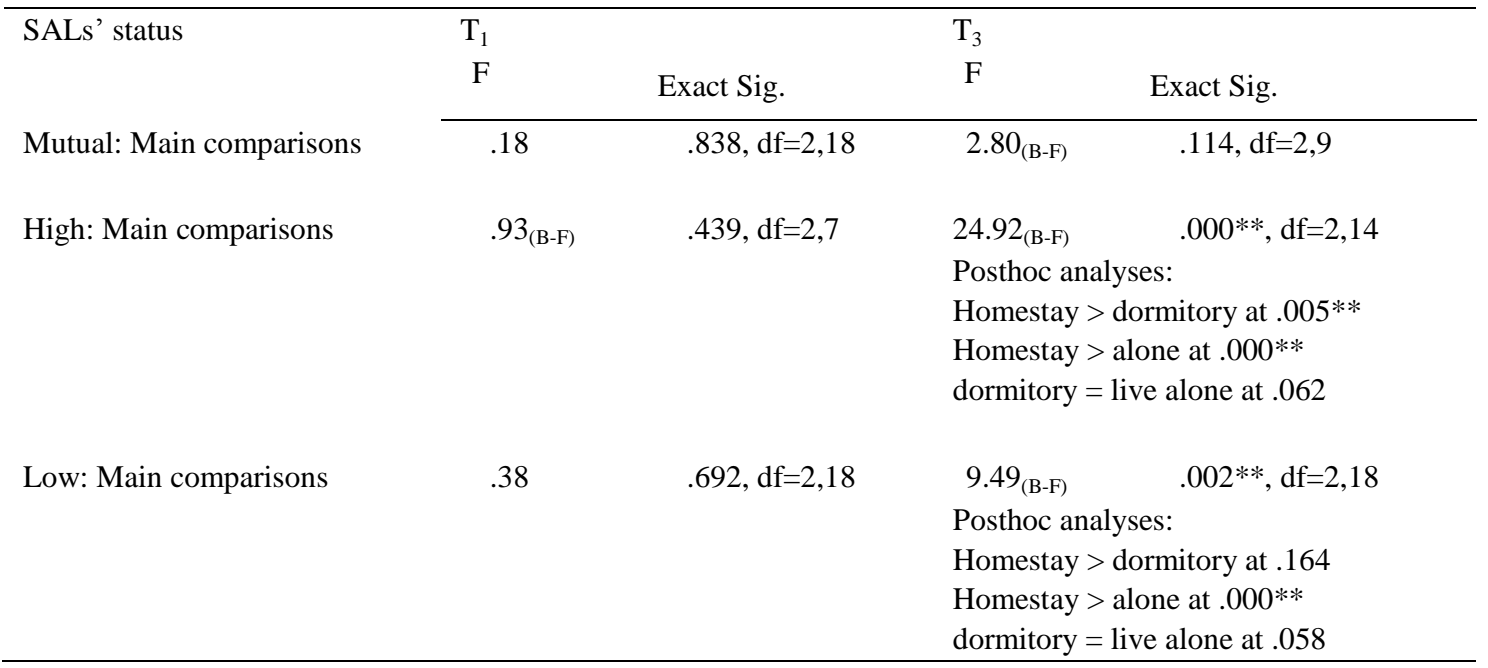

\section{Notes:}

1. F stats if it meets the homogeneity of variances (Levene tests), otherwise used the robust tests of equality means test values from Brown-Forsythe(B-F))

2. Statistical significance: $* * \mathrm{p}<.01, * \mathrm{p}<.05$ (2 tailed).

3. $(\mathrm{x})=$ equality not assumed. 


\subsection{Discussion of environmental and affective dimensions and SALs' pragmatic performance}

As discussed in Chapter 6, there was an overall increase in the total number of request external modifiers SALs used by the end of their first nine months of sojourn abroad. Section 6.4 has provided important results regarding the affective and environmental factors that could contribute to the increase in SALs' use of request external modifiers from $T_{1}$ to $T_{3}$. In $\mathrm{T}_{1}$, the results show only very weak correlations between the number of request external modifiers SALs used and affective and environmental factors. This is what we would expect to see because the data in $\mathrm{T}_{1}$ was collected two weeks after SALs had arrived in Australia, so it would have been too early to see any effect from affective and environmental factors. By $\mathrm{T}_{3}$, however, the results were more promising. Analyses revealed significant correlations were found between the number of request external modifiers SALs used and affective and environmental factors in $T_{3}$. The discussion below focuses on how affective and environmental factors influence SALs' use of request devices.

\subsubsection{Length of residence in Australia}

Firstly, the results revealed no increase in the number of request external modifiers AHLs used but an increase in the number of request external modifiers SALs used from $T_{1}$ to $T_{3}$. Consistent with previous research (e.g., Bardovi-Harlig \& Griffin 2005; Barron 2003, 2005 in Barron 2007a, 2007a, 2008; Kinginger \& Belz 2005; Kinginger \& Farrell 2004; MartínezFlor \& Fukuya 2005; Matsumura 2003, 2007; Olshtain \& Blum-Kulka 1985; Schauer 2006a,b, 2007, 2008; Shardakova 2005; Woodfield 2012), the results of this study show SALs were able to develop pragmatic awareness through exposure to the target language environment.

However, although there is consensus on the benefits of study abroad on learners' pragmatic performance, the length of time that SALs needed to acquire pragmatic devices was unconfirmed. Researchers have shown SALs are able to improve on the use, types and varieties of request/refusal devices used during their sojourn abroad. In nine months in the L2 community, they were able to approximate NSs' use of a range of devices (Barron 2003, 2005 in Barron 2007a; Felix-Brasdefer 2004; Schauer 2006a,b, 2007, 2008). Bouton (1994, 1996) also found that learners who spent $4 \frac{1}{2}$ years in the host environment were able to 
interpret implicatures that the 17-month learners could not. In contrast, Martinsen (2008) found a non-linear relationship between length of residence and pragmatic gain in terms of interlanguage processes.

In this study, a request softener 'I was wondering + VP.' and request external modifiers which ENGs frequently employed were not acquired and used by SALs in $T_{3}$. In the nine months the SALs spent abroad, they had increased the number of request external modifiers used and had acquired the ability to use request external modifiers like greetings, prewarnings and consequences request modifications in similar ways to ENGs. There was also a reduction in the number of times they repeated requests. This supports the premise that the length of residence is a factor that contributed to SALs' acquisition of request external modifiers by $\mathrm{T}_{3}$. Hence, consistent with Schauer's (2006a,b) findings, the SALs in this study acquired a broader repertoire of request modifiers by their tenth month in the target community. It also appears that SALs' request developmental sequence is linked to the length of stay in the target environment but that individual learners developed the use of modifiers at different rates. This study suggests learners acquire modifiers such as grounders first, followed by making promises, but they did not acquire cajolers, compliments, selfintroductions and alerts.

As can be seen, the SALs did not acquire all the pragmatic features which were frequently employed by ENGs. As research has correctly pointed out (e.g., Kinginger \& Belz 2005; Matsumura 2003; Schauer 2006a,b, 2007, 2008), learners' different lengths of stay as a factor to explain learners' pragmatic development cannot account for why they acquire certain pragmatic features before others. Using learners' lengths of stay as an explanation alone also fails to consider why some pragmatic elements do not appear in their performance until very late in their year abroad and learners' individual preferences for choosing modifiers.

This group of SALs reported they liked Australia and had important reasons to want to learn English and, more importantly, they liked learning English in Australia. Therefore, it is also possible that learners did not acquire the 'I was wondering...' structure and certain external modifiers to soften a request because they lacked the desire to stay or adapt to the L2 community. 
The acquisition of certain modifiers could be because this group of SALs had learned to chunk certain modifiers in $\mathrm{T}_{1}$ and continued to learn different request external modifiers with increasing time. There is no evidence of a nonlinear relationship between chunking and increased time as reported by Warga and Schölmberger (2007). Instead, the SALs in this study were more likely to replace the chunks from the target language with using modifiers in their own words.

The only evidence from this study to indicate there is a 'backsliding' effect with SALs' acquisition of request external modifiers is their decision to use conventional indirect requests in cases where the learners had higher and lower status than their interlocutor in $\mathrm{T}_{1}$. Yet they chose to use direct requests with an increased use of request external modifiers when they faced the same situation in $\mathrm{T}_{3}$. This may be because the SALs' had learned conventional indirect requests were the most socially appropriate form of request to use in English; but after they experimented with this and the direct request form, learners perceived it was socially acceptable to use in different situations when they had higher and lower status than their interlocutor, thus increasing their use direct requests in $\mathrm{T}_{2}$ and $\mathrm{T}_{3}$. Moreover, it is likely that when the SALs' used direct requests, their interlocutor (whether it is NSs or NNSs) did not give them feedback about whether it was actually socially appropriate in Australia. Therefore, they continued to use direct requests in $\mathrm{T}_{2}$ and $\mathrm{T}_{3}$.

\subsubsection{Self-perceived proficiency and self-rated confidence}

The results in Chapter 5 showed learners' self-perceived proficiency and self-perceived confidence in speaking, communication, and grammar increased during their sojourn abroad, and that learners' self-perceived proficiency and self-perceived confidence scores in these factors are related. Consistent with previous finding (Clément 1986; Clément, Dörnyei \& Noels 2004; Clément, Smythe \& Gardner 1978; Li 2006; Magnan \& Back 2007), the analyses in this chapter revealed there were significant correlations between the number of request external modifiers SALs used and their self-rated proficiency and self-rated confidence scores on speaking and communication but not grammar across all three statuses in $\mathrm{T}_{3}$.

It is believed that the SALs' self-perceived proficiency and self-perceived confidence would increase through contact with NSs, and thus would increase during their sojourn in the target community. Like Li's (2006) finding, SALs' self-confidence increased when they believed 
they became more proficient in L2. This logically explains why learners' self-perceived proficiency and self-perceived confidence in speaking, communication and grammar are related.

Li (2006) suggested learners' self-perceived confidence affects their use of request modifiers. Similar to Li's (2006) learners, many SALs at the beginning of this study lacked confidence in speaking, particularly to NSs. They felt inadequate and embarrassed expressing themselves in English due to a lack of fluency, and had poor grammar and vocabulary which prevented them from communicating effectively. It is likely that the SALs' self-perceived difficulties consequently lowered the learners' self-confidence and inhibited them from speaking English, thus affecting their motivation to further practise spoken English in real life and participate in informal conversations. High proficiency learners and those who had a little more contact with NSs in Hong Kong were more confident in their English ability than the low proficiency learners. Even though learners reported difficulties in English aural understanding and the hindrance of thinking in Chinese by the end of the study, at least some learners' self-confidence increased. They also felt more willing to take the initiative to talk with increasing confidence.

The results of this study can also offer further support for research (Færch \& Kasper 1989; Hassall 2001) which found a relationship between learners' self-perceived proficiency and self-perceived confidence and the use of request modifiers. Like previous findings, the SALs here used external more than internal modifiers. Hassall (2001) and Economidou-Kogetsidis (2009) explained this may be because learners with limited L2 linguistic proficiency feel more confident using external modification (in this case softener structure 'I was wondering + VP.'). Perhaps it is because the politeness function is more explicit and learners can derive their politeness value directly from the illocutionary meaning from context (Blum-Kulka \& Olshtain 1986).

\subsubsection{Input and interactions in target language community}

Interestingly, not all environmental factors had significant correlations with the number of request external modifiers SALs used in $\mathrm{T}_{3}$. Analyses revealed only listening input and interaction with fluent/NS English speakers had significant correlations with the number of request external modifiers SALs used. 
Some researchers (Coleman 1998; Regan 1995, 2003) suggest that SA environments offer a wide variety of ways to increase L2 input through, for example, watching television or films, reading newspapers, listening to music, and even overhearing native-speaker conversations. However, Rivers (1998) and Gubbins and Holt (2002) argued that students spending time in front of the television set is detrimental to learners' pragmatic development because it detracts from time talking with NSs, and that the only really beneficial input is from more fluent learners or NSs. This study reveals that although there was an increase in the listening input for SALs, typically they had extremely limited interaction with fluent/native Australian English speakers. Yet, this study shows there are significant correlations between the amount of listening input from overhearing native-speaker conversations and interaction with fluent/NS English speakers and increased number of request external modifiers SALs used in $\mathrm{T}_{3}$.

The group of SALs in this study faced a similar situation as SALs in other studies in that there were very little interactions between SALs and NSs during learners' sojourn abroad (e.g., Barron 2003; Long 1983; Maiworm, Steube \& Teichler 1993). In this study, a majority of the SALs, too, ended up mixing with the same L1 speakers or with other international students in the same class.

The SALs generally had very limited contact with teachers and NSs outside the classroom. Most SALs had predominantly NNS-NNS interaction during their first nine months abroad. As Magnan and Back (2007) found that, even intermediate-level learners cannot participate as sufficient proficient partners in L2 conversations and that two learners at this level tend to converse in minimal or fractured L2. They point out that it is essential for SALs to seek more fluent speakers as guides for language improvement and cultural growth. This could possibly explain why this group of SALs did not acquire a number of the pragmatic features which were used by ENGs. As Maiworm, Steube \& Teichler (1993) pointed out, contact with other L1 speakers is beneficial in that it can support learners and reduce culture shock, but too much L1 talk amongst learners can potentially limit learners' L2 development.

Similar to what Long (1983) and Marriott (1995) found with NS-NNS interactions, it is possible that the SALs did not acquire all the pragmatic features measured because even if they have opportunities to interact with other NSs, the SALs reported they were mostly exposed to the plain style usage because NSs aim to prevent misunderstanding in 
communication. NSs have been found to use less complex utterances, use more confirmation and comprehension checks, clarifications of requests, as well as self- and other repetitions in interactions with NNSs (Kasper \& Zhang 1995). Students also rarely received negative feedback on pragmatic devices since most feedback was on grammatical errors or on message content. One cannot take for granted that learners' interactions with NSs can lead to pragmatic improvement. In order for a pragmatic feature to be learned, it must be salient for the learners to notice it. If SALs did not receive feedback on their errors, they cannot notice the features and see the gaps in the production (DeKeyser 1991). Thus, this suggests that it is possible that learners do not get exposure to a full range of pragmatic features that are used in the host environment and the L2 culture. In fact, several SALs in this study were hosted by families with other international students.

Research shows that even when there are interactions between SALs and NSs, this contact may not necessarily be sufficient for learners' pragmatic development (Teichler 1991). Martinsen (2008) explained that one possibility is that the interactions students have during study abroad can be repetitive or simple enough that they do not push students to improve.

\subsubsection{Living environment}

This section will discuss the extent to which a homestay environment may affect learners' pragmatic development during their sojourn abroad. Living environment has been suggested as a factor which promotes learners' pragmatic development. The results in Section 6.4 showed in $T_{1}$ there was very little difference between the number of request external modifiers used by SALs in homestay, student dormitories and those living alone/NNSs in all three statuses. By $\mathrm{T}_{3}$ the trend shows that in general SALs who lived with a homestay family used more request external modifiers than those in student dormitories and those who lived alone or with other NNSs, and there was no significant difference between the number of request external modifiers used by SALs who lived in a dormitory and those who lived alone or with other NNSs.

This indeed offers further support to the literature regarding the overall potential benefits of staying with a homestay family over living in a dormitory and alone/sharing a flat with NNSs. Thus, it is plausible that homestay is one of the factors that promoted the increase in the overall number of request external modifiers used by SALs from $T_{1}$ to $T_{3}$. Nonetheless, 
the large standard deviation in the number of hours SALs interacted with fluent/native Australian English speakers in each living environment suggests there were big differences between the number of hours SALs within each group actually had the opportunity to interact with fluent/native Australian English speakers. Furthermore, as seen in Section 6.3, the SALs had request features frequently used by ENGs (greetings, pre-warnings, making promises and consequences), but SALs did not acquire cajolers, compliments, self-introductions and alerts.

Research has shown that SALs often have limited interaction with their host family (e.g., Magnan \& Back 2007; Wilkinson 1998a,b, 2000) and that even if students felt very comfortable with their families at the end of the experience, some were disappointed that their home did not offer more linguistic and social interaction. Students have said they wanted to be included in family activities (Knight \& Schmidt-Rinehart 2002; SchmidtRinehart \& Knight 2004). The SALs in this study also reported they stayed in their room to study and actually had limited time with the host family and only a few students were fortunate to be included in family activities. Several students had bad experiences with their homestay families, which affected their decision to interact with their homestay family. As mentioned in the previous chapter, Sally and Ruby both had a bad time with their host families. It appeared the problem arose when the host mothers expected the students to do too many chores at home. In these cases, when a less fortunate student like Ruby interacted with her host mother, it was predominantly based on instructions given to Ruby.

This study also supports research on NNS-NNS interaction from Gutel (2008) and Jackson (2008) which shows students who had a roommate with a significantly higher or lower language level at the host family believed that this impacted on (hindered or helped) their ability to interact with the host family. We have seen this in the case of an SAL student at a homestay, Janice. The more proficient learners, like Janice, hindered lesser learners who relied on the more proficient learners to communicate by helping the less proficient learner from Macau. Janice did not want to help to translate so frequently and the host mother did not have the patience nor the tolerance to listen to Janice translate and felt annoyed that she was excluded from the two NNS speaking in Chinese. This, in turn, affected Janice's relationship with the host mum. The lower proficiency learners did not speak to their host family due to limited English competence and shyness. As a result, interaction between students and hosts became very limited and, in turn, affected learning outcomes. As for the more proficient learners, they suffered as they spent more time helping the lower level learners which gave 
them less time to communicate with other proficient learners. Thus, learners would typically interact more with other NNSs at the homestay family. As reported in the literature, NNSNNS interactions can have detrimental effects on learners' pragmatic acquisition and development. As discussed in Chapter 5, the SALs who had more interaction between the homestay family have acquired more request external modifiers.

\subsection{Summary}

The chapter addressed the results of the fifth question on the extent to which environmental, affective or attitudinal factors in the study abroad experience correlate with the acquisition of more native-like request devices in English. It investigated the correlations between affective and environmental factors and SALs' performance in using requests and request external modifiers during their sojourn abroad. More specifically, it measured the relationship between learners' request performance and their length of stay abroad, self-perceived proficiency and self-perceived confidence in speaking, communication and grammar, input and interaction in target language community and their living environment. Data used for this study are from participants' oral responses for three oral EDCTs where the participants were of mutual, higher and lower status than the interlocutor in a given scenario.

The results presented here also indicated that the overall increase in the number of request external modifiers used by SALs between $T_{1}$ and $T_{3}$ is linked to the length of time learners' stay abroad. It suggests that by the time SALs had stayed in Australia for nine months, they had acquired some but not all request features employed by ENGs. Affective factors such as learners' self-perceived proficiency and self-perceived confidence in speaking and communication (but not grammar) in $\mathrm{T}_{3}$ correlate with the increase in the number of request external modifiers used by SALs by $\mathrm{T}_{3}$. In addition, other environmental factors such as listening input in fluent/native Australian English speaker conversations and interaction with fluent/native Australian English speaker conversations also significantly contribute to the increase in the number of request external modifiers SALs used. Finally, the results also revealed learners in homestay families used significantly more request external modifiers by $\mathrm{T}_{3}$.

Therefore, this study suggests that, in addition to learners' length of residence abroad, learners' pragmatic performance relates to a number of environmental and affective factors: 
learners' overall English input, learners' face-to-face interaction with English speakers in the living environment, as well as learners' self-perceived proficiency and self-perceived confidence in speaking and communication, but not with their self-perceived proficiency in grammar. 



\section{Chapter 8 Conclusion}

This thesis has investigated the pragmatic performance of a group of SALs over their ninemonth sojourn abroad, compared to their counterparts in Hong Kong (AHLs) and native Australian English speakers. More specifically, it examined the affective and environmental dimensions of SALs' experience during their sojourn abroad, their pragmatic performance of request devices over this period, and the types of affective and environmental factors that influenced their pragmatic performance. This chapter summarises the major findings, discusses this study's contributions to academic knowledge, and suggests directions for future research.

\subsection{Major findings}

Five research questions were posed in Chapter 1. The following sections summarise the findings that were revealed by the data analyses in Chapters 5, 6 and 7 .

\subsubsection{Environmental and affective dimensions of the study abroad experience}

The first three research questions are related to the environmental and affective dimensions of SALs' experience during their sojourn in Australia as discussed in Chapter 5. To date, substantial evidence shows exposure to the target language environment has an overall positive effect on learners' L2 pragmatic performance. However, very little is known about the affective and environmental dimensions of SALs' experience abroad. The results in this study revealed that even though SALs had more opportunities for English listening input and interaction in Australia than when they were in Hong Kong, a majority of students mostly interacted with other Hong Kong learners and NNSs in the first nine months of their sojourn abroad, and the dramatic increase in the SALs' English listening input and interaction plateaued by about the fourth to fifth month of learners' sojourn abroad.

In terms of living environment, the SALs who stayed in dormitories had more interaction time than those living in a host family, though the results showed interaction in English was not always with NSs. Additionally, and contrary to the common belief that there is a 
'homestay advantage', interaction between the host and the learner depended heavily on the individual learners' attitude towards the host family. Furthermore, learners' English input and face-to-face interaction correlated significantly with the increase in learners' self-perceived confidence in speaking, communication and grammar, but not self-perceived proficiency.

In terms of the affective dimension of SALs' experience abroad, the learners' self-perceived proficiency and self-perceived confidence in speaking, communication and grammar increased from $T_{1}$ to $T_{3}$. There were strong correlations between SALs' self-perceived proficiency and self-perceived confidence scores in both $\mathrm{T}_{1}$ and $\mathrm{T}_{3}$. Interestingly, this study indicates some environment and affective dimensions were related. The results showed that, overall, SALs' self-perceived proficiency and self-perceived confidence in speaking, communication and grammar were significantly related to the number of hours they listened and interacted face-to-face in English as well as their living environment. Those who lived in dormitories and homestay families had higher self-perceived proficiency and self-perceived confidence than those who lived alone/with other Hong Kong learners and NNSs at $\mathrm{T}_{3}$.

\subsubsection{Performance of English request devices by study abroad learners}

Chapter 6 presented results related to SALs' performance of request devices during their sojourn abroad. The main findings will be highlighted here.

Firstly, although the SALs used conventional indirect requests 'Can/Could/Would you +VP?' irrespective of their status with the interlocutor in $\mathrm{T} 1$, they used more direct requests with an increase of request external modifiers when they had higher and lower status than their interlocutor by $T_{3}$. Previous researchers would explain this feature as learners displaying 'non-nativeness' in their learning curve in their interlanguage. However, this study argues that it is not likely to be due to their interlanguage because learners only chose direct requests along with using request external modifiers when at a higher and lower status than interlocutor. Instead, it is possible that learners have tested and confirmed it is socially appropriate to use direct requests when they had higher and lower status than their interlocutor amongst their network of friends. According to the Complexification Hypothesis (Trosborg 1995) and Bulge Theory (Wolfson 1986), it is likely that direct request structure is a more routinised and familiar structure for Cantonese speakers; so in $T_{3}$ they used direct requests to free up more processing capacity as they attempted to use more request external 
modifiers in English. Interestingly, these SALs were also able to use the softener 'Would/Do you mind +VP?', but not the 'I was wondering + VP.' structure in situations regardless of their status with the interlocutor. This further suggests that learners did not 'notice' the grammatically correct use of this structure even when they heard NSs using it, or points to the possibility that learners' errors were not corrected by NSs.

Secondly, although SALs' increased their use of external modifiers between $T_{1}$ and $T_{3}$, they did so at different rates. This supports the Complexification Hypothesis (Trosborg 1995). It is possible that the learners did not acquire the devices that they recognise as pragmatic routines such as cajolers, compliments, self-introductions and alerts. However, by $\mathrm{T}_{3}$, this group of SALs 'noticed' and used the more routinised pragmatic features such as greetings and more warnings (precommitments, preparators and disarmers) before launching the request, and post-request devices such as making promises, stating consequences and repetition of the request. It also supports the Bulge Theory (Wolfson 1986) that speakers choose to use different speech in accordance with the speakers' social distance. By $\mathrm{T}_{3}$, learners continued to use conventional indirect requests with mutual status interlocutors but they used direct requests with external modifiers with higher and lower status interlocutors. This supports the claim that with closer social relationship speakers, such as with friends, learners would use a less familiar conventional indirect request. In more distant interactions between higher and lower status interlocutors, learners employed direct requests to lessen the cognitive burden and to free more capacity for using external modifiers.

\subsubsection{Effect of affective and environmental factors on SALs' performance of English requests}

Chapter 7 identified the correlations between affective and environmental factors and SALs' performance in using requests and request external modifiers during their sojourn abroad. By $\mathrm{T}_{3}$, the number of request external modifiers that study abroad learners used correlated significantly with factors including learners' overall English input, face-to-face interaction with English speakers in the living environment, as well as self-perceived proficiency and self-perceived confidence in speaking and communication, but not self-perceived proficiency in grammar. 


\subsection{Research contribution}

Chapter 1 identified three gaps in the literature which this research sought to address. Firstly, few studies have investigated the pragmatic development of Chinese learners of English, and those that have, have involved Mandarin Chinese. Secondly, this study has provided an indepth longitudinal analysis of study abroad learners' pragmatic performance of request devices over a nine-month period. It provides further evidence of Chinese learners' acquisition of request devices (such as request heads, softeners and external modification) in both the interlanguage pragmatics and study abroad disciplines.

Thirdly, previous studies have focused primarily on providing qualitative analyses of learners' experience abroad, particularly on their homestay experience. This study collected quantitative and qualitative data on a number of environmental and affective dimensions such as the length of stay in the target language community, amount and types of input and interactions in the target language community, attitude towards learning L2, and attitudes towards the target language community-particularly their living environment; as well as self-rated proficiency and self-perceived confidence in speaking, communication and grammar. In addition, the research examined the extent to which these environmental and affective dimensions on learners' performance of request devices influenced learners' pragmatic performance abroad. Most importantly, this study has provided a much clearer picture of the amount and types of English input and interaction learners have access to in Australia, whether these learners stay in homestay, dormitories or alone/with other NNSs.

This is the first study that not only measured the quantitative and qualitative analyses of the environmental and affective dimensions of study abroad learners' experience during their sojourn abroad and examined in-depth learners' pragmatic performances, but also measured the relationship between study abroad learners' pragmatic performance of request devices and environmental and affective dimensions.

The results of this study have provided a much richer picture of learners' experience abroad and the extent to which the environmental and affective dimensions influence their pragmatic performance on request external modifiers. As suggested in this study, the noticing hypothesis, as well as the Complexification Hypothesis and Bulge Theory can account for the variation in learners' pragmatic performance. However, this study also revealed how factors 
such as learners' self-perceived proficiency and self-perceived confidence in speaking and communication shape SALs’ pragmatic performance.

\subsection{Limitations}

This study has contributed to the existing study abroad literature by providing a richer picture of the effect of both the environmental and the affective dimensions on SALs' experience during their nine-month sojourn abroad. It has shed further light on the types and sequence of SALs' development of request external modifiers. Most importantly, this study has identified the types of affective and environmental factors that influence variations between learners' rate and sequence of their acquisition of request devices. However, a number of limitations need to be acknowledged.

Firstly, the request responses from participants in this study are collected from the oral EDCTs and roleplays. One of the major criticisms of DCTs is that they do not adequately represent natural conversations in that speakers' DCT responses lack actual wording, emotions, a range of formulas and devices, and the number of repetitions and elaborations that occur in a real conversation, and excludes details related to context and settings (Beebe \& Cummings, in Kasper \& Dahl 1991; Wolfson, Marmor \& Jones 1989).

Secondly, this study indicates the Language Contact Profile and the additional questions designed for the purposes of this study elicited a lot of important information related to the affective and environmental dimensions of study abroad experience. The answers were based on learners' self-reporting. No other instrument was implemented to measure how accurate learners' self-reporting was compared to the real picture. Thus, it is possible that learners rated their scores higher or better than they were, or reported what they thought was appropriate or expected.

Future research should address the existing methodological problems to increase the reliability and validity of the results. 


\subsection{Future research}

The results of this study point to the need to include the following in future research.

Firstly, to address the data collection problem of using EDCTs to collect data, future longitudinal studies should substantiate data collected from EDCTs with naturalistic data. The use of natural data can provide a more realistic account of learners' knowledge and use of request devices in spontaneous conversations in different social settings.

Secondly, future studies should look at ways of increasing the reliability of self-reporting by recording a detailed account in diaries. Learners can report the types and amount of time learners spend on each activity, and reflect on what works for him/her and what does not so that he/she can focus time and energy on those activities which are most beneficial to promoting successful learning.

Thirdly, one of the most important results this study has highlighted in the study abroad context is that the nature of the homestay environment is complex. There is no guarantee that learners have more opportunities for more English input and face-to-face interaction with a host family. Similarly, the learners in dormitories do not necessarily have fewer opportunities. The results show the complex relationship between learners and host families deserves a more in-depth study in order to discover the impact of living environment on learners. This study only obtained responses from learners. It is important for future studies to include interviews from host families so that we can gain a deeper understanding of the factors, expectations and mis-matches between learners and host families.

It is vital to address these three points in future research to improve on its methodology and understand learners' experience abroad.

\subsection{Concluding remarks}

The study abroad experience is rapidly becoming a common part of the learning experience as part of the move to internationalised education. It is, therefore, crucial for research to engage with and provide evidence to help improve study abroad language programmes and the experience. 
As discussed above, this study has indicated there is potential for the 'homestay advantage' in promoting more interaction and, indeed, learners' pragmatic performance. However, the results showed that clearly not all learners gained from the homestay experience. There sometimes appears to be a mis-match between learners' and host families' expectations and responsibilities. Thus, programme managers and study abroad agencies should specify more clearly the expectations and responsibilities of host families and learners during the time learners stay with a host family.

This study also shows that language programmes typically offer English academic skills at a university level, focussing on reading, writing, listening and speaking. Learners reported they received no education on communication skills. As we have seen in this study, many learners did not have any regular contact with NSs except for the language teacher. Thus, it is important for language programmes to explicitly teach some essential pragmatic skills as part of the curriculum. Teachers have to play a more active role in the classroom in teaching communication skills to help learners build more confidence in using English to communicate with NSs. As Winke and Teng (2010) have pointed out, even though learners improve pragmatic ability from native-speaker interaction in a study-abroad program, students after two to three years abroad lack sufficient pragmatic ability on a range of speech acts such as complimenting, apologizing, declining, asking for a favour, asking to borrow something, refusing (to both friends and supervisors), responding to rudeness, requesting help, bargaining, giving. Hence Winke and Teng (2010) suggested learners would benefit from explicit teaching of pragmatic skills in the study abroad curriculum.

Another finding from this study is that language learners establish contacts very early during their sojourn abroad. And, understandably, learners' initial social network includes other same L1 speakers and NNSs from the same programme. Results also suggest learners establish their main circle of friends quite early, and tend to stay with their friends during their sojourn abroad. They do not go beyond this circle of friends to establish new contacts outside this network. The learners themselves reported they mostly interacted with other Cantonese speakers or NNSs. They rarely had contact with NSs beyond requesting services. This limits learners' opportunities to learn and benefit from being in the target language community. As the results of this study suggest, learners gain most from English input and face-to-face interaction with fluent/native English speakers. Further, as literature suggests, 
interaction between NNSs could be detrimental to learners' pragmatic acquisition and performance.

Therefore, language educators and study abroad programme organisers could usefully improve and expand a buddy system at universities. In such systems, each learner is paired with a NS at the university so they actually gain an opportunity to have face-to-face interaction with the NSs. The NSs could be asked to teach learners about the target language community culture, how to interact socially with other NSs and to increase opportunities to learn by explicitly teaching learners pragmatic skills and providing feedback.

These are the immediate steps which language educators and study abroad programme organisers could introduce to ensure study abroad learners are better integrated into the target language community, have plenty of opportunities to gain exposure to the target language culture, interact with native speakers, and have a positive experience in the target language community. 


\section{Appendices}

\section{Appendix I Advertisement for the recruitment of native speakers of Australian English}

\section{Are you an Australian English native speaker?}

\section{Are you interested in earning some cash?}

\section{If yes, then please join a short study on the use of English}

This study investigates how Australian English native speakers use English compared to nonnative English speakers. In this study, you will be asked to fill in a questionnaire, partake in a quick interview and a role-play. It will take you approximately 2 hours to complete all the tasks for which there is an honorarium of \$20.

The data collected will be strictly confidential, they will be used anonymously for academic and research purposes only. If you agree to take part in this study, please contact Dr Keith Allan at Keith.Allan@arts.monash.edu.au or Misty Cook at misty.cook@vuw.ac.nz/mistycook28@yahoo.com.au.We can arrange a suitable time to meet at Monash University in the week of date. 


\section{Appendix II Advertisement for the recruitment of SALs}

\section{Are you a Hong Kong student who has just arrived in Australia?}

\section{Are you interested in improving your English?}

\section{If yes, then please join a study on improving your English language skills.}

This study focuses on investigating how Hong Kong students learn and use English as second language in Australia. In this study, you will be asked to fill in questionnaires and keep a diary to share your learning experience and your knowledge of English. You will also be asked to talk about your learning experience, join in conversations and take part in role plays. I also hope that we can chat regularly on-line so we can share our experiences in living in Australia and questions about the English language.

Throughout the study, you can practise your written and oral English by joining in some interesting activities. At the end of the study, you will be given some feedback about your strengths and weaknesses in using English and some suggestions on how to improve on your English. I believe you will improve on your English usage. You will receive an honorarium of $\$ 90$ upon the completion of all tasks at the end of the study.

The results collected from this project will be strictly confidential, they will be used anonymously for academic and research purposes only. If you agree to take part in this study, please complete the consent form, date it and sign it. I look forward to your reply.

Contact details: Misty Cook, Victoria University of Wellington. E-mail: mistycook28@yahoo.com.au or mistycook@vuw.ac.nz 


\section{Appendix III Introductory letter}

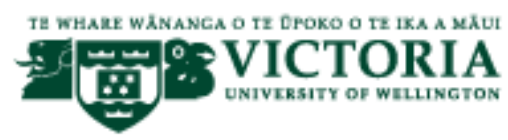

Dear Participant,

Thank you for agreeing to complete this questionnaire, which will be included as a part of my project entitled 'Interlanguage Pragmatics: Is the development of English pragmatic competence affected by different learning environments and instructions?' This project aims to examine to way native and non-native English speakers use English for communication.

The results collected from this project will be strictly confidential, they will be used anonymously for academic and research purposes only. If you agree to take part in this study, please fill in the consent form, date it and sign it.

Please provide your name and email address if you would like to be contacted for future research purposes.

Name:

E-mail address:

Please do not hesitate to contact me if you have questions regarding the questionnaire. My email address is: mistycook28@yahoo.com.au

Once again, thank you very much for your help. Your participation in this study is greatly appreciated.

Yours sincerely,

Misty So-Sum Wai-Cook 


\section{Appendix IV Consent form}

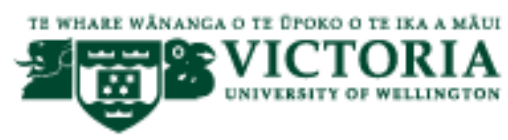

\section{CONSENT FORM}

Tentative project title: Interlanguage Pragmatics: Is the development of English pragmatic competence affected by different learning environments and instructions?

Researcher's name: Misty So-Sum Wai-Cook, Department of English, The Chinese University of Hong Kong.

1. I have read the Participant Information Sheet and the nature and purpose of the research project has been explained to me. I understand and agree to take part.

2. I understand the purpose of the research project and my involvement in it.

3. I understand that I may withdraw from the research project at any stage and that this will not affect my status now or in the future.

4. I understand that while information gained during the study may be published, I will not be identified and my personal results will remain confidential.

5. I understand the statement in the information sheet concerning payment to me for taking part in the study. Omit this point if no payment will be made.

Name of participant

Signed Date

I have provided information about the research to the research participant and believe that he/she understands what is involved.

Researcher's signature and date 


\section{Appendix V Language Contact Profile (LCP)}

\section{PRE-TEST VERSION OF THE LANGUAGE CONTACT PROFILE}

\section{PROJECT: ACQUISITION OF ENGLISH AS A SECOND LANGUAGE}

The responses that you give in this questionnaire will be kept confidential. This cover sheet is to allow the researcher to associate your responses with your name if needed. However, only the people entering your responses into the computer will see this name. An identification number will be used in place of your name when referring to your responses in publications. Every effort will be made to keep your responses confidential. Thank you for your cooperation. The information that you provide will help us to better understand the backgrounds of students who are studying English in various contexts. Your honest and detailed responses will be greatly appreciated.

Name:

\section{Part 1: Background Information}

1. Gender: Male / Female

2. Age:

3. Country of birth:

4. What is your native language? 1) English

2) Cantonese 3) Other

5. What languages do you speak at home?

1) English 2) Cantonese 3) Other

5a. If more than one, with whom do you speak each of these languages?

6. In what languages did you receive the majority of your pre-university education?

1) English 2) Cantonese 3) Other

6a. If more than one, please give the approximate number of years for each language.

7. Have you ever been to a English-speaking region for the purpose of studying English? Circle one: Yes / No

7a. If yes, when? 7b. Where?

7c. For how long? 1 semester or less 2 semesters more than 2 semesters

8. Other than the experience mentioned in Question 7, have you ever lived in a situation where you were exposed to a language other than your native language (e.g., by living in a multilingual community; visiting a community for purposes of study abroad or work; exposure through family members, etc.)? Circle one: Yes / No 
If Yes, please give details below. If more than three, list others on back of this page.

\begin{tabular}{|l|l|l|l|}
\hline & Experience 1 & Experience 2 & Experience 3 \\
\hline Country / region & & & \\
\hline Language & & & \\
\hline Purpose & & & \\
\hline From when to when & & & \\
\hline
\end{tabular}

9. In the boxes below, rate your language ability in each of the languages that you know. Use the following ratings: 0) Poor, 1) Good, 2) Very good, 3) Native / nativelike.

How many years (if any) have you studied this language in a formal school setting?

\begin{tabular}{|l|l|l|l|l|l|}
\hline Language & Listening & Speaking & Reading & Writing & Number of years of study \\
\hline English & & & & & \\
\hline Chinese & & & & & \\
\hline Other & & & & & \\
\hline
\end{tabular}

10. Have you studied English in school in the past at each of the levels listed below? If yes, for

how long?
a) Primary school:
_No _Yes: _less than 1 year__1-2 years _more than 2 years
b) Secondary school (Forms1-5): _No _ Yes: _less than 1 year _ 1-2 years _more than 2 years
c) Secondary school (Forms 6-7): _No _Yes: _less than 1 year _ 1-2 years _more than 2 years
d) Post-secondary College:__No_Yes: _less than 1 year _ 1-2 years _more than 2 years
e) University:
f)Other
(Please
_No_Yes: _less than 1 year_ $1-2$ years _more than 2 years specify)
_No_Yes: _less than 1 year__1-2 years__more than 2 years

11. What year are you in school? (circle one): Freshman Sophomore Junior Senior Graduate student Other

12. What is major?

13. List any other activities that you commonly did using English prior to this semester. 
14. Please list all the English courses you are taking this semester. This includes English language courses as well as content area courses taught in the English language.

Course name

Course number Brief

description
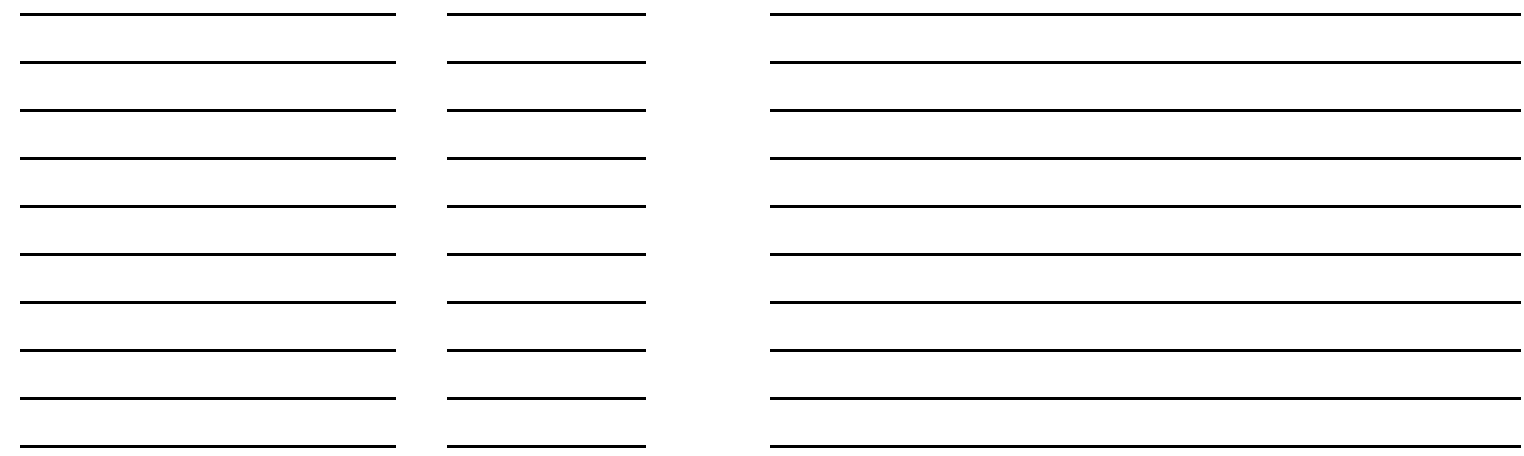

15. Which situation best describes your living arrangements before this semester?

a. I lived in the home of a English-speaking family. i. List the members of the family (e.g., mother, father and one 4-year-old daughter).

ii. Did they speak English? Circle one: Yes / No

iii. Were there other nonnative speakers of English living with your host family? Circle one: Yes / No

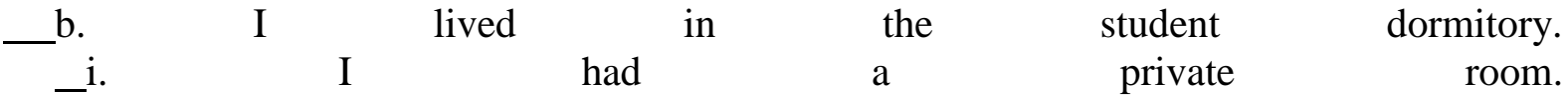

_ii. I had a roommate who was a native or fluent English speaker. iii. I lived with others who are NOT native or fluent English speakers.

c. I lived alone in a room or an apartment.

d. I lived in a room or an apartment with native or fluent English speaker(s).

e. I lived in a room or an apartment with others who are NOT native or fluent English speakers.

f. Other. Please specify:

For the following items, please specify:

(i) How many days per week you typically used English in the situation indicated, and

(ii) on average how many hours per day you did so. 
Part 2: All of the questions below refer to your use of English, not your native language, unless the question says otherwise.

For the following items, please specify:

(i) How many days per week you typically used English in the situation indicated, and

(ii) on average how many hours per day you did so.

Circle the appropriate numbers.

\section{Frequency of using Cantonese:}

1. On average, how much time did you spend speaking, in Cantonese before this semester?

i. Typically, how many days per week? $\quad \begin{array}{lllllllll} & 0 & 1 & 2 & 3 & 4 & 5 & 6 & 7\end{array}$

ii. On those days, typically how many hours per day? 0-1 $1-2 \quad 2-3 \quad 3-4 \quad 4-5$ more than 5

\section{Frequency of using English:}

2. On average, how much time did you spend speaking, in English, outside of class with native or fluent English speakers before this semester? i. Typically, how many days per week? $\quad \begin{array}{llllllllll} & 0 & 1 & 2 & 3 & 4 & 5 & 6 & 7\end{array}$ ii. On those days, typically how many hours per day? $0-1 \quad 1-2 \quad 2-3 \quad 3-4 \quad 4-5$ more than 5

3. Before this semester, outside of class, I tried to speak English to: 3a. my instructor i. Typically, how many days per week? $\quad \begin{array}{lllllllll} & 0 & 1 & 2 & 3 & 4 & 5 & 6 & 7\end{array}$ ii. On those days, typically how many hours per day? $0-1 \quad 1-2 \quad 2-3 \quad 3-4 \quad 4-5$ more than 5

3b. friends who are native or fluent English speakers i. Typically, how many days per week? $\quad \begin{array}{lllllllll}0 & 1 & 2 & 3 & 4 & 5 & 6 & 7\end{array}$ ii. On those days, typically how many hours per day? $0-1 \quad 1-2 \quad 2-3 \quad 3-4 \quad 4-5$ more than 5

$3 \mathrm{c}$. classmates

i. Typically, how many days per week? $\quad \begin{array}{lllllllll}0 & 1 & 2 & 3 & 4 & 5 & 6 & 7\end{array}$ ii. On those days, typically how many hours per day? $0-1 \quad 1-2 \quad 2-3 \quad 3-4 \quad 4-5$ more than 5

3d. strangers whom I thought could speak English i. Typically, how many days per week? $\quad \begin{array}{llllllllll} & 0 & 1 & 2 & 3 & 4 & 5 & 6 & 7\end{array}$ ii. On those days, typically how many hours per day? $0-1 \quad 1-2 \quad 2-3 \quad 3-4 \quad 4-5$ more than 5

3e. a host family, English roommate, or other English speakers in the dormitory i. Typically, how many days per week? $\quad \begin{array}{lllllllll} & 0 & 1 & 2 & 3 & 4 & 5 & 6 & 7\end{array}$ ii. On those days, typically how many hours per day? $0-1 \quad 1-2 \quad 2-3 \quad 3-4 \quad 4-5$ more than 5

3f. $\quad$ service

i. Typically, how many days per week? $\quad \begin{array}{lllllllll} & 0 & 1 & 2 & 3 & 4 & 5 & 6 & 7\end{array}$ 
ii. On those days, typically how many hours per day? 0-1 $1-2 \quad 2-3 \quad 3-4 \quad 4-5$ more than 5

3g. other; specify:

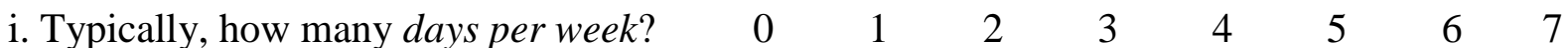

ii. On those days, typically how many hours per day? $0-1 \quad 1-2 \quad 2-3 \quad 3-4 \quad 4-5$ more than 5

\section{Purpose of using English:}

4. Before this semester, how often did you use English outside the classroom for each of the following purposes?

4a. to clarify classroom-related work

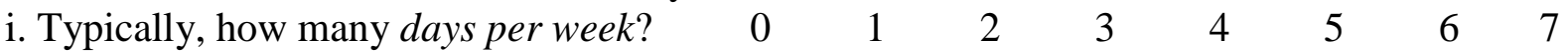
ii. On those days, typically how many hours per day? $0-1 \quad 1-2 \quad 2-3 \quad 3-4 \quad 4-5$ more than 5

4b. to obtain directions or information (e.g., "Where is the post office?", "What time is the train to . . . ?", "How much are stamps?") i. Typically, how many days per week? $\quad \begin{array}{llllllllll}0 & 1 & 2 & 3 & 4 & 5 & 6 & 7\end{array}$ ii. On those days, typically how many hours per day? 0-1 $1-2 \quad 2-3 \quad 3-4 \quad 4-5$ more than 5

4c. for superficial or brief exchanges (e.g., greetings, "Please pass the salt," "I'm leaving," ordering in a restaurant) with my host family, English roommate, or acquaintances in a English-speaking

i. Typically, how many days per week? $\quad \begin{array}{lllllllrrrr} & 0 & 1 & 2 & 3 & 4 & 5 & 6 & 7\end{array}$ ii. On those days, typically how many hours per day? $0-1 \quad 1-2 \quad 2-3 \quad 3-4 \quad 4-5$ more than 5

4d. extended conversations with my host family, English roommate, friends, or acquaintances in a English-speaking dormitory, native speakers of English with whom I speak English i. Typically, how many days per week? $\quad \begin{array}{lllllllll} & 0 & 1 & 2 & 3 & 4 & 5 & 6 & 7\end{array}$ ii. On those days, typically how many hours per day? 0-1 $1-2 \quad 2-3 \quad 3-4 \quad 4-5$ more than 5

\section{Using what you have learned in class:}

5a. How often did you try deliberately to use things you were taught in the classroom (grammar, vocabulary, expressions) with native or fluent speakers outside the classroom?

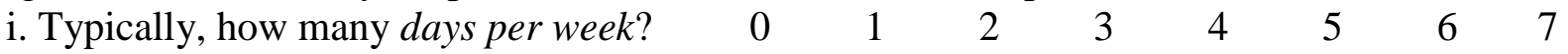
ii. On those days, typically how many hours per day? 0-1 $1-2 \quad 2-3 \quad 3-4 \quad 4-5$ more than 5

5b. How often did you take things you learned outside of the classroom (grammar, vocabulary, expressions) back to class for question or discussion? i. Typically, how many days per week? $\quad \begin{array}{lllllllll} & 0 & 1 & 2 & 3 & 4 & 5 & 6 & 7\end{array}$ ii. On those days, typically how many hours per day? $0-1 \quad 1-2 \quad 2-3 \quad 3-4 \quad 4-5$ more than 5 


\section{Speaking in English:}

6. How much time did you spend doing the following each week before this semester? 6a. speaking a language other than English or Chinese to speakers of that language (e.g., French with a french-speaking friend) i. Typically, how many days per week? $\quad \begin{array}{lllllllll} & 0 & 1 & 2 & 3 & 4 & 5 & 6 & 7\end{array}$ ii. On those days, typically how many hours per day? $0-1 \quad 1-2 \quad 2-3 \quad 3-4 \quad 4-5$ more than 5

6b. speaking English to native or fluent speakers of English i. Typically, how many days per week? $\quad \begin{array}{lllllllll}0 & 1 & 2 & 3 & 4 & 5 & 6 & 7\end{array}$ ii. On those days, typically how many hours per day? $0-1 \quad 1-2 \quad 2-3 \quad 3-4 \quad 4-5$ more than 5

6c. speaking English to nonnative speakers of English (i.e., classmates) i. Typically, how many days per week? $\quad \begin{array}{lllllllll}0 & 1 & 2 & 3 & 4 & 5 & 6 & 7\end{array}$ ii. On those days, typically how many hours per day? $0-1 \quad 1-2 \quad 2-3 \quad 3-4 \quad 4-5$ more than 5

\section{Activities outside class:}

7. How much time did you spend doing each of the following activities outside of class before this

semester? 7a. overall, in reading in English outside of class i. Typically, how many days per week? $\quad \begin{array}{lllllllll} & 0 & 1 & 2 & 3 & 4 & 5 & 6 & 7\end{array}$ ii. On those days, typically how many hours per day? $0-1 \quad 1-2 \quad 2-3 \quad 3-4 \quad 4-5$ more than 5

7b. reading English newspapers outside of class i. Typically, how many days per week? $\quad \begin{array}{llllllllll}0 & 1 & 2 & 3 & 4 & 5 & 6 & 7\end{array}$ ii. On those days, typically how many hours per day? $0-1 \quad 1-2 \quad 2-3 \quad 3-4 \quad 4-5$ more than 5

7c. reading novels in English outside of class i. Typically, how many days per week? $\quad \begin{array}{lllllllll}0 & 1 & 2 & 3 & 4 & 5 & 6 & 7\end{array}$ ii. On those days, typically how many hours per day? $0-1 \quad 1-2 \quad 2-3 \quad 3-4 \quad 4-5$ more than 5

7d. reading English language magazines outside of class i. Typically, how many days per week? $\quad \begin{array}{lllllllll} & 0 & 1 & 2 & 3 & 4 & 5 & 6 & 7\end{array}$ ii. On those days, typically how many hours per day? $0-1 \quad 1-2 \quad 2-3 \quad 3-4 \quad 4-5$ more than 5

7e. reading schedules, announcements, menus, and the like in English outside of class i. Typically, how many days per week? $\quad \begin{array}{lllllllll} & 0 & 1 & 2 & 3 & 4 & 5 & 6 & 7\end{array}$ ii. On those days, typically how many hours per day? $0-1 \quad 1-2 \quad 2-3 \quad 3-4 \quad 4-5$ more than 5

7f. reading e-mail or Internet web pages in English outside of class

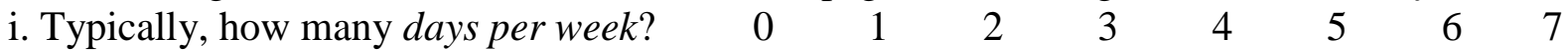
ii. On those days, typically how many hours per day? $0-1 \quad 1-2 \quad 2-3 \quad 3-4 \quad 4-5$ more than 5

7g. overall, in listening to English outside of class

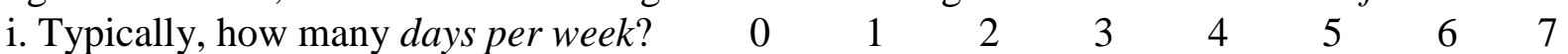


ii. On those days, typically how many hours per day? 0-1 $1-2 \quad 2-3 \quad 3-4 \quad 4-5$ more than 5

7h. listening to English television and radio outside of class i. Typically, how many days per week? $\quad \begin{array}{lllllllll} & 0 & 1 & 2 & 3 & 4 & 5 & 6 & 7\end{array}$ ii. On those days, typically how many hours per day? $0-1 \quad 1-2 \quad 2-3 \quad 3-4 \quad 4-5$ more than 5

7i. listening to English movies or videos outside of class

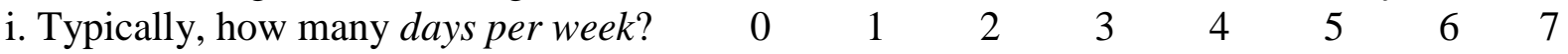
ii. On those days, typically how many hours per day? $0-1 \quad 1-2 \quad 2-3 \quad 3-4 \quad 4-5$ more than 5

7j. listening to English songs outside of class i. Typically, how many days per week? $\quad \begin{array}{lllllllll}0 & 1 & 2 & 3 & 4 & 5 & 6 & 7\end{array}$ ii. On those days, typically how many hours per day? $0-1 \quad 1-2 \quad 2-3 \quad 3-4 \quad 4-5$ more than 5

7k. trying to catch other people's conversations in English outside of class i. Typically, how many days per week? $\quad \begin{array}{lllllllll} & 0 & 1 & 2 & 3 & 4 & 5 & 6 & 7\end{array}$ ii. On those days, typically how many hours per day? $0-1 \quad 1-2 \quad 2-3 \quad 3-4 \quad 4-5$ more than 5

71. overall, in writing in English outside of class i. Typically, how many days per week? $\quad \begin{array}{lllllllll} & 0 & 1 & 2 & 3 & 4 & 5 & 6 & 7\end{array}$ ii. On those days, typically how many hours per day? 0-1 $1-2 \quad 2-3 \quad 3-4 \quad 4-5$ more than 5

$7 \mathrm{~m}$. writing homework assignments in English outside of class i. Typically, how many days per week? $\quad \begin{array}{llllllllll} & 0 & 1 & 2 & 3 & 4 & 5 & 6 & 7\end{array}$ ii. On those days, typically how many hours per day? 0-1 $1-2 \quad 2-3 \quad 3-4 \quad 4-5$ more than 5

7n. writing personal notes or letters in English outside of class i. Typically, how many days per week? $\quad \begin{array}{lllllllll} & 0 & 1 & 2 & 3 & 4 & 5 & 6 & 7\end{array}$ ii. On those days, typically how many hours per day? $0-1 \quad 1-2 \quad 2-3 \quad 3-4 \quad 4-5$ more than 5

7o. writing e-mail in English outside of class i. Typically, how many days per week? $\quad 0 \quad 0 \begin{array}{llllllll} & 0 & 2 & 3 & 4 & 5 & 6 & 7\end{array}$ ii. On those days, typically how many hours per day? $0-1 \quad 1-2 \quad 2-3 \quad 3-4 \quad 4-5$ more than 5

7p. filling in forms or questionnaires in English outside of class i. Typically, how many days per week? $\quad \begin{array}{lllllllll} & 0 & 1 & 2 & 3 & 4 & 5 & 6 & 7\end{array}$ ii. On those days, typically how many hours per day? $0-1 \quad 1-2 \quad 2-3 \quad 3-4 \quad 4-5$ more than 5

\section{Other activities involving the use of English:}

8. On average, how much time did you spend speaking in English outside of class before this semester? i. Typically, how many days per week? $\quad \begin{array}{lllllllll}0 & 1 & 2 & 3 & 4 & 5 & 6 & 7\end{array}$ ii. On those days, typically how many hours per day? $0-1 \quad 1-2 \quad 2-3 \quad 3-4 \quad 4-5$ more than 5 
9. How often did you do the following activities in English before this semester in Australia?

9a. reading newspapers, magazines, or novels or watching movies, television, or videos i. Typically, how many days per week? $\quad \begin{array}{lllllllll} & 0 & 1 & 2 & 3 & 4 & 5 & 6 & 7\end{array}$ ii. On those days, typically how many hours per day? $0-1 \quad 1-2 \quad 2-3 \quad 3-4 \quad 4-5$ more than 5

9b. reading e-mail or Internet web pages in English i. Typically, how many days per week? $\quad \begin{array}{lllllllll}0 & 1 & 2 & 3 & 4 & 5 & 6 & 7\end{array}$ ii. On those days, typically how many hours per day? $0-1 \quad 1-2 \quad 2-3 \quad 3-4 \quad 4-5$ more than 5

9c. writing e-mail in english i. Typically, how many days per week? $\quad \begin{array}{lllllllll}0 & 1 & 2 & 3 & 4 & 5 & 6 & 7\end{array}$ ii. On those days, typically how many hours per day? $0-1 \quad 1-2 \quad 2-3 \quad 3-4 \quad 4-5$ more than 5

9d. writing personal notes and letters in English i. Typically, how many days per week? $\quad \begin{array}{lllllllll}0 & 1 & 2 & 3 & 4 & 5 & 6 & 7\end{array}$ ii. On those days, typically how many hours per day? $0-1 \quad 1-2 \quad 2-3 \quad 3-4 \quad 4-5$ more than 5 
Self-rated proficiency and self-rated confidence levels:

1. How would you rate your English level BEFORE you came to Australia (SALs)/this semester (AHLs)?

$1=$ Very poor, $2=$ Poor, $3=$ Average, $4=$ Good, $5=$ Very good

\begin{tabular}{|l|l|l|l|l|l|}
\hline & 1 & 2 & 3 & 4 & 5 \\
\hline Speaking & & & & & \\
\hline Reading & & & & & \\
\hline Listening & & & & & \\
\hline Writing & & & & & \\
\hline Ability to Communicate effectively & & & & & \\
\hline Grammar & & & & & \\
\hline
\end{tabular}

2. How would you rate your English level AFTER you came to Australia (SALs)/this semester (AHLs)?

$1=$ Very poor, $2=$ Poor, $3=$ Average, $4=$ Good, $5=$ Very good

\begin{tabular}{|l|l|l|l|l|l|}
\hline & 1 & 2 & 3 & 4 & 5 \\
\hline Speaking & & & & & \\
\hline Reading & & & & & \\
\hline Listening & & & & & \\
\hline Writing & & & & & \\
\hline Ability to Communicate effectively & & & & & \\
\hline Grammar & & & & & \\
\hline
\end{tabular}

3. How confident were you in using English level BEFORE you came to Australia (SALs)/this semester (AHLs)?

$1=$ Very poor, $2=$ Poor, $3=$ Average, $4=$ Good, $5=$ Very good

\begin{tabular}{|l|l|l|l|l|l|}
\hline & 1 & 2 & 3 & 4 & 5 \\
\hline Speaking & & & & & \\
\hline Reading & & & & & \\
\hline Listening & & & & & \\
\hline Writing & & & & & \\
\hline Ability to Communicate effectively & & & & & \\
\hline Grammar & & & & & \\
\hline
\end{tabular}

4. How confident are you in using English level AFTER you came to Australia (SALs)/this semester (AHLs)?

$1=$ Very poor, $2=$ Poor, $3=$ Average, $4=$ Good, $5=$ Very good

\begin{tabular}{|l|l|l|l|l|l|}
\hline & 1 & 2 & 3 & 4 & 5 \\
\hline Speaking & & & & & \\
\hline Reading & & & & & \\
\hline Listening & & & & & \\
\hline Writing & & & & & \\
\hline Ability to Communicate effectively & & & & & \\
\hline Grammar & & & & & \\
\hline
\end{tabular}

This is the end of the questionnaire. Thank you very much for your time.

Adapted from The Language Contact Profile, Barbara F. Freed, Dan Dewey and Norman Segalowitz. 
2. POST-TEST VERSION OF THE LANGUAGE CONTACT PROFILE (Rounds 2 and 3)

\section{PROJECT: ACQUISITION OF ENGLISH AS A SECOND LANGUAGE}

The responses that you give in this questionnaire will be kept confidential. This cover sheet is to allow the researcher to associate your responses with your name if needed. However, only the people entering your responses into the computer will see this name. An identification number will be used in place of your name when referring to your responses in publications. Every effort will be made to keep your responses confidential.

The information that you provide will help us to better understand the learning experiences of students of English. Your honest and detailed responses will be greatly appreciated.

Name:

Please indicate the English language courses you are taking this semester:

Course name

Course number Brief description
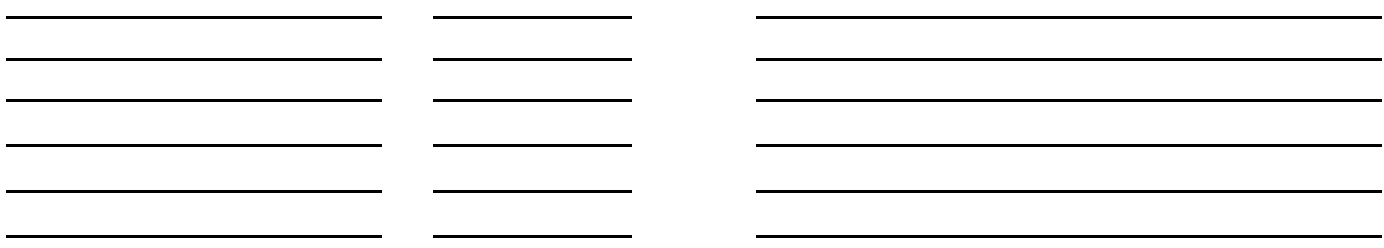

Part 1. Which situation best describes your living arrangements in Australia during the past semester?

a. I lived in the home of a English-speaking family. i. List the members of the family (e.g., mother, father and one 4-year-old daughter).

ii. Did they speak English? Circle one: Yes / No

iii. Were there other nonnative speakers of English living with your host family? Circle one: Yes / No

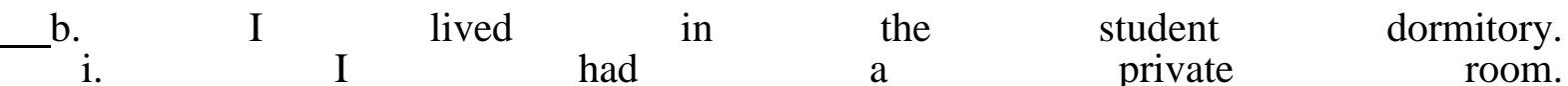
-ii. I had a roommate who was a native or fluent English speaker. _iii. I lived with others who are NOT native or fluent English speakers.

c. I lived alone in a room or an apartment.

_ d. I lived in a room or an apartment with native or fluent English speaker(s).

e. I lived in a room or an apartment with others who are NOT native or fluent English speakers.

f. Other. Please specify: 
Part 2: All of the questions below refer to your use of English, not your native language, unless the question says otherwise.

For the following items, please specify:

(i) How many days per week you typically used English in the situation indicated, and

(ii) on average how many hours per day you did so.

\section{Circle the appropriate numbers.}

\section{Frequency of using Cantonese:}

1. On average, how much time did you spend speaking, in Cantonese this semester?

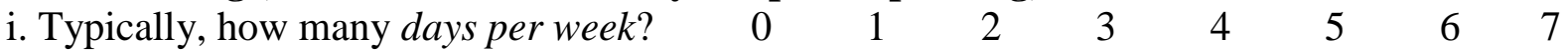
ii. On those days, typically how many hours per day? $0-1 \quad 1-2 \quad 2-3 \quad 3-4 \quad 4-5$ more than 5

\section{Frequency of using English:}

2. On average, how much time did you spend speaking, in English, outside of class with native or fluent English speakers during this semester?

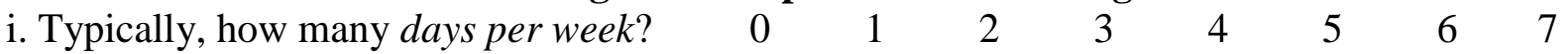
ii. On those days, typically how many hours per day? $0-1 \quad 1-2 \quad 2-3 \quad 3-4 \quad 4-5$ more than 5

3. This semester, outside of class, I tried to speak English to: 3a. my instructor i. Typically, how many days per week? $\quad \begin{array}{lllllllll} & 0 & 1 & 2 & 3 & 4 & 5 & 6 & 7\end{array}$ ii. On those days, typically how many hours per day? $0-1 \quad 1-2 \quad 2-3 \quad 3-4 \quad 4-5$ more than 5

3b. friends who are native or fluent English speakers i. Typically, how many days per week? $\quad \begin{array}{lllllllll} & 0 & 1 & 2 & 3 & 4 & 5 & 6 & 7\end{array}$ ii. On those days, typically how many hours per day? $0-1 \quad 1-2 \quad 2-3 \quad 3-4 \quad 4-5$ more than 5

3c. classmates

i. Typically, how many days per week? $\quad \begin{array}{llllllllll}0 & 1 & 2 & 3 & 4 & 5 & 6 & 7\end{array}$ ii. On those days, typically how many hours per day? 0-1 $1-2 \quad 2-3 \quad 3-4 \quad 4-5$ more than 5

3d. strangers whom I thought could speak English i. Typically, how many days per week? $\quad \begin{array}{llllllllll} & 0 & 1 & 2 & 3 & 4 & 5 & 6 & 7\end{array}$ ii. On those days, typically how many hours per day? $0-1 \quad 1-2 \quad 2-3 \quad 3-4 \quad 4-5$ more than 5

3e. a host family, English roommate, or other English speakers in the dormitory

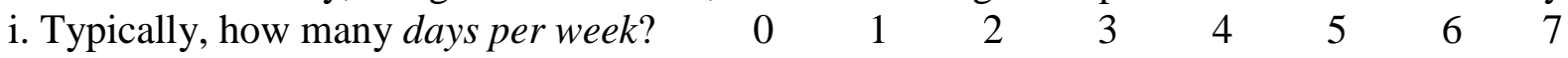
ii. On those days, typically how many hours per day? $0-1 \quad 1-2 \quad 2-3 \quad 3-4 \quad 4-5$ more than 5

3f. service personnel

i. Typically, how many days per week? $\quad \begin{array}{llllllllll}0 & 1 & 2 & 3 & 4 & 5 & 6 & 7\end{array}$ ii. On those days, typically how many hours per day? 0-1 $1-2 \quad 2-3 \quad 3-4 \quad 4-5$ more than 5 
3g. other; specify:

i. Typically, how many days per week? $\quad \begin{array}{lllllllll}0 & 1 & 2 & 3 & 4 & 5 & 6 & 7\end{array}$ ii. On those days, typically how many hours per day? $0-1 \quad 1-2 \quad 2-3 \quad 3-4 \quad 4-5$ more than 5

\section{Purpose of using English:}

4. How often did you use English outside the classroom for each of the following purposes?

4a. to clarify classroom-related work i. Typically, how many days per week? $\quad \begin{array}{lllllllll} & 0 & 1 & 2 & 3 & 4 & 5 & 6 & 7\end{array}$ ii. On those days, typically how many hours per day? $0-1 \quad 1-2 \quad 2-3 \quad 3-4 \quad 4-5$ more than 5

4b. to obtain directions or information (e.g., "Where is the post office?", "What time is the train to . . . ?", "How much are stamps?") i. Typically, how many days per week? $\quad \begin{array}{lllllllll} & 0 & 1 & 2 & 3 & 4 & 5 & 6 & 7\end{array}$ ii. On those days, typically how many hours per day? 0-1 $1-2 \quad 2-3 \quad 3-4 \quad 4-5$ more than 5

4c. for superficial or brief exchanges (e.g., greetings, "Please pass the salt," "I'm leaving," ordering in a restaurant) with my host family, English roommate, or acquaintances in a English-speaking

i. Typically, how many days per week? $\quad \begin{array}{lllllllll} & 0 & 1 & 2 & 3 & 4 & 5 & 6 & 7\end{array}$ ii. On those days, typically how many hours per day? $0-1 \quad 1-2 \quad 2-3 \quad 3-4 \quad 4-5$ more than 5

4d. extended conversations with my host family, English roommate, friends, or acquaintances in a English-speaking dormitory, native speakers of English with whom I speak English i. Typically, how many days per week? $\quad \begin{array}{lllllllll} & 0 & 1 & 2 & 3 & 4 & 5 & 6 & 7\end{array}$ ii. On those days, typically how many hours per day? $0-1 \quad 1-2 \quad 2-3 \quad 3-4 \quad 4-5$ more than 5

\section{Using what you have learned in class:}

5a. How often did you try deliberately to use things you were taught in the classroom (grammar, vocabulary, expressions) with native or fluent speakers outside the classroom?

i. Typically, how many days per week? $\quad \begin{array}{lllllllll} & 0 & 1 & 2 & 3 & 4 & 5 & 6 & 7\end{array}$ ii. On those days, typically how many hours per day? $0-1 \quad 1-2 \quad 2-3 \quad 3-4 \quad 4-5$ more than 5

5b. How often did you take things you learned outside of the classroom (grammar, vocabulary, expressions) back to class for question or discussion? i. Typically, how many days per week? $\quad 0 \quad 0 \quad 1 \quad r \begin{array}{lllllll} & 2 & 3 & 4 & 5 & 6 & 7\end{array}$ ii. On those days, typically how many hours per day? $0-1 \quad 1-2 \quad 2-3 \quad 3-4 \quad 4-5$ more than 5 


\section{Speaking in English:}

6. How much time did you spend doing the following each week this semseter? 6a. speaking a language other than English or English to speakers of that language (e.g., $\begin{array}{llll}\text { Chinese with } & \text { Chinese-speaking friend) }\end{array}$ i. Typically, how many days per week? $\quad \begin{array}{lllllllll} & 0 & 1 & 2 & 3 & 4 & 5 & 6 & 7\end{array}$ ii. On those days, typically how many hours per day? $0-1 \quad 1-2 \quad 2-3 \quad 3-4 \quad 4-5$ more than 5

6b. speaking English to native or fluent speakers of English i. Typically, how many days per week? $\quad \begin{array}{lllllllll}0 & 1 & 2 & 3 & 4 & 5 & 6 & 7\end{array}$ ii. On those days, typically how many hours per day? $0-1 \quad 1-2 \quad 2-3 \quad 3-4 \quad 4-5$ more than 5

6c. speaking English to nonnative speakers of English (i.e., classmates) i. Typically, how many days per week? $\quad \begin{array}{lllllllll}0 & 1 & 2 & 3 & 4 & 5 & 6 & 7\end{array}$ ii. On those days, typically how many hours per day? $0-1 \quad 1-2 \quad 2-3 \quad 3-4 \quad 4-5$ more than 5

\section{Activities outside class:}

7. How much time did you spend doing each of the following activities outside of class this semester? 7a. overall, in reading in English outside of class i. Typically, how many days per week? $\quad \begin{array}{lllllllll} & 0 & 1 & 2 & 3 & 4 & 5 & 6 & 7\end{array}$ ii. On those days, typically how many hours per day? $0-1 \quad 1-2 \quad 2-3 \quad 3-4 \quad 4-5$ more than 5

7b. reading English newspapers outside of class i. Typically, how many days per week? $\quad \begin{array}{llllllllll}0 & 1 & 2 & 3 & 4 & 5 & 6 & 7\end{array}$ ii. On those days, typically how many hours per day? $0-1 \quad 1-2 \quad 2-3 \quad 3-4 \quad 4-5$ more than 5

7c. reading novels in English outside of class i. Typically, how many days per week? $\quad \begin{array}{lllllllll}0 & 1 & 2 & 3 & 4 & 5 & 6 & 7\end{array}$ ii. On those days, typically how many hours per day? $0-1 \quad 1-2 \quad 2-3 \quad 3-4 \quad 4-5$ more than 5

7d. reading English language magazines outside of class i. Typically, how many days per week? $\quad \begin{array}{llllllllll} & 0 & 1 & 2 & 3 & 4 & 5 & 6 & 7\end{array}$ ii. On those days, typically how many hours per day? $0-1 \quad 1-2 \quad 2-3 \quad 3-4 \quad 4-5$ more than 5

7e. reading schedules, announcements, menus, and the like in English outside of class i. Typically, how many days per week? $\quad \begin{array}{lllllllll} & 0 & 1 & 2 & 3 & 4 & 5 & 6 & 7\end{array}$ ii. On those days, typically how many hours per day? $0-1 \quad 1-2 \quad 2-3 \quad 3-4 \quad 4-5$ more than 5

7f. reading e-mail or Internet web pages in English outside of class i. Typically, how many days per week? $\quad \begin{array}{lllllllll} & 0 & 1 & 2 & 3 & 4 & 5 & 6 & 7\end{array}$ ii. On those days, typically how many hours per day? $0-1 \quad 1-2 \quad 2-3 \quad 3-4 \quad 4-5$ more than 5 
7g. overall, in listening to English outside of class i. Typically, how many days per week? $\quad \begin{array}{lllllllll}0 & 1 & 2 & 3 & 4 & 5 & 6 & 7\end{array}$ ii. On those days, typically how many hours per day? $0-1 \quad 1-2 \quad 2-3 \quad 3-4 \quad 4-5$ more than 5

7h. listening to English television and radio outside of class

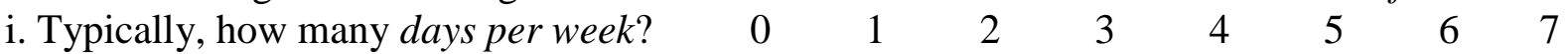
ii. On those days, typically how many hours per day? $0-1 \quad 1-2 \quad 2-3 \quad 3-4 \quad 4-5$ more than 5

7i. listening to English movies or videos outside of class i. Typically, how many days per week? $\quad \begin{array}{llllllllll} & 0 & 1 & 2 & 3 & 4 & 5 & 6 & 7\end{array}$ ii. On those days, typically how many hours per day? $0-1 \quad 1-2 \quad 2-3 \quad 3-4 \quad 4-5$ more than 5

$7 \mathrm{j}$. listening to English songs outside of class i. Typically, how many days per week? $\quad \begin{array}{llllllllll}0 & 1 & 2 & 3 & 4 & 5 & 6 & 7\end{array}$ ii. On those days, typically how many hours per day? $0-1 \quad 1-2 \quad 2-3 \quad 3-4 \quad 4-5$ more than 5

7k. trying to catch other people's conversations in English outside of class

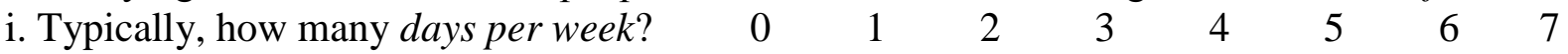
ii. On those days, typically how many hours per day? $0-1 \quad 1-2 \quad 2-3 \quad 3-4 \quad 4-5$ more than 5

71. overall, in writing in English outside of class i. Typically, how many days per week? $\quad \begin{array}{lllllllll} & 0 & 1 & 2 & 3 & 4 & 5 & 6 & 7\end{array}$ ii. On those days, typically how many hours per day? $0-1 \quad 1-2 \quad 2-3 \quad 3-4 \quad 4-5$ more than 5

$7 \mathrm{~m}$. writing homework assignments in English outside of class

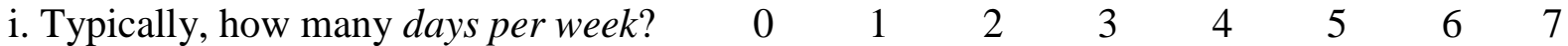
ii. On those days, typically how many hours per day? $0-1 \quad 1-2 \quad 2-3 \quad 3-4 \quad 4-5$ more than 5

7n. writing personal notes or letters in English outside of class

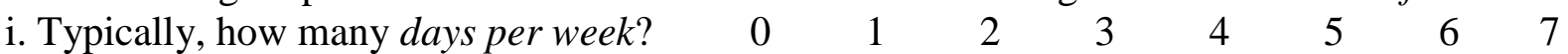
ii. On those days, typically how many hours per day? $0-1 \quad 1-2 \quad 2-3 \quad 3-4 \quad 4-5$ more than 5

7o. writing e-mail in English outside of class i. Typically, how many days per week? $\quad \begin{array}{llllllllll}0 & 1 & 2 & 3 & 4 & 5 & 6 & 7\end{array}$ ii. On those days, typically how many hours per day? $0-1 \quad 1-2 \quad 2-3 \quad 3-4 \quad 4-5$ more than 5

7p. filling in forms or questionnaires in English outside of class i. Typically, how many days per week? $\quad \begin{array}{lllllllll} & 0 & 1 & 2 & 3 & 4 & 5 & 6 & 7\end{array}$ ii. On those days, typically how many hours per day? 0-1 $1-2 \quad 2-3 \quad 3-4 \quad 4-5$ more than 5 


\section{Other activities involving the use of English:}

8. On average, how much time did you spend speaking in English outside of class during this semester?

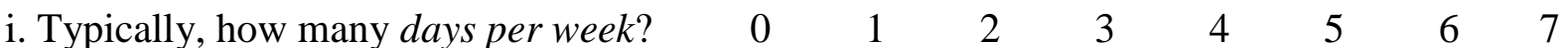
ii. On those days, typically how many hours per day? $0-1 \quad 1-2 \quad 2-3 \quad 3-4 \quad 4-5$ more than 5

9. How often did you do the following activities in English during this semester in Australia?

9a. reading newspapers, magazines, or novels or watching movies, television, or videos i. Typically, how many days per week? $\quad \begin{array}{lllllllll} & 0 & 1 & 2 & 3 & 4 & 5 & 6 & 7\end{array}$ ii. On those days, typically how many hours per day? $0-1 \quad 1-2 \quad 2-3 \quad 3-4 \quad 4-5$ more than 5

9b. reading e-mail or Internet web pages in English i. Typically, how many days per week? $\quad \begin{array}{lllllllll}0 & 1 & 2 & 3 & 4 & 5 & 6 & 7\end{array}$ ii. On those days, typically how many hours per day? $0-1 \quad 1-2 \quad 2-3 \quad 3-4 \quad 4-5$ more than 5

9c. writing e-mail in i. Typically, how many days per week? $\quad \begin{array}{llllllllll} & 0 & 1 & 2 & 3 & 4 & 5 & 6 & 7\end{array}$ ii. On those days, typically how many hours per day? $0-1 \quad 1-2 \quad 2-3 \quad 3-4 \quad 4-5$ more than 5

9d. writing personal notes and letters in English i. Typically, how many days per week? $\quad \begin{array}{lllllllll} & 0 & 1 & 2 & 3 & 4 & 5 & 6 & 7\end{array}$ ii. On those days, typically how many hours per day? $0-1 \quad 1-2 \quad 2-3 \quad 3-4 \quad 4-5$ more than 5 


\section{Self-rated proficiency and self-rated confidence levels:}

1. How would you rate your English level BEFORE you came to Australia (SALs) / this semester (AHLs)?

$1=$ Very poor, $2=$ Poor, $3=$ Average, $4=$ Good, $5=$ Very good

\begin{tabular}{|l|l|l|l|l|l|}
\hline & 1 & 2 & 3 & 4 & 5 \\
\hline Speaking & & & & & \\
\hline Reading & & & & & \\
\hline Listening & & & & & \\
\hline Writing & & & & & \\
\hline Ability to Communicate effectively & & & & & \\
\hline Grammar & & & & & \\
\hline
\end{tabular}

2. How would you rate your English level AFTER you came to Australia (SALs) / this semester (AHLs)?

$1=$ Very poor, $2=$ Poor, $3=$ Average, $4=$ Good, $5=$ Very good

\begin{tabular}{|l|l|l|l|l|l|}
\hline & 1 & 2 & 3 & 4 & 5 \\
\hline Speaking & & & & & \\
\hline Reading & & & & & \\
\hline Listening & & & & & \\
\hline Writing & & & & & \\
\hline Ability to Communicate effectively & & & & & \\
\hline Grammar & & & & & \\
\hline
\end{tabular}

3. How confident were you in using English level BEFORE you came to Australia (SALs) / this semester (AHLs)?

$1=$ Very poor, $2=$ Poor, $3=$ Average, $4=$ Good, $5=$ Very good

\begin{tabular}{|l|l|l|l|l|l|}
\hline & 1 & 2 & 3 & 4 & 5 \\
\hline Speaking & & & & & \\
\hline Reading & & & & & \\
\hline Listening & & & & & \\
\hline Writing & & & & & \\
\hline Ability to Communicate effectively & & & & & \\
\hline Grammar & & & & & \\
\hline
\end{tabular}

4. How confident are you in using English level $\boldsymbol{A F T E R}$ you came to Australia (SALs) / this semester (AHLs)?

$1=$ Very poor, $2=$ Poor, $3=$ Average, $4=$ Good, $5=$ Very good

\begin{tabular}{|l|l|l|l|l|l|}
\hline & 1 & 2 & 3 & 4 & 5 \\
\hline Speaking & & & & & \\
\hline Reading & & & & & \\
\hline Listening & & & & & \\
\hline Writing & & & & & \\
\hline Ability to Communicate effectively & & & & & \\
\hline Grammar & & & & & \\
\hline
\end{tabular}

This is the end of the questionnaire. Thank you very much for your time.

Adapted from The Language Contact Profile, Barbara F. Freed, Dan Dewey and Norman Segalowitz. 


\section{Appendix VI Pre- and post- oral EDCTs (The questions were presented in different order in the three rounds of data collection.}

Here are some scenarios. Please say aloud what you feel is a good response to each situation. There is no word limit.

There are some situations. Listen to each one carefully. Put yourself in the situation and think about what you would say based on your past experiences. Then say aloud your answer. There is no right or wrong answer. If you don't understand the situation after I read it out, let me know and I will read it out to you again. Do you understand? Remember, there is no right or wrong answer, OK.

\section{Participant with equal status as interlocutor:}

i. It is 2am on a Wednesday night and you have a very important exam for your major at 8am tomorrow morning. You have been trying to sleep for three hours and you can't because you hear loud music coming from another student's room down the hall. You decide to ask her to turn the volume down. The television has been on at this volume for three hours. You have occasionally seen the student, Anita Jones, in the same dorm during the past six months. She is a student like you and she is your friend. You have heard other people in the dormitory complain about the volume of her music on several occasions, although you never have because you usually sleep late. However, you must sleep early before the exam otherwise you will be tired and can't concentrate during the exam. You know that the professor is very strict with marking and the exam is very difficult. What would you say?

ii. You are at the end of a history class and you are sitting next to Tom Yates. You missed last week's class and need to borrow his notes. He has been in the same program as you for one year and you see him socially about once a month in a group. You will also be taking classes together in the future. He is a good note taker and one of the best students in the class. You have borrowed his notes twice before for the same class and the last time you borrowed them he was reluctant to give them up. In two weeks, you both have final exam for your class. What would you say?

\section{Participant has higher status than interlocutor:}

i. You are an associate professor teaching an English course. You want your graduate student to teach an undergraduate class a week earlier than scheduled. It is the middle of the term and you know your graduate student is very busy. You want your graduate student who is a native English speaker to teach the class how to write an essay. Your student, Rose Goodwin, is very hardworking and clever. She always gives you very good work and submits work on time. Even though you didn't know her until this semester, she has a reputation as one of the best students in the department. You want her to teach your class next week instead of three weeks from now because her lesson is more relevant to next week's lecture. However, midterm exams are next week and you know she has a heavy course load. She has made several contributions to the department, and has been given some good feedback from you. 
You ask her if you could see her for a minute when you saw her in the canteen. No one else is there and you are talking to her alone. What would you say?

ii. You (an associate professor teaching a course on Environmental Science) want a student to write a paper in class a week earlier than scheduled. It is the middle of the term and topics were assigned at the beginning of the course. The paper is 1,500 words about how to improve the pollution problem. Your student, Rose Goodwin, is a very hardworking and clever student who always contributes to class discussions and is very well prepared for class. Even though you have never had her in class before this semester, she has a reputation as one of the best students in the department. You want her to submit the paper next week instead of three weeks from now because her article is more relevant to next week's lecture. However, midterm exams are next week and you know she has a heavy course load. She has made several contributions during this class, and has been given some good feedback from you. You ask her if you could see her for a minute after class. The students have all left and you are talking to her alone. What would you say?

\section{Participant has low status than interlocutor:}

i. Your final essay for your major is due today, but you haven't finished it yet. You want to ask the teacher Mr James Wilson for an extension. You had a lot of difficulty writing the essay, but you know you can make it better if you could have another week to finish it. You have never handed work in late before, and have contributed a lot of ideas in class and prepared well for all the classes. In fact, you got an A for Mr James Wilson's course last semester. But you haven't seen him a lot since then. You know Mr James Wilson doesn't give extensions to students because he is usually very busy. However, you think you might have a chance because you have been a good student in the past. You are with him at the end of the class. What would you say?

ii. It is $5.30 \mathrm{pm}$, your last lesson has just finished and you need a lift home. You realise that a fellow classmate who was supposed to give you a lift is not in lesson today. You have a lot of books with you tonight, the snow has made walking difficult and you need a lift home from school. As you come out of lesson, you see Amy Bernstead, an assistant professor in the department who teaches a lesson that ends at the same time as yours. She lives on the same street as you and she is standing talking to some other students. She is smiling and laughing. You have never spoken to her before but you have seen her on occasion in the department in the last few months and have both nodded to each other once or twice in the neighbourhood. You know that she has a car and you once saw her give a lift to one of the students. What would you say? 


\section{Appendix VII Open role-plays}

\section{Instructions for open role-plays}

Tasks:

1. All of you must put together a conversation right from the beginning to the end.

2. You must find a solution.

3. Everyone in the group must speak.

\section{Participant with equal status as interlocutor:}

\section{i. Plagiarism (letting your friends copy your work)}

You have always got good marks for your English essays and all your friends know that.

Your friends (including your boyfriend/girlfriend) always ask if they can copy of your work. You always let them in the past.

One day, you got sick of ALL your friends copying of your work, including your boyfriend/girlfriend. How will you tell them you do not want them to copy anymore??? You may lose your friends if you tell them!

\section{ii. Dinner with classmates}

You just got paid from your part-time job and you invited your classmates out for dinner and told them you will pay, so your classmates agreed to go to dinner with you.

Many of your classmates hate ' $X$ ', so many of them enjoyed saying so many bad things about ' $\mathrm{X}$ ' during dinner. You are the only person who likes ' $\mathrm{X}$ '.

During the dinner, you got so angry about how nasty your classmates were about ' $X$ ' that you do not want to pay for their dinner anymore!

How embarrassing!!! What are you going to do?? How are you going to tell your friends?

\section{Participant has higher status than interlocutor:}

\section{i. Presenting work earlier than scheduled}

You are a supervisor working in a company

You lent one of your team members money because there were problems with his/her family.

You really need to get the money back for emergency.

\section{ii. Asking students to submit work earlier than scheduled}

You are a professor.

You know your students are all very busy.

You need one of your students to teach your class about essay writing but you feel very bad. What will you do? 


\section{Participant has low status than interlocutor:}

\section{i. Returning book}

Your professor let you borrow his book so you could do your assignment.

When you got home one day, you found that your dog has bitten the book into pieces.

You did not want to tell your professor the book yet because you were hoping you could find another copy. Unfortunately, you cannot find another copy in any bookshop in HK.

After two months, you friend wanted you to return the book. What are you going to do?

\section{ii. Borrowing an umbrella}

You just finished a lecture with your professor.

It's raining very heavily outside.

None of your friends has umbrellas.

You urgently need to get to work. You need to get to the bus-stop to catch a bus to work.

You start work in 15 minutes in a restaurant so you can't let your uniform get wet.

You can see your professor has an umbrella. 


\section{Appendix VIII Interview questions on at-home and study abroad learners' experiences and attitudes towards learning English}

\section{HK students (pre- and post- tests):}

\section{i. Pre-test}

1. What is the main reason for you to come to CUHK?

2. Are you a first year CUHK student?

3. Where do you live-Hostel or home?

4. Do you speak in English or Cantonese/Putonghua in your living environment?

5. Did you go to an EMI or CMI school?

6. How long have you been learning English?

7. Did you go to additional English classes outside school?

If so, what courses?

Length of course?

how often?

8. Did you speak in English outside the classroom in secondary school?

If yes, with whom?

how often per week? Never, 1-5 hours, 6-10 hours, 11-15 hours, 16-20 hours or more than 21 hours?

9. Do you speak in English outside the classroom since coming to university?

If yes, with whom?

how often per week? Never, 1-5 hours, 6-10 hours, 11-15 hours, 16-20 hours or more than 21 hours?

10. In your spare time, do you only mix with local HK people or mainland people?

What language do you use-Chinese or English?

11. Tell me three things you like and dislike about CUHK so far.

12. What are your experiences in learning English so far? Diff between sec and uni?

13. Are you confident in communicating in English?

14. Have you had to use English to communicate?

15. Have you had difficulties communicating in English? (Give two or three examples)

16. Tell me three situations in which you had to use English to ask for help or someone to give you information. 


\section{Post-tests}

1. How do you find studying at CUHK so far?

2. What are three things you have most improved on since coming to CUHK?

3. Can you please tell me what courses you have taken this semester (English courses and lectures)?

4. How do you feel about learning English at CUHK?

5. What is the most important thing you have learned about English from the courses at CUHK? Why?

6. Have you had more opportunities to use English this semester than the past? WHEN? WHY?

7. Have you had to ask people to do something or give you something in English? Successful? How do you feel?

8. Three situations you feel very good / bad about in communicating in English (i.e. when people don't understand what you say).

9. Do you spend much time speaking in English inside and outside class? WHY? WHY NOT?

10. What are your strengths and weaknesses? What will you do to improve on them?

11. How confident are you in speaking English? (REFER TO SHEET)

12. Refer to any comments from the pre-test?

\section{Hong Kong study abroad learners in Australia (pre- and post-tests):}

\section{i. Pre- test}

1. When did you arrive in Australia? How long do you plan to stay?

2. What is the main reason for you to come to Australia?

3. What did you do before you came to Australia? Highest level of course studied - e.g EMI or CMI sec school / foundation course?

4. How long have you been learning English in home country and in Australia?

5. Did you go to additional English classes outside school in home country and Australia?

If so, what courses?

Length of course?

how often?

6. Did you speak in English outside the classroom in secondary school? 
If yes, with whom?

how often per week? Never, 1-5 hours, 6-10 hours, 11-15 hours, 16-20 hours or more than 21 hours?

7. Do you speak in English outside the classroom in Hong Kong compared with now?

If yes, with whom?

how often per week? Never, 1-5 hours, 6-10 hours, 11-15 hours, 16-20 hours or more than 21 hours?

8. Why do you need to improve on your English?

9. Where are you staying?

10. Where do you live? Do you have many chances to speak in English?

11. In your spare time, do you see Hong Kong students or local Western Australian students?

12. Tell me three main differences between learning English in Australia compared to Hong Kong.

13. Tell me three things you like and dislike most about Australia.

14. What are your experiences in learning English so far? Diff between Hong Kong/China and Australia?

15. How do you like learning English in Australia so far?

16. Have you had difficulties communicating in English? (Give two or three examples)

17. Are you confident in communicating in English?

18. Tell me three situations in which you had to use English to ask for help or someone to give you information.

19. How would you rate your English level before you came to Australia?

\section{During the study and post-test}

1. How do you find studying in Australia so far?

2. How do you feel about learning English in Australia?

3. What are the main differences between studying in the Australia and Hong Kong?

4. Do/did the courses meet your expectations?

5. What are three things you have most improved on since coming to Australia?

6. What are the three things you have enjoyed most?

7. Can you please tell me what courses you have taken this semester (English courses and lectures)?

8. What is the most important thing you have learned about English from the courses at Australia? Why? 
9. Have you had more opportunities to use English this semester than the past? WHEN? WHY?

10. Have you had to ask people to do something or give you something in English? Successful? How do you feel?

11. Three situations you feel very good / bad about in communicating in English (i.e. when people don't understand what you say).

12. Do you spend much time speaking in English inside and outside class? WHY? WHY NOT?

13. What are your strengths and weaknesses? What will you do to improve on them?

14. How confident are you in speaking English? (REFER TO SHEET)

15. Refer to any comments from the pre-test?

16. Evaluation:

1. You did the same listening exercise at the beginning of the semester. How do you feel about doing it again this time? (SAME, EASIER OR MORE DIFFICULT, NO DIFFERENCE). What was easy, or difficult or why?

2. How do you feel about having to respond immediately afterwards?

3. Any difference between reading, then writing and listening and speaking?

4. Difference between short and long listening time?

5. Comment on the length of written and verbal responses and address.

6. Check awareness of talking so much before asking questions. 


\section{Appendix IX: Instructions for writing diaries}

\section{Diary instructions}

What should you write in the diary?

Think about situations you come across where you have to speak in English. Write down the times where you communicate successfully and unsuccessfully and try to work out the reasons why your communication is successful or unsuccessful.

1. Write down what you learn.

2. Write down the situations you face where you have to speak in English.

3. What was your conversation and discussion like?

4. How did you feel?

5. Did you have to ask someone to give you something or do something for you?

6. What did you say? How did your listener respond?

7. Did your listener(s) understand what you want - why or why not?

8. Feel free to write down anything else that you would like to share with me, or any questions you may have.

It is important for you to write down the good and bad experiences, then try to work out why you are successful or unsuccessful in the communication you have when you speak in English.

You will see how much you improve over time. More importantly, I will read it and give you feedback at the end of the programme. This is a good learning process for you.

Please write in a diary (i.e. exercise book) at least once per week. Your diary will be collected at the end of the study. Don't forget to write your name on the diary, and to include the date every time you write in it.

Please write to me at any time you have problems.

Email is: mistycook28@yahoo.com.au / misty.cook@vuw.ac.nz

Thank you so much for your help. 


\section{Appendix X: Transcription conventions}

(.)

:

$=$

[ ]
Pause of specific number of seconds (above two seconds)

Section of transcript omitted

Incomplete or cut-off utterance

Stress

Simultaneous speech

comments 


\section{References}

Achiba, M. (2003). Learning to request in a second language: A study of child interlanguage pragmatics (Vol. 2). Clevedon: Multilingual Matters Ltd.

Ahrenholz, B. (2000). Modality and referential movement in instructional discourse: Comparing the production of Italian learners of German with native German and native Italian production. Studies in Second Language Acquisition, 22, 337-368.

Allen, H. W. (2010a). Language-learning motivation in short-term study abroad. Foreign Language Annals, 43(1), 27-49.

Allen, H. W. (2010b). Interactive contact as linguistic affordance during short-term study abroad: Myth or reality? Frontiers: the Interdisciplinary Journal of Study Abroad, Volume XIX (Fall/Winter), in print.

Allen, H. W., \& Herron, C. (2003). A mixed-methodology investigation of the linguistic and affective outcomes of summer study abroad. Foreign Language Annals, 36(3), 370385.

Austin, J. L. (1962). How to Do Things With Words. Oxford: Clarendon Press.

Bailey, K. M., \& Ochsner, R. (1983). A methodological review of the diary studies: Windmill tilting or social science? In K. M. Bailey, L. M. H. \& S. Peck (Eds.), Second Language Acquisition Studies (pp. 188-198). Mass: Newbury House.

Bardovi-Harlig, K. (1999). Exploring the interlanguage pragmatics: A research agenda for acquisitional pragmatics. Language learning, 49(4), 677-713. 
Bardovi-Harlig, K. (2005). Contextualising interlanguage pragmatics. In A. Tyler, M. Takada, Y. Kim \& D. Marinova (Eds.), Language in Use: Cognitive and Discourse Perspectives on Language and Language Learning. Washington, D.C.: Georgetown University Press.

Bardovi-Harlig, K. (2006). On the role of formulas in the acquisition of L2 Pragmatics. In K. Bardovi-Harlig, C. Felix-Brasdefer \& A. S. Omar (Eds.), Pragmatics Language Learning (Vol. 11, pp. 1-28). Honolulu, Hawaii: University of Hawaii Press.

Bardovi-Harlig, K. (2008). Recognition and production of formulas in L2 pragmatics. In Z. H. Han (Ed.), Understanding Second Language Process (pp. 205-222). Clevedon, UK: Multilingual Matters.

Bardovi-Harlig, K. (2009a). Conventional expressions as a pragmalinguistic resource: Recognition and production of conventional expressions in L2 pragmatics. Language Learning, 59(4), 755-795.

Bardovi-Harlig, K. (2009b). Recognition of formulaic sequences in L2 pragmatics. In D. Y. G. Kasper, H. Nguyen, \& J. Yoshioka (Ed.), Pragmatics and Language Language Learning (Vol. 59:4. December 2009, pp. 755-795). Honolulu: University of Hawai'i, National Foreign Language Resource Centre.

Bardovi-Harlig, K., \& Dörnyei, Z. (1998). Do language learners recognise pragmatic violations? Pragmatic versus grammatical awareness in instructed L2 learning. TESOL Quarterly, 32(2), 233-261.

Bardovi-Harlig, K., \& Griffin, R. (2005). L2 pragmatic awareness: Evidence from the ESL classroom. System, 33, 401-415.

Bardovi-Harlig, K., \& Hartford, B. S. (1996). Input in an institutional setting. Studies in second language acquisition, 18, 171-188. 
Bardovi-Harlig, K., Rose, K. R., \& Nickels, E. L. (2008). The use of conventional expressions of thanking, apologizing and refusing. In M. Bowles, R. Foote, S. Perpiñán \& R. Bhatt (Eds.), Second Language Research Forum (pp. 113-130): Cascadilla Proceedings Project. www.lingref.com, document \#1739.

Barron, A. (2003). Acquisition in Interlanguage Pragmatics. Learning How to Do Things with Words. Amsterdam: John Benjamins.

Barron, A. (2005). Variational pragmatics in the foreign language classroom. System, 33(3), 519-536.

Barron, A. (2007a). 'Ah no honestly we're okay:' Learning to upgrade in a study abroad context. Intercultural Pragmatics, 4(2), 129-166.

Barron, A. (2007b). Acquisitional pragmatics: Focus on foreign language learners. Intercultural Pragmatics, 4(2), 113-127.

Barron, A. (2008). Contrasting requests in inner circle Englishes: A study in variational pragmatics. In M. Pütz \& J. N.-V. Aertselaer (Eds.), Developing Contrastive Pragmatics: Interlanguage and Cross-Cultural Perspectives (pp. 355-402). Berlin \& New York: Mouton de Gruyter.

Bataineh, R., \& Bataineh, R. F. (2006). Apology strategies of Jordanian EFL university students. Journal of Pragmatics, 38, 1901-1927.

Beebe, L. M., \& Cummings, M. C. (1996). Natural speech act data versus written questionnaire date: How data collection method affects speech act performance. In S. M. Gass \& N. Joyce (Eds.), Speech Acts across Cultures: Challenges to Communication in a Second Language (Vol. 11, Studies on Language Acquisition, pp. 66-86). Berlin: Mouton de Gruyter.

Billmyer, K., \& Varghese, M. (2000). Investigating instrument-based pragmatic variability: Effects of enhancing discourse completion tests. Applied Linguistics, 21(4), 517-552. 
Blum-Kulka, S. (1982). Learning to say what you mean in a second language: A study of the speech act performance of learners of Hebrew as a second language. Applied Linguistics, 3, 29-59.

Blum-Kulka, S. (1983). Interpreting and performing speech acts in a second language: A cross-cultural study of Hebrew and English. In N. Wolfson \& E. Judd (Eds.), Sociolinguistics and language acquisition (pp. 36-55). Rowley, MA: Newbury House.

Blum-Kulka, S. (1987). Indirectness and politeness in requests: Same or different? Journal of Pragmatics, 11, 145-160.

Blum-Kulka, S. (1989). Playing it safe: The role of conventionality in indirect requests. In S. Blum-Kulka, J. House \& G. Kasper (Eds.), Cross-cultural Pragmatics: Requests and Apologies (pp. 37-70). New Jersey: Ablex.

Blum-Kulka, S. (1991). Interlanguage pragmatics: The case of requesting. In R. Phillipson, E. Kellerman, L. Selinker, M. S. Smith \& M. Swain (Eds.), Foreign/second language pedagogy research (pp. 255-272). Clevedon: Multilingual matters.

Blum-Kulka, S., Danet, B., \& Gerson, R. (1985). The language of requesting in Israeli society. In J. Forgas (Ed.), Language and social situation (pp. 113-141). New York: Springer.

Blum-Kulka, S., \& House, J. (1989). Cross-cultural and situational variation in requesting behaviour. In S. Blum-Kulka \& G. Kapser (Eds.), Cross-cultural Pragmatics: Requests and Apologies (pp. 123-154). Norwood, NJ: Ablex.

Blum-Kulka, S., House, J., \& Kasper, G. (1989a). The CCSARP coding manual. In S. BlumKulka, J. House \& G. Kasper (Eds.), Cross-cultural Pragmatics: Requests and Apologies (pp. 273-294). Norwood, NJ: Ablex.

Blum-Kulka, S., House, J., \& Kasper, G. (Eds.). (1989b). Cross-cultural pragmatics: Requests and apologies (Vol. XXXI). New Jersey: Ablex. 
Blum-Kulka, S., \& Levenston, E. (1987). Lexical-grammatical pragmatic indicators. Studies in Second Language Acquisition, 9, 155-170.

Blum-Kulka, S., \& Olshtain, E. (1984). Requests and apologies: A cross-cultural study of Speech act realisation patterns (CCSARP). Applied Linguistics, 5(3), 196-213.

Blum-Kulka, S., \& Olshtain, E. (1986). Too many words: Length of utterance and pragmatic failure. Studies in Second Language Acquisition, 8, 165-180.

Bourdieu, P. (1977). Outline of a Theory of Practice. Cambridge: Cambridge University Press.

Bourdieu, P. (1991). Language and Symbolic Power. Cambridge: Polity Press.

Bouton, L. F. (Ed.). (1996). Pragmatics and Language Learning Monograph Series (Vol. 7). Illinois: Intensive English Institute, University of Illinois at Urbana-Champaign.

Bouton, L. F. (1988). A Cross-cultural study of ability to interpret implicatures in English. World Englishes, 7(2), 183-196.

Bouton, L. F. (1992). The interpretation of implicature in English by NNS: Does it come automatically-without being explicitly taught? In L. F. Bouton \& Y. Kachru (Eds.), Pragmatics and Language Learning (Vol. 3, pp. 53-65). Urbana-Champaign, IL: University of Illinois.

Bouton, L. F. (1994). Conversational implicature in the second language: Learned slowly when not deliberately taught. Journal of Pragmatics, 22, 157-167.

Bouton, L. F. (1999). Developing non-native speaker skills in interpreting conversational implicatures in English. In L. F. Bouton (Ed.), Pragmatics and Language Learning (Vol. 9, pp. 47-70). Urbana-Champaign, IL: University of Illinois.

Bouton, L. F., \& Kachru, Y. (Eds.). (1994). Pragmatics and Language Learning Monograph Series (Vol. 5). Illinois: Intensive English Institute, University of Illinois at UrbanaChampaign. 
Brown, H. D. (1990). M\&Ms for language classrooms? Another look at motivation. In J. Alatis (Ed.), Georgetown University round table on language and linguistics 1990 (pp. 383-393). Washington, DC: Georgetown University Press.

Brown, H. D. (2000). Principles of language learning and teaching. New York: Addison Wesley Longman.

Brown, P., \& Levinson, P. (1978). Universals in language usage: Politeness phenomena. In E. N. Goody (Ed.), Questions and Politeness: Strategies in Social Interaction Cambridge (pp. 56-289). England: Cambridge University Press.

Brown, P., \& Levinson, S. C. (1987). Politeness: Some universals in language usage. Cambridge: Cambridge University Press.

Carreira, M. J. (2005). New framework of intrinsic/extrinsic and integrative/instrumental motivation in second language acquisition. The Keiai Journal of International Studies, 16(December 2005), 39-64.

Carrell, P. (1984). Schema theory and ESL reading: Classroom implications and applications. Modern Language Journal, 68, 332-343.

Celce-Murcia, M., Dörnyei, Z., \& Thurrell, S. (1995). A pedagogical framework for communicative competence: A pedagogically motivated model with content specifications. Issues in Applied Linguistics 6(2), 5-35.

Cheng, S. W-J. (2005). An exploratory cross-sectional study of interlanguage pragmatic development of expressions of gratitude by Chinese learners of English. $\mathrm{PhD}$ Dissertation, University of Iowa. Retrieved from http://ir.uiowa.edu/etd/104

Clément, R. (1986). Second language proficiency and acculturation: An investigation of the effects of language status and individual characteristics. Journal of Language and Social Psychology, 5, 271-290.

Clément, R., Dornyei, Z., \& Noels, K. (1994). Motivation, self-confidence, and group cohesion in the foreign language classroom. Language Learning, 44, 417-448. 
Clément, R., Smythe, P., \& Gardner, R. (1978). Persistence in second language study: Motivational considerations. Canadian Modern Language Review, 34, 688-694.

Code, S., \& Anderson, A. (2001). Requests by young Japanese: A longitudinal studyThe Language Teacher Online (Vol. 25). Retrieved from http://www.jaltpublications.org/tlt/articles/2001/08/anderson.

Cohen, A. D. (2005). Strategies for learning and performing L2 speech acts. Intercultural Pragmatics, 2(3), 275-301.

Cohen, A. D., \& Shively, R. L. (2007). Acquisition of requests and apologies in Spanish and French: Impact of study abroad and strategy-building intervention. The Modern Language Journal, 91(ii), 189-212.

Coleman, J. A. (1998). Language learning and study abroad: The European Perspective. Frontiers: The interdisciplinary journal of study abroad, IV(Fall), 167-203.

Collentine, J., \& Freed, B. F. (2004). Learning context and its effects on second language acquisition. Studies in second language acquisition, 26, 153-171.

Cook, M., \& Liddicoat, A. J. (2002). The development of comprehension in interlanguage pragmatics: The case of request strategies in English. Australian Review of Applied Linguistics, 25, 19-39.

Cook, V. (1999). Going beyond the negative speaker in language teaching. TESOL Quarterly, 33, 185-209.

Curl, T. S., \& Drew, P. (2008). Contingency and action: A comparison of two forms of requesting. Research on Language and Social Interaction, 41(2), 129-153.

Dalton-Puffer, C. (2005). Negotiating interpersonal meanings in naturalistic classroom discourse: Directives in content-and-language-integrated classrooms. Journal of Pragmatics, 37, 1275-1293. 
DeKeyser, R. M. (1996). Exploring automatization process. TESOL Quarterly, Summer, 349355.

Duan, L., \& Wannaruk, A. (2010). The effects of explicit and implicit instruction in English refusal. Chinese Journal of Applied Linguistics (Bimonthly), 33(3), 93-109.

DuFon, M. A., \& Churchill, E. (2006). Language Learners in Study Abroad Contexts (Vol. 15). Toronto: Multilingual Matters Ltd.

Duthler, K. W. (2006). The politeness of requests made via email and voicemail: Support for the hyperpersonal model. Journal of Computer-Mediated Communication, 11(2), Article 6.

Economidou-Kogetsidis, M. (2005). 'Yes, tell me please, what time is the midday flight from Athens arriving?': Telephone service encounters and politeness. Intercultural Pragmatics, 2, 253-273.

Economidou-Kogetsidis, M. (2008). Internal and external mitigation in interlanguage request production: The case of Greek learners of English. Journal of Politeness Research, 4, 111-138.

Economidou-Kogetsidis, M. (2009). Interlanguage request modification: The use of lexical/phrasal downgraders and mitigating supportive moves. Multilingua, 28, 79112.

Economidou-Kogetsidis, M. (2010). Cross-Cultural and Situational Variation in Requesting Behaviour: Perceptions of social situations and strategic usage of request patterns. Journal of Pragmatics, 42, 2262-2281.

Edmondson, W., \& Juliane, H. (1991). Do learners talk too much? The waffle phenomenon in interlanguage pragmatics. In R. Phillipson, E. Kellerman, L. Selinker, M. SharwoodSmith \& M. Swain (Eds.), Foreign/Second Language Pedagogy Research (pp. 273286). Clevedon: Multilingual Matters.

Eelen, G. (2001). A Critique of Politeness Theories. Manchester: St Jerome. 
Eisenstein, M., \& Bodman, J. (1993). Expressing gratitude in American English. In G. Kasper \& S. Blum-Kulka (Eds.), Interlanguage Pragmatics (pp. 64-81). Oxford: Oxford University Press.

Ellis, R. (1994). The Study of Second Language Acquisition. Oxford: Oxford University Press.

Færch, C., \& Kasper, G. (1989). Pragmatic knowledge: Rules and procedures. Applied Linguistics, 5(3), 214-225.

Felix-Brasdefer, J. C. (2004). Interlanguage Refusals: Linguistic Politeness and Length of Residence in the Target Community. Language Learning, 54(4), 587-635.

Felix-Brasdefer, J. C. (2005). Indirectness and politeness in Mexican Requests. Paper presented at the The 7th Hispanic Linguistics Symposium, Somerville, MA.

Felix-Brasdefer, J. C. (2007). Pragmatic development in the Spanish as a FL classroom: A cross-sectional study of learner requests. Intercultural Pragmatics, 4(2), 253-286.

Felix-Brasdefer, J. C. (2009). Pragmatic variation across Spanish(es): Requesting in Mexican, Costa Rican, and Dominican Spanish. Intercultural Pragmatics, 6-4(4), 473-515.

Fletcher, J. K. (1999). Disappearing Acts: Gender, Power, and Relational Practice at Work. Cambridge: MIT Press.

Fraser, B., Rintell, E., \& Walters, J. (1980). An approach to conducting research on the acquisition of pragmatic competence in a second language. In D. Larsen-Freeman (Ed.), Discourse Analysis in Second Language Research. Massachusetts: Newbury House.

Freed, B. F. (1995). What makes us think that students who study abroad become fluent? In B. F. Freed (Ed.), Second language acquisition in a study abroad context (9 ed., pp. 123-148). Philadelphia: John Benjamins North America. 
Freed, B. F., Dewey, D. P., Segalowitz, N., \& Halter, R. (2004). The language contact profile. Studies in second language acquisition, 26, 346-356.

Fukushima, S. (2002). Requests and Culture: Politeness in British English and Japanese. New York: Peter Lang.

Garcia, P. (2004). Pragmatic comprehension of high and low level langauge learners. TESLEJ, 8(2), 1-17.

Gardner, R. C. (1985). Social Psychology and Second Language Learning: The Role of Attitudes and Motivation. London, UK: Edward Arnold.

Gardner, R. C. (2001). Integrative Motivation: Past, Present and Future. Paper presented at the Temple University Japan, Distinguished Lecturer Series, Tokyo, February 17, 2001. Osaka, February 24, 2001.

Gardner, R. C. (2005). Integrative Motivation and Second Language Acquisition. . Paper presented at the Canadian Association of Applied Linguistics/Canadian Linguistics Association Joint Plenary Talk, London, Ontario.

Gass, S., \& Selinker, L. (2001). Second Language Acquisition: An Introductory Course. London, UK: Lawrence Erlbaum Associates.

Geyer, N. (2007). Self-qualification in L2 Japanese: An interface of pragmatic, grammatical, and discourse competence. Language Learning, 57(3), 337-367.

Geyer, N. (2008). Discourse and Politeness: Ambivalent Face in Japanese London: Continuum.

Gillette, B. (1994). The role of learner goals in L2 success. In J. P. Lantolf \& G. Appel (Eds.), Vygotskyan Approaches to Second Language Research (pp. 195-213). Westpot, CT: Ablex Publishing Company.

Gleason, J., Perlmann, R., \& Greif, E. (1984). What's the magic word: learning language through routines. Discourse Processes, 6, 493-502. 
Goffman, E. (1967). Interaction Ritual: Essays on Face-to-Face Behavior. Garden City, NY: Anchor Books.

Goffman, E. (1974). Frame Analysis: An Essay on the Organization of Experience. London: Harper and Row.

Golato, A. (2003). Studying compliment responses: A comparison of DCTs and recordings of naturally occurring talk. Applied Linguistics, 24(1), 90-121.

Grice, H. P. (1957). Meaning Philosophical Review, 67, 377-388.

Grice, H. P. (1975). Logic and Conversation In P. Cole \& J. Morgan (Eds.), Syntax and Semantics (Vol. 3, Speech Acts, pp. 411-458). New York: Academic Press. .

Gu, Y. (1990). Politeness phenomena in modern Chinese. Journal of Pragmatics, 14(2), $237-$ 257.

Gubbins, P., \& Holt, M. (2002). Beyond boundaries: Language and identity in contemporay Europe. Clevedon, UK: Multilingual Matters.

Gutel, H. (2008). The Home Stay: A gendered perspective. Frontiers: The Interdisciplinary Journal of Study Abroad, XV, 173-188.

Harris, S. (2003). Politeness and power: Making and responding to 'requests' in institutional settings. Text, 23(1), 27-52.

Hassall, T. (2001). Modifying requests in a second language. IRAL, 39, 259-283.

Hassall, T. (2003). Requests by Australian learners of Indonesian. Journal of pragmatics, 35, 1903-1928.

Hassall, T. (2006). Learning to take leave in social conversations: A diary study. In M. DuFon \& E. Churchill (Eds.), Language Learners in Study Abroad Contexts (pp. 3158). Clevedon: Multilingual Matters. 
Hassall, T. (2008). Pragmatic performance: What are learners thinking? In E. A. Soler \& A. Martinez-Flor (Eds.), Investigating Pragmatics in Foreign Language Learning, Teaching and Testing (Vol. 30, pp. 72-93). Bristol: Multilingual Matters.

Heinemann, T. (2006). 'Will you or can't you?' Displaying entitlement in interrogative requests. Journal of Pragmatics, 38, 1081-1104.

Heritage, J. (2004). Conversation analysis and institutional talk: Analysing data. In D. Silverman (Ed.), Qualitative research (pp. 161-182). London: Sage.

Holmes, J. (2005). Politeness and postmodernism--an appropriate approach to the analysis of language and gender? Journal of Sociolinguistics, 9(1), 108-117.

Holmes, J. (2006). Gendered Talk at Work: Constructing Gender Identity through Workplace Discourse. New York, Oxford: Blackwell.

Holmes, J. (2012). Politeness in intercultural discourse and communication. In C. B. Paulston, S. F. Kiesling \& E. S. Rangel (Eds.), Handbook of Intercultural Discourse and Communication (pp. 205-228). Oxford: Blackwell.

Holmes, J., \& Marra, M. (2004). Relational practice in the workplace: women's talk or gendered discourse? Language in Society, 33, 377-398.

Holmes, J., Marra, M., \& Schnurr, S. (2008). Impoliteness and ethnicity: Māori and Pākehā discourse in New Zealand workplaces. Journal Politeness Research, 4(2), 193-219.

Holmes, J., \& Schnurr, S. (2005). Politeness, humor and gender in the workplace: Negotiating norms and identifying contestation. Journal of Politeness Research 1, 121-149.

Holtgraves, T. (2007). Second language learners and speech act comprehension. Language Learning, 57(4), 595-610.

Horwitz, E. K., Horwitz, M. B., \& Cope, J. (1986). Foreign language classroom anxiety. Modern Language Journal, 70, 125-132. 
House, J. (1989). Politeness in English and German: The functions of Please and Bitte. In S. Blum-Kulka, J. House \& G. Kasper (Eds.), Cross-Cultural Pragmatics: Requests and Apologies (pp. 96-119). Ablex: Norwood.

House, J., \& Kasper, G. (1981). Politeness markers in English and German. In F. Coulmas (Ed.), Conversational Routine: Explorations in Standardized Communication Situations and Prepatterned Speech. (pp. 157-185). The Hague: Mouton.

House, J., \& Kasper, G. (1987). Interlanguage pragmatic: Requesting in a foreign language. In W. Loscher \& R. Schulze (Eds.), Perspectives on Language in Performance (pp. 1250-1288). Tuingen: Gunter Narr.

Hudson, T., Detmer, E., \& Brown, J. D. (1992). A Framework for Testing Cross-Cultural Pragmatics (Vol. Technical report 2). Honolulu: University of Hawaii Press.

Hymes, D. (1972). Models for the interaction of language and social life. In J. J. Gumperz \& D. Hymes (Eds.), Directions in Sociolinguistics: The Ethnography of Communication (pp. 35-71). New York: Holt.

Ide, S. (1989). Formal forms and discernment: two neglected aspects of universals of linguistics politeness. Multilingua, 8(2/3), 223-248.

International, A. E. (2011). International student data 2011: 2011 pivot tables. Australia: Australian Government. Retrieved from https://www.aei.gov.au/research/ International -Student- Data/Pages/InternationalStudentData2011.aspx\#1.

International, A. E. (December 2010). International Student Survey 2010: Overview Report. ACT, Australia: Australian General's Department. Retrieved from https://aei.gov.au/ research/Publications/Documents/2010_International_Student_Report.pdf.

Jackson, J. (2008). Language, Identity and Study Abroad. UK: Equinox Publishing Ltd.

Jalilifar, A. (2009). Request Strategies: Cross-Sectional Study of Iranian EFL Learners and Australian Native Speakers. English Language Teaching, 2(1), 46-61. 
Jaworski, A. (1994). Apologies and non-apologies: Negotiation in speech act realisation. Text, 14(2), 185-206.

Kasper, G. (1984). Pragmatic comprehension in learner--native speaker discourse. Language Learning, 34(4), 1-21.

Kasper, G. (1989). Interactive procedures in interlanguage discourse. In W. Oleksy (Ed.), Contrastive Pragmatics (pp. 189-229). Amsterdam: John Benjamins Publishing Company.

Kasper, G. (1990). Linguistic politeness. Journal of Pragmatics, 14, 193-218.

Kasper, G. (1997). Can pragmatic competence be taught?NetWork \#6. Honolulu: University of Hawai'i, Second Language Teaching \& Curriculum Center. Retrieved from http://www.lll.hawaii.edu/nflrc/NetWorks/NW6.

Kasper, G. (2001). Classroom research on interlanguage pragmatics. In R. K. R \& G. Kasper (Eds.), Pragmatics in language teaching (pp. 33-60). Cambridge: Cambridge University Press.

Kasper, G. (2006). Speech acts in interaction: Towards discursive pragmatics. In K. BardoviHarlig, C. Felix-Brasdefer \& A. S. Omar (Eds.), Pragmatics Language Learning (Vol. 11, pp. 281-314). Honolulu, Hawaii: University of Hawaii Press.

Kasper, G., \& Blum-Kulka, S. (1993). Interlanguage pragmatics. Oxford: Oxford University Press.

Kasper, G., \& Dahl, M. (1991). Research methods in interlanguage pragmatics. Hawaii: University of Hawaii Press: University of Hawaii Press.

Kasper, G., \& Roever, C. (2005). Pragmatics in second language learning. In E. HInkel (Ed.), Handbook of Research in Second Language Teaching and Learning (pp. 317-334). Mahwah, NJ: Lawrence Erlbaum Associates. 
Kasper, G., \& Rose, K. R. (2002). Individual differences in L2 pragmatic development Pragmatic development in second language (pp. 275-303). Oxford: Blackwell Publishing Ltd.

Kasper, G., \& Schmidt, R. (1996). Developmental issues in interlanguage pragmatics. Studies in second language acquisition, 18.

Kasper, G., \& Zhang, Y. (1995). It's good to be a bit Chinese: Foreign students' experience of Chinese pragmatics. In G. Kasper (Ed.), Pragmatics of Chinese as Native and Target Language (Vol. 5, pp. 1-22). Honolulu, Hawaii: University of Hawaii Press.

Keshavarz, M. H., Eslami, Z. R., \& Ghahraman, V. (2006). Pragmatic transfer and Iranian EFL refusals: A cross-cultural perspective of Persian and English. In K. BardoviHarlig, C. Felix-Brasdefer \& A. S. Omar (Eds.), Pragmatics Language Learning (Vol. 11, pp. 359-402). Honolulu, Hawaii: University of Hawaii Press.

Kinginger, C., \& Belz, J. A. (2005). Socio-cultural perspectives on pragmatic development in foreign language learning: Microgenetic case studies from telecollaboration and residence abroad. Intercultural Pragmatics, 2(4), 369-421.

Kinginger, C., \& Farrell, K. (2004). Assessing development of meta-pragmatic awareness in study abroad. Frontiers: the Interdisciplinary Journal of Study Abroad, X, 2004, 1942.

Knight, S. M., \& Schmidt-Rinehart, B. C. (2002). Enhancing the Homestay: Study abroad from the host family's perspective. Foreign Language Annals, 35(2), 190-201.

Knight, S. M., \& Schmidt-Rinehart, B. C. (2010). Exploring Conditions to enhance student/host family interaction abroad. Foreign Language Annals, 43(1), 64-79.

Koike, D. A. (1989). Pragmatic competence and adult L2 acquisition: Speech acts in interlanguage. The Modern Language Journal, 73(3), 279-289. 
Koike, D. A. (1996). Transfer of pragmatic competence and suggestions in Spanish foreign language learning. In S. G. J. Neu (Ed.), Speech Acts Across Cultures (pp. 257-281). New York: Mouton de Gruyter.

Kouritzin, S. G., Piquemal, N. A., \& Renaud, R. D. (2009). An international comparison of socially constructed language learning motivation and beliefs. Foreign Language Annals, 42(2), 287-317.

Krashen, S. (1981). Second Language Acquisition and Second Language Learning. Oxford: Pergamon.

Kreutel, K. (2007). 'I'm not agree with you.' ESL learners' expressions of disagreement. Teaching English as a second or foreign language, 11(3), 1-35.

Krishnan, L. A., \& Hoon, L. H. (2002). Diaries: Listening to 'voices' from the multicultural classroom. ELT Journal, 56(3), 227-238.

Lakoff, R. (1973). The logic of politeness: or minding your P's and Q's. Chicago Linguistic Society 9, 9:292-305.

Larsen-Freeman, D., \& Long, M. (1991). An Introduction to Second Language Acquisition Research. London and New York: Longman.

Lave, J., \& Wenger, E. (1991). Situated Learning: Legitimate Peripheral Participation. Cambridge: Cambridge University Press.

Lee, C. (2005). A cross-linguistic study on the linguistic expressions of Cantonese and English requests. Pragmatics 14(4), 395-422.

Lee, C. (2011). Strategy and linguistic preference of requests by Cantonese learners of English: An interlanguage and crosscultural comparison. Multilingua, 30, 99-129.

Leech, G. (1983). The principles of pragmatics. Essex: Longman. 
Lee-Wong, S. M. (1994a). Qing/please-a polite or requestive marker?: Observations from Chinese. Multilingua, 13, 343-360.

Lee-Wong, S. M. (1994b). Imperatives in requests: Direct or impolite-observations from Chinese. Pragmatics, 4(4), 491-515.

Lee-Wong, S. M. (1998). Face support--Chinese particles as mitigators: A study of ba, a/ya and ne. Pragmatics 8(3), 387-404.

Lee-Wong, S. M. (2000). Politeness and Face in Chinese Culture. Frankfurt, Germany: Peter Lang GmbH.

Li, D. (2000). The pragmatics of making requests in the L2 workplace: A case study of language socialisation. Canadian Modern Language Review, 57(1), 1-18.

Li, D. (2006). Motivation in second language acquisition in Chinese research students in the UK. Evaluation and Research in Education, 19(1), 38-58.

Li, R. (2007). The relationship between linguistic proficiency and pragmatic ability. USChina Foreign Language, $5(1$ (40)), 1-5.

Liang, G., \& Han, J. (2005). A Contrastive Study on Disagreement Strategies for Politeness between American English \& Mandarin Chinese. Asian EFL Journal, 7(1), Article 10.

Liu, J. (2010). Testing interlanguage pragmatic knowledge. In A. Trosborg (Ed.), Pragmatics Across Languages and Cultures (pp. 467-487). Berlin/New York: Walter de Gruyter Mouton.

Liu, M., \& Jackson, J. (2008). An exploration of Chinese EFL learners' unwillingness to communicate and foreign language anxiety. The Modern Language Journal, 92(i), 7186.

LoCastro, V. (2001). Individual differences in second language acquisition: Attitudes, learner subjectivity, and L2 pragmatic norms. System, 29, 69-89. 
Long, M. (1983). Native speaker/non-native speaker conversation and the negotiation of comprehensible input. Applied Linguistics, 4, 126-141.

Lörscher, W. (1986). Conversational structures in the foreign language classroom In G. Kasper (Ed.), Learning, Teaching and Communication in the Foreign Language Classroom (pp. 11-22). Århus: Aarhus University Press.

Lörscher, W., \& Schulze, R. (1988). On polite speaking and foreign language classroom discourse. International Review of Applied Linguistics in Language Teaching, 26, 183-200.

Lwanga-Lumu, C. (2002). Internal request modification by first and second Language speakers. Journal for Language Teaching, 36, 289-304.

Maeshiba, N., Yoshinaga, N., Kasper, G., \& Ross, S. (1996). Transfer and proficiency in interlanguage apologizing. In S. Gass \& J. Neu (Eds.), Speech Acts Across Cultures (pp. 155-187). Berlin: Mouton de Gruyter.

Magnan, S. S., \& Back, M. (2007). Social interaction and linguistic gain during study abroad. Foreign Language Annals, 40(1), 43-61.

Maiworm, F., Steube, W., \& Teichler, U. (1993). Experiences of ERASMUS strudents 1990/91 (Vol. 17). Brussels and Luxembourg: Office for Official Publications of the European Communities.

Mao, L. M. R. (1994). Beyond Politeness Theory: 'Face' revisited and renewed. Journal of Pragmatics, 21, 451-486.

Marriott, H. (1995). The acquisition of politeness patterns by exchange students in Japan. In B. F. Freed (Ed.), Second Language Acquisition in a Study Abroad Context. Amsterdam and Philadephia: John Benjamins.

Martinez-Flor, A. (2009). The use and function of 'please' in learners' oral requestive behaviour: A pragmatic analysis. Journal of English Studies, 7, 35-54. 
Martinez-Flor, A., \& Fukuya, Y. J. (2005). The effects of instruction on learner's production of appropriate and accurate suggestions. System, 33(3), 463-480.

Martinsen, R. A. (2008). Short-term study abroad: Predicting changes in oral skills. Foreign Language Annals, 43(3), 504-530.

Matsumoto, Y. (1988). Reexamination of the universality of face: Politeness phenomena in Japanese. Journal of Pragmatics, 12, 403-426.

Matsumoto, Y. (1989). Politeness and conversational universals: Observations from Japan. Multilingua, $8(2 / 3)$.

Matsumura, S. (2003). Modelling the relationships among interlanguage pragmatic development, L2 proficiency, and exposure to L2. Applied linguistics, 24(4), 465-491.

Matsumura, S. (2007). Exploring the after effects of study abroad on interlanguage pragmatic development. Intercultural Pragmatics, 4(2), 167-192.

Meisel, J., Clashen, H., \& Pienemann, M. (1981). On determining developmental stages in natural second language acquisition. Studies in Second Language Acquisition, 3, 109135.

Mills, S. (2003). Gender and Politeness. New York: Cambridge University Press.

Morrison, A., \& Holmes, J. (2006). Eliciting refusals: A methodological challenge. Te Reo, 46, 47-66.

Mullany, L. (2004). Gender, politeness and institutional power roles: Humour as a tactic to gain compliance in workplace business meetings. Multilingua, 23, 13-37.

Mullany, L. (2006). Girls on tour: Politeness, small talk, and gender in managerial business meetings. Journal of Politeness Research 2, 55-77.

Mullany, L. (2007). Gendered Discourse in the Professional Workplace. Hampshire: Palgrave Macmillan. 
Niezgoda, K., \& Rover, C. (2001). Pragmatic and grammatical awareness: A function of the learning environment? In K. R. Rose \& G. Kasper (Eds.), Pragmatics in Language Teaching (pp. 63-79). Cambridge: Cambridge University Press.

Nugraha, M. (2002). Triangulation of instrumentation and data source: A stronger method in assessing English language needs. $K @ t a, 4(2), 148-159$.

Nwoye, O. G. (1992). Linguistics politeness and socio-cultural variations of the notion of face. Journal of pragmatics, 18, 309-328.

O'Driscoll, J. (2007a). Brown and Levinson's face: How it can--and can't--help us to understand interaction across cultures. Intercultural Pragmatics, 4(4), 463-492.

O'Driscoll, J. (2007b). What's in an FTA? Reflections on a chance meeting with Claudine. Journal of Politeness Research, 3(2), 243-268.

Okamoto, S. (1999). Situated politeness: Coordinating honorific and non-honorific expressions. Pragmatics, 9(1), 51-74.

Olshtain, E., \& Blum-Kulka, S. (1985). Degree of approximation: Non-native reactions to native speech act behavior. In S. Gass (Ed.), Input in Second Language Acquisition (pp. 303-329). Rowley, MA: Newbury House.

Otçu, B., \& Zeyrek, D. (2008). Development of requests: A study on Turkish learners of English. In M. Pütz \& J. N.-V. Aertselaer (Eds.), Developing Contrastive Pragmatics: Interlanguage and Cross-Cultural Perspectives (pp. 265-299). Berlin \& New York: Mouton de Gruyter.

Pearson, L. (2006). Teaching pragmatics in Spanish L2 courses: What do learners think? In K. Bardovi-Harlig, C. Felix-Brasdefer \& A. S. Omar (Eds.), Pragmatics Language Learning (Vol. 11, pp. 109-134). Honolulu, Hawaii: University of Hawaii Press.

Pedlow, R., Wales, R., \& Sanson, A. (2001). Children's production and comprehension of politeness in requests: Relationships to behavioral adjustment in middle childhood. Journal of Language and Social Psychology 20, 23-60. 
Peirce, B. N. (1995). Social identity, investment, and language learning. TESOL Quarterly, 29, 9-31.

Pellegrino, V. A. (1998). Student perspectives on language learning in a study abroad context. Frontiers: The Interdisciplinary Journal of Study Abroad, VI(Fall), 91-120.

Pienemann, M. (1987). Determining the influence of instruction on L2 speech processing. Australian Review of Applied Linguistics, 10, 83-113.

Pienemann, M. (1989). Is language teachable? Psycholinguistic experiments and hypotheses. Applied Linguistics, 10, 52-79.

Regan, V. (1995). The acquisition of sociolinguistic native speech norms: Effects of a year abroad on second language learners of French. In B. E. Freed (Ed.), Second Language Acquisition in a Study Abroad Context (pp. 245-268).

Regan, V. (2003). Sociolinguistics and language learning in a study abroad context. Frontiers: The Interdisciplinary Journal of Study Abroad, 4, 61-90.

Richards, J. (2001). Curriculum development in language teaching. Cambridge: Cambridge University Press.

Rintell, E., \& Mitchell, C. J. (Eds.). (1989). Studying requests and apologies: An inquiry into method. Norwood, N.J.: Ablex.

Rivers, W. P. (1998). Is being there enough? The effects of homestay placements on language gains during study abroad. Foreign Language Annals, 31(4), 492-500.

Rose, K. R. (1992). Speech acts and questionnaires: The effect of hearer response. Journal of Pragmatics, 17(1), 49-62. doi: 10.1016/0378-2166(92)90028-a

Rose, K. R. (2000). An exploratory cross-sectional study of interlanguage pragmatic development. Studies in second language acquisition, 22, 27-67. 
Rose, K. R. (2005). On the effects of instruction in second language pragmatics. System, 33(3), 385-399.

Rose, K. R., \& Ono, R. (1995). Eliciting speech act data in Japanese: The effect of questionnaire type. Language Learning, 45, 191-223.

Salsbury, T., \& Bardovi-Harlig, K. (2001). 'I know your mean, but I don't think so': Disagreements in L2 English. In L. Bouton (Ed.), Pragmatics and Language Learning (Vol. 10, pp. 131-151). Urbana-Champaign: University of Illinois, Division of English as an International Language.

Sasaki, M. (1998). Investigating EFL students' production of speech acts: A comparison of production questionnaires and role plays. Journal of pragmatics, 30, 457-484.

Sato, S. (2008). Use of 'Please' in American and New Zealand English. Journal of Pragmatics, 40, 1249-1278.

Schauer, G. A. (2004). May you speak louder maybe? Interlanguage pragmatic development in requests. In S. H. Foster-Cohen, M. S. Smith, A. Sorace \& M. Ota (Eds.), EUROSLA Yearbook (Vol. 4, pp. 253-273). Amsterdam: John Benjamins.

Schauer, G. A. (2006a). Pragmatic awareness in ESL and EFL contexts: contrast and development. Language learning, 56(2), 269-318.

Schauer, G. A. (2006b). The development of ESL learners' pragmatic competence: A longitudinal investigation of awareness and production. In K. Bardovi-Harlig, C. Felix-Brasdefer \& A. S. Omar (Eds.), Pragmatics Language Learning (pp. 135-164). Manoa, HI: Second Language teaching and Curriculum Center University of Hawaii.

Schauer, G. A. (2007). Finding the right words in the study abroad context: The development of German learners' use of external modifiers in English. Intercultural Pragmatics, 4(2), 193-220. 
Schauer, G. A. (2008). Getting better in getting what you want: Langauge learners' pragmatic development in requests during study abroad sojourns. In M. Pütz \& J. N.-V. Aertselaer (Eds.), Developing Contrastive Pragmatics: Interlanguage and CrossCultural Perspectives (pp. 403-431). Berlin \& New York: Mouton de Gruyter.

Schauer, G. A. (2009). Interlanguage pragmatic development: The study abroad context. London: Continuum Intl.

Schmidt, R. (1983). Interaction, acculturation, and the acquisition of communicative competence: A case study of one adult. In N. Wolfson \& E. Judd (Eds.), Sociolinguistics and language acquisition (pp. 137-174). Rowley, MA: Newbury House.

Schmidt, R. (1992). Psychological mechanisms underlying second language fluency. Studies in Second Language Acquisition, 14, 357-385.

Schmidt, R. (1993). Consciousness, learning and interlanguage pragmatics. In G. Kasper \& S. Blum-Kulka (Eds.), Interlanguage Pragmatics (pp. 21-42). New York: Oxford University Press.

Schmidt, R. (2001). Evaluating the empirical evidence: Grounds for instruction in pragmatics? In K. R. Rose \& G. Kasper (Eds.), Pragmatics in Language Teaching (pp. 13-32). Cambridge: Cambridge University Press.

Schmidt-Rinehart, B. C., \& Knight, S. M. (2004). The homestay component of study abroad: Three perspectives. Foreign Language Annals, 37, 254-262.

Searle, J. (1969). Speech Acts. Cambridge: Cambridge University Press.

Searle, J. (1975). Indirect Speech Acts. In P. Cole \& J. Morgan (Eds.), Syntax and Semantics (Vol. 3, Speech Acts, pp. 59-82). New York: Academic Press.

Searle, J. (1979). Expression and Meaning: Studies in the Theory of Speech Acts. Cambridge: Cambridge University Press. 
Segalowitz, N., \& Freed, B. (2004). Context, contract, and cognition in oral fluency aquisition: Learning Spanish in at home and study abroad contexts. Studies in second language acquisition, 26, 173-199.

Selinker, L. (1972). Interlanguage. International Review of Applied Linguistics, 10, 209-231.

Shardakova, M. (2005). Intercultural pragmatics in the speech of American L2 learners of Russian: Apologies offered by Americans in Russian. Intercultural Pragmatics, 2(4), 423-451.

Sifianou, M. (1993). Off-record indirectness and the notion of imposition. Multilingua, 12(1), 69-79.

Sifianou, M. (1995). Do we need to be silent to be extremely polite? Silence and FTAs. International Journal of Applied Linguistics, 5(1), 95-110.

Sifianou, M. (1999). Politeness phenomena in England and Greece: A cross-cultural perspective. Oxford: Oxford University Press.

Soler, E. A. (2005). Does instruction work for learning pragmatics in the EFL context? System, 33, 417-435.

Spencer-Oatey, H. (Ed.). (2000a). Culturally Speaking: Managing Rapport through Talk across Cultures. London: Continuum.

Spencer-Oatey, H. (2000b). Introduction: Language, culture and rapport management. In H. Spencer-Oatey (Ed.), Culturally Speaking: Managing Rapport through Talk across Cultures (pp. 1-8). London: Continuum.

Spencer-Oatey, H. (2000c). Rapport management: A framework for analysis. In H. SpencerOatey (Ed.), Culturally Speaking: Managing Rapport through Talk across Cultures (pp. 11-46). London: Continuum. 
Spencer-Oatey, H. (2002). Managing rapport in talk: Using rapport sensitive incidents to explore the motivational concerns underlying the management of relations. Journal of Pragmatics, 34 529-545.

Spencer-Oatey, H. (2005). (Im)politeness, face and perceptions of rapport: Unpackaging their bases and interrelationships. Journal of Politeness Research, 1(1), 95-119.

Spencer-Oatey, H. (2007). Theories of identity and the analysis of face. Journal of Pragmatics, 39, 639-656.

Spencer-Oatey, H., \& Jiang, W. (2003). Explaining cross-cultural pragmatic findings: Moving from politeness maxims to sociopragmatic principles. Journal of Pragmatics 35(10-11), 1633-1650.

Spencer-Oatey, H., \& Jianyu, X. (2003). Managing rapport in intercultural business interactions: A comparison of two Chinese-British welcome meetings. Journal of Intercultural Studies, 24(1), 33-46.

Stubbs, M. (1983). Discourse Analysis: The Sociolinguistic Analysis of Natural Language and Culture. Oxford: Blackwell.

Taguchi, N. (2002). An application of relevance theory to the analysis of L2 interpretation processes: The comprehension of indirect replies. International Review of Applied Linguistics, 40, 151-176.

Taguchi, N. (2005). Comprehending implied meaning in English as a foreign language. The Modern language journal, 89, 543-562.

Taguchi, N. (2008a). Cognition, language contact, and the development of pragmatic comprehension in a study-abroad context. Langauge Learning, 58(1), 33-71.

Taguchi, N. (2008b). The role of learning environment in the development of pragamatic comprehension: A comparison of gains between EFL and ESL learners. Studies in second language acquisition, 30, 423-452. 
Taguchi, N. (2010). Longitudinal studies in interlanguage pragmatics. In A. Trosborg (Ed.), Handbook of Pragmatics (Vol. vol.7: Pragmatics Across Languages and Cultures, pp. 333-361). Berlin: Mouton de Gruyter.

Takahashi, S. (1990). Exploring the comprehension process of nonliteral utterances and some implication for automaticity. University of Hawaii Working Papers in ESL, 9(2), 6797.

Takahashi, S. (1992). Transferability of indirect request strategies. University of Hawaii Papers in ESL, 11(1), 69-124.

Takahashi, S. (1996). Pragmatic transferability. Studies in Second Language Acquisition, 18, 189-223.

Takahashi, S. (2001). The role of input enhancement in developing pragmatic competence. In R. K. R \& G. Kasper (Eds.), Pragmatics in Language Teaching (pp. 171-199). Cambridge: Cambridge University Press.

Takahashi, S. (2005). Pragmalinguistic awareness: Is it related to motivation and proficiency. Applied Linguistics, 26, 90-120.

Takahashi, S., \& DuFon, M. A. (1989). Cross-linguistic influence in indirectness: The case of English directives performed by native Japanese speakers. Department of English as a Second Language, University of Hawai`i at Manoa.

Takahashi, S., \& Roitblat, H. L. (1994). Comprehension processes of second language indirect requests. Applied Psycholinguistics, 15, 475-506.

Takahashi, T., \& Beebe, L. M. (1987). The development of pragmatic competence by Japanese learners of English. JALT Journal, 8(2), 131-155.

Takimoto, M. (2006). The effects of explicit feedback on the development of pragmatic proficiency. Language Teaching Research, 10(4), 393-417. 
Talburt, S., \& Steward, M. A. (1999). What's the subject of study abroad?: Race, gender, and 'living culture'. Modern Language Journal, 83(2), 163-175.

Tannen, D. (1984). Conversational Style: Analyzing Talk among Friends. NJ: Ablex Publishing Corporation.

Tateyama, Y. (2001). Explicit and implicit teaching of pragmatic routines: Japanese sumimasen. In R. K. R \& G. Kasper (Eds.), Pragmatics in language teaching (pp. 200-222). Cambridge: Cambridge University Press.

Teichler, U. (1991). Experiences of EKASMUS students. Select findings of the 1988/89 survey. Kassel, Germany: Gesamthochschule Kassel.

Terkourafi, M. (2004). Testing Brown \& Levinson's theory in a corpus of conversational data from Cypriot Greek. International Journal of the Sociology of Language, 168(119$34)$.

Terkourafi, M. (2005). Beyond the micro-level in politeness research. Journal of Politeness Research, 1(2), 237-262.

Thomas, J. (1983). Cross-cultural pragmatic failure. Applied Linguistics, 4, 91-112.

Triandis, H. C., \& Singelis, T. M. (1998). Training to recognize individual differences in collectivism and individualism within culture. International Journal of Intercultural Relations, 22(1), 35-47.

Trosborg, A. (1987). Apology strategies in native/non-natives. Journal of Pragmatics, 11, 147-167.

Trosborg, A. (1995). Interlanguage Pragmatics: Requests, Complaints and Apologies. New York: Mouton de Gruyter. 
Tsai, I.-T. (2007). Studying apologies: A comparison of DCT and role-play data. Masters Masters, National Sun Yat-sen University, National Sun Yat-sen University. (http://etd.lib.nsysu.edu.tw/ETD-db/ETD-search/getfile?URN=etd-0903107200352\&filename=etd-0903107-200352.pdf)

Twombly, S. B. (1995). Piropos and friendships: Gender and culture clash in study abroad. Frontiers: The Interdisciplinary Journal of Study Abroad, 1, Retrieved from http://www.frontiersjournal.com/issues/vol2011/index.htm.

Vyatkina, N., \& Belz, J. A. (2006). A learner corpus-driven intervention for the development of L2 pragmatic competence. In K. Bardovi-Harlig, C. Felix-Brasdefer \& A. S. Omar (Eds.), Pragmatics Language Learning (Vol. 11, pp. 315-358). Honolulu, Hawaii: University of Hawaii Press.

Warga, M., \& Scholmberger, U. (2007). The acquisition of French apologetic behaviour in a study abroad Intercultural Pragmatics, 4(2), 221-251.

Watts, R. J. (2003). Politeness. Cambridge: Cambridge University Press.

Weizman, E. (1989). Requestive hints. In S. Blum-Kulka, J. House \& G. Kasper (Eds.), Cross-cultural pragmatics: Requests and apologies (pp. 71-95). Norwood, N. J.: Ablex.

Weizman, E. (1993). Interlanguage requestive hints. In G. Kasper \& S. Blum-Kulka (Eds.), Interlanguage pragmatics (pp. 123-157). Oxford: Oxford University Press.

Wenger, E. (1998). Communities of Practice: Learning, Meaning, and Identity. Cambridge: Cambridge University Press.

Wesely, P. M. (2009). The language learning motivation of early adolescent French immersion graduates. Foreign Language Annals, 42(2), 270-286.

Wichmann, A. (2004). The intonation of please-requests: A corpus-based study. Journal of Pragmatics, 36, 1521-1549. 
Wilkinson, S. (1998a). Study abroad from the participants' perspective: A challenge to common beliefs. Foreign Language Annals, 31, 23-39.

Wilkinson, S. (1998b). On the nature of immersion during study abroad: Some participant perspectives. Frontiers: The Interdisciplinary Journal of Study Abroad, Fall, 121138.

Wilkinson, S. (2000). Emerging questions about study abroad. ADFL Bulletin, 32(1), 36-41.

Winke, P. M., \& Teng, C. (2010). Using task-based pragmatics tutorials while studying abroad in China. Intercultural Pragmatics, 7(2), 363-399.

Wolfson, N. (1986). The bulge: A theory of speech behavior and social distance Penn Working Papers in Educational Linguistics 2(2), 55-83.

Wolfson, N., Marmor, R., \& Jones, S. (1989). Problems in the comparison of speech acts across cultures. In S. Blum-Kulka, J. House \& G. Kasper (Eds.), Cross-cultural pragmatics: Requests and apologies (Vol. 31, pp. 174-196). NJ: Ablex.

Wood, D. (2004). An empirical investigation into the facilitating role of automatized lexical phrases in second language fluency development. Journal of Language and Learning, $2(1), 27-50$.

Wood, D. (2006). Uses and functions of formulaic sequences in second language speech: An exploration of the foundations of fluency. The Canadian Modern Language Review, 63(1), 13-33.

Woodfield, H. (2008a). Problematizing discourse completion tasks: Voices from verbal report. Journal of Evaluation and Research in Education 21, 43-69.

Woodfield, H. (2008b). Interlanguage requests in English: A contrastive study. In M. Pütz \& J. N. V. Aertselaer (Eds.), Contrastive pragmatics: Interlanguage and Cross-cultural Perspectives (pp. 231-264). Berlin/New York: Mouton De Gruyter. 
Woodfield, H. (2010). What lies beneath?: Verbal report in interlanguage requests in English. Multilingua, 29, 1-27.

Woodfield, H. (2012). 'I think maybe I want to lend the notes from you': Development of request modification in graduate learners. In M. Economidou-Kogetsidis \& $\mathrm{H}$. Woodfield (Eds.), Interlanguage Request Modification (pp. 9-50). Amsterdam/Philadelphia: John Benjamins.

Woodfield, H., \& Economidou-Kogetsidis, M. (2010). 'I just need more time': A study of native and non-native students' requests to faculty for an extension. Multilingua, 29, $77-118$.

Woodfield, H., \& Economidou-Kogetsidis, M. (2012). Modification in interlanguage requests: Introduction. In M. Economidou-Kogetsidis \& H. Woodfield (Eds.), Interlanguage Request Modification (pp. 1-8). Amsterdam/Philadelphia: John Benjamins.

Woodfield, H., \& Kogetsidis, M. (Eds.). (2007). Interlanguage requests in academic encounters (Vol. Proceedings of the BAAL Annual Conference 2007). Edinburgh University: London, UK: Scitsiugnil Press.

Wu, M. F. M. (2004). Problems Faced by Chinese Learners in L2 English Learning and Pedagogic Recommendations from an Inter-Cultural Communication Perspective Karen's Linguistics Issues, August 2004, 1-11.

Xiang, C. H. (2007). Production and perception of apologies: Interlanguage pragmatics of British learners of Mandarin Chinese. Paper presented at the Pragmatics in the CJK classroom: The State of the Art, University of Hawai'i-Manoa in Honolulu, Hawai'i.

Xu, W., Case, R. E., \& Wang, Y. (2009). Pragmatic and grammatical competence, length of residence, and overall L2 proficiency. System, 37(2), 205-216.

Yabuuchi, A. (2006). Hierarchy politeness: What Brown and Levinson refused to see. Intercultural Pragmatics, 3(3), 323-351. 
Yager, K. (1998). Learning Spanish in Mexico: The effect of informal contact and student attitudes on language gain. Hispania, 81, 898-913.

Yamanaka, J. E. (2003). Effects of proficiency and length of residence on the pragmatic comprehension of Japanese ESL. Second Language Studies, 22(1), 107-175.

Yashima, T. a. Z.-N., L. (2008). The impact of learning contexts on proficiency, attitudes, and L2 communication: Creating an imagined international community. System, 36, $566-585$.

Ye, L. (1995). Complimenting in Mandarin Chinese. In G. Kasper (Ed.), Pragmatics of Chinese as Native and Target Language (Vol. 5, pp. 207-296). Honolulu, Hawaii: University of Hawaii Press.

Yeung, L. N. T. (1997). Polite requests in English and Chinese business correspondence in Hong Kong. Journal of Pragmatics, 27, 502-522.

Yoshimi, D. R. (2007). Unlocking the promise of pragmatics. Paper presented at the Pragmatics in the CJK classroom: The State of the Art, University of Hawai'i-Manoa in Honolulu, Hawai'i.

Zhang, Y. (1995a). Strategies in Chinese requesting. In G. Kasper (Ed.), Pragmatics of Chinese as Native and Target Language (Vol. 5, pp. 23-68). Honolulu, Hawaii: University of Hawaii Press.

Zhang, Y. (1995b). Indirectness in Chinese requesting. In G. kasper (Ed.), Pragmatics of Chinese as Native and Target Language (pp. 69-118). Hawaii: University of Hawaii. 